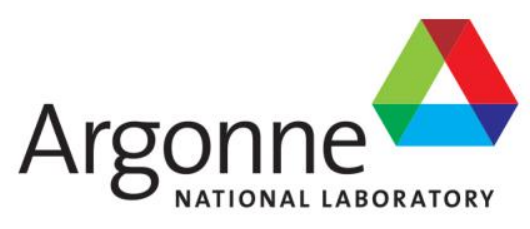

ANL-16/19

\title{
U.S. Natural Gas Storage Risk-Based Ranking Methodology and Results
}

Global Security Sciences Division Energy Systems Division 


\begin{abstract}
About Argonne National Laboratory
Argonne is a U.S. Department of Energy laboratory managed by UChicago Argonne, LLC under contract DE-AC02-06CH11357. The Laboratory's main facility is outside Chicago, at 9700 South Cass Avenue, Argonne, Illinois 60439. For information about Argonne and its pioneering science and technology programs, see www.anl.gov.
\end{abstract}

\title{
DOCUMENT AVAILABILITY
}

Online Access: U.S. Department of Energy (DOE) reports produced after 1991 and a growing number of pre-1991 documents are available free via DOE's SciTech Connect (http://www.osti.gov/scitech/).

Reports not in digital format may be purchased by the public from the National Technical Information Service (NTIS):

U.S. Department of Commerce

National Technical Information Service

5301 Shawnee Rd

Alexandria, VA 22312

www.ntis.gov

Phone: (800) 553-NTIS (6847) or (703) 605-6000

Fax: (703) 605-6900

Email: orders@ntis.gov

Reports not in digital format are available to DOE and DOE contractors from the Office of Scientific and Technical Information (OSTI):

U.S. Department of Energy

Office of Scientific and Technical Information

P.O. Box 62

Oak Ridge, TN 37831-0062

www.osti.gov

Phone: (865) 576-8401

Fax: (865) 576-5728

Email: reports@osti.gov

\section{Disclaimer}

This report was prepared as an account of work sponsored by an agency of the United States Government. Neither the United States Government nor any agency thereof, nor UChicago Argonne, LLC, nor any of their employees or officers, makes any warranty, express or implied, or assumes any legal liability or responsibility for the accuracy, completeness, or usefulness of any information, apparatus, product, or process disclosed, or represents that its use would not infringe privately owned rights. Reference herein to any specific commercial product, process, or service by trade name, trademark, manufacturer, or otherwise, does not necessarily constitute or imply its endorsement, recommendation, or favoring by the United States Government or any agency thereof. The views and opinions of document authors expressed herein do not necessarily state or reflect those of the United States Government or any agency thereof, Argonne National Laboratory, or UChicago Argonne, LLC. 


\section{U.S. Natural Gas Storage Risk-Based Ranking Methodology and Results}

prepared by:

Steve Folga, Edgar Portante, Shabbir Shamsuddin, Angeli Tompkins, Leah Talaber, Mike McLamore, Jim Kavicky, Guenter Conzelmann, and Todd Levin

Risk and Infrastructure Science Center, Global Security Sciences Division and

Center for Energy, Environmental, and Economic Systems Analysis, Energy Systems Division

prepared for:

U.S. Department of Energy, Office of Electricity Delivery and Energy Reliability

October 2016 



\section{Contents}

Acronyms and Abbreviations ...................................................................................... viii

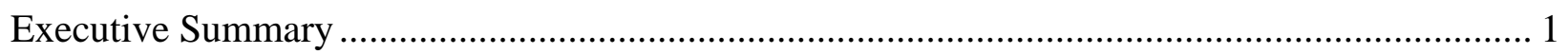

ES.1 Results_-UGS Facilities ....................................................................... 2

ES.2 Results —Electric Sector Impacts ............................................................... 3

ES.3 Results - Overall Supply Risk .................................................................... 5

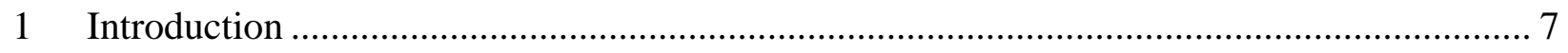

2 Description of Underground Storage Sector .............................................................. 8

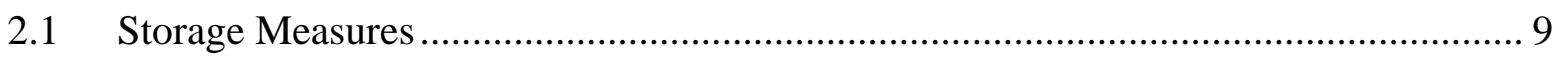

2.2 Owners and Operators of UGS Facilities.................................................... 11

2.2.1 Interstate Pipeline Companies................................................................. 11

2.2.2 LDCs and Intrastate Pipeline Companies .............................................. 12

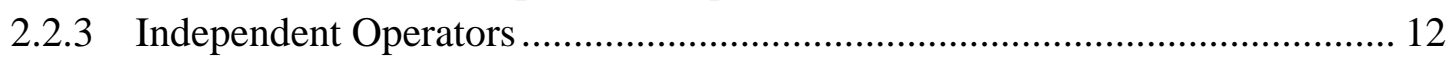

3 Analytical Methodology, General Assumptions, and Data Sources ................................. 13

3.1 Methodology for Estimating the Consequences of a UGS Disruption ...................... 14

3.1.1 Assumptions for Estimating the Consequences of a

UGS Facility Disruption ....................................................................... 15

3.1.2 Data Sources for Estimating the Consequences of a

UGS Facility Disruption ................................................................ 16

3.1.3 Methodology of UGS-LDC Impact Analysis Model................................... 21

3.1.4 Methodology of UGS-Pipeline Impact Analysis Model............................... 23

3.1.5 Methodology of UGS Third-Party Impact Analysis Model ......................... 25

3.2 Methodology for Identifying Affected Electric Power Plants ................................ 27

3.3 Methodology for Screening-Level Electric Reliability Assessment.......................... 30

3.3.1 Power Flow Modeling........................................................................ 30

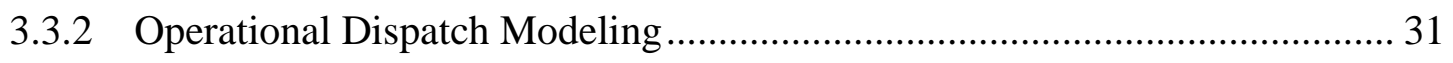

3.4 Methodology for Estimating Incident Likelihood ............................................ 33

3.4.1 Assumption for Estimating Incident Frequencies of a UGS Facility ............. 34

3.4.2 Data Sources for Incident Likelihood ........................................................ 34

3.4.3 Gas Leaks: A Pervasive Concern.................................................................. 36

3.5 Methodology for Developing a Common Measure and Overall

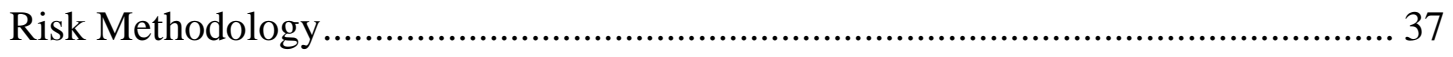

3.5.1 Developing a Common Measure …........................................................ 37

3.5.2 Estimating Overall Supply Risk......................................................... 41

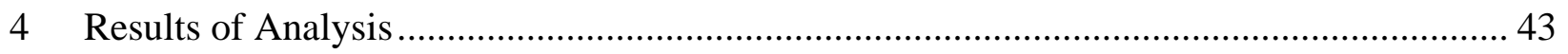

4.1 Consequence Analysis ............................................................................... 43

4.1.1 Consequence of the Loss of LDC-Owned UGS Facilities........................... 45 


\section{Contents (Cont.)}

4.1.2 Consequence of the Loss of Pipeline-Owned UGS Facilities ....................... 46

4.1.3 Consequence of the Loss of Independent Third-Party-Owned

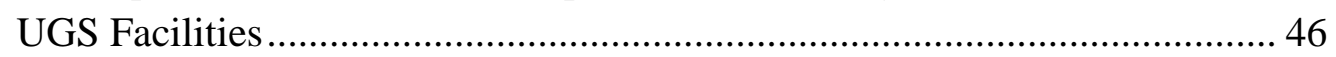

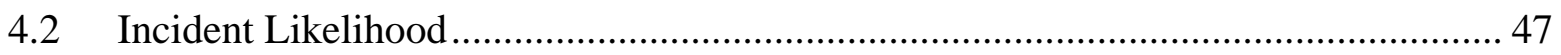

4.3 Distribution of Well Age and Potential Aging Issues........................................... 54

4.4 Estimated Impact to Electric Generating Plants .................................................. 60

4.5 Screening-Level Electric Reliability Assessment ................................................... 62

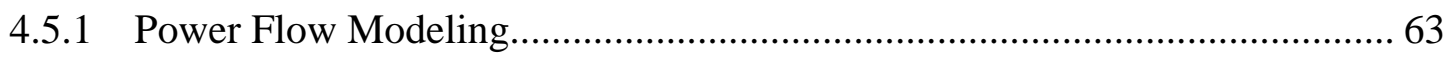

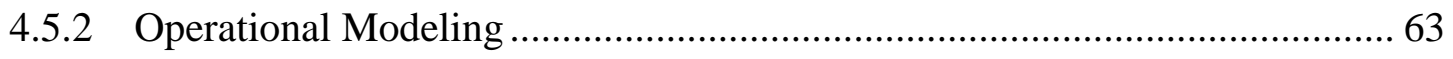

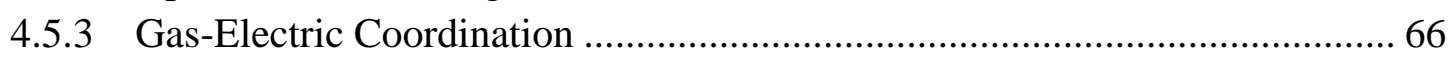

4.6 Overall UGS Supply Risk Assessment ................................................................ 68

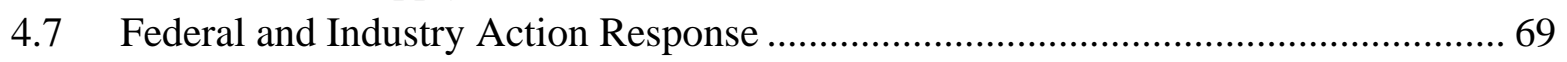

5 Summary of Findings and Recommendations.............................................................. 72

5.1 Topic I: Ensuring Electric Reliability and Managing Gas-Electric

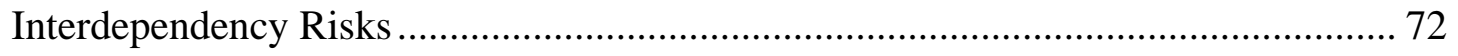

5.2 Topic II: Further Analyses and Tools Required .............................................. 73

5.3 Topic III: Data Needed for Additional Gas/Electric Reliability Studies .................. 76

5.4 Topic IV: Regulatory Requirements and Standards ......................................... 76

Appendix A: Common UGS Facility Characteristics ....................................................... 78

Appendix B: Summary of Documented Events Reported at U.S. UGS Facilities

Which May Have Led to Leakage and/or Failure ............................................. 85 


\section{Figures}

ES-1 Locations of 12 UGS Facilities, Disruption of Which Could Potentially

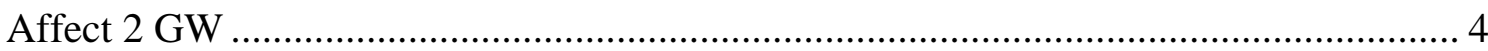

ES-2 Potential Electric Reliability Impacts from Hypothetical Loss of UGS Facilities ............ 5

ES-3 Locations of UGS Facilities with a Non-Zero Risk Value................................................ 6

2-1 Types of Underground Natural Gas Storage Facilities.................................................. 9

2.1-1 Natural Gas UGS Facilities in the Lower 48 States ....................................................... 11

3-1 Underground Gas Storage Supply to Markets............................................................. 13

3.1-1 Electric Power Generating Stations Connecting to a Natural Gas System ...................... 15

3.1.2-1 Field-Level UGS Data, including Data on the Annual Operations of All Active UGS Facilities in the United States ................................................................... 17

3.1.2-2 EIA Annual Demand Data by Customer Class by LDC for 2014 ……………................ 17

3.1.2-3 Single- and Three-Day Peak Delivery Data for Equitrans, LP ...................................... 18

3.1.2-4 Peak Day Demand and Supply Requirements for Southern California Gas Company and San Diego Gas \& Electric ............................................................... 20

3.1.2-5 Underground Gas Storage Data for the Peoples Gas Light and Coke

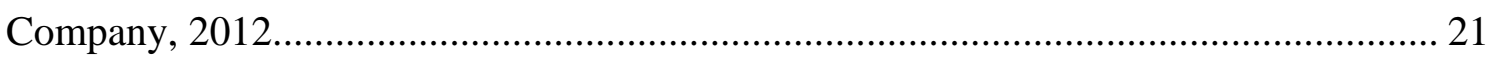

3.1.3-1 "Input-Output" Screen of the UGS-LDC Impact Analysis Model.................................. 23

3.1.4-1 "Input-Output” Screen of the UGS-Pipeline Impact Analysis Model.............................. 25

3.1.5-1 "Input-Output" Screen of the UGS-Third-Party Impact Analysis Model ......................... 26

3.2-1 Dependence of Potentially Affected Electric Capacity with UGS

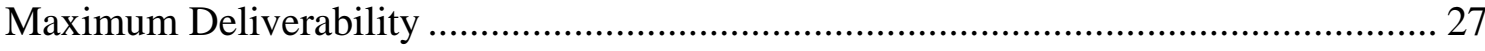

3.3.1-1 EPfast Network Configuration for the Eastern Interconnection....................................... 31

3.3.2-1 The Zonal Topology of the Eastern Interconnection as Represented in

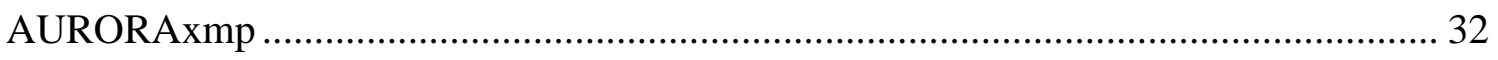

3.4-1 Approach to Estimating UGS Incident Frequencies ………............................................ 34

3.4.2-1 Calculated Failure Rates for Storage Cavity Integrity Failure ......................................... 36

3.5.1-1 Estimated Interruption Cost per Electric Outage Event, Average kW and Unserved kWh by Duration and Customer Class ........................................................... 39

4-1 Estimated Impacts from a One-Month Disruption in Natural Gas Supply from the Aliso Canyon UGS Facility 


\section{Figures (Cont.)}

4-2 Estimated Impacts from a Disruption of Aliso Canyon Operations under

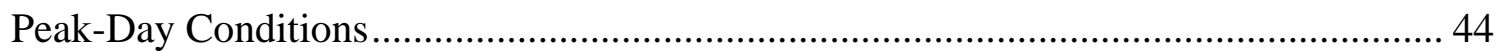

4.2-1 Locations of Documented Incidents at UGS Facilities in the United States ................. 50

4.2-2 Examples of UGS Facilities Closed Due to Gas Migration or Cap Rock Failure........... 52

4.3-1 Example Well Completion Date Data for SoCalGas's Aliso Canyon UGS Field .......... 55

4.3-2 Well Completion Date Data for UGS Fields in California........................................ 55

4.3-3 Well Completion Date Data for SoCalGas's Aliso Canyon UGS Field ....................... 56

4.3-4 Well Completion Date Data for UGS Fields in Michigan ........................................ 56

4.3-5 Well Completion Date Data for UGS Storage Fields in West Virginia ......................... 57

4.3-6 UGS Well Completion Dates Supporting UGS Operations ....................................... 60

4.4-1 Locations of 12 UGS Facilities, Disruption of Which Could Potentially

Affect $2 \mathrm{GW}$ or More of Generation Capacity ...................................................... 62

4.5-1 Potential Electric Reliability Impacts from Hypothetical Loss of UGS Facilities ......... 63

4.5-2 Potential Electric Reliability Impacts from Hypothetical Loss of UGS Facilities .......... 64

4.5-3 System Outcome during Peak Load Conditions under Baseline

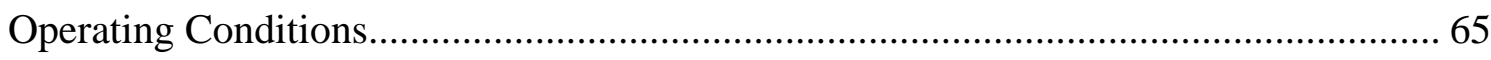

4.5-4 System Outcome during Peak Load Conditions under a Disruption to

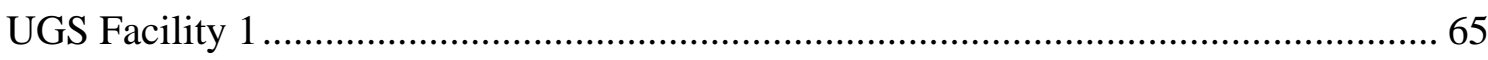

4.5-5 System Outcome during the Peak Load Conditions under a Disruption to

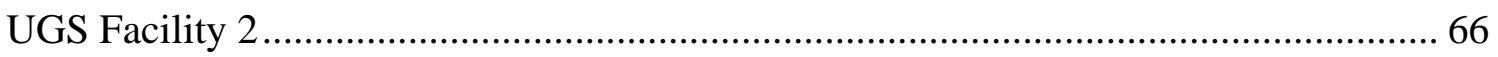

4.6-1 Locations of UGS Facilities with a Non-Zero Risk Value.......................................... 68

A-1 Schematic of Natural Gas Production, Processing, Transmission, and Storage ............ 77

A.1-1 Salt Cavern Underground Natural Gas Storage Station ............................................. 79

A.1-2 Integral Reciprocating Natural Gas Compressor ................................................... 79

A.1-3 Solar T-1001 Gas Turbine-Driven Centrifugal Gas Compressor ............................... 79

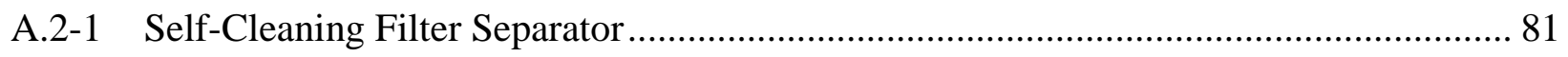




\section{Figures (Cont.)}

A.3-1 Forced-Draft Gas Aftercooler.......................................................................... 81

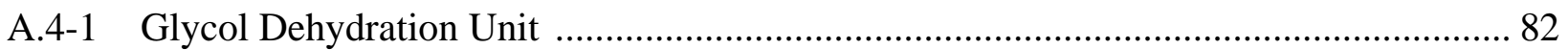

A.4-2 Solid Adsorbent Dehydration System .............................................................. 82

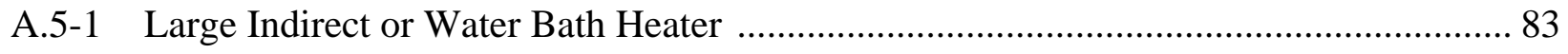

A.6-1 SCADA Operator at the Control Center Console ..................................................... 84

\section{Tables}

3.1.2-1 FERC Form 549A Data for Peoples Gas Light and Coke Company ............................ 19

3.2-1 Index of Customer Data for Bluewater Gas Storage, LLC ........................................ 28

3.2-2 Power Plants Identified by the EIA Form 923 to Have Been Provided

Natural Gas by Shell Energy North America in 2015 .............................................. 28

3.5.1-1 Estimated Interruption Cost and Equivalent Number of Residential

Customers as a Function of Natural Gas Customer Class ......................................... 40

4.2-1 Summary of Documented Events Reported at U.S. Underground Gas

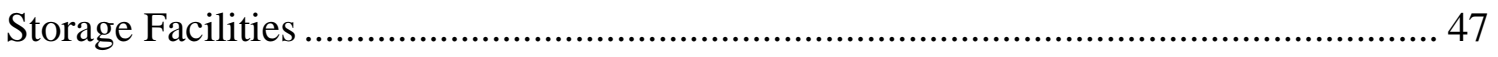

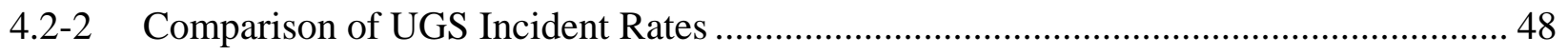

4.2-3 Summary of Main Processes Leading to Events at Underground Gas

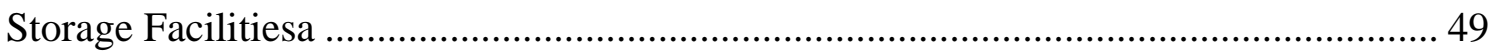

4.2-4 Details of Recent Incidents Reported at the Ryckman Creek Storage

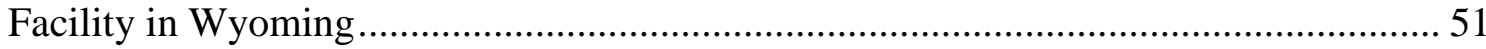

4.2-5 Literature Values on the Projected Frequency of Incidents for UGS Facilities ............. 53

4.3-1 Breakdown of Completion Dates of Underground Wells Supporting

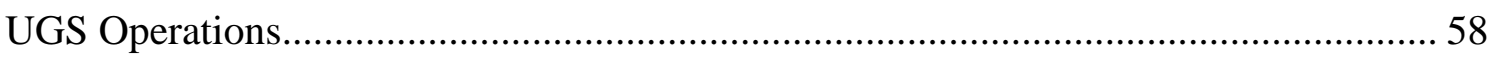

B-1 Summary of Documented Events at Depleted Oil and Gas Underground

Storage Facilities, Some of Which Have Led to Leakage and/or Failure ...................... 86

B-2 Summary of Documented Events at Aquifer Underground Storage Facilities,

Some of Which Have Led to Leakage and/or Failure.....

B-3 Summary of Documented Events at Salt Cavern Underground Storage

Facilities, Some of Which Have Led to Leakage and/or Failure 106 


\section{Acronyms and Abbreviations}

\begin{tabular}{|c|c|}
\hline API & American Petroleum Institute \\
\hline Btu & British thermal unit(s) \\
\hline $\mathrm{CHP}$ & combined heat and power \\
\hline C\&I & commercial and industrial \\
\hline $\mathrm{d}$ & $\operatorname{day}(\mathrm{s})$ \\
\hline DHS & U.S. Department of Homeland Security \\
\hline DOE & U.S. Department of Energy \\
\hline DOE-OE & $\begin{array}{l}\text { U.S. Department of Energy, Office of Electricity Delivery and Energy } \\
\text { Reliability }\end{array}$ \\
\hline DOT & U.S. Department of Transportation \\
\hline ECIP & Enhanced Critical Infrastructure Program \\
\hline EIA & Energy Information Administration \\
\hline EPA & U.S. Environmental Protection Agency \\
\hline FERC & Federal Energy Regulatory Commission \\
\hline FRCC & Florida Reliability Coordinating Council \\
\hline $\mathrm{ft}$ & foot (feet) \\
\hline GW & gigawatt(s) $-1,000$ megawatts \\
\hline HSE & Health and Safety Executive \\
\hline IOGCC & Intrastate Oil and Gas Compact Commission \\
\hline IP & Informational Posting \\
\hline ISO & Independent System Operator \\
\hline $\mathrm{kW}$ & kilowatt(s) \\
\hline $\mathrm{kWh}$ & kilowatt-hour(s) \\
\hline LDC & local distribution company \\
\hline LMP & locational marginal price \\
\hline LNG & liquefied natural gas \\
\hline LPG & liquid petroleum gas \\
\hline MAOP & maximum allowable operating pressure \\
\hline Mcf & thousand cubic feet \\
\hline MISO & Midcontinent Independent System Operator \\
\hline MMcf & million cubic feet \\
\hline MMcf/d & million cubic feet per day \\
\hline MTU & master terminal unit \\
\hline
\end{tabular}




$\begin{array}{ll}\text { MW } & \text { megawatt(s) }-1,000,000 \text { watts } \\ \text { mWh } & \text { Nogawatt-hour(s) } \\ \text { NERC } & \text { National Fire Incident Reporting System } \\ \text { NFIRS } & \text { natural gas } \\ \text { NG } & \text { Kinder Morgan Natural Gas Pipeline of America } \\ \text { NGPL } & \text { National Response Center } \\ \text { NRC } & \text { Pacific Gas and Electric } \\ \text { PG\&E } & \text { Pipeline and Hazardous Materials Safety Administration } \\ \text { PHMSA } & \text { Protecting our Infrastructure of Pipelines and Enhancing Safety Act } \\ \text { PIPES Act } & \text { public utility commission } \\ \text { PUC } & \text { Regional Transmission Organization } \\ \text { RTO } & \text { remote terminal unit } \\ \text { RTU } & \text { supervisory control and data acquisition (system) } \\ \text { SCADA } & \text { San Diego Gas and Electric Company } \\ \text { SDG\&E } & \text { subject-matter expertise } \\ \text { SME } & \text { Southern California Gas Company } \\ \text { SoCalGas } & \text { Southern Power Pool } \\ \text { SPP } & \text { trillion cubic feet } \\ \text { Tcf } & \text { underground gas storage }\end{array}$


This page left intentionally blank. 


\section{Executive Summary}

This report summarizes the methodology and models developed to assess the risk to energy delivery from the potential loss of underground gas storage (UGS) facilities located within the United States. The U.S. has a total of 418 existing storage fields, of which 390 are currently active. The models estimate the impacts of a disruption of each of the active UGS facilities on their owners/operators, including (1) local distribution companies (LDCs), (2) directly connected transporting pipelines and thus on the customers in downstream States, and (3) third-party entities and thus on contracted customers expecting the gas shipment. Impacts are measured across all natural gas customer classes. For the electric sector, impacts are quantified in terms of natural gas-fired electric generation capacity potentially affected from the loss of a UGS facility. For the purpose of calculating the overall supply risk, the overall consequence of the disruption of an UGS facility across all customer classes is expressed in terms of the number of expected equivalent residential customer outages per year, which combines the unit business interruption cost per customer class and the estimated number of affected natural gas customers with estimated probabilities of UGS disruptions. All models and analyses are based on publicly available data. The report presents a set of findings and recommendations in terms of data, further analyses, regulatory requirements and standards, and needs to improve gas/electric industry coordination for electric reliability.

Natural gas storage plays a critical role in meeting natural gas demand on peak-demand days. Underground natural gas storage provides pipelines, local distribution companies, producers, and pipeline shippers with an inventory management tool, seasonal supply backup, and access to natural gas needed to avoid imbalances between receipts and deliveries on a pipeline network. Safety is a primary concern at underground storage (UGS) sites. Natural gas is a colorless, odorless, and gaseous hydrocarbon. It may be stored in a number of different ways. It is most commonly held in inventory underground under pressure in one of three types of facilities: (1) depleted reservoirs in oil and/or gas fields, (2) aquifers, and (3) salt cavern formations. These facilities are owned and operated by interstate/intrastate pipelines, independent third parties ${ }^{1}$, and LDCs.

Most existing natural gas storage in the United States is in depleted natural gas or oil fields that are close to consumption centers. Conversion of a field from production to storage duty takes advantage of existing wells, gathering systems, and pipeline connections. Depleted oil and natural gas reservoirs are the most commonly used underground storage sites because of their wide availability.

In some areas, most notably the Midwestern United States, natural aquifers have been converted to natural gas storage reservoirs. An aquifer is suitable for gas storage if the water-bearing sedimentary rock formation is overlaid with an impermeable cap rock. Although the geology of aquifers is similar to depleted production fields, their use for natural gas storage usually requires more base (cushion) gas and allows less flexibility in injecting and withdrawing. Deliverability rates may be enhanced by the presence of an active water drive, which supports the reservoir pressure through the injection and production cycles.

1 Also known as "merchant stand-alone" facilities. 
Salt caverns provide very high withdrawal and injection rates relative to their working gas capacity. Base gas requirements are relatively low. Most salt cavern storage facilities have been developed in salt dome formations located in the Gulf Coast States. Salt caverns have also been made (by a process called leaching) in bedded salt formations in Northeastern, Midwestern, and Southwestern States. Cavern construction is more costly than depleted field conversions when measured on the basis of dollars per thousand cubic feet of working gas capacity, but the ability to perform several withdrawal and injection cycles each year reduces the per-unit cost of each thousand cubic feet of gas injected and withdrawn. ${ }^{2}$

\section{ES.1 Results-UGS Facilities}

Examination of U.S. Energy Information Administration (EIA) and Federal Energy Regulatory Commission (FERC) data indicates a heavy dependence of the Northeast and Midwest on UGS withdrawals (between 50 and 55\% in the Midwest) during the winter heating season. This study indicates that working gas capacity and maximum deliverability alone do not determine UGS facility criticality, and other factors including UGS facility utilization factor and unreserved or uncontracted pipeline capacity (which is generally limited) need to be considered.

Pipeline and Hazardous Materials Safety Administration (PHMSA) data shows, on average, 2 to 3 UGS incidents annually, with a total of 94 incidents from 1984 to 2015 . This results in an annual frequency of $3.6 \times 10^{-3}$ per facility-year. The downstream impacts of these incidents are not typically provided in the PHMSA data.

Corrosion is a primary cause (35 incidents out of 94 total, 37\%). It should be noted that the PHMSA data does not include incidents involving underground components such as wells, etc. It also does not cover UGS facilities owned by companies other than interstate pipelines (i.e., local distribution companies, intrastate pipelines, and independent storage operators) which combined account for approximately half of all UGS facilities in the United States.

Additional incident data is available to supplement the PHMSA incident data including data from the National Response Center (NRC), the U.S. Fire Administration National Fire Incident Reporting System (NFIRS), and detailed literature search.

A literature review indicates that the risk of UGS facilities is dominated by releases from wells connecting the storage reservoir to the surface, which results in a rapid release up the well to the surface. A literature search indicates that the failure rate for geological failure of the storage reservoir in a UGS facility into nearby media is much lower and results in slow release of stored gas.

Well data for UGS facilities is publicly available for some States, and contains information on the date when a well was initially drilled, whether for injection or withdrawal, etc. However,

${ }^{2}$ URL: https://www.eia.gov/naturalgas/storage/basics/. 
there is no single database containing all of the required information on UGS wells in the United States.

The available State well data for UGS facilities indicate many wells were drilled before the 1970s, which implies that many UGS wells were not built to current standards. The data shows that some wells were installed as early as 1900. It should be noted that State well data is missing critical information (well age, etc.). Further investigation is needed to examine UGS incident causality with well age.

\section{ES.2 Results-Electric Sector Impacts}

The analysis indicates that the largest potential impact from the loss of the natural gas supply from UGS facilities would be on natural gas-fired power plants. The impact on downstream residential and commercial customers is estimated to be minimal. This analysis predicts $7.8 \mathrm{GW}$ of natural gas-fired capacity potentially affected by a loss of the Aliso Canyon facility in California at peak-month conditions. A Joint Workshop predicted approximately $9.8 \mathrm{GW}$ at-risk at peak-day conditions. It is assumed that the difference in the natural gas-fired electric capacity between the two estimates is due to the higher assumed peak-day requirements versus those for peak-month in this study.

This study also finds that Aliso Canyon is not a unique UGS in terms of potential electric power impacts. The loss of a single power plant generally does not affect electric capacity unless the power plant is relatively large (two gigawatts $[\mathrm{GW}]$ or more). A total of $12 \mathrm{UGS}$ facilities appear to have the potential to affect $2 \mathrm{GW}$ or more of available generation capacity. Note, however, that these figures are preliminary, because the operators of the affected power plants may or may not have dual-fuel capability (i.e., diesel or equivalent liquid fuels, with access at short notice to sufficient inventories of alternative sources of natural gas, or access to alternative generation via transmission). The general locations of these UGS facilities are shown in Figure ES-1. Two are located in California (one of which is Aliso Canyon). Five are in Mississippi, three are in Louisiana, one is in Michigan, and one is in New York.

This analysis indicates that the greatest impact to natural gas-fired electricity-generating plants would occur from the hypothetical loss of a high-deliverability UGS facility owned by a thirdparty independent storage service provider. This finding apparently agrees with the recent evolution of the natural gas sector, in which the deregulation of underground storage combined with other factors such as the growth in the number of natural gas-fired electricity generating plants has placed a premium on high-deliverability storage facilities. This analysis shows that nine of the top-12 UGS facilities (in terms of impacts to natural gas-fired electricity generating plants) are owned by independent storage service providers.

The projected impacts for pipeline-owned UGS facilities were shown to be less than those for third-party independent storage service providers, because the analysis showed that pipelines generally have adequate resources in the form of unreserved pipeline capacity or the potential for additional withdrawals from unaffected pipeline-owned UGS facilities to compensate for the total loss of withdrawals from a single affected UGS facility. The results show that one of the 
top-12 UGS facilities (in terms of impacts to natural gas-fired electricity generating plants) is owned by an interstate pipeline company, with 2 other pipeline-owned UGS facilities estimated to have impacts on electric generation capacity. The results also show that the impacts for

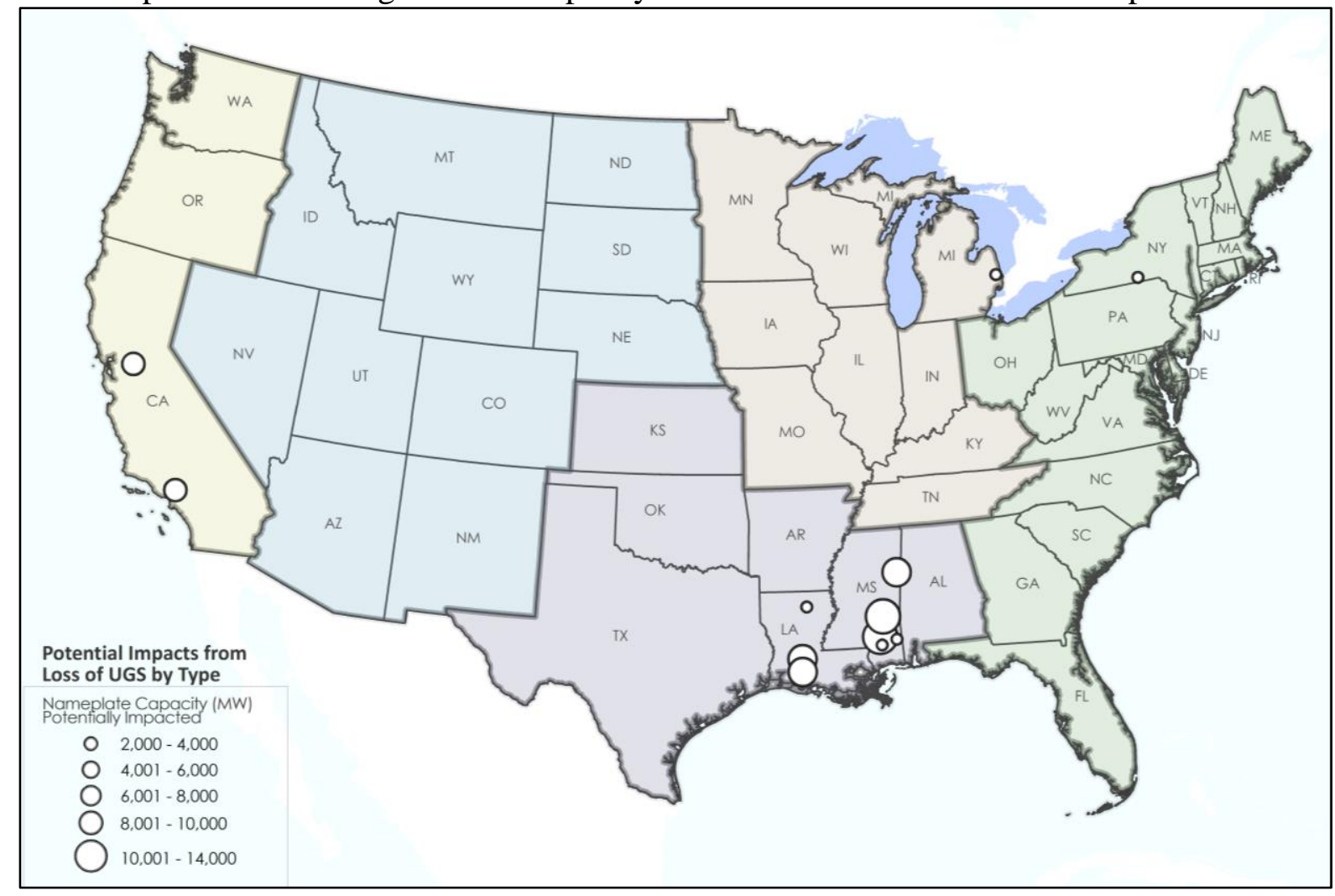

Figure ES-1 Locations of 12 UGS Facilities, Disruption of Which Could Potentially Affect 2 GW or More of Generation Capacity

underground gas storage facilities owned by interstate pipeline companies would be spread out over a wider area and affect multiple States.

The analysis projected impacts for UGS facilities owned by LDCs, with two of the top-12 UGS facilities owned by LDCs. Both of these top-12 UGS facilities are located in California. The results also show that the impacts for underground gas storage facilities owned by LDCs would be limited to the LDCs' service territories.

An initial screening-level reliability assessment for the two UGS facilities with the highest potentially affected gas-fired capacity was conducted using two power grid simulation tools - an instantaneous power flow model and an operational economic dispatch model. As shown in Figure ES-2, both models show the prospect for reliability impacts for both facilities in terms of potential electric customer outages (shaded areas shown in top part of Figure ES-2) and electric customer price impacts (up to 50-140\% increase in peak-day price in affected market zones shown in bottom part of Figure ES-2). 


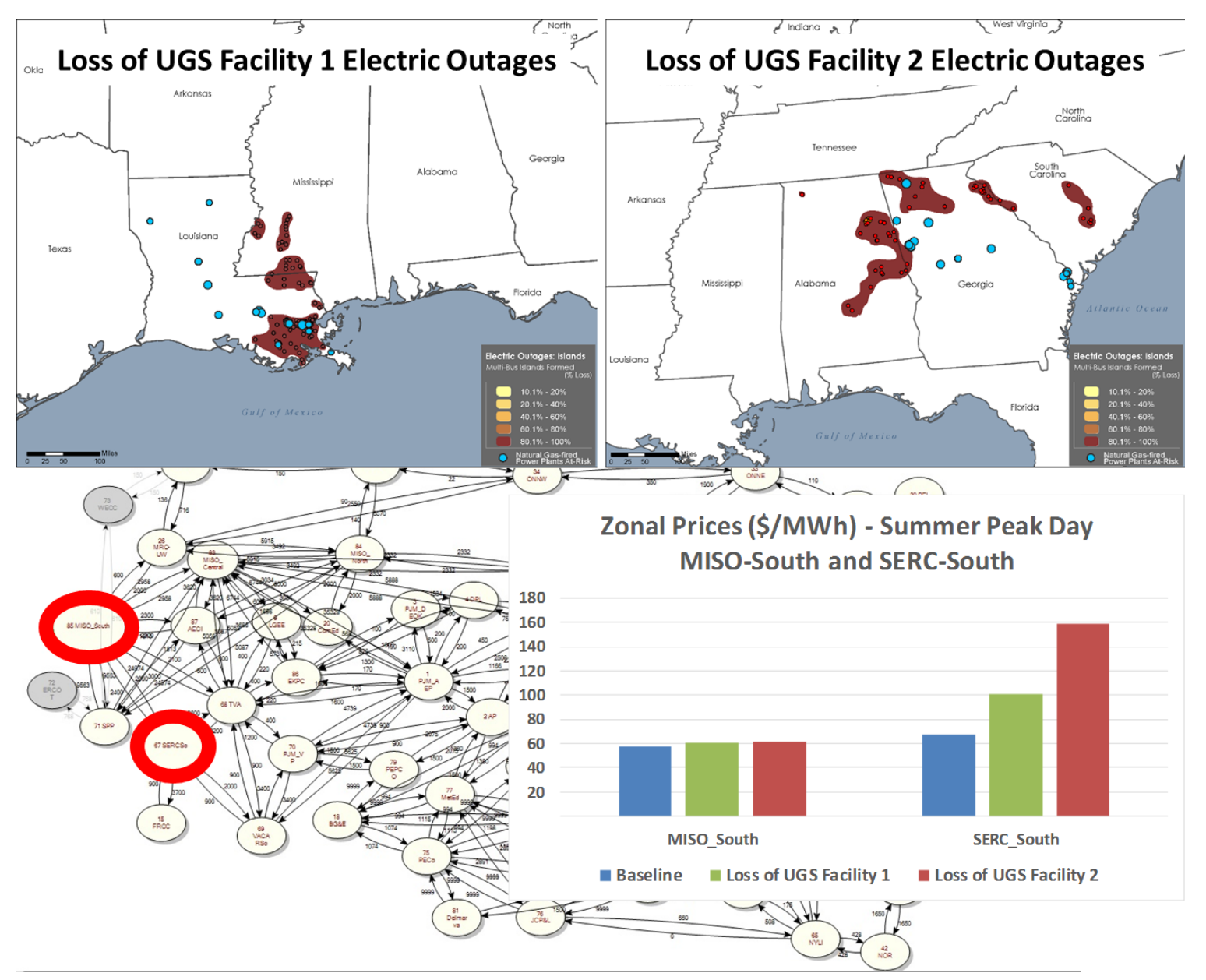

Figure ES-2 Potential Electric Reliability Impacts from Hypothetical Loss of UGS Facilities (Top: Potential Outage Areas; Bottom: Potential Price Impacts for Two Market Zones) ${ }^{3}$

\section{ES.3 Results-Overall Supply Risk}

Figure ES-3 provides the estimated risk values based on the expected equivalent number of residential customer outages per year. It can be seen that the predicted risk is low (maximum value of approximately 32,000 expected equivalent residential customer outages per year), with most UGS facilities having a predicted risk of less than 1,000 expected equivalent residential customer outages per year.

${ }^{3}$ Source: Argonne staff 


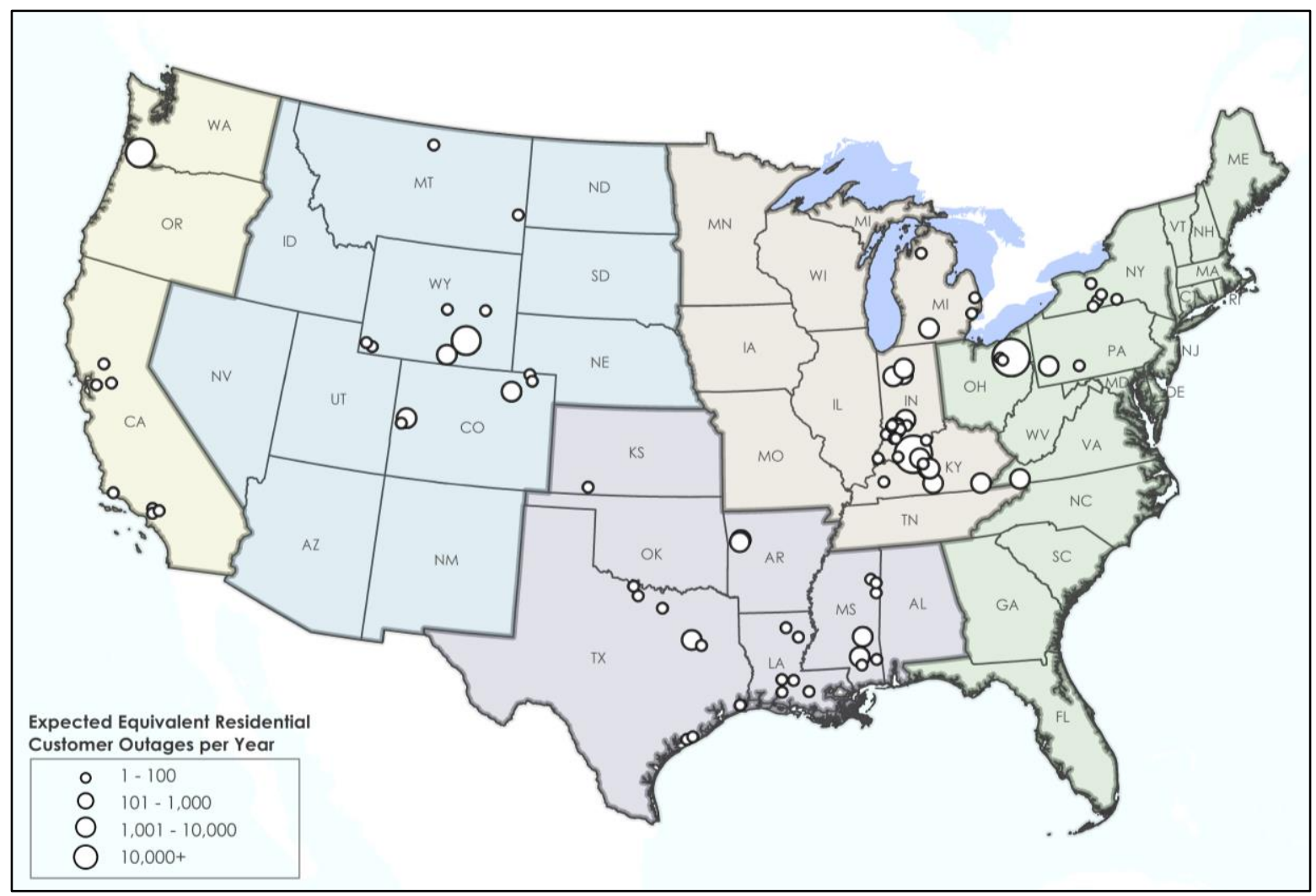

Figure ES-3 Locations of UGS Facilities with a Non-Zero Risk Value

The results in Figure ES-3 agree with the observation that the loss of gas service to a large number of customers is a relatively rare occurrence. In the last 35 years in the Chicago Metropolitan Area, the largest number of customers losing gas service at any one time has been on the order of 4,500. ${ }^{4}$ Similarly, the Southwest cold weather event of February 1-5, 2011, led to extensive curtailments of gas service to more than 50,000 customers in New Mexico, Arizona, and Texas. ${ }^{5}$ When compared with customers affected by electric power outages (which can be in excess of 100,000), the estimated number of expected annual customer outages in Figure ES-3 can be considered to be relatively small.

This study additionally finds that a number of urban centers are highly dependent on local gas storage facilities for timely delivery of gas for electricity generation and residential, commercial, and industrial requirements.

\footnotetext{
${ }^{4}$ URL: http://www.ipd.anl.gov/anlpubs/2003/02/45798.pdf.

5 URL: http://www.ferc.gov/legal/staff-reports/08-16-11-report.pdf.
} 


\section{Introduction}

The United States used about 26.8 trillion cubic feet (Tcf) of natural gas in 2014, the equivalent of 27.5 quadrillion British thermal units (Btu) and $28 \%$ of total U.S. energy use. Natural gas storage plays a critical role in meeting natural gas demand on peak-demand days.

Natural gas is a colorless, odorless, and gaseous hydrocarbon. It may be stored in a number of different ways. It is most commonly held in inventory underground under pressure in one of three types of facilities: (1) depleted reservoirs in oil and/or gas fields, (2) aquifers, and (3) cavern formations. These facilities are owned and operated by interstate/intrastate pipelines, independent third parties, and local distribution companies (LDCs).

Safety is a primary concern at underground storage (UGS) sites. A massive natural gas storage facility operated by Southern California Gas (SoCalGas) in Southern California's Aliso Canyon had an integrity incident resulting in a loss of primary containment in October 2015. The leak was approximately 400 feet underground and proved very difficult to close, leading to measurably significant emissions of methane and resulting in major health risks for nearby residents. The Aliso Canyon facility is one of 418 existing underground gas storage units nationwide, of which 390 are currently active, according to the U.S. Energy Information Administration (EIA). The largest, with nearly twice the capacity of Aliso Canyon, is located in Montana. Michigan, Illinois, Texas, Pennsylvania, and Louisiana all store more natural gas underground than California. Nationwide, storage volumes has grown steadily over the past decade, as hydraulic fracturing has created a boom in gas production, delivery, and use.

Gaps exist in our current understanding of the risks to energy delivery from the potential unexpected loss of natural gas storage facilities located within the United States. (In this context, risk is defined as the potential for an unwanted outcome resulting from an incident, event, or occurrence, as determined by its likelihood and the associated consequences.) Development of an empirical, rigorous risk-based method that is validated by the natural gas sector would provide greater understanding of the major threats and consequences to the Energy Sector from the loss of underground gas storage facilities.

Argonne National Laboratory's (Argonne's) task for the U.S. Department of Energy (DOE) Office of Electricity Delivery and Energy Reliability (DOE-OE) focused on development of an empirical and rigorous risk-based method to rank the risk to energy delivery from the potential loss of underground gas storage facilities located within the United States (including Alaska), and application of the method to existing underground gas storage facilities in the United States. 


\section{Description of Underground Storage Sector}

The demand for gas changes with the seasons. Natural gas demand has traditionally been at its highest in winter, primarily as a result of home heating requirements. This is when pipelines would typically move large quantities of natural gas for their customers. In the summer, demand for natural gas is reduced, so pipeline deliveries are lower. The development of gas storage fields near major consumption markets has enabled transmission pipelines to maintain a fairly constant delivery level throughout the year. Surplus gas is transported to the storage facility and injected during the summer, and withdrawn during the winter to help meet the increased demand. Natural gas in storage also serves as insurance against any unforeseen accidents, natural disasters, or other occurrences that may affect the production or delivery of natural gas.

In recent years, demand has become somewhat less seasonal, mostly due to increased demand from natural gas-fired power plants. Because of this shift, well-placed natural gas storage has become even more important to natural gas operations. To maximize the use of pipeline capacity all year and to create additional operational flexibility, many gas storage fields are no longer cycled but only on an annual basis. Today, operational considerations of many facilities include both demand and market economics. These considerations motivate industry participants to buy additional gas supplies for storage when prices are low, and to withdraw and sell additional supplies when prices are high.

Natural gas is a colorless, odorless, and gaseous hydrocarbon. It may be stored in a number of different ways. It is most commonly held in inventory underground under pressure in one of three types of facilities: (1) depleted reservoirs in oil and/or gas fields, (2) aquifers, and (3) cavern formations. In theory, cavern formations may be depleted mines, caverns carved out of hard-rock formations, or caverns leached out of naturally occurring salt domes or reefs. In practice, salt domes are currently the only significant form of cavern storage. Each type has its own physical characteristics (porosity, permeability, and retention capability) and economics (geographic location, site preparation costs, deliverability rates, and cycling capability) that govern its suitability to particular applications.

Most existing gas storage in the United States is in depleted natural gas or oil fields that are close to consumption centers. Conversion of a field from production to storage duty takes advantage of existing wells, gathering systems, and pipeline connections. Depleted oil and gas reservoirs are the most commonly used underground storage sites because of their wide availability.

In some areas, most notably the Midwestern United States, natural aquifers have been converted to gas storage reservoirs. An aquifer is suitable for gas storage if the water-bearing sedimentary rock formation is overlaid with an impermeable layer of cap rock. While the geology of aquifers is similar to depleted production fields, their use in gas storage usually requires more base (cushion) gas and greater monitoring of withdrawal and injection performance. Deliverability rates may be enhanced by the presence of an active water drive. Aquifer storage facilities are more expensive to develop than depleted reservoirs. These types of storage facilities are usually used only in areas where there are no nearby depleted reservoirs, such as in the Midwest. 
Salt caverns provide very high withdrawal and injection rates relative to their working gas capacity. Base gas requirements are relatively low. The majority of salt cavern storage facilities have been developed in salt dome formations located in the Gulf Coast States. Salt caverns have also been leached from bedded salt formations in Northeastern, Midwestern, and Southwestern States to take advantage of the high injection/withdrawal rates and flexible operations possible with a cavern facility.

Efforts have been made to use abandoned mines to store natural gas, with at least one such facility having been in use in the United States in the past. Further, the potential for commercial use of hard-rock cavern storage is currently undergoing testing. No abandoned mines are operational as natural gas storage sites at present.

Figure 2-1 is a stylized representation of the various types of UGS facilities, and Figure 2.1-1 shows the locations of the 418 storage facilities in the Lower 48 States, of which 390 are currently active. Currently, about 120 entities operate these active UGS facilities in the United States.

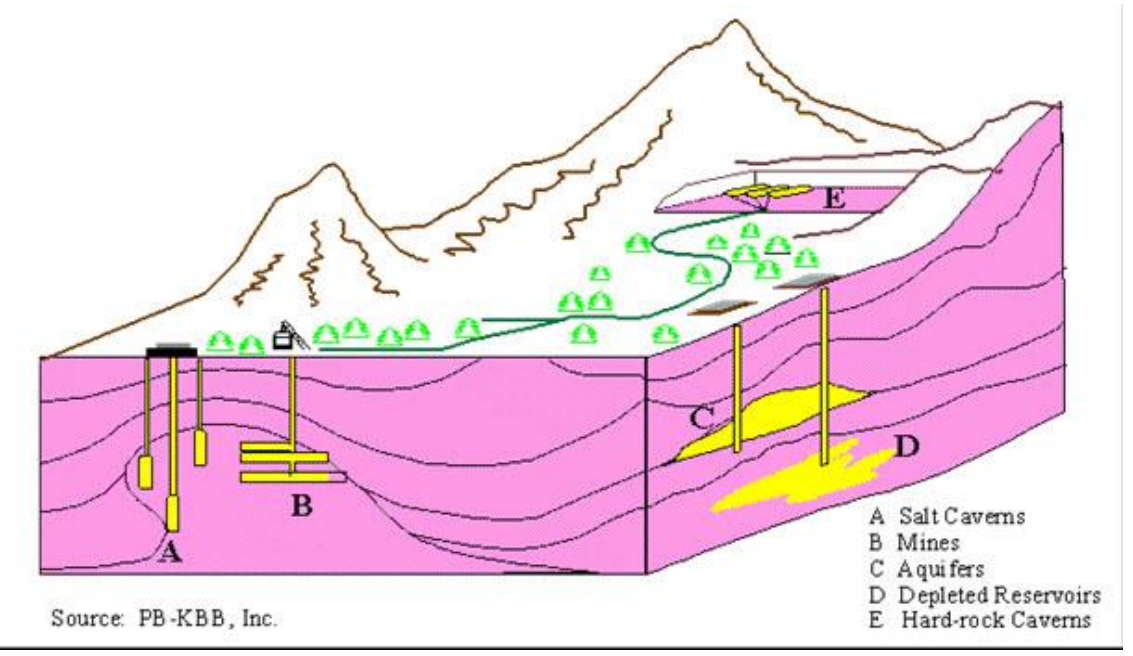

Figure 2-1 Types of Underground Natural Gas Storage Facilities ${ }^{6}$

Information on common UGS facility characteristics is provided in Appendix A.

\subsection{Storage Measures}

Several volumetric measures are used to quantify the fundamental characteristics of a UGS facility and the gas contained within it. For some of these measures, it is important to distinguish between a characteristic of a facility, such as its capacity, and a characteristic of the natural gas within the facility, such as the actual inventory level. These measures are as follows:

6 Energy Information Administration (EIA), 1999. "Types of Underground Natural Gas Storage Facilities," available at https://www.eia.gov/pub/oil_gas/natural_gas/presentations/1999/nat_gas_pipeline_storage_deliverability/sld014.h tm. . 
- Total natural gas storage capacity is the maximum volume of natural gas that can be stored in a UGS facility in accordance with its design, which comprises the physical characteristics of the reservoir, installed equipment, and operating procedures particular to the site.

- Total gas in storage is the volume of natural gas in the UGS facility at a particular time.

- Base gas (or cushion gas) is the volume of natural gas intended as permanent inventory in a storage reservoir to maintain adequate pressure and deliverability rates throughout the withdrawal season.

- Working gas capacity refers to total gas storage capacity minus base gas.

- Working gas is the volume of gas in the reservoir above the level of base gas. Working gas is available to the marketplace.

- Deliverability is most often expressed as a measure of the amount of gas that can be delivered (withdrawn) from a storage facility on a daily basis. Also referred to as the deliverability rate, withdrawal rate, or withdrawal capacity, deliverability is usually expressed in terms of millions cubic feet per day (MMcf/d). Occasionally, deliverability is expressed in terms of the equivalent heat content of the gas withdrawn from the facility, most often in dekatherms per day (a therm is 100,000 Btu, which is roughly equivalent to 100 cubic feet of natural gas; a dekatherm is the equivalent of about one thousand cubic feet [Mcf]). The deliverability of a given storage facility is variable. It depends on factors such as the amount of natural gas in the reservoir at any particular time, the pressure within the reservoir, the compression capability available to the reservoir, the configuration and capabilities of surface facilities associated with the reservoir, and other factors. In general, a facility's deliverability rate varies directly with the total amount of natural gas in the reservoir: it is at its highest when the reservoir is most full and declines as working gas is withdrawn.

- Injection capacity (or rate) is the complement of the deliverability or withdrawal rate - it is the amount of natural gas that can be injected into a storage facility on a daily basis. As with deliverability, injection capacity is usually expressed in MMcf/d, although dekatherms/day is also used. The injection capacity of a storage facility is also variable, and it is dependent on factors comparable to those that determine deliverability. By contrast, the injection rate varies inversely with the total amount of gas in storage; it is at its lowest when the reservoir is most full and increases as working gas is withdrawn.

None of these measures for any given storage facility are fixed or absolute. The rates of injection and withdrawal change as the level of natural gas varies within the facility. In practice, a storage facility may be able to exceed certificated total capacity in some circumstances by exceeding certain operational parameters. The facility's total capacity can also vary, temporarily or permanently, as its defining parameters vary. Measures of base gas, working gas, and working gas capacity can also change from time to time. These changes occur, for example, when a storage operator reclassifies one category of natural gas to the other, often as a result of new 
wells, equipment, or operating practices (such a change generally requires approval by the appropriate regulatory authority). Finally, storage facilities can withdraw base gas for supply to market during times of particularly heavy demand, although by definition, this gas is not intended for that use. ${ }^{7}$ Figure 2.1-1 shows the locations of storage facilities in the Lower 48 States.

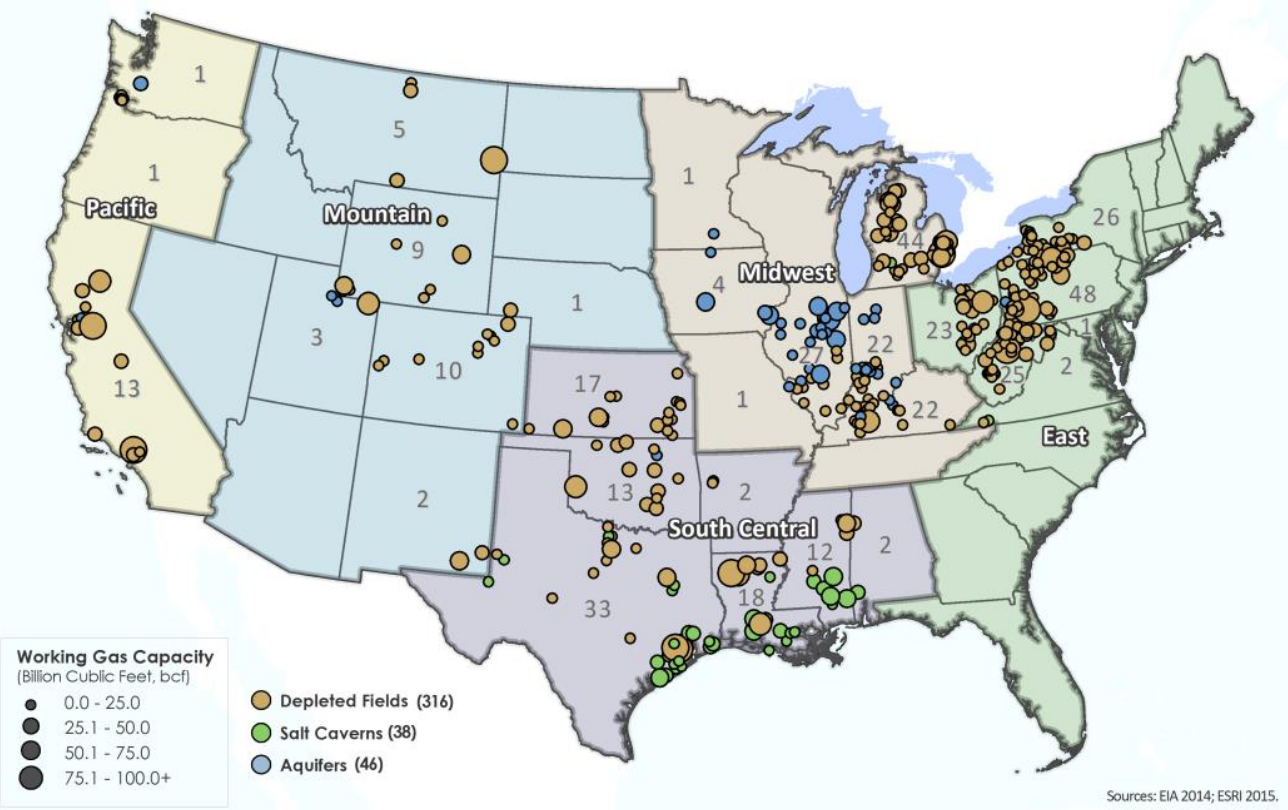

Figure 2.1-1 Natural Gas UGS Facilities in the Lower 48 States (Sources: EIA 20144, ESRI 2015²)

\subsection{Owners and Operators of UGS Facilities}

The principal owners and operators of UGS facilities are (1) interstate pipeline companies, (2) LDCs and intrastate pipeline companies, and (3) independent storage service providers. If the facility serves the interstate market, it is subject to Federal Energy Regulatory Commission (FERC) regulations; otherwise, it is State-regulated. Owners and operators of storage facilities are rarely more than minority owners of the gas held in storage. In fact, most working gas held in storage facilities is held under lease with shippers, LDCs, or end users who own the gas. ${ }^{9}$ The type of entity that owns and operates the facility will determine to some extent how that facility's storage capacity is utilized.

\subsubsection{Interstate Pipeline Companies}

Interstate pipeline companies operate about $55 \%$ of all working gas capacity in the United States (Source: Form EIA-191, Monthly Underground Gas Storage Report, June 2002). Underground

\footnotetext{
7 Ibid.

8 URL: http://www.esri.com/

9 Ibid.
} 
storage is important to interstate pipeline companies directly because they depend heavily on storage inventories to facilitate load balancing and system supply management on their long-haul transmission lines. The bulk of their storage capacity, however, is leased to other industry participants.

\subsubsection{LDCs and Intrastate Pipeline Companies}

LDCs and intrastate pipeline companies account for about $35 \%$ of working gas capacity. LDCs generally use gas from storage sites to serve customer needs directly, whereas intrastate pipeline companies use UGS for operational balancing and system supply as well as to supply the energy needs of end-use customers.

\subsubsection{Independent Operators}

Independent operators operate about $10 \%$ of current working gas capacity. Many of the salt formation and high-deliverability sites currently being developed have been initiated by independent storage service operators to serve third-party customers.

Seasonal factors have become less important in the management of underground storage inventories in recent years. Market conditions play a much larger role than in the past. Since 1994, almost all of the UGS facilities that are operated by interstate pipeline companies, which are subject to the jurisdiction of FERC, operate on an open-access basis. That is, the major portion of working gas capacity (beyond what may be reserved by the pipeline/operator to maintain system integrity and for load balancing) at each site must be made available for lease to third parties on a nondiscriminatory basis.

Prior to 1992, the use and control of capacity at a storage facility owned by an interstate pipeline was the purview of the pipeline owner. In 1992, FERC issued Order 636, which mandated unbundling of all pipeline transportation, sales, and storage services. The biggest impact of Order 636 was to convert pipelines from being sellers of gas to being primarily shippers of gas that is bought and sold by other parties. Because pipelines could no longer sell gas, and because they still needed the flexibility provided by storage, their storage facilities became entirely dependent on third-party volumes for their operational viability.

Today, in addition to the interstate storage sites, many storage facilities not subject to FERC jurisdiction (owned and operated by large LDCs, intrastate pipelines, and independent operators) also operate on an open-access basis, especially those sites affiliated with natural gas market centers. At these facilities, the use of working gas capacity has become market-oriented in addition to serving as a backup or supplemental seasonal supply source. For instance, marketers and other third parties have the opportunity to move gas into and out of storage (subject to the operational capabilities of the site or the tariff limitations) as changes in price levels present arbitrage opportunities. 


\section{Analytical Methodology, General Assumptions, and Data Sources}

The risk-based approach for ranking UGS sites nationwide required the estimation of the two most vital components of risk - probability of disruption and consequence of such disruption. For this report, the word "disruption" generally refers to the overall dysfunction or cessation of operation of the UGS facility due to an incident. The consequence of a UGS disruption was estimated using three Excel-based models developed internally by Argonne specifically for this study. The models estimate the impacts of the disruption of UGS facilities owned by local distribution companies (LDCs), interstate natural gas pipelines, and third-party independent operators. Figure 3-1 illustrates the three underground storage supply-to-customer processes that were modeled. In all three models, a compensated mode was assumed in which mitigation measures are assumed to be implemented whenever a supply shortfall is estimated by the models. Such mitigation measures include increased withdrawals from unaffected UGS facilities owned by the UGS operators, additional contributions from liquefied natural gas (LNG) storage facilities (if available), raised output from natural gas production fields, and increased contributions from other interstate transmission pipelines via interconnection points. The overall mitigating effect of these compensating mechanisms depends on the available supply, unreserved transportation capacity of the delivery system, and contractual obligations of the natural gas shippers (i.e., owners, transporters).

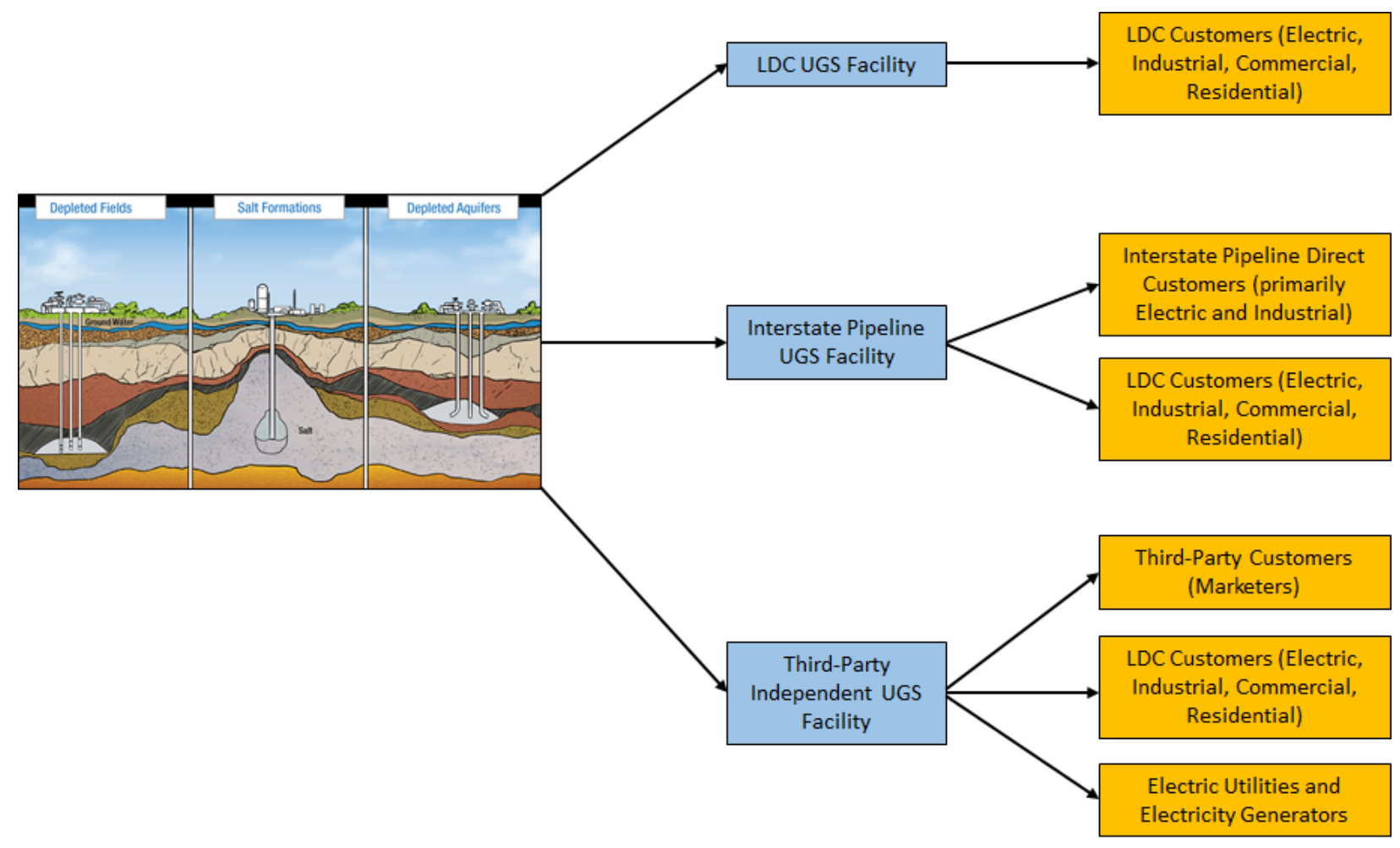

Figure 3-1 Underground Gas Storage Supply to Markets 
The consequence of a UGS disruption was expressed in terms of the number of customers affected per sector and the amount of gas flow lost. For the purposes of this study, customers in the electric sector are usually of particular interest because of the interdependency that exists between the electric and gas systems, and the impacts in the electric sector are often expressed in terms of megawatts (MW) lost. For the purpose of calculating risk, the overall consequence of the disruption of an UGS facility is expressed in terms of the number of expected equivalent residential customers, which combines the unit business interruption cost per customer class and the estimated number of affected natural gas customers.

Section 3.1 describes the logic of the three Excel-based models previously mentioned. Section 3.2 discusses the approach taken to estimate the probability component of risk associated with each UGS facility. Section 3.3 describes a screening-level electric reliability analysis for two select UGS facilities. Section 3.4 discusses the approach taken to estimate the probability component of risk associated with each UGS facility. In addition, Section 3.5 presents the approach for developing a common risk measure and the overall risk methodology.

\subsection{Methodology for Estimating the Consequences of a UGS Disruption}

Natural Gas Pipeline System to Natural Gas Fired Power Plants-Electric power generating stations are either served directly from a natural gas transmission line or metered through an LDC. Interstate and intrastate transmission pipeline companies deliver about $40 \%$ of transported gas directly to large-volume end users, such as industrial gas consumers and independent power generators. The remainder is delivered by way of the "city gate," where ownership of the gas changes (custody transfer) to LDCs, which then deliver the gas to their residential and business customers through their own networks of lower pressure, smaller diameter distribution lines and still smaller laterals (Figure 3.1-1). ${ }^{10}$

The Federal Energy Regulatory Commission (FERC) requires interstate natural gas pipelines that provide transportation service to maintain Informational Postings (IPs) on its publicly available Internet website that include location names and codes for all current and inactive receipt and delivery points on its system. This includes delivery of natural gas to electric power plants; therefore, those electric generating plants directly receiving natural gas from a transmission pipeline should be listed as a receipt point on the respective transmission pipeline's IP.

S\&P Global Platts, a private company, compiles receipt and delivery points from each of the company's IPs, and geospatially references each point. These data were used, in conjunction with publicly available data from the EIA, to determine whether each natural gas power plant receives natural gas directly via a transmission pipeline, or whether it is brokered through a LDC. If the plant is not directly connected, the serving LDC was determined by spatial proximity of that power plant to the LDC service territory.

\footnotetext{
${ }^{10}$ Curtis, J.B., and Schwochow, 2010, "From Reservoir to Burner Tip: a Primer on Natural Gas," in Potential Supply of Natural Gas -2008, pp. 193-208, Potential Gas Committee, available at http://www.potentialgas.org/download/PGC08_NGPrimer.pdf.
} 


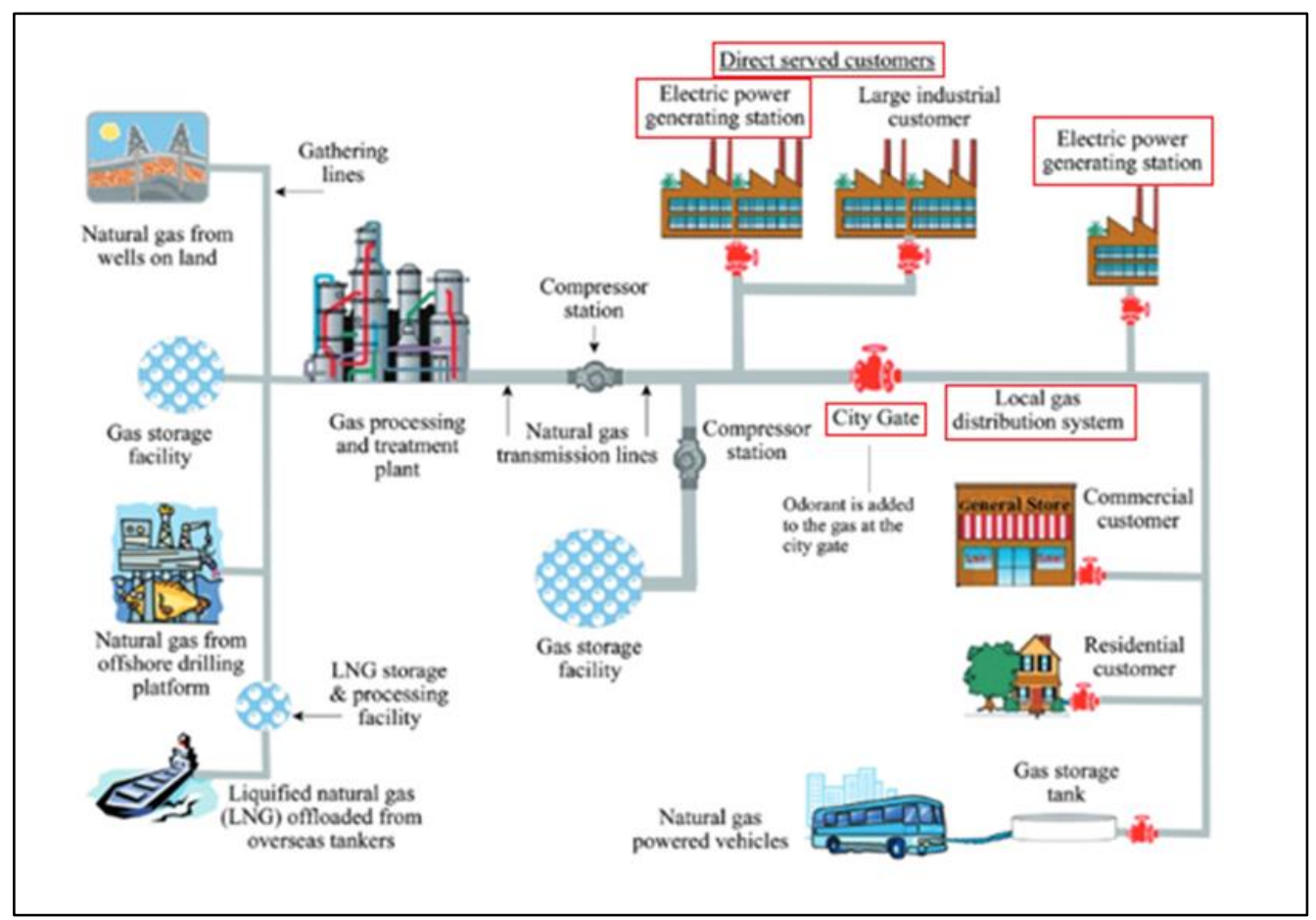

Figure 3.1-1 Electric Power Generating Stations Connecting to a Natural Gas System ${ }^{11}$

\subsubsection{Assumptions for Estimating the Consequences of a UGS Facility Disruption}

As in any study, assumptions had to be made to simplify the problem, qualify the ensuing impacts, and contextualize the recommended mitigation option(s). Some of the major assumptions made for this study are described below.

1. The period of the event (i.e., the occurrence of the loss of the UGS facility) was assumed to occur at the month of the worst supply-demand balance over the operational historical record of the UGS facility under consideration. This period is usually characterized by very high customer demand and very high storage withdrawal values.

2. The ability of other UGS facilities (as well as interconnecting points) to compensate for the loss of a specific UGS facility is limited by the unreserved capacity of the delivery system connecting the UGS facilities and the load centers.

3. An "incident" was assumed to cause the entire UGS facility to totally shut down and to reduce its pre-event output to zero. No partial shutdown was assumed.

4. The sequence of load shedding due to a natural gas supply shortfall is to proceed as follows: electric, industrial, commercial, and residential. Within each sector, interruptible

${ }^{11}$ DOT, 2011. "Fact Sheet: Pump and Compressor Stations," available at https://primis.phmsa.dot.gov/comm/FactSheets/FSPumpStations.htm. 
loads would be shed first with firm loads to be shed last. It must be emphasized that the current study does not address the aspect of how the electric sector would replace the lost electric generation capacity due to a UGS outage. The significance to an electric utility of the loss of gas supply to one or more electric generators would depend on whether the utility has access via transmission to other generation capacity to make up the shortfall. There is a need to address this topic in a follow-on study.

5. The overall measure of consequence would be in terms of the number of equivalent electric customers affected by the long-term loss of an UGS facility. This consequence value would be used along with the probability of disruption (disruption rates) value to calculate the risk associated with the UGS facility under consideration. The period for calculating the risk would be one month.

6. At all times, a steady-state commodity movement was assumed for the pre-event, duringevent, and post-event assessments.

\subsubsection{Data Sources for Estimating the Consequences of a UGS Facility Disruption}

Argonne has collected UGS operational and facility data available from several publicly available sources, as described below.

\section{Energy Information Administration}

- EIA Form-191, "Underground Natural Gas Working Storage Capacity" - annual data collected from storage operators on a field-level basis in the U.S.;

- Form EIA-176, "Annual Report of Natural and Supplemental Gas Supply and Disposition"- detailed information for gas withdrawn from storage facilities, gas added to storage facilities, deliveries of company-owned natural gas, and natural gas transported for the account of others.

Note that UGS data from the EIA are provided only at the State level, which is not very useful for predicting the impacts of the loss of a single UGS facility. Figure 3.1.2-1 shows Form EIA191 underground gas storage field data on an annual basis for all the active facilities in the United States, including the following information:

- U.S. field-level storage data;

- Total monthly storage by base gas and working gas, and storage activity by State; and

- Planned storage projects. 


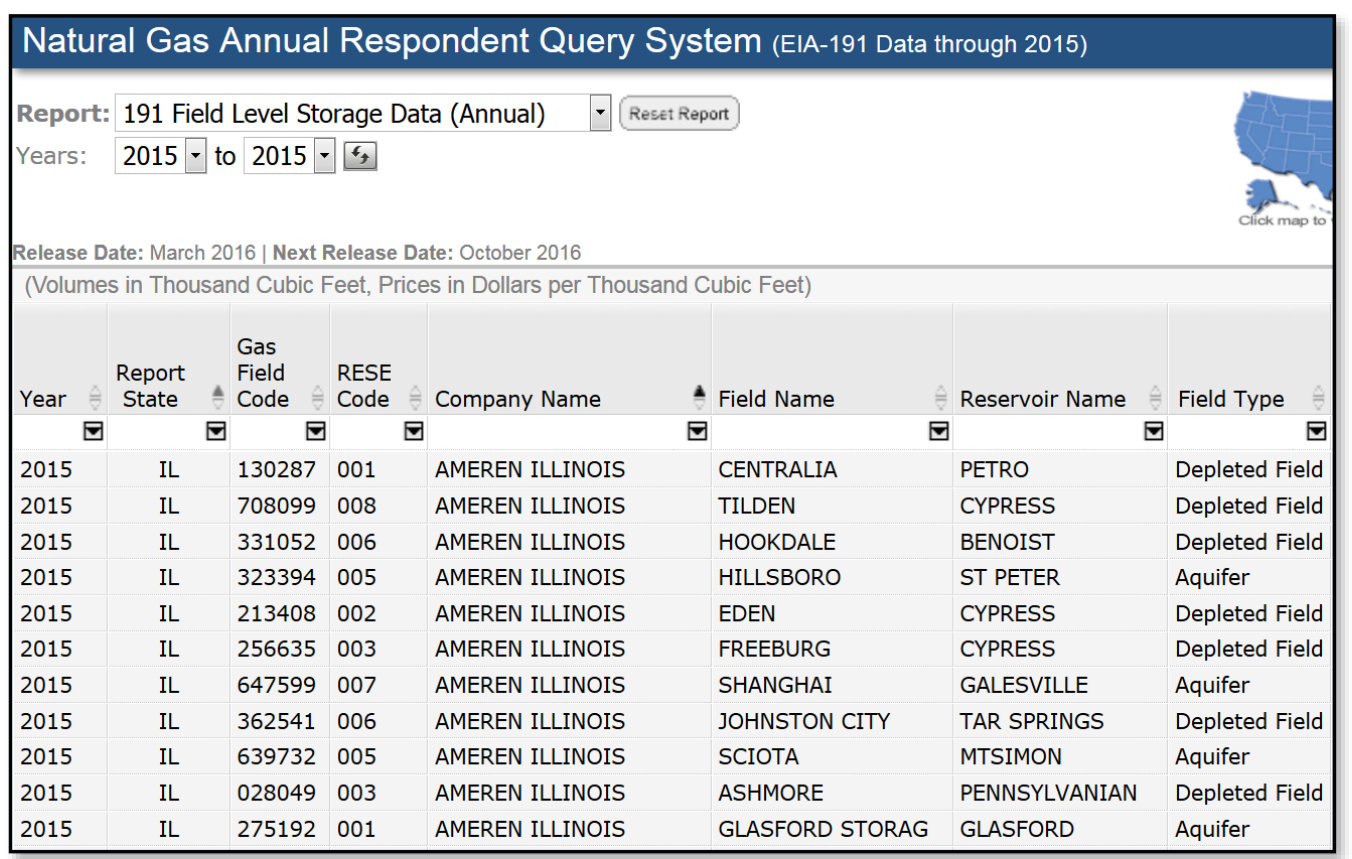

Figure 3.1.2-1 Field-Level UGS Data, including Data on the Annual Operations of All Active UGS Facilities in the United States

In addition, Form EIA-176 provides annual demand data by customer class by LDC and State, on a monthly and annual basis. Figure 3.1.2-2 shows an example of the customer-demand data.

\begin{tabular}{|c|c|c|c|c|c|c|c|c|c|c|c|c|c|c|c|c|}
\hline \multirow[b]{2}{*}{ State } & \multirow[b]{2}{*}{ EIA-176 Company Name } & \multicolumn{5}{|c|}{ Annual Demand (Mct/vr) } & \multicolumn{5}{|c|}{ Annual Average Daily Demand (MMc/d) } & \multicolumn{5}{|c|}{ Annual Number of Customers } \\
\hline & & Residential & Commercial & Industrial & $\begin{array}{c}\begin{array}{c}\text { Vehicle + } \\
\text { Other }\end{array} \\
\end{array}$ & $\begin{array}{l}\text { Electric } \\
\text { Power }\end{array}$ & Residential & Commercial & Industrial & \begin{tabular}{|c|}
$\begin{array}{c}\text { Vehicle } \\
\text { Other }\end{array}$ \\
\end{tabular} & \begin{tabular}{l|} 
Electric \\
Power
\end{tabular} & Residential & Commercial & Industrial & $\begin{array}{c}\text { Vehicle + } \\
\text { Other }\end{array}$ & $\begin{array}{l}+ \text { Electric } \\
\text { Power }\end{array}$ \\
\hline Alabama & ALABAMA GAS CORP & $22,472,903$ & $14,619,318$ & $36,595,885$ & 305,454 & $9,594,275$ & 61.57 & 40.05 & 100.26 & 0.84 & 26.29 & 391,032 & 29,632 & 1,420 & 0 & 0 \\
\hline Alabama & ALEXANDER CITY MUN GAS CO & 118,110 & 151,785 & 1,426 & 0 & 0 & 0.32 & 0.42 & 0.00 & 0.00 & 0.00 & 3,335 & 590 & & 0 & 0 \\
\hline Alabama & AMERICAN MIDSTREAM ALA INTRASTATE & 0 & 0 & 235,944 & 0 & 0 & 0.00 & 0.00 & 0.65 & 0.00 & 0.00 & 0 & 0 & 1 & 0 & 0 \\
\hline Alabama & AMERICAN MIDSTREAM ALATENN UC & 0 & 0 & $6,261,151$ & 0 & 0 & 0.00 & 0.00 & 17.15 & 0.00 & 0.00 & 0 & 0 & 10 & 0 & 0 \\
\hline Alabama & AMERICAN MIDSTREAM BAMAGAS ULC & 0 & 0 & 0 & 0 & $36,800,126$ & 0.00 & 0.00 & 0.00 & 0.00 & 100.82 & 0 & 0 & 0 & 0 & 0 \\
\hline Alabama & AMERICAN MIDSTREAM TENNESSEE RIVER & 0 & 0 & $2,607,905$ & 0 & 0 & 0.00 & 0.00 & 7.14 & 0.00 & 0.00 & 0 & 0 & & 3 & 0 \\
\hline Alabama & ATHENS GAS DEPT CITY OF & 242,447 & 370,800 & 658,507 & 2,018 & 0 & 0.66 & 1.02 & 1.80 & 0.01 & 0.00 & 7,748 & 1,002 & 37 & 707 & \\
\hline Alabama & BAY GAS STORAGE & 0 & 0 & $11,015,123$ & 0 & $55,844,866$ & 0.00 & 0.00 & 30.18 & 0.00 & 153.00 & 0 & 0 & 4 & 0 & 0 \\
\hline Alabama & BERRY GAS BOARD & 0 & 0 & 0 & 0 & 0 & 0.00 & 0.00 & 0.00 & 0.00 & 0.00 & 0 & 0 & 0 & & 0 \\
\hline Alabama & BOAZ CITY OF GAS BD & 134,678 & 122,738 & 67,346 & 0 & 0 & 0.37 & 0.34 & 0.18 & 0.00 & 0.00 & 2,929 & 399 & & & 0 \\
\hline Alabama & BREWTON CITY OF & 57,905 & 29,698 & $4,545,830$ & 0 & 0 & 0.16 & 0.08 & 12.45 & 0.00 & 0.00 & 1,644 & 249 & 6 & & 0 \\
\hline Alabama & BRIDGEPORT UTIL BD & 24,085 & 5,839 & 228,753 & 0 & 0 & 0.07 & 0.02 & 0.63 & 0.00 & 0.00 & 634 & 39 & 11 & 1 & 0 \\
\hline Alabama & BROOKSIDE GAS SYSTEM & 8,664 & 819 & 0 & 0 & 0 & 0.02 & 0.00 & 0.00 & 0.00 & 0.00 & 231 & 16 & 0 & & 0 \\
\hline Alabama & CALERA CITY OF & 85,477 & 50,868 & 401,719 & 0 & 0 & 0.23 & 0.14 & 1.10 & 0.00 & 0.00 & 2,121 & 353 & 8 & & 0 \\
\hline Alabama & CAMP HILL TOWN OF & 8,600 & 4,800 & 0 & 0 & 0 & 0.02 & 0.01 & 0.00 & 0.00 & 0.00 & 97 & 5 & & & \\
\hline Alabama & CARBON HILL UTIL BD CTYY OF & 28,426 & 3,387 & 0 & 0 & 0 & 0.08 & 0.01 & 0.00 & 0.00 & 0.00 & 630 & 5 & & & 0 \\
\hline Alabama & CHEROKEE TOWN OF & 7,020 & 8,240 & 0 & 0 & 0 & 0.02 & 0.02 & 0.00 & 0.00 & 0.00 & 195 & 47 & 0 & & 0 \\
\hline Alabama & CHILDERSBURG WTR SWR GAS BD & 51,403 & 35,499 & $2,709,369$ & 0 & 0 & 0.14 & 0.10 & 7.42 & 0.00 & 0.00 & 1,395 & 151 & 15 & & 0 \\
\hline Alabama & CLARKE MOBIIE COUNTIES GAS DISTRICT & 174,326 & 199,206 & $12,262,074$ & 0 & 88,217 & 0.48 & 0.55 & 33.59 & 0.00 & 0.24 & 5,329 & 768 & 23 & & 0 \\
\hline Alabama & CLEAN ENERGY & & 0 & 0 & 0 & 0 & 0.00 & 0.00 & 0.00 & 0.00 & 0.00 & 0 & 0 & & & 0 \\
\hline Alabama & CORDOVA WTR WKS AND GAS BD & 10,756 & 5,041 & 120,477 & 0 & 0 & 0.03 & 0.01 & 0.33 & 0.00 & 0.00 & 274 & 20 & & & 0 \\
\hline Alabama & CULIMAN JEFFERSON GAS & 500,321 & 542,007 & $2,173,038$ & 1,827 & 0 & 1.37 & 1.48 & 5.95 & 0.01 & 0.00 & 10,009 & 1,672 & 230 & 13 & 3 \\
\hline Alabama & DADEVILLE GAS BOARD & 19,427 & 23,545 & 0 & 0 & 0 & 0.05 & 0.06 & 0.00 & 0.00 & 0.00 & 442 & 127 & & & 0 \\
\hline Alabama & DAPHNE UTILS BD CITY OF & 97,930 & 116,406 & 0 & 0 & 0 & 0.27 & 0.32 & 0.00 & 0.00 & 0.00 & 3,932 & 332 & 0 & & 0 \\
\hline Alabama & DECATUR UTIL GAS DEPT & 530,247 & 548,371 & $5,516,258$ & 0 & 0 & 1.45 & 1.50 & 15.11 & 0.00 & 0.00 & 13,442 & 1,850 & 45 & & \\
\hline Alabama & DEKALB CHEROKEE COUNTIES & 260,073 & 675,446 & 554,030 & 0 & 0 & 0.71 & 1.85 & 1.52 & 0.00 & 0.00 & 5,700 & 1,387 & 12 & & 0 \\
\hline Alabama & DORA GAS BD & 28,668 & 5,052 & 0 & 0 & 0 & 0.08 & 0.01 & 0.00 & 0.00 & 0.00 & 684 & 44 & & & \\
\hline Alabama & EAST CENTRAL ALABAMA GAS DISTRICT & 129,654 & 126,257 & 100,205 & 643 & 0 & 0.36 & 0.35 & 0.27 & 0.00 & 0.00 & 2,417 & 120 & 2 & 2 & 1 \\
\hline Alabama & FAIRHOPE CITY OF & 302,352 & 138,029 & 43,663 & 0 & 0 & 0.83 & 0.38 & 0.12 & 0.00 & 0.00 & 9,337 & 429 & 8 & & \\
\hline Alabama & FAYETTE GAS BOARD & 83,432 & 77,370 & 360,345 & 0 & 0 & 0.23 & 0.21 & 0.99 & 0.00 & 0.00 & 1,742 & 279 & 2 & & 0 \\
\hline Alabama & FLORALA GAS DEPARTMENT & 7,399 & 2,917 & 6,114 & 0 & 0 & 0.02 & 0.01 & 0.02 & 0.00 & 0.00 & 385 & 25 & & & 0 \\
\hline Alabama & FLORENCE NATURAL GAS DEPT CITY OF & 610,535 & 401,431 & $1,095,199$ & 0 & 0 & 1.67 & 1.10 & 3.00 & 0.00 & 0.00 & 13,447 & 1,604 & 20 & & \\
\hline Alabama & FLORIDA GAS TRANSMISSION COMPANY & 0 & 0 & 61,726 & 0 & $24,359,891$ & 0.00 & 0.00 & 0.17 & 0.00 & 66.74 & 0 & 0 & & 1 & 0 \\
\hline Alabama & FOLEY UTILS BD CTTY OF & 86,799 & 267,746 & 236,305 & 0 & 0 & 0.24 & 0.73 & 0.65 & 0.00 & 0.00 & 3,687 & 726 & & 0 & 0 \\
\hline Alabama & FULTONDALE GAS BOARD & 340,530 & 100,436 & 0 & 0 & 0 & 0.93 & 0.28 & 0.00 & 0.00 & 0.00 & 7,260 & 425 & & 0 & \\
\hline Alabama & GENEVA CTY GAS DIST & 31,897 & 38,518 & 120,929 & 0 & 0 & 0.09 & 0.11 & 0.33 & 0.00 & 0.00 & 901 & 273 & 49 & & 0 \\
\hline Alabama & GORDO WATER GAS SEWER BD & 30,956 & 65,019 & 0 & 0 & 0 & 0.08 & 0.18 & 0.00 & 0.00 & 0.00 & 425 & 76 & & 0 & 0 \\
\hline Alabama & GRAYSVILE CTYY OF & 285,125 & 0 & 0 & 0 & 0 & 0.78 & 0.00 & 0.00 & 0.00 & 0.00 & 4,871 & 0 & & 0 & 0 \\
\hline Alabama & GULF SOUTH PIPELINE COMPANY LP & 0 & 0 & $12,000,026$ & 0 & 0 & 0.00 & 0.00 & 32.88 & 0.00 & 0.00 & 0 & 0 & & 0 & 0 \\
\hline Alabama & HARTSELLE UTILTIES & 114,221 & 94,215 & 44,251 & 0 & 0 & 0.31 & 0.26 & 0.12 & 0.00 & 0.00 & 3,772 & 424 & 11 & & 0 \\
\hline Alabama & HUNTSVILE UTIUTIES NAT GAS DEPT & $2,122,702$ & $2,341,573$ & $1,973,778$ & 0 & 0 & 5.82 & 6.42 & 5.41 & 0.00 & 0.00 & 45,084 & 5,369 & 28 & 0 & 0 \\
\hline Alabama & JACKSONVILLE WTR WKS GAS BD & 98,935 & 69,472 & 13,404 & 0 & 0 & 0.27 & 0.19 & 0.04 & 0.00 & 0.00 & 2,545 & 7 & 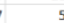 & 0 & 0 \\
\hline
\end{tabular}

Figure 3.1.2-2 EIA Annual Demand Data by Customer Class by LDC for 2014 


\section{Federal Energy Regulatory Commission}

- FERC Form 2, "Major Natural Gas Pipeline Annual Report"-compilation of financial and operational information from major interstate natural gas pipelines subject to the jurisdiction of the FERC; and

- FERC Form 549A, "Index of Customers" - consists of a list of firm transportation and storage customers under contract as of the first business day of each calendar quarter.

Data collected from FERC Form 2 provides:

- Monthly and single-day peak deliveries by UGS facility for interstate pipeline companies, and

- Monthly UGS injection and withdrawals for intrastate and natural gas utilities.

Figure 3.1.2-3 shows an example of FERC data of single- and three-day peak deliveries to gas consumers of the Equitrans, LP interstate gas transmission pipeline.

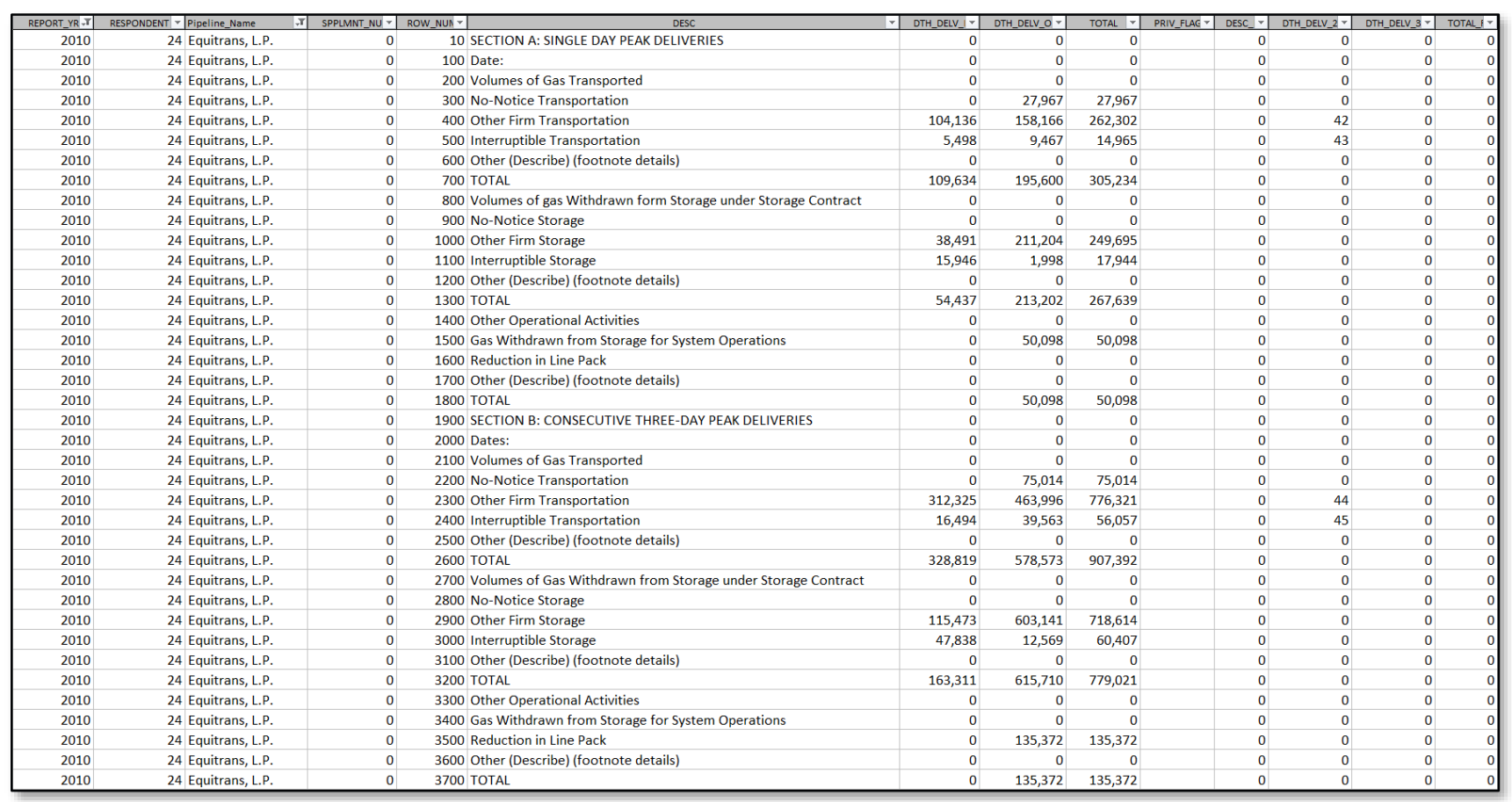

Figure 3.1.2-3 Single- and Three-Day Peak Delivery Data for Equitrans, LP

FERC Form 549A provides information on the contractual obligations of UGS facility owners to deliver natural gas to customers, such as LDCs, electric utilities, and gas marketers. As an example, Table 3.1.2-1 provides information on the contractual supply mix for the LDC Peoples Gas Light and Coke Company in Illinois, which consists of contracts with interstate gas 
Table 3.1.2-1 FERC Form 549A Data for Peoples Gas Light and Coke Company (October 2015)

\begin{tabular}{|c|c|c|c|c|}
\hline Shipper Name & $\begin{array}{c}\text { Rate } \\
\text { Schedule }\end{array}$ & $\begin{array}{l}\text { Contract } \\
\text { Eff Date }\end{array}$ & $\begin{array}{l}\text { Trans_- } \\
\text { MaxDaily } \\
\text { (Mcf/d) }\end{array}$ & Pipeline Name \\
\hline The Peoples Gas Light and Coke Company & DSS & $4 / 1 / 1998$ & 208,000 & Natural Gas Pipeline Company of America LLC \\
\hline The Peoples Gas Light and Coke Company & FTS & $4 / 1 / 1998$ & 0 & Natural Gas Pipeline Company of America LLC \\
\hline The Peoples Gas Light and Coke Company & FTS & $4 / 1 / 2000$ & 24,500 & Natural Gas Pipeline Company of America LLC \\
\hline The Peoples Gas Light and Coke Company & FTS & $5 / 1 / 2012$ & 20,000 & Natural Gas Pipeline Company of America LLC \\
\hline The Peoples Gas Light and Coke Company & FTS & $11 / 1 / 2012$ & 37,167 & Natural Gas Pipeline Company of America LLC \\
\hline The Peoples Gas Light and Coke Company & FTS & $11 / 1 / 2012$ & 50,000 & Natural Gas Pipeline Company of America LLC \\
\hline The Peoples Gas Light and Coke Company & FTS & $5 / 1 / 2013$ & 62,016 & Natural Gas Pipeline Company of America LLC \\
\hline The Peoples Gas Light and Coke Company & FTS & $5 / 1 / 2014$ & 23,055 & Natural Gas Pipeline Company of America LLC \\
\hline The Peoples Gas Light and Coke Company & NSS & $5 / 1 / 2013$ & 0 & Natural Gas Pipeline Company of America LLC \\
\hline The Peoples Gas Light and Coke Company & NSS & $7 / 1 / 2013$ & 0 & Natural Gas Pipeline Company of America LLC \\
\hline The Peoples Gas Light and Coke Company & ETS & $4 / 1 / 2004$ & 0 & ANR Pipeline Company \\
\hline The Peoples Gas Light and Coke Company & FSS & $4 / 1 / 2004$ & 0 & ANR Pipeline Company \\
\hline The Peoples Gas Light and Coke Company & NNS & $4 / 1 / 2004$ & 40,644 & ANR Pipeline Company \\
\hline The Peoples Gas Light and Coke Company & FSS & $9 / 5 / 2014$ & 0 & ANR Pipeline Company \\
\hline The Peoples Gas Light and Coke Company & $\mathrm{T}-1$ & $4 / 1 / 2009$ & 59,614 & Northern Border Pipeline \\
\hline The Peoples Gas Light and Coke Company & FT-1 & $9 / 1 / 2014$ & 30,000 & Vector Pipeline L.P. \\
\hline The Peoples Gas Light and Coke Company & FT-1 & $12 / 1 / 2014$ & 40,000 & Vector Pipeline L.P. \\
\hline The Peoples Gas Light and Coke Company & FTS & $12 / 20 / 200 \&$ & 360,000 & Kinder Morgan Illinois Pipeline LLC \\
\hline
\end{tabular}

transmission pipelines such as Natural Gas Pipeline Company of America LLC (NGPL) and ANR Pipeline Company.

\section{State Public Utility Commissions (PUCs)}

State PUCs can provide system load data for normal and peak-day conditions by each LDC.

One example is the "California Gas Report," which is prepared by the California gas and electric utilities. $^{12}$ This report was used to determine the percentage of the peak-day natural gas demand that could be met by withdrawals from UGS as a function of LDCs in California, an example of which is shown in Figure 3.1.2-4.

\footnotetext{
12 California Gas \& Electric Utilities, 2014, 2014 California Gas Report, available at https://www.sdge.com/sites/
} default/files/documents/2061011959/2014-cgr.pdf?nid=16736, accessed July 13, 2016. 


\begin{tabular}{|c|c|c|c|c|c|c|}
\hline & Year & $\begin{array}{l}\text { SoCalGas } \\
\text { Retail Core } \\
\text { Demand(1) }\end{array}$ & $\begin{array}{l}\text { SDG\&E } \\
\text { Retail Core } \\
\left.\text { Demand( }{ }^{2}\right)\end{array}$ & $\begin{array}{c}\text { Total } \\
\text { Demand }\end{array}$ & $\begin{array}{l}\text { Firm Storage } \\
\text { Withdrawal(3) }\end{array}$ & $\begin{array}{c}\text { Flowing } \\
\text { Supply }\end{array}$ \\
\hline & 2014 & 3,101 & 389 & 3,490 & 2,225 & 1,265 \\
\hline & 2015 & 3,061 & 388 & 3,449 & 2,225 & 1,224 \\
\hline & 2016 & 3,050 & 390 & 3,440 & 2,225 & 1,215 \\
\hline & 2017 & 3,035 & 390 & 3,425 & 2,225 & 1,200 \\
\hline & 2018 & 3,027 & 391 & 3,419 & 2,225 & 1,194 \\
\hline & 2019 & 3,008 & 393 & 3,401 & 2,225 & 1,176 \\
\hline & 2020 & 2,979 & 393 & 3,372 & 2,225 & 1,147 \\
\hline \multicolumn{7}{|c|}{$\begin{array}{l}\text { Notes: } \\
\text { (1) } 1 \text {-in- } 35 \text { peak temperature cold day SoCalGas core sales and transportation. } \\
\text { (2) } 1 \text {-in- } 35 \text { peak temperature cold day SDG\&E core sales and transportation. } \\
\text { (3) This amount was approved by the CPUC for SoCalGas and SDG\&E to serve the combined core } \\
\text { portfolio of SoCalGas' and SDG\&E's retail core customers in CPUC D.08-12-020 on } 12 / 4 / 2008 \text { at } \\
\text { p. } 12 \text {. }\end{array}$} \\
\hline
\end{tabular}

Figure 3.1.2-4 Peak Day Demand and Supply Requirements (MMcf/d) for Southern California Gas Company (SoCalGas) and San Diego Gas \& Electric (SDG\&E)

Similarly, LDCs in Illinois are required to provide natural gas operational data to the Illinois Commerce Commission, including information on natural gas storage operations (as shown in Figure 3.1.2-5). These data were used to validate important storage characteristics such as maximum authorized daily withdrawal quantity and the number of wells supporting UGS operations.

Other States were contacted to request similar information on peak-day LDC demand and supply values, annual dependence on natural gas storage to meet natural gas demand, monthly underground gas storage injection and withdrawal volumes, and other information. This information, however, was not available for this study except for the data from California and Illinois. 


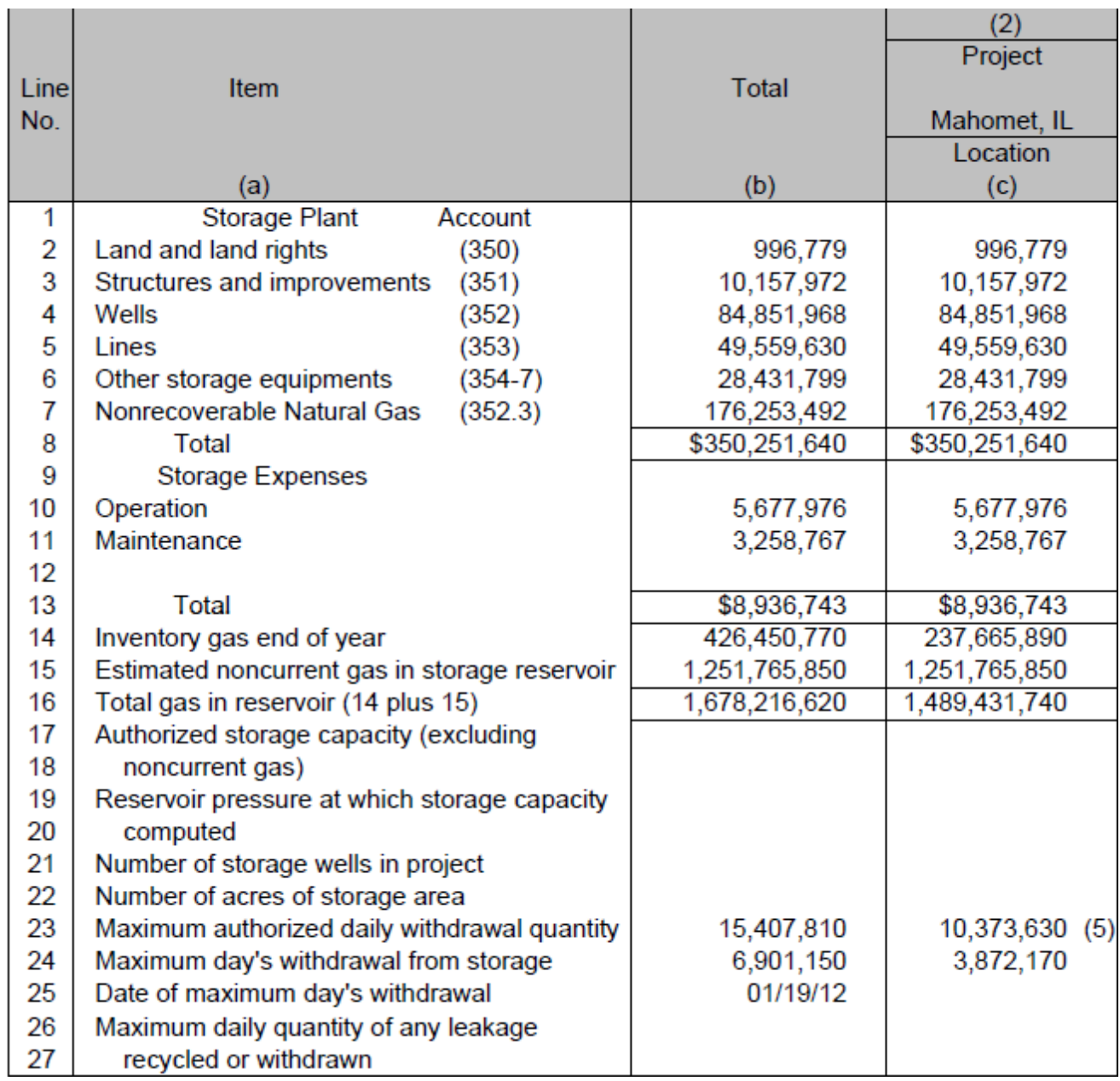

Figure 3.1.2-5 Underground Gas Storage Data for the Peoples Gas Light and Coke Company, 2012 13

\subsubsection{Methodology of UGS-LDC Impact Analysis Model}

The UGS-LDC Impact Analysis Model examines the impacts of the loss of a specific UGS facility on the LDC which owns it. The assumption is that the UGS facility is located within the service area of the LDC under consideration. The flow of the calculation logic proceeds as follows:

1. The user identifies the UGS facility of interest. The model automatically identifies the LDC directly served by the UGS facility. The supply-demand balance within the primary LDC (i.e., LDC of interest) is assessed using a variety of publicly available information. Demand is broken into two parts: (1) gas that is entirely consumed by the primary LDC itself, and (2) gas supplied to nearby or adjacent LDCs but which flows through the

${ }^{13}$ Illinois Commerce Commission, 2012, Annual Report of Electric Utilities Licensees and/or Natural Gas Utilities to The Illinois Commerce Commission, Peoples Gas Light and Coke Company, FORM 21 ILCC, submitted December 31. 
delivery system of the primary LDC. The supply is likewise broken into two components: (1) natural gas supplied by the delivery network of the primary LDC but delivered by an interstate pipeline external to the primary LDC, and (2) natural gas supplied by the UGS facility under consideration. The condition under which the assessment is made is the worst month on record characterized by maximum demand and minimum reserves.

2. The transport capability of the delivery system within the primary LDC is then assessed in terms of its maximum deliverability vis-à-vis its "current" load under the loading conditions selected. The available unreserved capacity of the LDC is then established by simply taking the difference between the "current" load and its maximum deliverability. The unreserved capacity value plays an important role in determining the available "compensating" flow when a UGS facility is assumed to be disrupted (thus creating a supply shortfall).

3. The ability of other UGS facilities owned by the LDC to provide additional natural gas supply under the selected loading condition is then examined. The amount of additional natural gas supply is measured in terms of million cubic feet per day (MMcf/d) that each UGS facility contributes to the overall supply resource for the LDC. The relative importance of each UGS facility's contribution is determined by taking the percentage share provided by each UGS facility compared to the total UGS-based supply.

4. Impacts of the loss of a specific UGS facility are calculated by reducing its output (i.e., withdrawal amount) to zero and then calculating the resulting imbalance in the LDC's supply-demand balance. If the estimated supply is less than the demand, an attempt to mitigate the resulting imbalance or shortfall is made by allowing the "unreserved" capacity calculated in Item 2 to compensate for the supply loss. During peak-demand periods, the unreserved is usually not enough to supplant the loss created by a relatively large UGS facility and usually a net shortfall would be created. The net shortfall or flow loss is then used to calculate the impacts on the LDC in terms of the amount and number of natural gas customers that may need to be curtailed.

5. With the amount of shortfall now determined, the sequence of load shedding by the LDC would then commence. For the gas system, the order of load shedding among various customer types is usually as follows: electric, industrial, commercial, and residential. LDC gas customers with interruptible ${ }^{14}$ contracts are shed first and those with firm contracts are shed last.

6. The overall consequence is then expressed in terms of the number of customers shed per sector and the amount of gas flow lost. Customers in the electric generation sector are usually of particular interest because of the interdependency that exists between electric and gas systems, and the impacts are often expressed in terms of MW lost (electric

${ }^{14}$ Interruptible service is a low-priority service offered to customers under schedules or contracts which anticipate and permit interruption on short notice, generally in peak-load seasons. Firm service is offered to customers (regardless of Class of Service) under schedules or contracts which anticipate no interruptions. The period of service may be for only a specified part of the year. 
generating capacity). The overall impact could also be expressed in terms of the business interruption costs that could result from the loss of supply from the UGS facility. ${ }^{15}$

Figure 3.1.3-1 shows the "Input-Output" screen of the UGS-LDC Impact Analysis Model, assuming that Southern California Gas Company and Aliso Canyon are the LDC and UGS facility of interest, respectively.

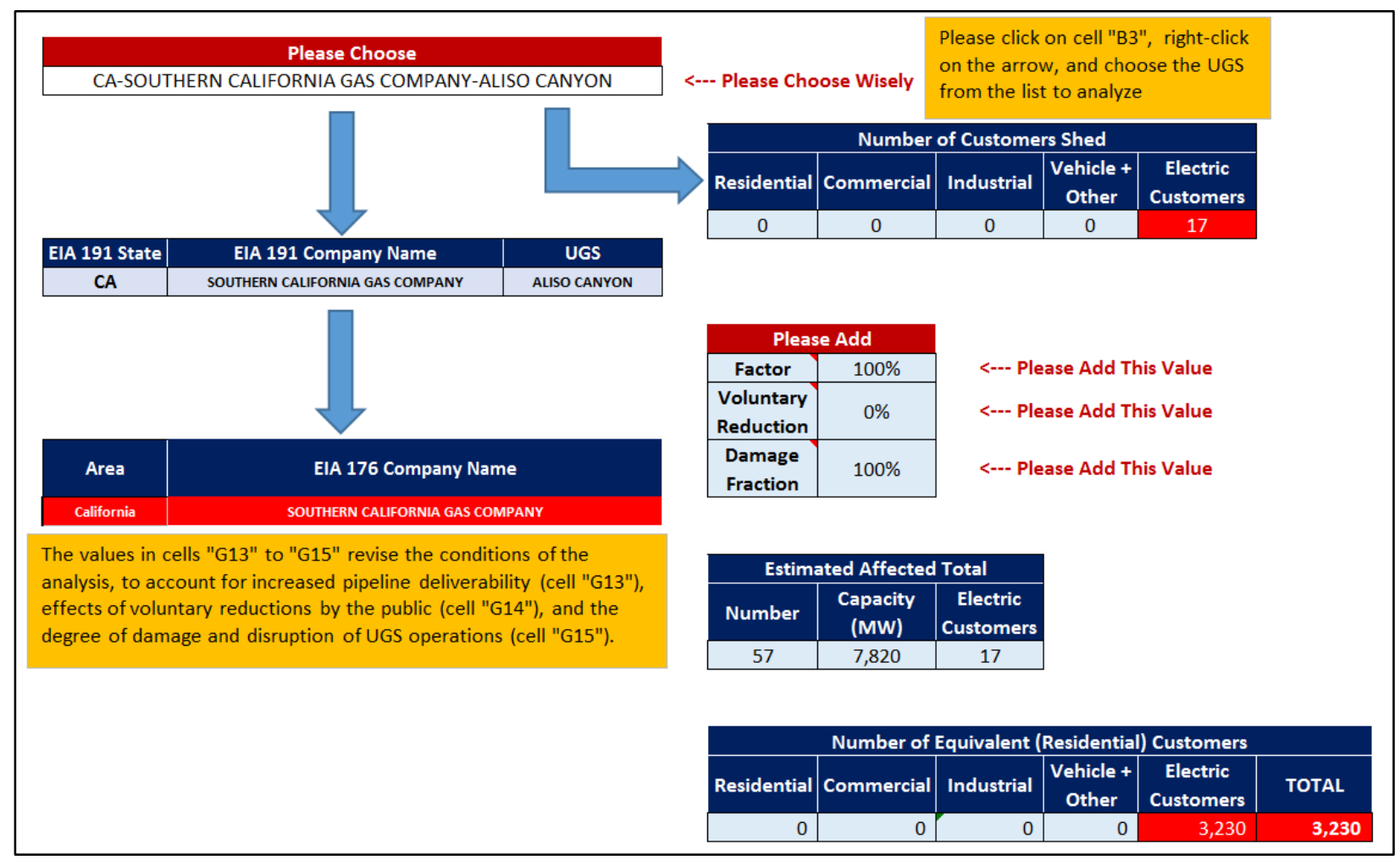

Figure 3.1.3-1 "Input-Output" Screen of the UGS-LDC Impact Analysis Model

\subsubsection{Methodology of UGS-Pipeline Impact Analysis Model}

The UGS-Pipeline Impact Analysis Model examines the impacts of the loss of an UGS facility owned by an interstate gas transmission pipeline. The connected pipeline is assumed to be in transport mode and supplying the gas withdrawn from the UGS facility to in-State as well as outof-State customers. These customers can include multiple LDCs, industrial customers, and independent electric generators. The model initially determines the amount of natural gas supplied by the UGS facility to the interstate gas transmission pipeline. When the UGS facility is postulated as disrupted, the flow from the UGS facility to the pipeline is reduced to zero, and the gas flow in the pipeline is correspondingly reduced by an amount equal to the pre-event output from the UGS facility. The flow of the calculation logic proceeds as follows:

15 It should be noted that relighting gas customers is more resource-intensive than restoring electricity to customers. The gas company has to visit each customer individually to shut off valves, repair damage, purge lines, and relight equipment. 
1. The user identifies the UGS facility of interest. The model automatically identifies the pipeline directly connected to it. The supply-demand balance for the interstate gas pipeline is assessed using a variety of publicly available information. Demand or transported gas is broken into two parts: (1) gas owned and transported by the primary pipeline, and (2) gas transported for others (gas not owned by the primary company but by other shippers). The supply is likewise broken into two components: (1) natural gas supplied by the other receipt points along the pipeline, and (2) gas supplied by the specific UGS facility under consideration. There are three operating conditions under which the assessment is made: single peak-day delivery, consecutive three-day peak deliveries, and annual average delivery for years 2010 to 2014. The peak-month conditions are estimated through interpolation of the single peak-day, consecutive three peak-days, and annual average-day conditions. This interpolation is performed five times, one for each year (from 2010 to 2014).

2. The compensating capability of the interstate transmission pipeline system is then assessed in terms of its maximum transport supply vis-à-vis its "current" demand under the peak-month conditions for each year in 2010 to 2014 . The unreserved capacity is then estimated by the difference between the peak-month demand and the maximum pipeline deliverability for that year. The unreserved capacity value plays an important role in determining the available "compensating" flow when a UGS facility is assumed to be disrupted (thus creating a supply shortfall).

3. The impact of the loss of a specific UGS facility is calculated by reducing its output (i.e., withdrawal amount) to zero and then calculating the resulting imbalance in the supply-demand balance for the interstate gas transmission pipeline. An attempt to mitigate the resulting imbalance or shortfall is made by allowing the "unreserved" capacity calculated in Item 2 to compensate for the loss in gas supply from the assumed disruption of UGS operations. Under peak-month conditions, the estimated unreserved pipeline capacity is generally not sufficient to supplant the loss created by a relatively large UGS facility, and usually a net shortfall is created. The net shortfall or flow loss is then used to calculate the impacts on both the in-State and out-of-State customers of the interstate gas transmission pipeline.

4. With the amount of shortfall now determined, it is assumed that the force majeure ${ }^{16}$ event at the interstate gas transmission pipeline would mandate that any remaining operational gas pipeline capacity would be pro-rationed among firm customers. All non-firm customers would be immediately asked to curtail their consumption of gas. Gas customers of the interstate gas transmission pipeline would lose a portion of their gas supply. The supply to industrial customers and electric generators directly connected to the interstate gas transmission pipeline would be reduced by the ratio of the total supply shortfall divided by the total gas supply. For LDCs directly connected to the interstate gas trasmission pipeline, load shedding occurs in the following order: electric (first),

16 Force majeure means superior or irresistible force that excuses a failure to perform. It has been defined by the United States Supreme Court as a cause that is "beyond the control and without the fault or negligence" of the party excused. 
industrial (second), commercial (third), and residential (last). Customers with interruptible contracts are shed first, and those with firm contracts are shed last.

5. The overall consequences are then expressed in terms of the number of customers shed per sector and the amount of gas flow lost. Customers in the electric generation sector are usually of particular interest because of the interdependency that exists between electric and gas systems, and the impacts are often expressed in terms of MW lost (electric generating capacity). The overall impact could also be expressed in terms of the business interruption costs that could result from the loss of supply from the UGS facility.

Figure 3.1.4-1 shows the "Input-Output" screen of the UGS-Pipeline Impact Analysis Model, assuming that Texas Eastern Transmission LP and Egan Storage Dome are the pipeline and UGS facility of interest, respectively. Please note that the assumed disruption of the Egan Storage Dome is projected to result in a limited number of residential customers being shed (10 total) because this UGS supplies a number of LDCs and the decrease in supply to these LDCs results in load shedding of residential customers.

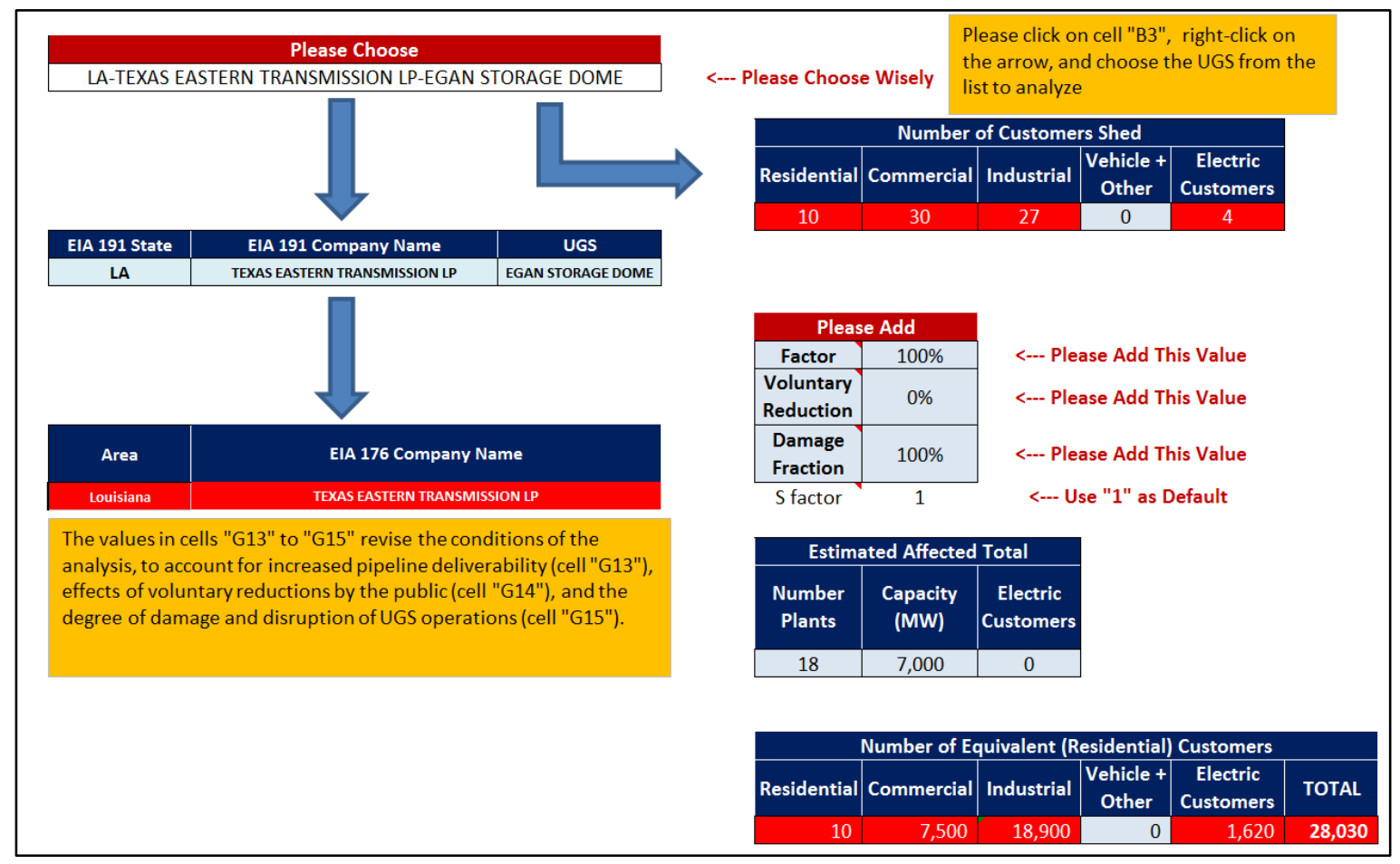

Figure 3.1.4-1 "Input-Output" Screen of the UGS-Pipeline Impact Analysis Model

\subsubsection{Methodology of UGS Third-Party Impact Analysis Model}

The UGS Third-Party Impact Analysis Model examines the impacts of the loss of a specific UGS facility on the scheduled nominations by entities such as electric utilities, natural gas marketers, and LDCs. Natural gas marketers arrange gas shipments from the UGS for delivery to specific customers. The amounts planned for shipment are normally stored in a UGS facility conveniently located near the receiving customer. The disruption of the UGS facility could void the scheduled 
gas shipments and therefore cause a supply shortfall to the receiving customers. The flow of the calculation logic proceeds as follows:

1. The user identifies the UGS facility of interest. The model automatically identifies the third-party independent storage operator who owns the UGS facility. The amount of gas "owned" by the third-party entity relative to the UGS facility is determined and is assumed to be volume lost or undeliverable because of the postulated UGS disruption.

2. Since third-party independent storage operators do not own any mitigating assets such as pipelines or other UGS facilities, it is not possible to simulate a compensation mechanism similar to what was done for the cases of the LDC and pipeline impact models. The condition under which the assessment is made is the worst month on record, generally characterized by maximum demand and minimum reserves.

3. Impacts of the loss of a specific UGS facility are calculated by determining the amount of gas in storage contracted to be delivered to its various customers and then using that value to shed the deliveries to all receiving customers.

4. The load-shedding sequence follows that appropriate to each UGS customer, as described in the previous models for LDCs and interstate gas trasmission pipelines.

5. The overall consequences are the same as described in the previous models for LDCs and interstate gas trasmission pipelines.

Figure 3.1.5-1 shows the "Input-Output" screen of the UGS Third-Party Impact Analysis Model, assuming that Ryckman Creek Resources and Ryckman Creek are the third-party independent storage operator and UGS facility of interest, respectively.

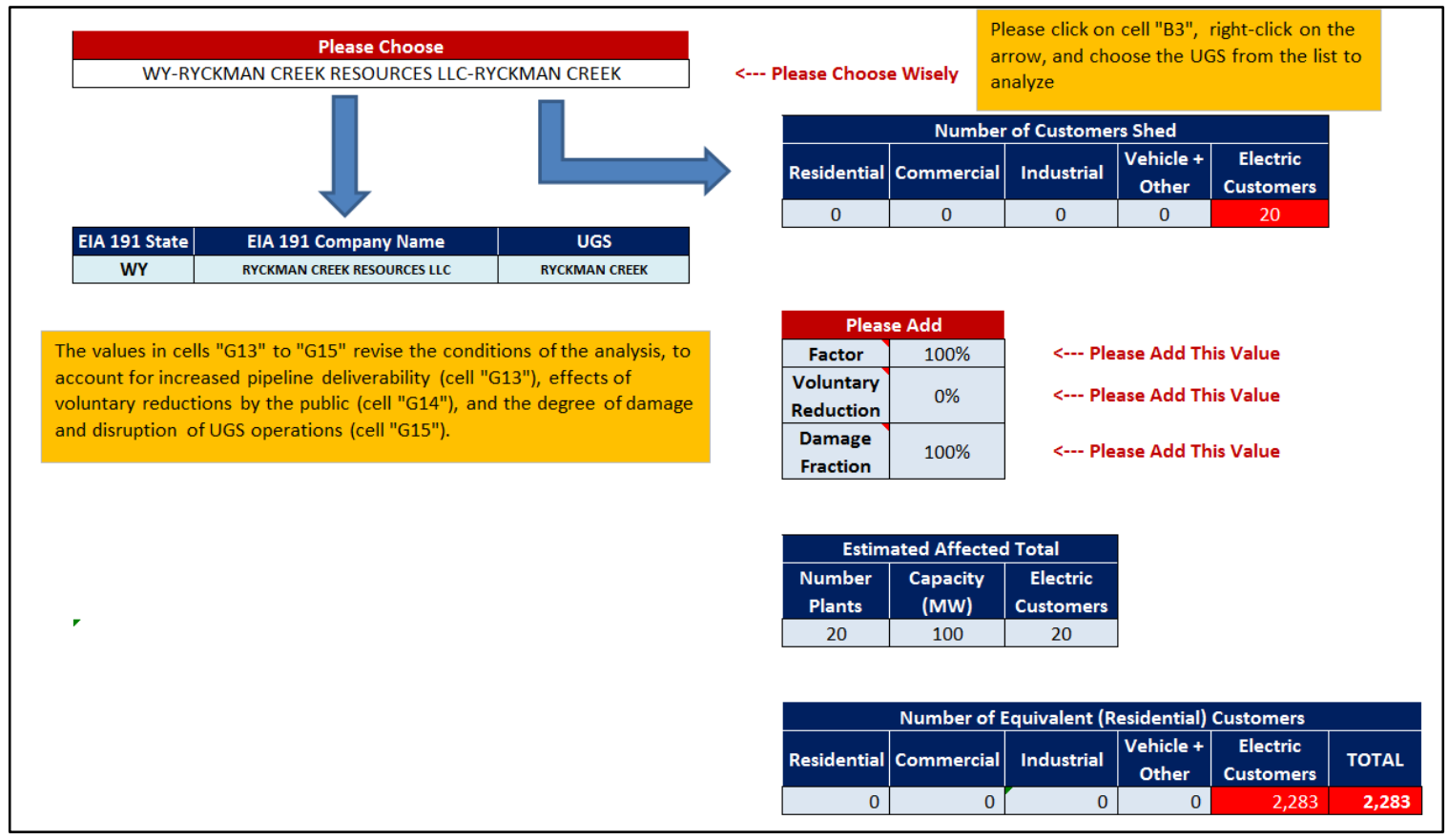

Figure 3.1.5-1 "Input-Output" Screen of the UGS-Third-Party Impact Analysis Model 


\subsection{Methodology for Identifying Affected Electric Power Plants}

The potentially affected electric capacity was assumed to be correlated with key UGS facility operating characteristics such as maximum deliverability, as high-deliverability UGS facilities would be expected to be used to support natural gas-fired power plant operations. Figure 3.2-1 shows the dependence of the potentially affected electric capacity from the UGS facility maximum deliverability. It can be seen that the estimated electric capacity increases with maximum deliverability, with some outliers. (This figure is not meant to suggest that a way to minimize the risk to electric capacity is to have no storage supply available.)

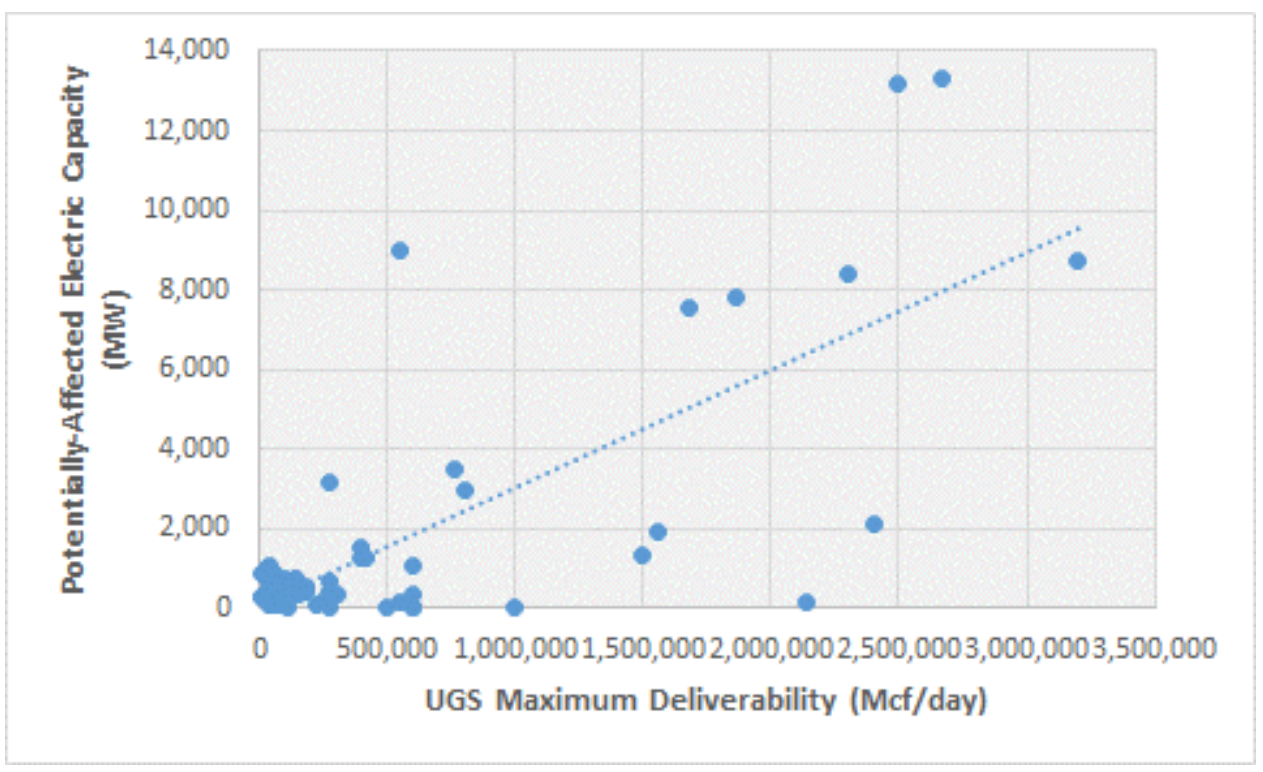

Figure 3.2-1 Dependence of Potentially Affected Electric Capacity with UGS Maximum Deliverability

The approach to determining the power plants at-risk from UGS facility disruptions uses public information on the maximum daily storage quantity of natural gas each UGS facility is obligated to store and supply for a shipper (electric utility, LDC, marketer) under each contract. This is combined with information on the amount of gas consumed by the electric sector and which power plants are served by a given supplier. The monthly quantity for each power plant and supplier is then used to determine the potential consequence of a shortfall in natural gas supply due to a disruption in UGS facility operations. The overall procedure to determine the potentially affected power plants is as follows:

- The FERC Index of Customers is used to determine which organizations (natural gas LDCs, gas marketer, electric utility, or interstate transmission gas pipeline) have contracted with a given UGS company for natural gas supply. ${ }^{17}$ Table 3.2-1 provides example information for Bluewater Gas Storage, LLC and identifies each shipper as

17 The FERC Index of Customers also identifies the supply sources for a given LDC. It was assumed in this analysis that the LDC would attempt to purchase gas and transport it over the transmission pipelines identified in the FERC Index of Customers, in the event of a disruption in UGS operations. 
being a natural gas marketer, LDC, pipeline, or electric utility as well as the contracted amount of maximum daily storage volumes.

Table 3.2-1 Index of Customer Data for Bluewater Gas Storage, LLC (2015)

\begin{tabular}{|l|l|r|}
\hline \multicolumn{1}{|c|}{ Shipper Name } & \multicolumn{1}{|c|}{ Type } & \multicolumn{1}{c|}{$\begin{array}{c}\text { Maximum Daily } \\
\text { Storage (Mcf/day) }\end{array}$} \\
\hline Cargill Inc. & Marketer & 500 \\
\hline CIMA Energy Ltd. & Marketer & 1,000 \\
\hline Enbridge & Marketer & 3,000 \\
\hline Enterprise Products Operating LLC & Pipeline & 5,000 \\
\hline Guardian Pipeline, LLC & Pipeline & 761 \\
\hline Hess Energy Trading Company, LLC & Marketer & 1,070 \\
\hline Marysville Ethanol, LLC & Marketer & 176 \\
\hline PAA Natural Gas Canada ULC & Marketer & 7,137 \\
\hline SEMCO Energy, Inc., d/b/a SEMCO Energy Gas Company & LDC & 210 \\
\hline Shell Energy North America (US), LP & Marketer & 2,000 \\
\hline Shell Energy North America US, LP & Marketer & 2,000 \\
\hline Suncor Energy Marketing Inc. & Marketer & 1,391 \\
\hline Wisconsin Electric Power Company & Electric Utility & 4,879 \\
\hline Wisconsin Gas LLC & LDC & 3,239 \\
\hline
\end{tabular}

- Data from the EIA Form 923 is used to establish the natural gas supplier to each electric power plant and to identify which power plants could be affected by a disruption in natural gas supply for a given UGS facility. Table 3.2-2 provides example data for Shell Energy North America which identifies the power plants that received natural gas from this marketer as well as the type of contract ("F" = firm, "I": = interruptible).

Table 3.2-2 Power Plants Identified by the EIA Form 923 to Have Been Provided Natural Gas by Shell Energy North America in 2015

\begin{tabular}{|r|r|l|r|r|r|r|}
\hline Year & Month & \multicolumn{1}{|c|}{ Plant Name } & $\begin{array}{c}\text { Plant } \\
\text { State }\end{array}$ & Quantity & $\begin{array}{c}\text { Natural Gas } \\
\text { Transportation } \\
\text { Service }\end{array}$ & $\begin{array}{c}\text { Nameplate } \\
\text { Capacity } \\
\text { (MW) }\end{array}$ \\
\hline 2014 & 1 & Baconton Power Plant & GA & 8,771 & I & 242 \\
\hline 2014 & 2 & McWilliams & AL & 232,230 & F & 654 \\
\hline 2014 & 2 & Baconton Power Plant & GA & 8,860 & I & 242 \\
\hline 2014 & 3 & Coughlin Power Station & LA & 124,852 & I & 922.8 \\
\hline 2014 & 3 & Teche & LA & 11,035 & I & 411.8 \\
\hline 2014 & 3 & Brame Energy Center & LA & 4,826 & I & 445.5 \\
\hline 2014 & 3 & Baconton Power Plant & GA & 6,738 & I & 242 \\
\hline 2014 & 4 & Coughlin Power Station & LA & 326,273 & I & 922.8 \\
\hline 2014 & 4 & Teche & LA & 19,646 & I & 411.8 \\
\hline 2014 & 4 & Brame Energy Center & LA & 19,884 & I & 445.5 \\
\hline 2014 & 4 & Baconton Power Plant & GA & 92,324 & I & 242 \\
\hline
\end{tabular}


Table 3.2-2 Power Plants Identified by the ElA Form 923 to Have Been Provided Natural Gas by Shell Energy North America in 2015

\begin{tabular}{|l|c|l|c|c|c|r|}
\hline Year & Month & \multicolumn{1}{|c|}{ Plant Name } & $\begin{array}{c}\text { Plant } \\
\text { State }\end{array}$ & Quantity & $\begin{array}{c}\text { Natural Gas } \\
\text { Transportation } \\
\text { Service }\end{array}$ & $\begin{array}{c}\text { Nameplate } \\
\text { Capacity } \\
\text { (MW) }\end{array}$ \\
\hline 2014 & 5 & Coughlin Power Station & LA & 774,255 & I & 922.8 \\
\hline 2014 & 5 & Teche & LA & 113,949 & I & 411.8 \\
\hline 2014 & 5 & Brame Energy Center & LA & 540,318 & I & 445.5 \\
\hline 2014 & 5 & Baconton Power Plant & GA & 117,287 & I & 242 \\
\hline
\end{tabular}

The EIA-923 data also establishes whether a gas-fired generator that is connected to a pipeline has a storage or asset management contract (and what type of contract).

- The potentially affected electric capacity that is affected by the disruption of natural gas supply from the UGS facility is provided by the three models.

- A list of potentially affected power plants is then developed for each UGS facility that identifies the supplier, type, potentially affected electric capacity (MW), and natural gas contract.

- It is assumed that power plants with interruptible contracts would be interrupted before those with firm contracts. The power plants closest to the UGS facility would be assumed to be first disrupted first, as it is assumed that power plants farther away from the UGS facility have a higher probability of finding another source of natural gas.

This study notes that gas transportation and storage capacity is reserved for those firm customers that pay for that higher level of service. Natural gas-fired generators in many regions rely on services which are interruptible. If natural gas-fired generators do not have firm supply contracts coupled with firm transportation contract paths that reach from the supply points directly to the power plant, the ability of natural gas-fired generation to be available to meet the power demand during constrained circumstances will be limited.

The caveat to the preliminary list of potentially affected power plants is that it is based on public data, which was found to have a number of problems in terms of the names of suppliers of natural gas to power plants and in terms of existing contracts for gas purchases and gas transportation services provided in the EIA Form 923. The accuracy and confidence of the analytical results could be improved through the use of additional but proprietary or restrictedaccess information on UGS facilities and their relationship to pipeline operations that are available from sources such as EIA (Form 191, Monthly Underground Gas Storage Report) and FERC (Form No. 567, System Flow Diagrams). 


\subsection{Methodology for Screening-Level Electric Reliability Assessment}

An initial screening-level reliability assessment for the two UGS facilities with the highest potentially affected gas-fired capacity was conducted using two power grid simulation tools - an instantaneous power flow model and an operational economic dispatch model. Both models were run for the entire Eastern Interconnection under summer peak conditions with default datasets based on publically available information in combination with commercial datasets. Due to time constraints, this analysis was conducted with limited customization and model validation efforts, and only for 2 out of the 12 UGS facilities with the potential to affect $2+$ gigawatts $(\mathrm{GW})$ of natural gas-fired capacity.

This analysis is meant to illustrate the value of and insights gained with future in-depth systemwide studies to assess and rank the potential grid reliability impacts of each of the 12 UGS facilities.

\subsubsection{Power Flow Modeling}

The power flow modeling was performed with EPfast, a grid simulation tool developed by Argonne National Laboratory. ${ }^{18,19}$ EPfast is a highly efficient electric system simulator intended to solve large-scale problems caused by catastrophic as well regular grid events.

EPfast provides four basic capabilities: (1) standard load flow analysis, (2) contingency analysis, (3) islanding analysis, and (4) power outage estimation. For this analysis, the model was run for the network configuration in Figure 3.3.1-1 to study whether outage areas would develop if natural gas-fired power plants potentially affected from the loss of particular UGS facilities were taken out of service. These outage areas (or pockets of unserved areas) could emerge because of capacity limitations in surrounding transmission lines moving replacement power from outside areas to load centers inside these pockets. Should outage areas develop, the model quantifies the potential amount of load to be shed, identifies the affected substations and lines, and spatially estimates the territorial extent of the power outage areas. A basic assumption is that pre-event generation dispatch and demand schedules remain unchanged even during the occurrence of gasfired power plant disruptions.

18 Portante, E., Craig, B., Talaber Malone, L., Kavicky, J., and Folga, S., 2011, "EPFast: A Model for Simulating Uncontrolled Islanding in Large Power Systems," available at http://ieeexplore.ieee.org/stamp/stamp.jsp?arnumber=6147891\&tag=1, accessed September 8, 2016.

19 Portante, E., Folga, S., Kavicky, J., and Talaber Malone, L., 2014. "Simulation of the September 8, 2011, San Diego Blackout," Proceedings of the 2014 Winter Simulation Conference, available at http://delivery.acm.org/10.1145/2700000/2694043/p1527portante.pdf?ip=130.202.242.115\&id=2694043\&acc=ACTIVE\%20SERVICE\&key=DF76D8700996952A\%2E4 D4702B0C3E38B35\%2E4D4702B0C3E38B35\%2E4D4702B0C3E38B35\&CFID=835637934\&CFTOKEN=517

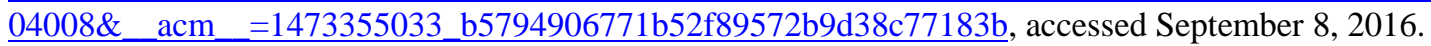




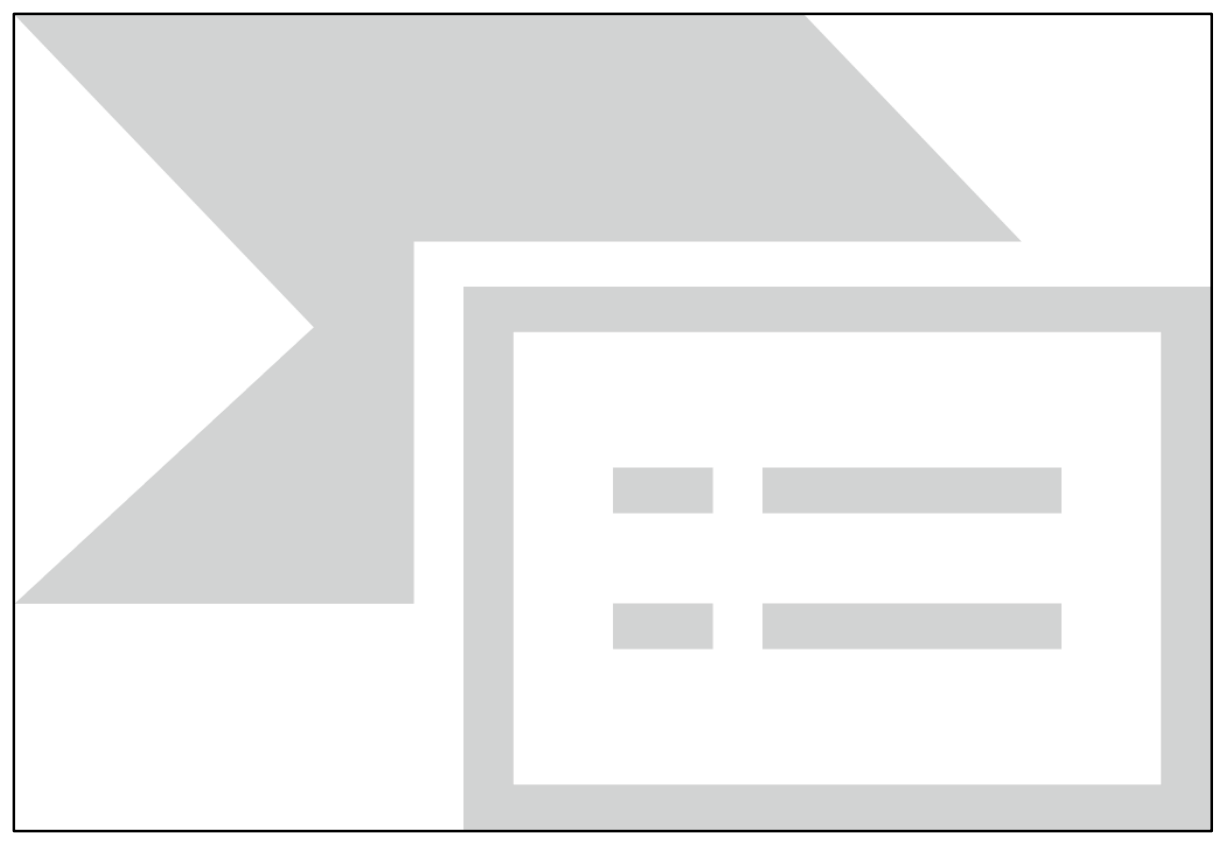

Figure 3.3.1-1 EPfast Network Configuration for the Eastern Interconnection ${ }^{20}$

\subsubsection{Operational Dispatch Modeling}

The operational modeling was performed with a commercially available power grid simulation tool, AURORAxmp ${ }^{21}$. At its core, AURORAxmp is a comprehensive power market tool that optimizes hourly unit commitment and dispatch strategies across a user-defined system. The results of these model runs can be used to forecast day-ahead or long-term electricity prices in each zone throughout the system. The model comes preloaded with numerous databases that contain detailed information on existing generation facilities and projected hourly electricity demands by region. The inclusion of these databases reduces the need for time-consuming data acquisition, processing, and formatting. This also enables AURORAxmp to perform immediate out-of-the-box analysis for a number of important systems. These predefined territories are represented by a set of interconnected zones, each with their own demand profiles, generation resources, and accompanying transmission constraints. For this analysis, the default grid configuration and dataset for the Eastern Interconnection was used (Figure 3.3.2-1).

20 Argonne staff.

${ }^{21}$ EPIS, LLC, 2016, “AURORAxmp - Electric Market Model, Modelling and Forecasting Software," available at http://epis.com/aurora_xmp/, accessed September 8, 2016. 


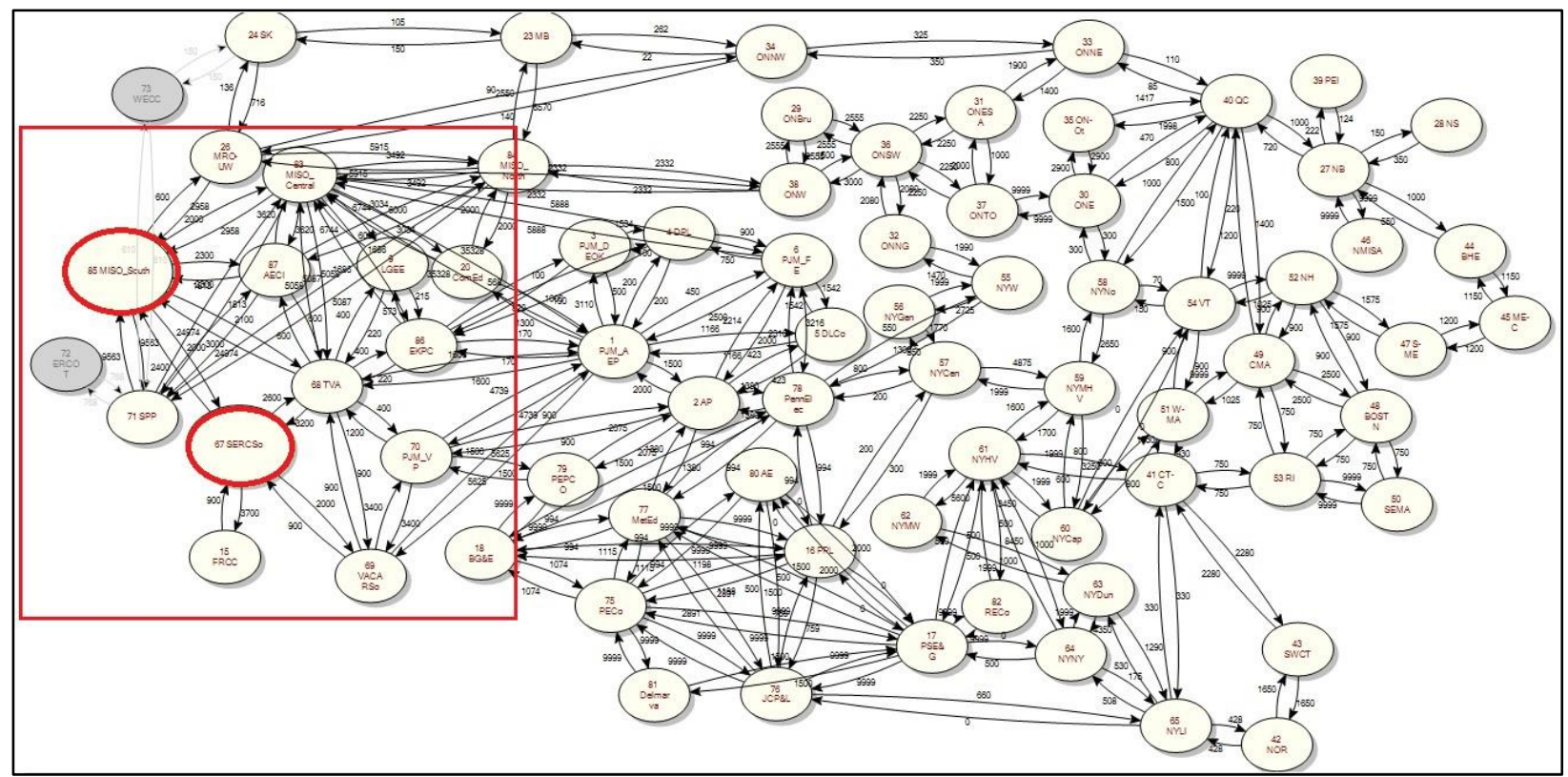

Figure 3.3.2-1 The Zonal Topology of the Eastern Interconnection as Represented in AURORAxmp. The SERC Southern Zone (bottom) and MISO South Zone (top) Are Highlighted with Red Circles. ${ }^{22}$

AURORAxmp is particularly useful when applied to analyzing the impacts of potential policy implementations and changes in key system parameters, such as operating characteristics of existing power plants, as was done here by changing fuel availability for certain generating stations. Model runs can be conducted with these updated parameters to determine the impacts to various model outputs, such as the hourly generation profiles of specific units and the hourly locational marginal prices (LMPs) in different zones.

For this analysis, AURORAxmp was operated in its short-term operational mode with fixed unit availability and no new investments or retirements allowed. In operational mode, the model solves a mixed-integer program for the least-cost, security-constrained unit commitment and economic dispatch of all generation units in the region to serve predefined zonal demand profiles. In the event that there is insufficient generation to meet demand, economic demand response and forced load curtailment may be dispatched.

All generation units that would be impacted by the loss of the two UGS facilities are contained within two load zones that are defined by the topology of AURORAxmp. The units that would be affected by a loss of UGS Facility 1 are all located in the MISO South zone, while the units that would be affected by a disruption to UGS Facility 2 are split between the MISO South and SERC Southern zones.

Figure 3.3.2-1 shows the zonal topology that is utilized by AURORAxmp to model the Eastern Interconnection. Each of the 74 zones that comprise the Eastern Interconnection have a unique hourly load profile, an internal set of generation units, and transmission capacity to neighboring zones. The two zones that contain the units affected by disruptions to the UGS facilities are

${ }^{22}$ Argonne staff. 
highlighted, as is a regional subset of the Eastern Interconnection where most of the impacts from these disruptions are registered.

\subsection{Methodology for Estimating Incident Likelihood}

The likelihood-of-incident values to be used in risk-ranking the UGS facilities are directly related to the likelihood of operation-stopping incidents occurring over a defined period of time (usually 1 year) for each UGS facility under consideration. The term "incident" covers a broad array of operational dysfunctions involving a wide variety of equipment or assets within the UGS complex. Examples of these incidents include gas leaks from gathering pipelines, gas leaks from broken junctions between wells, leaks from cap rock faults, fires and explosions, over-pressure, and other operational failures.

Incident likelihood (probability of an incident) can be viewed from different perspectives: by State, by cause, by type of storage, and by individual storage. About 87 of the 418 UGS facilities in the United States have recorded incidents, not all of them of equal severity. The probability of incidents for those UGS facilities that have recorded events may be straightforward, but for those without incident records, some general statistics may be used. Depending on the type of storage (aquifer, depleted oil, or salt cavern), a generalized incident rate can be employed. It should be noted that this approach does not account for potential contributing factors such as decreasing equipment integrity with time, changing environmental conditions, and other issues which can differentiate the probability of incidents between different UGS facilities. For the purposes of this study, these simplified extrapolations are applied, due to a lack of detailed data.

Also, as an example, if there are two UGS reservoirs of similar size, age, and geology, but one of them has 100 functioning wells and a second has 50 functioning wells, this approach would assume that the first UGS would have an overall incident rate twice as high as the second UGS facility for a storage well incident (based on well integrity only and assuming each well experiences a similar well incident rate). It should be noted that most incidents, whether pipeline, well, or other "field" and "non-station" incidents, would not shut down the entire facility for an extended outage unless (1) it is a single-well cavern facility; (2) the incident occurs at/on the pipeline header coming into the station; or (3) the incident occurs in the station, with no capability to bypass the incident point.

The standard procedure for calculating the incident likelihood for a specific UGS facility simply involves taking the ratio of the number of incidents associated with the UGS facility and then dividing that by the total number of years of operations for that UGS facility. As an example, if it is assumed that a UGS experienced one incident during 20 years of operation, then the incident rate is simply one incident per 20 years, or 0.05 incidents per year. The likelihood of an incident happening within a geographic region can be approximated by taking the ratio of the total recorded incidents within the area to the total number of UGS facilities within the area and then comparing the ratio with that of other States.

Figure 3.4-1 depicts the general procedure for estimating UGS incident frequencies used in this study. 


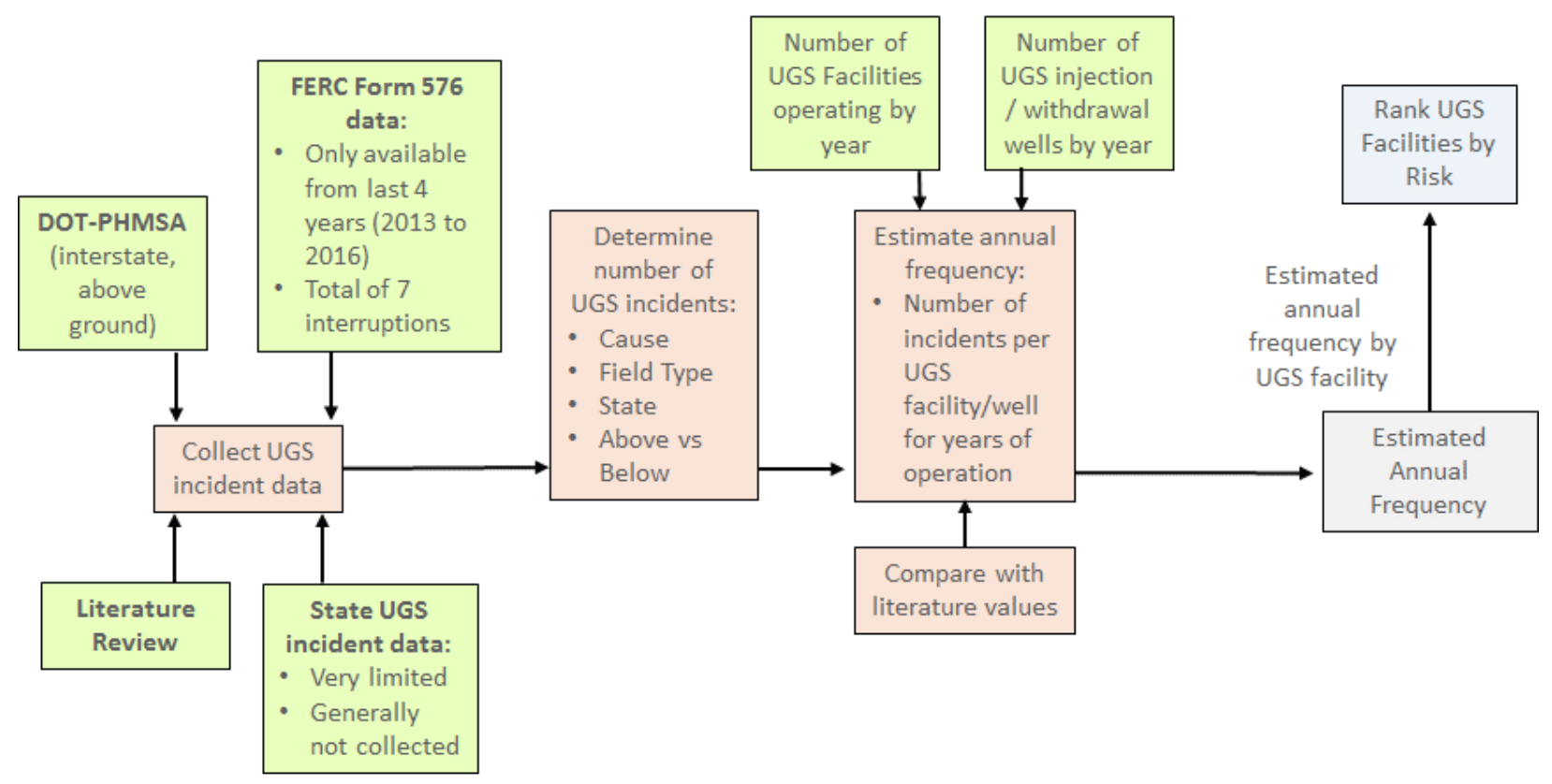

Figure 3.4-1 Approach to Estimating UGS Incident Frequencies

\subsubsection{Assumption for Estimating Incident Frequencies of a UGS Facility}

As in any study, assumptions had to be made to simplify the problem, qualify the ensuing impacts, and contextualize the recommended mitigation option(s). Some of the major assumptions made for this study are described below.

1. An individual UGS facility that has no incident records will be assumed to have incident likelihood based on generic information on the probability of incidents with respect to type of storage (e.g., salt cavern, aquifer, and depleted oil and gas).

2. Incident likelihoods for aquifer-type UGS facilities were assumed to be similar to those of "depleted oil and gas" UGS facilities.

3. All incident rate units of measure will be converted into a dimensionless number reflecting "frequency of incident per well-year" or "frequency of incident per facilityyear." This value, along with the consequence value (in number of equivalent customers), will be used to calculate the risk-ranking of all the UGS facilities.

\subsubsection{Data Sources for Incident Likelihood}

Incident rate data for UGS facilities were collected from a variety of sources including:

- Incident rate data for salt caverns from Health and Safety Executive (HSE), ${ }^{23}$

${ }^{23}$ Health and Safety Executive (HSE), 2008, Failure rates for Underground Gas Storage, Research Report RR671, available at http://www.hse.gov.uk/research/rrpdf/rr671.pdf, accessed March 2, 2016. 
- Data on aboveground incidents at UGS facilities that are regulated by the U.S. Department of Transportation's Pipeline and Hazardous Materials Safety Administration (DOT-PHMSA), ${ }^{24}$

- Well integrity data collected by the U.S. Environmental Protection Agency (EPA), ${ }^{25}$

- A risk assessment performed by the Halite Energy Group, ${ }^{26}$ and

- A review of worldwide underground fuel storage events prepared by D.J. Evans. ${ }^{27}$

The above datasets were supplemented by literature searches and subject-matter expertise (SME), as appropriate. In addition, State agencies were contacted for underground gas storage incident data. However, in most cases, these data are not collected or available in digital format (a few State agencies indicated that natural gas incident data are available in paper format but that research would have to be performed to collect only those incident records associated with natural gas storage operations). A similar situation exists with UGS well maintenance records and mechanical integrity studies which are generally unavailable in a consistent format across all States.

Information was also gathered on potential impacts from natural hazards such as fault lines, landslide potential, etc. (as available). These data were assessed to estimate the frequency of occurrence of commonly assessed threats to UGS operations.

This study was requested to determine whether well age could be a significant factor in future UGS well incidents. The effect of well age on the incident rate of UGS operations was assessed using SME, and it was decided that the available well data were too incomplete in terms of well completion dates, information on upgrades performed on each well, and other factors to adequately project the influence of well age and the operation/maintenance of the well during the well's lifetime on projected incident rates. More information is needed on well characteristics and previous incidents, to establish whether well age is a significant contributor to future UGS well failures.

Figure 3.4.2-1 provides calculated reported failure rates for storage cavity integrity failure based on data on UGS operations outside of the United States.

${ }^{24}$ DOT-PHMSA, 2016.

${ }^{25}$ Ingraffea, A., et al., 2013, Wellbore Integrity: Failure Mechanisms, Historical Record, and Rate Analysis, available at http://www.epa.gov/sites/production/files/documents/ingraffea.pdf, accessed March 2, 2016.

${ }^{26}$ Halite Energy Group, 2009, "Preesall Underground Gas Storage Facility, Lancashire, Risk Assessment," The Infrastructure Planning (Applications: Prescribed Forms and Procedure) Regulations, available at http://infrastructure.planningportal.gov.uk/wp-content/ipc/uploads/projects/EN030001/2.\%20PostSubmission/Application\%20Documents/Other\%20Documents/9.3.1\%20Risk\%20Assessment.pdf, accessed March 2, 2016.

${ }^{27}$ Evans, D.J., 2009, “A Review of Underground Fuel Storage Events and Putting Risk into Perspective with Other Areas of the Energy Supply Chain," in Underground Gas Storage, Worldwide Experiences and Future Development in the UK and Europe, The Geological Society, London, Special Publications, 313:173-216. 


\begin{tabular}{llllll}
\hline & & $\begin{array}{l}\text { Salt caverns }- \\
\text { Europe }\end{array}$ & $\begin{array}{l}\text { Salt caverns }- \\
\text { worldwide }\end{array}$ & $\begin{array}{l}\text { Oil/gas fields }- \\
\text { Europe }\end{array}$ & $\begin{array}{l}\text { Oil/gas fields - } \\
\text { worldwide }\end{array}$ \\
\hline Number of well failures & & 1 & 10 & 1 & 5 \\
$\begin{array}{l}\text { Operating experience } \\
\text { (well years) }\end{array}$ & Upper & 65,000 & 83,000 & 153,000 & 860,000 \\
& Lower & 24,000 & 59,000 & 81,000 & 603,000 \\
$\begin{array}{l}\text { Failure rate } \\
\text { (per well year) }\end{array}$ & Lower & $1.5 \times 10^{-5}$ & $1.2 \times 10^{-4}$ & $6.5 \times 10^{-6}$ & $5.8 \times 10^{-6}$ \\
\hline
\end{tabular}

Figure 3.4.2-1 Calculated Failure Rates for Storage Cavity Integrity Failure28

\subsubsection{Gas Leaks: A Pervasive Concern}

The need to contain natural gas without leakage or loss is the primary requirement of a UGS facility. One risk associated with the UGS operation is therefore related to a gas leakage from the storage structure. Fundamentally, leakage carries two different types of risk:

- The stored gas may escape from the storage structure, reaching drinking water aquifers and/or land surface, representing potentially significant health, safety, and environmental risk; and

- The stored gas may migrate from the storage structure into overlying or adjacent formations and become non-recoverable, representing an economic risk. As a result, a valuable commodity is lost.

Risk is commonly taken to be the probability of occurrence of an unwanted event multiplied by the consequence (loss) of the event. To determine and calculate risk, potential sources of damage have to be identified and the probability and consequence of their occurrence estimated. After the risk analysis, a process of comparing the estimated risk against several risk criteria is carried out, in order to determine the significance of the risk (risk evaluation/assessment).

Risk analysis of geological storage of natural gas is complicated, because only limited data or no data are available for the detailed characteristics of UGS facilities, such as well pressure and flow history, maintenance history, inspection data, known reservoir and geologic conditions, among others. There are two main UGS areas: the engineered system, including the infrastructure bringing the gas to the storage facility (on-surface components), and the geological system in which the gas will be stored. The latter, in addition to geological reservoir rock, also includes the man-made/engineered infrastructure (i.e., pipelines, valves, pressure vessels, pumps, compressors, wells, and their casings/cements).

${ }^{28}$ UK Government, 2008. Failure rates for underground gas storage, Health and Safety Executive, RR671, available at http://www.hse.gov.uk/research/rrpdf/rr671.pdf. 
The geological system is generally the main focus of UGS facility risk assessments. UGS operators are expected to provide regular assessments of geological structures of UGS reservoirs, for example, reservoir rock, cap rock, nature of a salt body (if the storage is made in a salt cavern), and geological features (e.g., faults), etc. The engineered system plays a major role in the development of any UGS facility, and the components of this system (e.g., wells, casings, and pipes) are tightly interconnected with the geological system, and, as a result, appear in most UGS facility risk assessments.

Commonly assessed risks or threats include, but are not limited to, the following: casing physical attributes (diameter, weight, and grade); presence of atmospheric or external corrosion at or near the surface; known metal loss indications from casing inspection surveys; presence of annulus pressure or flow; water production in the well; the presence of hydrogen sulfide, bacteria, or naturally corrosive zones; the well is located in an area prone to natural disasters, high population density, or sensitive environmental or cultural features; flow potential of the well; the well's role in providing natural gas service reliability; and well work history. Much of this information is known only to the natural gas storage owner and was not available for this study.

\subsection{Methodology for Developing a Common Measure and Overall Risk Methodology}

\subsubsection{Developing a Common Measure}

The consequence analysis estimates the impacts of a hypothetical loss of a UGS facility in terms of the number of affected customers, broken down by customer class (residential, commercial, industrial, and electric). It is necessary to develop a common measure that can convert the number of customers into a single normalized impact value that can be used to compare the overall impacts among all UGS facilities and customer classes. 
The definitions of the customer classes for the natural gas sector are as follows: ${ }^{29}$

- Residential: An energy-consuming sector that consists of living quarters for private households. The residential sector includes mobile homes and apartment buildings.

- Commercial: An energy-consuming sector that consists of service-providing facilities and equipment of businesses; federal, State, and local governments; and other private and public organizations, such as religious, social, or fraternal groups.

- Industrial: An energy-consuming sector that consists of all facilities and equipment used for producing, processing, or assembling goods.

- Electric power: An energy-consuming sector that consists of electricity-only plants and combined heat and power (CHP) plants, whose primary business is to sell electricity, or electricity and heat, to the public. It should be noted that there is a wide variation in the natural gas use by electric power customers which depends upon the electric generating capacity (MWs) that each electric power customer owns and operates. As an example, an electric power customer may be an electric utility with significant natural gas-fired electric generating capacity, while another electric power customer may have few and small natural gas-fired generation plants.

Data are publicly available concerning the estimated business interruption cost as a function of the duration of an electric outage as a function of electric customer class, as shown in

Figure 3.5.1-1. ${ }^{30} \mathrm{~A}$ similar approach was developed for natural gas disruptions and was used to determine the number of equivalent customers as a function of customer class.

There is limited information on the costs of a long-term gas outage on the residential sector, primarily because of the small number of reported historic incidents affecting a large number of natural gas customers. One such incident occurred during February 2011 when New Mexico Gas Company shut off service to an estimated 40,000 customers during several of the coldest days of the winter. ${ }^{31}$ To compensate its customers for the loss of natural gas service, New Mexico Gas Company has so far paid a little more than $\$ 700,000$ in customer claims from a voluntary $\$ 1$ million claims fund. Of the 2,000 claims that have been made, the company has written 1,174 checks. The interruption cost for a residential customer is estimated to be approximately $\$ 600$ per event $(\$ 700,000 / 1,174)$. (It should be noted that this cost does not include the costs incurred by the company to restore service to these 40,000 core customers.)

${ }^{29}$ EIA, undated, Annual Report of Natural and Supplemental Gas Supply and Disposition Form EIA-176 Instructions, available at http://www.eia.gov/survey/form/eia 176/instructions.pdf, accessed September 12, 2016.

${ }^{30}$ M.J. Sullivan, J. Schellenberg, and M. Blundell, 2015, Updated Value of Service Reliability Estimates for Electric Utility Customers in the United States, LBNL-6941E, Lawrence Berkeley National Laboratory, available at http://eetd.lbl.gov/sites/all/files/lbnl-6941e_ 0.pdf, accessed July 12, 2016.

31 Logan, J.R., 2011, "NM Gas Co. could face penalties for February outage," The Taos News, May 16, available at http://www.taosnews.com/news/article 4e55c8b0-5539-5a61-bd50-9de118649082.html. 


\begin{tabular}{|c|c|c|c|c|c|c|}
\hline \multirow{2}{*}{ Interruption Cost } & \multicolumn{6}{|c|}{ Interruption Duration } \\
\hline & Momentary & 30 Minutes & 1 Hour & 4 Hours & 8 Hours & 16 Hours \\
\hline \multicolumn{7}{|c|}{ Medium and Large C\&I (Over 50,000 Annual kWh) } \\
\hline Cost per Event & $\$ 12,952$ & $\$ 15,241$ & $\$ 17,804$ & $\$ 39,458$ & $\$ 84,083$ & $\$ 165,482$ \\
\hline Cost per Average kW & $\$ 15.9$ & $\$ 18.7$ & $\$ 21.8$ & $\$ 48.4$ & $\$ 103.2$ & $\$ 203.0$ \\
\hline Cost per Unserved kWh & $\$ 190.7$ & $\$ 37.4$ & $\$ 21.8$ & $\$ 12.1$ & $\$ 12.9$ & $\$ 12.7$ \\
\hline \multicolumn{7}{|c|}{ Small C\&I (Under 50,000 Annual kWh) } \\
\hline Cost per Event & $\$ 412$ & $\$ 520$ & $\$ 647$ & $\$ 1,880$ & $\$ 4,690$ & $\$ 9,055$ \\
\hline Cost per Average kW & $\$ 187.9$ & $\$ 237.0$ & $\$ 295.0$ & $\$ 857.1$ & $\$ 2,138.1$ & $\$ 4,128.3$ \\
\hline Cost per Unserved kWh & $\$ 2,254.6$ & $\$ 474.1$ & $\$ 295.0$ & $\$ 214.3$ & $\$ 267.3$ & $\$ 258.0$ \\
\hline \multicolumn{7}{|l|}{ Residential } \\
\hline Cost per Event & $\$ 3.9$ & $\$ 4.5$ & $\$ 5.1$ & $\$ 9.5$ & $\$ 17.2$ & $\$ 32.4$ \\
\hline Cost per Average kW & $\$ 2.6$ & $\$ 2.9$ & $\$ 3.3$ & $\$ 6.2$ & $\$ 11.3$ & $\$ 21.2$ \\
\hline Cost per Unserved kWh & $\$ 30.9$ & $\$ 5.9$ & $\$ 3.3$ & $\$ 1.6$ & $\$ 1.4$ & $\$ 1.3$ \\
\hline
\end{tabular}

Figure 3.5.1-1 Estimated Interruption Cost per Electric Outage Event, Average kW and Unserved kWh (U.S. 2013\$) by Duration and Customer Class

A detailed literature search did not identify estimates of the estimated costs of natural gas interruptions for commercial, industrial, and electric customers. Argonne conducted an analysis of the resilience information collected through U.S. Department of Homeland Security's (DHS's) Enhanced Critical Infrastructure Program (ECIP) Initiative, which conducts facility site visits and surveys. The primary objective of this analysis was to identify the dependence of surveyed critical infrastructure facilities on natural gas and to estimate the daily interruption costs resulting from a disruption in natural gas supply. The analysis was conducted on nearly 1,900 critical infrastructure facilities dependent on natural gas service, using data collected from January 2011 through May 2016.

Results from an Argonne analysis of the DHS ECIP Security Survey data on critical infrastructure facilities resulted in the following daily estimated interruption costs per natural gas event (see Table 3.5.1-1):

- $\$ 150,000$ per event for a commercial customer, based on an average of 462 commercial facilities;

- $\$ 420,000$ per event for an industrial customer, based on an average of 41 industrial facilities; and

- $\$ 68,000$ per event for an electric power customer, based on an average of 42 electric power facilities. 
Table 3.5.1-1 Estimated Interruption Cost and Equivalent Number of Residential Customers as a Function of Natural Gas Customer Class

\begin{tabular}{|l|c|c|l|}
$\begin{array}{c}\text { Natural Gas } \\
\text { Customer Class }\end{array}$ & $\begin{array}{c}\text { Interruption } \\
\text { Cost } \mathbf{( \$ )}\end{array}$ & $\begin{array}{c}\text { Equivalent Number of } \\
\text { Residential Customers }\end{array}$ & \multicolumn{1}{|c|}{ Source } \\
\hline Residential & $\$ 600$ & 1 & New Mexico Gas Company \\
\hline Commercial & $\$ 150,000$ & 250 & DHS ECIP Security Survey data \\
\hline Industrial & $\$ 420,000$ & 700 & DHS ECIP Security Survey data \\
\hline Electric & $\$ 68,000$ & 113 & DHS ECIP Security Survey data \\
\hline $\begin{array}{l}\text { Capacity Charge } \\
\text { (\$/MW-day) }\end{array}$ & $\$ 18$ & N/A & Subject matter expertise \\
\hline
\end{tabular}

The daily interruption cost per electric outage for an industrial electric customer in Figure 3.5.1-1 is $\$ 252,249,{ }^{32}$ which is lower than the estimated interruption cost per natural gas outage of $\$ 420,000$ for an industrial gas customer. The reason for this possible inconsistency cannot be explained at this time, but is being investigated.

The interruption cost for an electric customer estimated using the DHS ECIP Security Survey data (\$68,000 in Table 3.5.1-1) was validated against 2015 data available for electric power plant operations from EIA Form $923 .{ }^{33}$ During 2015, a total of 484,894,630 MWh were generated using natural gas from a total of 989 power plants. Assuming an average power plant operating expense of $\$ 42.6$ per MWh and a profit margin of $15 \%$, the estimated daily interruption cost is approximately $\$ 66,000(484,894,630 * 42.6 * 1.15 / 989 / 365)$ for an electric power customer, very similar to the $\$ 68,000$ per electric customer estimated using the DHS ECIP Security Survey data.

The estimated interruption cost per event may to some extent be a function of the region within the United States. There is also currently insufficient data to adequately estimate the interruption cost per event for residential and industrial customers as a function of region. As the DHS ECIP program continues in the future, the addition of more data may allow the calculation of regional values.

The results in Table 3.5.1-1 indicate that a commercial gas customer is equivalent to 250 residential gas customers, on a business-interruption cost basis. The number of gas customers estimated to be impacted by a hypothetical loss of a UGS facility could be determined using the unit factors in Table 3.5.1-1 for the equivalent number of residential customers. Using the unit factors by customer allows for an overall estimated impact across customer classes that results in the total number of equivalent residential customers.

In several electricity markets, independent system operators (ISOs) or regional transmission organizations (RTOs) make payments to power generators to keep their generation capacity available - in addition to paying for the energy actually produced. A literature search was performed to establish a "representative" cost value for these electric capacity charges (in terms of $\$$ per MW-day) that could be applied in this study. (The business interruption costs for electric

\footnotetext{
32 Sullivan et al., 2015.

33 EIA, 2016, "Electricity, Form EIA-923 detailed data," available at https://www.eia.gov/electricity/data/eia923/.
} 
power plants account for lost generation, but these costs do not include electric capacity charges.)

PJM recently held a 2019-2020 procurement auction, and the electric capacity charge was approximately $\$ 36.5 / \mathrm{kW}$-year ( $\$ 100 / \mathrm{MW}$-day), plus various locational adders. It can be expected that the electric capacity charge prices will differ from market to market depending on the capacity target and other market rules. ${ }^{34}$ Based on SME, it was decided that a capacity charge in the $\$ 40-\$ 60 / \mathrm{kW}$-year range would be roughly appropriate. An average value of $\$ 50 / \mathrm{kW}$-year (\$18/MW-day) was assumed in this analysis. The number of equivalent customers for this case was determined by multiplying the at-risk electric capacity (in MW) by the average value of $\$ 18 / \mathrm{MW}$-day and dividing this product by the residential business interruption cost of $\$ 600$.

\subsubsection{Estimating Overall Supply Risk}

The risk assessment combines the likelihood and consequences of identified untoward events. For events of extreme seriousness and sufficient likelihood, the risk is typically deemed unacceptable by the public, and efforts are made primarily to reduce or eliminate the risk. For events of minor consequence and low likelihood, the risk may be deemed acceptable, and a response plan to the event is then developed and exercised.

Underground natural gas storage projects have operated successfully for almost 100 years and in many parts of the world. In the United States, the 418 underground natural gas storage facilities are an integral part of the U.S. gas supply infrastructure. These projects provide for peak loads and balance seasonal fluctuations in gas supply and demand.

The original intent of the risk assessment in this analysis was to develop fault trees for all identified failure scenarios and then apply literature-predicted frequencies using UGS-specific data on the number of wells, types of equipment, and piping, which would have been similar to the approach described by Wickenhauser et al. (2006). ${ }^{35}$

Research revealed that public information is not available concerning this level of detail for each UGS facility; as an example, UGS well data is not publicly available for Maryland, Minnesota, and Texas. Because this analysis could only account for 11,746 wells of the total of approximately 17,500 UGS wells (67 percent), it was decided that the fault tree approach could not be applied without more complete well data.

Instead, a simpler approach is used that accounts for the potential disruption of a given UGS facility without delving into details about individual well failure rates. In this approach, the risk of each UGS facility was estimated by multiplying the frequency of a major incident (ranges from $8.4 \times 10^{-4}$ to $6.0 \times 10^{-3}$ per site-year) by the equivalent number of residential customers, using the methodology and results outlined in Section 3.5.1:

\footnotetext{
${ }^{34}$ http://www.eia.gov/electricity/annual/html/epa_08 04.html.

35 URL: http://www.cfertech.com/publication/quantitative-risk-assessment-underground-natural-gas-storagefacilities.
} 
[Equivalent Number of Residential Customers]UGS “i” $=\sum[$ Number of Customers] class “j” $\times$

[Unit Factor] class “j”

in which the "Unit Factor" of natural gas customer class " $\mathrm{j}$ " is determined by the values in Table 3.5.1-1 (e.g., a commercial gas customer is equivalent to 250 residential gas customers, on an economic basis).

The risk of a major incident affecting UGS operations is then determined using the following:

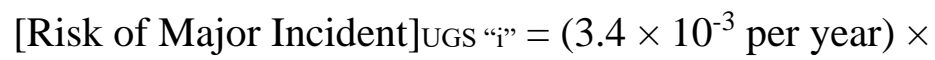

[Equivalent Number of Residential Customers]UGS “i”

where the value of $3.4 \times 10^{-3}$ per year is the average of the annual frequency range for the occurrence of a major incident at a given UGS facility (i.e., $3.4 \times 10^{-3}=$ average of $8.4 \times 10^{-4}$ and $6.0 \times 10^{-3}$ per year). Application of this annual frequency can be considered to represent a "reasonable worst-case" scenario. 


\section{Results of Analysis}

This chapter provides information on the potential risks associated with a long-term loss — one or another facility at a time - of UGS operations in the United States. Risk is taken in this analysis to be the product of the consequence and the likelihood of an unexpected and unwanted event.

This analysis attempted to validate the various tools used to estimate UGS facility risk. The consequence analysis in Chapter 3 was applied to estimate the potential impacts of the long-term loss of operations at Southern California Gas Company's Aliso Canyon facility. Figure 4-1 shows that a total of around $7.8 \mathrm{GW}$ of natural gas-fired electric generation capacity could be potentially affected from a 1-month loss of supply from the Aliso Canyon UGS facility.

\begin{tabular}{|c|c|c|c|c|c|c|c|c|c|c|c|c|c|c|c|c|c|c|c|c|}
\hline \multirow{2}{*}{\multicolumn{2}{|c|}{ UGS Facility }} & \multicolumn{4}{|c|}{ Projected Shortfall } & \multirow[b]{2}{*}{$\begin{array}{l}\text { UGS Loss } \\
\text { Critical? }\end{array}$} & \multirow{2}{*}{$\begin{array}{c}\text { Year of } \\
\text { Minimum }\end{array}$} & \multicolumn{6}{|c|}{ Number of Customers Shed } & \multicolumn{7}{|c|}{ Daily Average Demand (MMcf/d) } \\
\hline & & \multicolumn{2}{|c|}{$\begin{array}{l}\text { Monthly } \\
\text { (MMcf) }\end{array}$} & \multicolumn{2}{|c|}{$\begin{array}{c}\text { Daily } \\
\text { (MMcf/d) }\end{array}$} & & & Residential & \multicolumn{2}{|c|}{1 Commercial } & Industrial & \begin{tabular}{|c|} 
Vehicle + \\
Other
\end{tabular} & \begin{tabular}{|l|} 
Electric \\
Power
\end{tabular} & \multicolumn{2}{|c|}{ Residential } & \multicolumn{2}{|c|}{ Commercial } & Industrial & $\begin{array}{c}\text { Vehicle + } \\
\text { Other }\end{array}$ & $\begin{array}{l}\text { Electric } \\
\text { Power }\end{array}$ \\
\hline ALISO CANYC & & & $-5,557$ & & -183 & YES & 2011 & 0 & 0 & 0 & 0 & 0 & 17 & & 697 & & 279 & 720 & 28 & 454 \\
\hline \multicolumn{7}{|c|}{ Annual Number of Customers } & \multicolumn{6}{|c|}{ Estimated Amount of Load Shed (MMcf/d) } & \multicolumn{5}{|c|}{ LOC Total } & \multicolumn{3}{|c|}{ Estimated Affected Total } \\
\hline Residential & \multicolumn{2}{|c|}{ Commercial } & \multicolumn{2}{|c|}{ Industrial } & \begin{tabular}{|c|} 
Vehicle + \\
Other
\end{tabular} & \begin{tabular}{|l|} 
Electric \\
Power
\end{tabular} & \begin{tabular}{|c|c|} 
Electric \\
Power
\end{tabular} & Industrial & $\begin{array}{c}\text { Vehicle + } \\
\text { Other }\end{array}$ & \multicolumn{2}{|c|}{ Commercial } & Residential & \multicolumn{2}{|c|}{ No. Power Plants } & \multicolumn{2}{|c|}{$\begin{array}{l}\text { Capacity } \\
\text { (MW) }\end{array}$} & $\begin{array}{l}\text { Electric } \\
\text { Customers }\end{array}$ & \begin{tabular}{|l|} 
No. \\
Power \\
Plants
\end{tabular} & $\begin{array}{l}\text { Capacity } \\
\text { (MW) }\end{array}$ & $\begin{array}{c}\text { Electric } \\
\text { Customers }\end{array}$ \\
\hline $5,343,068$ & & 5,855 & 19, & 243 & 191 & 42 & 183 & 0 & 0 & & 0 & 0 & 140 & & 19,32 & & 42 & 57 & 7,820 & 17 \\
\hline
\end{tabular}

Figure 4-1 Estimated Impacts from a One-Month Disruption in Natural Gas Supply from the Aliso Canyon UGS Facility

For comparison, a Joint Agency Workshop held on April 8, 2016, predicted approximately 9.8 GW of power plant generation in the Los Angeles Basin would be at risk under peak-day conditions, as shown in Figure 4-2. ${ }^{36}$ However, the difference in at-risk power plant capacity may be due to the different time horizons: peak-day versus peak-month conditions. Further investigation is needed to resolve the potential difference in estimated at-risk power plant capacity.

\subsection{Consequence Analysis}

The consequence analysis was performed using the data and methodologies identified in Chapter 3. The consequence of the hypothetical loss of a UGS facility is provided in the form of the estimated number of customers by class (residential, commercial, industrial, vehicle + other, and electric) and impacts on the electric sector (potentially affected megawatts of electric power generating capacity).

The number of customers affected has a special implication for natural gas disruptions. Unlike dealing with electric power outages, which often require no visits to the inside of a customer premises to restore service (assuming conditions for access to the customer are comparable for natural gas and electric operators), the restoration of gas service involves an initial visit to each individual customer to shut off gas valves; work to repair any gas system damage, purge the gas lines, and test for integrity; and a second visit to each individual customer to relight each appliance or manufacturing process and piece of machinery. This process is tedious and

36 URL: http://www.energy.ca.gov/2016 energypolicy/documents/2016-0408 joint_agency_workshop/Aliso_Canyon_Risk_Assessment_Technical_Report.pdf. 


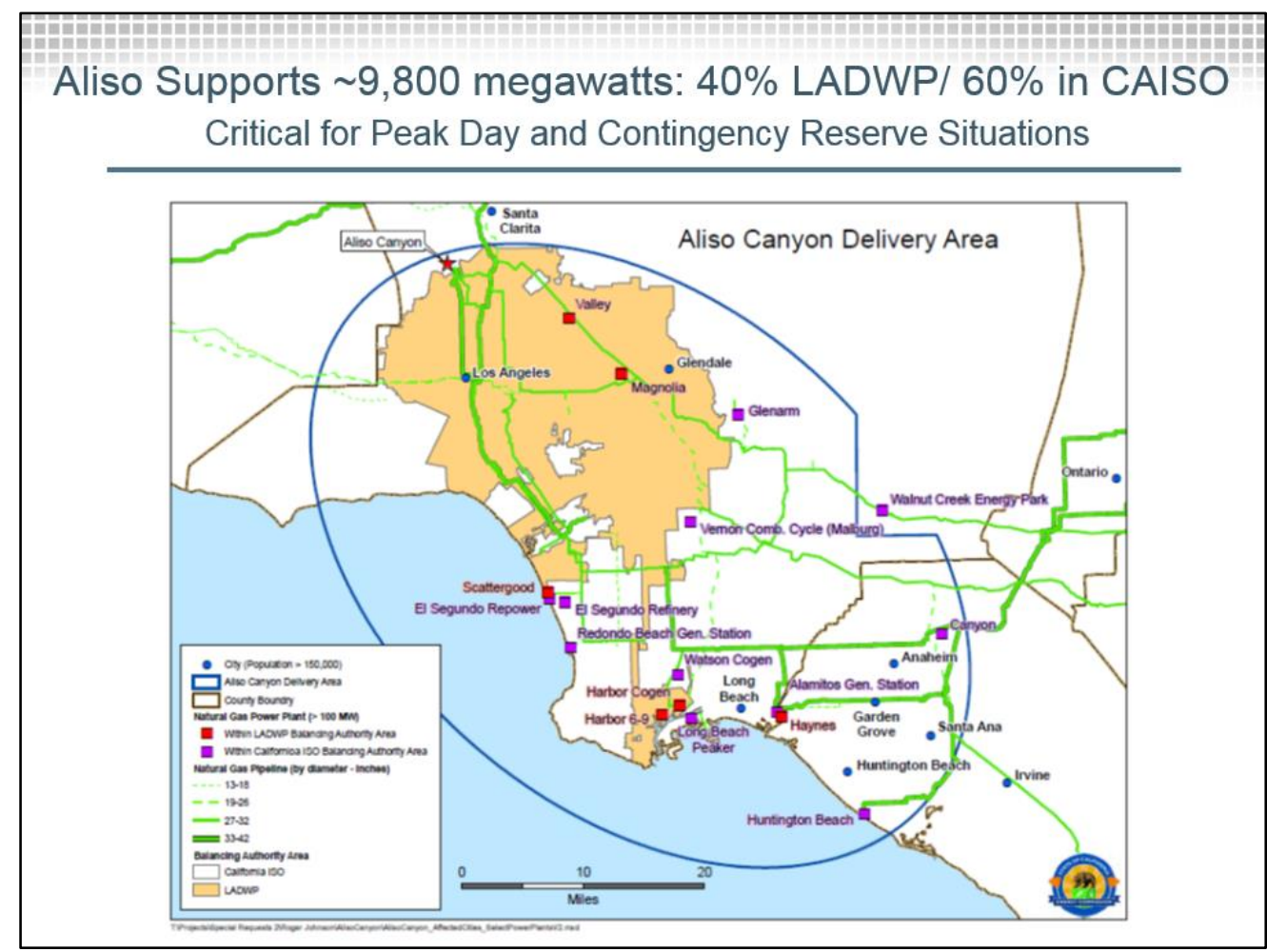

Figure 4-2 Estimated Impacts from a Disruption of Aliso Canyon Operations under Peak-Day Conditions

time-consuming and must be conducted with trained personnel with the safety of customers as the primary concern.

The present analysis did not consider the time of year when the disruption is postulated to occur, although that has an impact on the effects associated with a gas disruption. Gas interruptions during the summer in a residential area may be of low consequence (unless the affected electric utility systems are highly gas-dependent and are unable to access sufficient amounts of other generation capacity via transmission). During the winter, however, the same interruption scenario could affect the health and safety of the residents in a relatively short time, as well as cause significant economic damage (e.g., frozen water pipes). Even brief interruptions of gas service in a commercial or industrial area (e.g., metal manufacturing plant) can cause the loss of an entire product line or production batch. ${ }^{37}$ These effects are not included in this analysis.

Please note that the consequence results are based on the following assumptions:

- Complete loss of UGS withdrawals for a 1-month duration.

37 It should be noted that some industries are similarly very dependent on the quality of their power supplies. For these industries, a momentary fluctuation in voltage can spoil a production run. Many, but not all, companies in this situation "self-protect" by investing in their own on-site equipment to ensure power quality. 
- The order of load shedding by LDCs is (1) gas-fired power plants, (2) industrial customers, (3) commercial customers, and (4) residential customers.

- A force majeure ${ }^{38}$ event at an interstate pipeline would mandate that any remaining operational gas pipeline capacity would be pro-rationed among firm customers. All nonfirm customers would be immediately asked to curtail their consumption of gas. ${ }^{39}$ Firm customers of interstate pipelines generally consist of multiple LDCs, electric generators, and industrial customers.

- Additional pipeline supply is only available in the form of firm pipeline contracts for LDC-owned UGS facilities.

- Because of the lack of public information, any additional supply from emergency interconnects is not considered.

- Potential decrease in natural gas demand due to public calls for voluntary reductions is not taken into consideration.

- Potential increase in natural gas supply due to over-pressurization of the pipeline infrastructure is not included.

The results of this consequence analysis are described in the next three sections in terms of the different types of UGS ownership.

\subsubsection{Consequence of the Loss of LDC-Owned UGS Facilities}

Complete loss of UGS supply for a 1-month duration was assumed in the analysis. For a total of 53 LDC-owned UGS facilities, a 1-month loss of withdrawals would adversely affect LDC operations and result in the loss of supply to customers. Impacts on the residential sector are generally not seen, and impacts on commercial customers occur only at a limited number of UGS facilities. The concern about loss of supply to residential and commercial customers is due to the requirement for customer relighting. (Industry rules of thumb are that one trained professional could shut off 10 customers per hour and [later] relight 3 to 4 customers per hour.)

The largest impacts from the loss of natural gas supply are to natural gas-fired power plants. Such impacts may be significantly overstated, if the affected power plants have multiple sources of natural gas supply which are not public information. The authors suggest that the natural gas supply sources for power plants connected to local utilities concerned be further investigated through discussions with the natural gas companies involved.

${ }^{38}$ Force majeure means superior or irresistible force that excuses a failure to perform. It has been defined by the United States Supreme Court as a cause that is "beyond the control and without the fault or negligence" of the party excused.

39 NERC, 2016, Short-Term Special Assessment, Operational Risk Assessment with High Penetration of Natural Gas-Fired Generation, available at http://www.nerc.com/pa/RAPA/ra/Reliability\%20Assessments\%20DL/ NERC\%20Short-Term\%20Special\%20Assessment\%20Gas\%20Electric_Final.pdf, accessed September 2, 2016. 


\subsubsection{Consequence of the Loss of Pipeline-Owned UGS Facilities}

There are a small number of interstate gas transmission pipeline-owned UGS facilities for which a 1-month loss of withdrawals would adversely affect pipeline operations and result in the loss of supply to downstream customers.

Impacts on the residential sector are not expected, and impacts on commercial customers only occur at a limited number of UGS facilities. Impacts on residential and commercial customers are predicted, because some pipelines are connected to LDCs which serve only residential and commercial customers and a loss in natural gas supply to these LDCs would therefore affect commercial and then residential customers during load shedding. As expected, the largest impact from the loss of natural gas supply would be to natural gas-fired power plants.

In the past, before pipeline deregulation, natural gas transmission pipelines were constructed on behalf of natural gas LDCs, which typically serve a fairly predictable heating load in the winter. Those pipelines are not built to serve the vastly different load profiles with rapid and dramatic load swings that accompany electric generation.

The greatest impact from hypothetical loss of pipeline-owned UGS facilities would occur in the southeastern part of the United States and could potentially affect the Eastern Interconnect.

Proprietary design-day information on unreserved pipeline capacity and customer access to alternative pipeline systems was not available for this study, and further analysis using proprietary data may be needed to more exactly determine the impacts of the loss of a single UGS facility.

\subsubsection{Consequence of the Loss of Independent Third-Party-Owned UGS Facilities}

There are a number of independent third-party-owned UGS facilities for which a 1-month loss of withdrawals would result in the loss of gas supply to downstream customers. Impacts on the residential and commercial sectors are not generally seen; the concern about loss of supply to residential and commercial customers is due to the requirement for customer relighting. As expected, the largest impact from the loss of natural gas supply would be to natural gas-fired power plants. There are 25 independent third-party-owned UGS facilities with potential impacts on electric customers. Many third-party independent UGS facilities are salt caverns with highdeliverability located in the Southeast United States.

Similar to pipeline-owned UGS facilities, the greatest impact from the hypothetical loss of independent third-party-owned UGS facilities would occur in the southeastern part of the United States and could potentially affect the Eastern Interconnect. 


\subsection{Incident Likelihood}

Table 4.2-1 outlines documented events experienced at UGS facilities in the United States, classified by storage type (depleted oil-gas field, aquifer, and salt cavern). A total of 135 cases of failures or problems encountered at UGS facilities in the United States were identified in this study. Please refer to Appendix B for more information on these documented events.

The sources for these events include public literature, PHMSA data from 1984 to the present, and FERC Form 576 data on natural gas interruptions that occurred at UGS sites.

Texas has the highest number of documented events (20), but it also has the third-highest number of UGS sites (36 currently). California and Illinois have the next-highest number of documented events (16), although California has one-half the number of UGS sites compared to Illinois (14 in California versus 28 in Illinois). On a per-UGS site basis, California experienced the greatest number of storage field incidents in the United States, almost twice that of other States.

California is responsible for $18 \%$ of the UGS incidents at depleted oil-gas fields and has had three UGS facilities (El Segundo, East Whittier, and Montebello ${ }^{40}$ ) closed due to gas migration to the surface along old wells and faults. There are numerous old oilfields in California with migrating gas in an urban environment. Further study is required to assess the impact of abandoned oilfields and wells in an urban environment.

As shown in Table 4.2-1, events have not been documented for UGS facilities in the States of Alaska, Alabama, Arkansas, Maryland, Minnesota, Missouri, Oregon, Virginia, and Washington. In the attempt to collect data on any historical UGS facilities in these States, the appropriate State agencies were contacted. However, these agencies indicated that the data were not collected in a consistent or uniform manner over the years. Significant events were identified (such as the large losses in volume experienced by the Eminence salt dome in Mississippi) in the 1970s and 2010, ${ }^{41,42}$ but information on individual well blowouts or UGS failures are not tracked on a routine or consistent basis.

Table 4.2-1 Summary of Documented Events Reported at U.S. Underground Gas Storage Facilities

\begin{tabular}{|c|c|c|c|c|}
\hline \multirow[b]{2}{*}{ State } & \multicolumn{4}{|c|}{ Number of Storage Field Incidents } \\
\hline & $\begin{array}{c}\text { Depleted } \\
\text { Oil-Gas } \\
\text { Field }\end{array}$ & Aquifer & $\begin{array}{c}\text { Salt } \\
\text { Cavern }\end{array}$ & $\begin{array}{l}\text { State } \\
\text { Total }\end{array}$ \\
\hline CA & 16 & 0 & 0 & 16 \\
\hline $\mathrm{CO}$ & 5 & 0 & 0 & 5 \\
\hline IA & 0 & 2 & 0 & 2 \\
\hline IL & 1 & 15 & 0 & 16 \\
\hline IN & 0 & 4 & 0 & 4 \\
\hline
\end{tabular}

\footnotetext{
${ }^{40}$ At the Montebello oil field, gas that had been injected was subsequently found to be leaking to the surface along old wells. Leakages were found within a large housing development and injections ceased in 1986 and the facility closed in 2003.

${ }^{41}$ http://gasfreeseneca.com/wp-content/uploads/2011/06/Gas-Storage-Explosions.pdf.

42 http://www.ferc.gov/EventCalendar/Files/20130207144002-CP11-551-000.pdf.
} 
Table 4.2-1 Summary of Documented Events Reported at

U.S. Underground Gas Storage Facilities

\begin{tabular}{|c|c|c|c|c|}
\hline \multirow[b]{2}{*}{ State } & \multicolumn{4}{|c|}{ Number of Storage Field Incidents } \\
\hline & $\begin{array}{c}\text { Depleted } \\
\text { Oil-Gas } \\
\text { Field }\end{array}$ & Aquifer & $\begin{array}{c}\text { Salt } \\
\text { Cavern }\end{array}$ & $\begin{array}{l}\text { State } \\
\text { Total }\end{array}$ \\
\hline KS & 4 & 0 & 1 & 5 \\
\hline KY & 3 & 0 & 0 & 3 \\
\hline LA & 5 & 0 & 2 & 7 \\
\hline $\mathrm{MI}$ & 13 & 0 & 0 & 13 \\
\hline MS & 0 & 0 & 2 & 2 \\
\hline MT & 1 & 0 & 0 & 1 \\
\hline NE & 1 & 0 & 0 & 1 \\
\hline NM & 1 & 0 & 0 & 1 \\
\hline NY & 4 & 0 & 0 & 4 \\
\hline $\mathrm{OH}$ & 5 & 0 & 0 & 5 \\
\hline $\mathrm{OK}$ & 4 & 0 & 0 & 4 \\
\hline PA & 9 & 0 & 0 & 9 \\
\hline $\mathrm{TX}$ & 6 & 0 & 14 & 20 \\
\hline UT & 0 & 2 & 0 & 2 \\
\hline WV & 10 & 0 & 0 & 10 \\
\hline WY & 3 & 2 & 0 & 5 \\
\hline TOTAL & 91 & 25 & 19 & 135 \\
\hline
\end{tabular}

Table 4.2-2 shows a comparison of the UGS incident rates that accounts for the number of UGS sites by storage type in the United States (using 2015 EIA Form 191 data).

Table 4.2-2 Comparison of UGS Incident Rates

\begin{tabular}{|l|c|c|c|}
\hline \multicolumn{1}{|c|}{ Variable } & $\begin{array}{c}\text { Depleted Oil- } \\
\text { Gas Field }\end{array}$ & Aquifer & $\begin{array}{c}\text { Salt } \\
\text { Cavern }\end{array}$ \\
\hline Number of Incidents & 91 & 25 & 19 \\
\hline Number of UGS Sites & 328 & 46 & 39 \\
\hline Ratio of Incidents to UGS Sites & 0.28 & 0.54 & 0.49 \\
\hline
\end{tabular}

It can be seen that the incident rate is similar for aquifers (0.54) and salt caverns (0.49), but that a lower overall rate is observed for depleted oil-gas fields.

Given the paucity of disruption rate data for UGS facilities, it was assumed in this study that aquifers and salt caverns would have similar projected incident rates, but that depleted oil-gas fields could experience incident rates one-half those of salt caverns, which is explained further in the study and is evident in Table 4.2-3. 
Table 4.2-3 Summary of Main Processes Leading to Events at Underground Gas Storage Facilities ${ }^{a}$

\begin{tabular}{|c|c|c|c|c|c|c|}
\hline \multirow[b]{2}{*}{$\begin{array}{l}\text { Failure } \\
\text { Mechanism } \\
\text { ID }\end{array}$} & \multirow[b]{2}{*}{ Description } & \multicolumn{4}{|c|}{ Number of Storage Field Incidents } & \multirow[b]{2}{*}{ Rank } \\
\hline & & $\begin{array}{l}\text { Depleted } \\
\text { Oil-Gas } \\
\text { Field }\end{array}$ & Aquifer & $\begin{array}{c}\text { Salt } \\
\text { Cavern }\end{array}$ & Subtotal & \\
\hline 1 & $\begin{array}{l}\text { Well/casing/brine string/plug problems/failure } \\
\text { including blowout }\end{array}$ & 14 & 2 & 7 & 23 & 3 \\
\hline 2 & $\begin{array}{l}\text { Aboveground infrastructure-valve/pipes/well } \\
\text { head/compressor/gas detection system }\end{array}$ & 61 & 13 & 5 & 79 & 1 \\
\hline 3 & Loss of wellhead pressure or failed pressure test & 0 & 0 & 1 & 1 & 16 \\
\hline 4 & $\begin{array}{l}\text { Design/construction failure-including site } \\
\text { characterization, cap rock performance, leaching }\end{array}$ & 13 & 11 & 1 & 25 & 2 \\
\hline 5 & $\begin{array}{l}\text { Operational failure-over-pressure/fill reservoir } \\
\text { /aquifer/cavern, operational procedures (human } \\
\text { error) }\end{array}$ & 11 & 1 & 2 & 14 & 5 \\
\hline 6 & $\begin{array}{l}\text { Operational failure-hydrostatic pressure too low, } \\
\text { storage reservoir/cavern too shallow }\end{array}$ & 0 & 1 & 0 & 1 & 16 \\
\hline 7 & Operational failure-low pressures, salt creep & 0 & 0 & 1 & 1 & 16 \\
\hline 8 & $\begin{array}{l}\text { Operational failure-leaching (unknown and } \\
\text { uncontrolled), cavern communication, roof collapse } \\
\text { (salt or overburden) }\end{array}$ & 0 & 0 & 3 & 3 & 11.5 \\
\hline 9 & $\begin{array}{l}\text { Cavern/void problems-fractures, creep, high } \\
\text { insolubles, collapse/salt wall fall }\end{array}$ & 0 & 0 & 3 & 3 & 11.5 \\
\hline 10 & Inadvertent intrusion & 5 & 1 & 0 & 6 & 10 \\
\hline 11 & During repair/testing/maintenance & 6 & 0 & 1 & 7 & 8.5 \\
\hline 12 & $\begin{array}{l}\text { Migration from injection footprint/cavern (not due } \\
\text { entirely to well problems) }\end{array}$ & 10 & 10 & 0 & 20 & 4 \\
\hline 13 & Cap rock-not gas tight/salt thick enough & 2 & 9 & 0 & 11 & 6 \\
\hline 14 & Cap rock-fractured/faulted, not gas tight & 4 & 3 & 0 & 7 & 8.5 \\
\hline 15 & Mine shaft & 1 & 0 & 0 & 1 & 16 \\
\hline 16 & Wet rockhead/sinkholes & 0 & 0 & 1 & 1 & 16 \\
\hline 17 & Seismic activity & 2 & 0 & 0 & 2 & 13 \\
\hline 18 & Not available-unknown & 7 & 1 & 2 & 10 & 7 \\
\hline
\end{tabular}

a Please note that there is double-counting in this table.

There are several areas that can be addressed to minimize the likelihood of problems with a facility: reservoir integrity, casing integrity, wellheads, surface facilities, and pipelines.

Table 4.2-3 provides a summary of main processes that have led to events at UGS facilities, based on public information.

It should be noted from Table 4.2-3 that the majority of the UGS incidents reported in the public literature occur aboveground (ID=2), followed by design/construction failure (ID=4) and well failure, including blowout (ID=1).

This trend agrees with the public literature on UGS incident rates, in which well failures occur less frequently than a major outage at a UGS site.

The data in Table 4.2-3 indicate that well blowout is the primary cause of events at salt caverns, unlike depleted oil-gas fields and aquifers. The aboveground infrastructure for salt caverns is simpler than that for depleted fields or aquifers, and consists of a high-pressure compressor and dehydration units, as gas will pick up water from residual brine at the bottom of a cavity. 
Similarly, migration of natural gas and cap rock issues are major sources of events for aquiferbased UGS facilities and are the main reasons for gas leakage at nine aquifer sites, including six events in Illinois.

Historical events at depleted oil- and gas-based UGSs are dominated by aboveground incidents, including numerous releases of natural gas through malfunctioning valves and rupture of on-site underground storage lines. Only 6 events at depleted oil and gas UGSs were in part due to natural hazards, with 2 resulting from tornado strikes (Northern Natural Gas's Cunningham storage facility and Oneok Gas Storage's Edmond storage facility), another due to the 1994 Northridge Earthquake, 2 due to flooding, and the last resulting from exposure to extreme cold temperatures.

Figure 4.2-1 identifies UGS facilities for which events have been historically documented, some of which have led to leakage and/or failure (see Appendix B for more details). It can be seen that events have occurred historically throughout the United States and are not clustered in a single region. The data also indicate that most UGS facilities have experienced between 1 to 2 events with a median of one event.

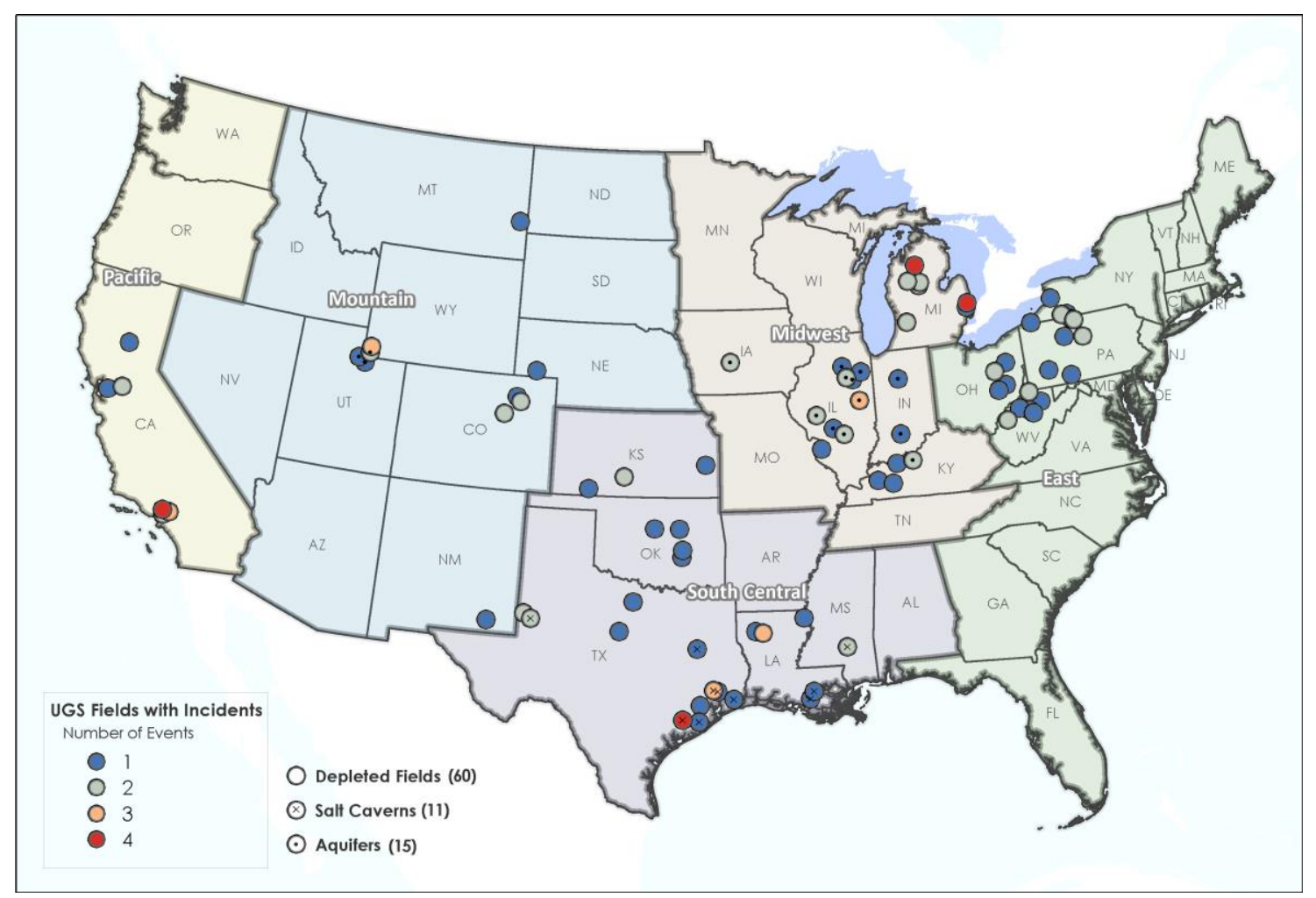

Figure 4.2-1 Locations of Documented Incidents at UGS Facilities in the United States 
There are, however, a number of UGS facilities with three or four documented incidents:

- Aliso Canyon, Southern California Gas Company, Los Angeles County, California (4 incidents);

- Playa Del Rey, Southern California Gas Company, Los Angeles County, California (3 incidents);

- $\quad$ Blue Lake 18-A, Blue Lake Storage Company, Kalkaska County, Michigan (4 incidents);

- Bluewater Gas Storage, Bluewater Gas Storage LLC, St. Clair County, Michigan (4 incidents);

- Boling, Enterprise Texas Pipeline, Wharton County, Texas (4 incidents);

- Dayton North, Kinder Morgan Texas Pipeline LP, Liberty County, Texas (3 incidents); and

- Ryckman Creek, Ryckman Creek Resources LLC, Unita County, Wyoming (three incidents).

FERC Form 576 data indicate that the Ryckman Creek facility has had a number of recent incidents which have led to interruptions in natural gas service to its customers, as shown in Table 4.2-4.

Table 4.2-4 Details of Recent Incidents Reported at the Ryckman Creek Storage Facility in Wyoming

\begin{tabular}{|c|l|l|l|}
$\begin{array}{c}\text { Date of } \\
\text { Incident }\end{array}$ & \multicolumn{1}{|c|}{ Description of Incident } & Cause of Incident & \multicolumn{1}{c|}{ Consequence } \\
\hline $4 / 20 / 13$ & $\begin{array}{l}\text { Fire at the Nitrogen Rejection } \\
\text { Unit at the facility. The plant was } \\
\text { shut down through an emergency } \\
\text { shutdown, and the fire was } \\
\text { allowed to burn itself out. }\end{array}$ & $\begin{array}{l}\text { Fire at the Nitrogen } \\
\text { Rejection Unit at } \\
\text { the facility. }\end{array}$ & $\begin{array}{l}\text { There were no injuries or casualties. Service was not } \\
\text { capable of being provided during the emergency } \\
\text { shutdown. One firm storage customer had been } \\
\text { affected and notified of the incident, as well as } \\
\text { posting of notices on the electronic bulletin board } \\
\text { (EBB). In addition, Ryckman posted an EBB notice } \\
\text { that beginning on April 25, 2013; Ryckman had the } \\
\text { limited ability to receive and deliver gas. }\end{array}$ \\
\hline $7 / 8 / 14$ & $\begin{array}{l}\text { Certain defects in the } \\
\text { construction of the Ryckman } \\
\text { Plant and possible jeopardy to } \\
\text { safe operations; Ryckman Creek } \\
\text { declared a force majeure } \\
\text { effective July 8, 2014. }\end{array}$ & $\begin{array}{l}\text { Certain defects in } \\
\text { the construction of } \\
\text { the Ryckman Plant } \\
\text { and possible } \\
\text { jeopardy to safe } \\
\text { operations }\end{array}$ & $\begin{array}{l}\text { Ryckman Creek was suspending all services } \\
\text { provided by the Ryckman Creek Plant; Ryckman } \\
\text { Creek declared a force majeure effective July 8, } \\
\text { 2014. }\end{array}$ \\
\hline $1 / 11 / 16$ & $\begin{array}{l}\text { Force Majeure: Equipment } \\
\text { failure. A thermal oxidizer } \\
\text { overheated and is down. }\end{array}$ & $\begin{array}{l}\text { Overheating of } \\
\text { thermal oxidizer }\end{array}$ & $\begin{array}{l}\text { Ryckman is able to inject gas and wheel gas, but all } \\
\text { withdrawals are shut-in; effective gas day } \\
1 / 12 / 2016 \text { and continuing until further notice. }\end{array}$ \\
\hline
\end{tabular}


Figure 4.2-2 identifies UGS facilities that have been closed, either due to excess gas migration or cap rock failure. These sites were closed due to safety concerns associated with their continued operations. For example, gas injected into the Montebello UGS facility was found to be leaking to the surface along old wells, many of which were drilled in the 1930s. Leaking natural gas was found in a large housing development on top of the Montebello UGS facility, and for safety reasons, injections ceased in 1986 and the facility closed in 2003. It can also be seen that a number of UGS facilities in California have been closed, in part due to the area being tectonically active and also due to the presence of many oil and gas wells the exact locations of which are generally not known accurately.

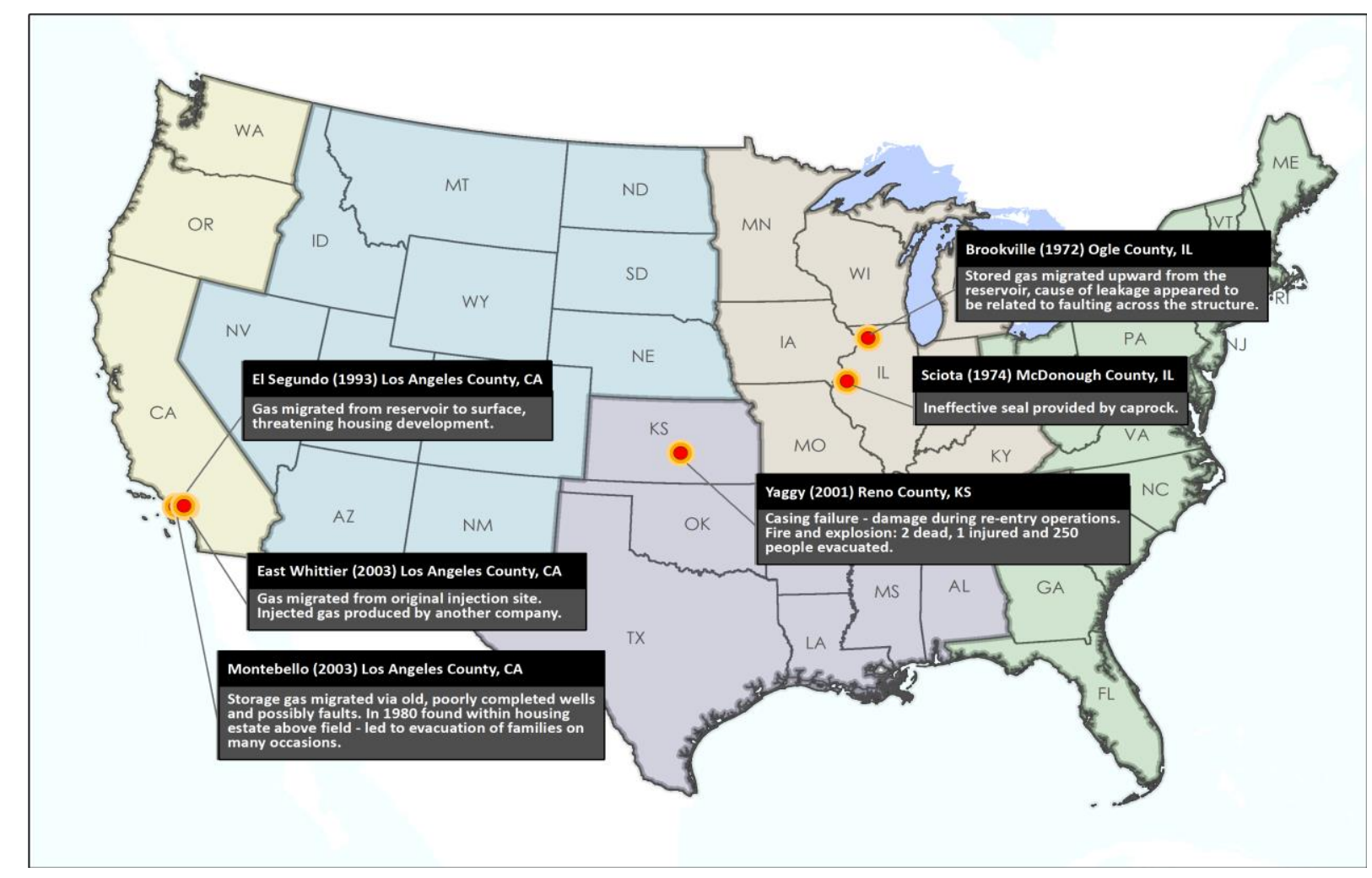

Figure 4.2-2 Examples of UGS Facilities Closed Due to Gas Migration or Cap Rock Failure

The hazards of gas migration are highlighted by the events associated with the Yaggy UGS facility in Kansas, in which natural gas from a storage field caused fires and explosions, killing two people. The downtown businesses were never rebuilt, the mobile home park was closed, and the Yaggy field was shut down. It took more than a month for flares to burn off the estimated 143 million cubic feet of gas that escaped from storage.

Due to the paucity of event data for UGS facilities in the U.S., a literature search was performed to collect information on the projected frequency of incidents (Table 4.2-5). Data are readily available for salt caverns and depleted oil and gas field UGSs, and it was assumed in this study that aquifer UGSs would experience a similar frequency of disruption as depleted oil and gas field UGSs (based on Table 4.2-2). 
Table 4.2-5 Literature Values on the Projected Frequency of Incidents for UGS Facilities

\begin{tabular}{|c|c|c|c|}
\hline Failure Mode & $\begin{array}{l}\text { Lower } \\
\text { Value }\end{array}$ & $\begin{array}{l}\text { Upper } \\
\text { Value }\end{array}$ & Units \\
\hline Major incident from a UGS facility & $8.4 \times 10^{-4}$ & $6.0 \times 10^{-3}$ & per facility year \\
\hline Integrity failure-salt cavern & $1.5 \times 10^{-5}$ & $3.4 \times 10^{-5}$ & per well-year \\
\hline Integrity failure-depleted oil \& gas field & $6.5 \times 10^{-6}$ & $9.9 \times 10^{-6}$ & per well-year \\
\hline Integrity failure-aquifer ${ }^{a}$ & $6.5 \times 10^{-6}$ & $9.9 \times 10^{-6}$ & per well-year \\
\hline Well failure-salt cavern & $1.2 \times 10^{-5}$ & $4.1 \times 10^{-5}$ & per well-year \\
\hline Well failure-depleted oil and gas field & $5.8 \times 10^{-6}$ & $1.2 \times 10^{-5}$ & per well-year \\
\hline Well failure-aquifer ${ }^{a}$ & $5.8 \times 10^{-6}$ & $1.2 \times 10^{-5}$ & per well-year \\
\hline Pipework (well riser)-major failure & \multicolumn{2}{|c|}{$6.5 \times 10^{-5}$} & per equipment-year \\
\hline Pipework (well riser)-minor failure & \multicolumn{2}{|c|}{$3.0 \times 10^{-4}$} & per equipment-year \\
\hline Major incident from a UGS well & $2.0 \times 10^{-5}$ & $5.0 \times 10^{-5}$ & per well-year \\
\hline Well blowout frequency & \multicolumn{2}{|c|}{$5.0 \times 10^{-5}$} & per well-year \\
\hline
\end{tabular}

a Data unavailable for aquifer-type UGS; this study assumes similar value for depleted oil and gas field-type UGSs.

The frequency of a major incident from a UGS facility ranges from $8.4 \times 10^{-4}$ to $6.0 \times 10^{-3}$ per site-year, or once every 167 to 1,190 years of UGS site operation. ${ }^{43}$ Assuming that there are 418 UGS facilities currently in the United States (of which 390 are currently active), this equates to a major $^{44}$ incident every 4 months to 3 years in the United States. This results in an average of 1.4 incidents per year. This estimate can be compared with FERC-supplied information that there have been seven UGS-related events from 2013 to 2016 that have led to natural gas interruptions, or about 1 to 2 events per year. ${ }^{45}$

On average, about eight incidents have been reported annually to the U.S. Department of Transportation (DOT), based on PHMSA data from the past 5 years (2011 to 2015). It is not known how many of these PHMSA-reported incidents resulted in disruption in UGS site operations or downstream impacts on natural gas customers. This study concludes that application of incident rates based on PHMSA-reported events would result in an overestimation of the frequency of occurrence of a major UGS incident.

This study applied the literature values for a major UGS incident shown in Table 4.2-5 because the literature values are based on multiple years of UGS site operations. Because of the nature of the data, it is assumed that the major incident rates applied in this study could be considered to represent a "reasonable worst-case" scenario.

43 Review of the 135 incidents in Appendix B indicates fourteen of those incidents resulted in a disruption or outage of one month or longer. Six of the 14 incidents were attributed to surface equipment issues and eight were attributed to sub-surface issues. This results in an annual frequency of a month-long disruption of $7.6 \times 10^{-4}$ per facility-year. However, the outage duration is unknown for a number of incidents in Appendix B.

44 A major incident is one that resulted in injury/fatality, property damage, site evacuation or uncontrolled leak; see URL: http://www.ieaghg.org/docs/General_Docs/Reports/2006-2\%20Safe\%20Storage\%20Report.pdf.

45 In 2016, two UGS facilities have experienced disruptions of one month or longer: Aliso Canyon and PG\&E McDonald Island. 
Table 4.2-5 also provides incident frequency estimates for well disruption that will be combined with the number of injection/withdrawal wells at each UGS facility, to estimate the potential for a major incident from a UGS well.

The information in this section indicates that major accidents are uncommon in the natural gas storage industry. Incident data show that smaller leaks occasionally happen when utilities inject new supplies of gas into the sites or withdraw them during the winter season.

\subsection{Distribution of Well Age and Potential Aging Issues}

Natural gas infrastructure faces aging and obsolescence concerns. The depreciated asset life of a gas storage facility is approximately 50 years (although actual operational life is longer with the proper maintenance). It has been stated that aging issues are being seen in natural gas UGS. As America shifts toward natural gas for energy, aging storage facilities may be at potential risk of leaks and fires, and these potential risks should be investigated further with additional analysis and data. ${ }^{46}$

Storage wells can be in operation for many years, and while the passage of time itself does not pose an additional threat if facility integrity is managed, the threats to each storage well can and likely will change over time. Examples include surface encroachments on well sites due to farm land being converted into housing developments or the discovery of new productive oil and gas formations below the storage reservoir leading to third-party drilling activity through or in proximity of the storage formation. ${ }^{47}$

Underground storage well data was collected from State sources. Many States provide this data on the Web. For example, California well data indicate SoCalGas's Aliso Canyon facility has wells drilled during the 1940s. Figure 4.3-1 shows an example of Aliso Canyon well SPUD date (beginning of drilling operations of a new well) data.

Aliso Canyon appears to have the oldest natural gas injection/withdrawal wells in California. Figures 4.3-2 and 4.3-3 show histograms of well completion dates for UGS fields in California and for Aliso Canyon.

Natural gas well data for other States indicate well construction dates starting in the 1900s. There is concern about depleted oil or gas fields that were discovered decades ago and contain aging wells not built or maintained to today's standards. Michigan has more active underground natural gas storage reservoirs similar to Aliso Canyon than any other U.S. State. For example, many of Michigan's natural gas storage facilities are in depleted oil and gas fields. Some of the State's underground well infrastructure is more than 70 years old, and some wells likely have not been

46 DOE, 2015, QER Report: Energy Transmission, Storage, and Distribution Infrastructure, available at http://energy.gov/sites/prod/files/2015/04/f22/QER\%20Summary\%20final_1.pdf, accessed September 6, 2016.

47 American Petroleum Institute (API) et al., 2016, Underground Natural Gas Storage, Integrity and Safe Operations, available at https://www.regulations.gov/contentStreamer?documentId=PHMSA-2016-00230002\&attachmentNumber=1\&disposition=attachment\&contentType=pdf, accessed September 6, 2016. 
remediated since the 1940s. ${ }^{48}$ Other State data, such as for West Virginia, indicate some of its storage well infrastructure is more than 100 years old. Figures 4.3-4 and 4.3-5 show histograms of well age SPUD date data for Michigan and West Virginia, respectfully.

\begin{tabular}{|c|c|c|c|c|c|c|c|c|c|c|c|c|c|c|}
\hline APINumber & BLMWell & RedrillCan & DryHole & Wellstatus & OperatorNa & CountyName & FieldName & Latitude & Longitude & WellNumber & Hydraulica & Confidenti & SPUDDate & WellDepthA \\
\hline 3700753 & $\mathrm{~N}$ & No & $\mathrm{N}$ & A & Southern California Gas Company & Los Angeles & Aliso Canyon & 34.311052 & -118.56246 & & $\mathrm{~N}$ & $\mathrm{~N}$ & $<$ Null $>$ & 0 \\
\hline 3700755 & $\mathrm{~N}$ & No & $\mathrm{N}$ & A & Southern California Gas Company & Los Angeles & Aliso Canyon & 34.314786 & -118.569017 & & $\mathrm{~N}$ & $\mathrm{~N}$ & 3/11/1943 & 0 \\
\hline 3700756 & $\mathrm{~N}$ & No & $\mathrm{N}$ & A & Southern California Gas Company & Los Angeles & Aliso Canyon & 34.312277 & -118.563706 & & $\mathrm{~N}$ & $\mathrm{~N}$ & $<$ Null $>$ & 9202 \\
\hline 3700757 & $\mathrm{~N}$ & No & $\mathrm{N}$ & A & Southern California Gas Company & Los Angeles & Aliso Canyon & 34.315067 & -118.57183 & & $\mathrm{~N}$ & $\mathrm{~N}$ & $<$ Null $>$ & 0 \\
\hline 3700758 & $\mathrm{~N}$ & No & $\mathrm{N}$ & A & Southern California Gas Company & Los Angeles & Aliso Canyon & 34.31381 & -118.566439 & & $\mathrm{~N}$ & $\mathrm{~N}$ & $<$ Null $>$ & 0 \\
\hline 3700759 & $\mathrm{~N}$ & No & $\mathrm{N}$ & A & Southern California Gas Company & Los Angeles & Aliso Canyon & 34.314057 & -118.57008 & & $\mathrm{~N}$ & $\mathrm{~N}$ & $6 / 6 / 1945$ & 0 \\
\hline 3700761 & $\mathrm{~N}$ & No & $\mathrm{N}$ & A & Southern California Gas Company & Los Angeles & Aliso Canyon & 34.313254 & -118.568336 & & $\mathrm{~N}$ & $\mathrm{~N}$ & $5 / 14 / 1946$ & \\
\hline 3700762 & $\mathrm{~N}$ & No & $\mathrm{N}$ & A & Southern California Gas Company & Los Angeles & Aliso Canyon & 34.313524 & -118.563698 & & $\mathrm{~N}$ & $\mathrm{~N}$ & $<$ Null $>$ & \\
\hline 3700763 & $\mathrm{~N}$ & No & $\mathrm{N}$ & A & Southern California Gas Company & Los Angeles & Aliso Canyon & 34.311307 & -118.566364 & & $\mathrm{~N}$ & $\mathrm{~N}$ & 9/14/1947 & 0 \\
\hline 3700765 & $\mathrm{~N}$ & No & $\mathrm{N}$ & A & Southern California Gas Company & Los Angeles & Aliso Canyon & 34.309885 & -118.563719 & & $\mathrm{~N}$ & $\mathrm{~N}$ & $10 / 5 / 1945$ & 0 \\
\hline 3700766 & $\mathrm{~N}$ & No & $\mathrm{N}$ & A & Southern California Gas Company & Los Angeles & Aliso Canyon & 34.309517 & -118.569518 & & $\mathrm{~N}$ & $\mathrm{~N}$ & $3 / 23 / 1949$ & 0 \\
\hline 3700768 & $\mathrm{~N}$ & No & $\mathrm{N}$ & A & Southern California Gas Company & Los Angeles & Aliso Canyon & 34.309694 & -118.5666007 & & $\mathrm{~N}$ & $\mathrm{~N}$ & 9/3/1949 & \\
\hline 3700769 & $\mathrm{~N}$ & No & $\mathrm{N}$ & A & Southern California Gas Company & Los Angeles & Aliso Canyon & 34.311217 & -118.568488 & & $\mathrm{~N}$ & $\mathrm{~N}$ & $3 / 5 / 1952$ & 0 \\
\hline 3700775 & $\mathrm{~N}$ & No & $\mathrm{N}$ & A & Southern California Gas Company & Los Angeles & Aliso Canyon & 34.311056 & -118.571154 & & $\mathrm{~N}$ & $\mathrm{~N}$ & 2/7/1953 & 0 \\
\hline 3700776 & $\mathrm{~N}$ & No & $\mathrm{N}$ & A & Southern California Gas Company & Los Angeles & Aliso Canyon & 34.315083 & -118.564069 & & $\mathrm{~N}$ & $\mathrm{~N}$ & 10/1/1953 & 0 \\
\hline 3700781 & $\mathrm{~N}$ & No & $\mathrm{N}$ & A & Southern California Gas Company & Los Angeles & Aliso Canyon & 34.311017 & -118.564658 & & $\mathrm{~N}$ & $\mathrm{~N}$ & $<$ Null $>$ & 0 \\
\hline 3700788 & $\mathrm{~N}$ & No & $\mathrm{N}$ & A & Southern California Gas Company & Los Angeles & Aliso Canyon & 34.312483 & -118.565571 & 44 & $+\mathrm{N}$ & $\mathrm{N}$ & $<$ Null $>$ & 0 \\
\hline 3700041 & $\mathrm{~N}$ & No & $\mathrm{N}$ & A & Southern California Gas Company & Los Angeles & Aliso Canyon & 34.315276 & -118.566506 & & $\mathrm{~N}$ & $\mathrm{~N}$ & $4 / 26 / 1953$ & 0 \\
\hline 3700192 & $\mathrm{~N}$ & No & $\mathrm{N}$ & A & Southern California Gas Company & Los Angeles & Aliso Canyon & 34.317723 & -118.546761 & & $\mathrm{~N}$ & $\mathrm{~N}$ & $<$ Null $>$ & 0 \\
\hline 3700647 & $\mathrm{~N}$ & No & $\mathrm{N}$ & A & Southern California Gas Company & Los Angeles & Aliso Canyon & 34.308254 & -118.567401 & & $\mathrm{~N}$ & $\mathrm{~N}$ & 11/6/1942 & 0 \\
\hline 3700649 & $\mathrm{~N}$ & No & $\mathrm{N}$ & A & Southern California Gas Company & Los Angeles & Aliso Canyon & 34.31229 & -118.563714 & & $\mathrm{~N}$ & $\mathrm{~N}$ & $\langle$ Null $\rangle$ & 0 \\
\hline 3700653 & $\mathrm{~N}$ & No & $\mathrm{N}$ & A & Southern California Gas Company & Los Angeles & Aliso Canyon & 34.306677 & -118.568451 & & $\mathrm{~N}$ & $\mathrm{~N}$ & $<$ Null $>$ & 10222 \\
\hline 3700665 & $\mathrm{~N}$ & No & $\mathrm{N}$ & A & Southern California Gas Company & Los Angeles & Aliso Canyon & 34.315434 & -118.574546 & & $\mathrm{~N}$ & $\mathrm{~N}$ & $10 / 19 / 1943$ & 0 \\
\hline 3700666 & $\mathrm{~N}$ & No & $\mathrm{N}$ & A & Southern California Gas Company & Los Angeles & Aliso Canyon & 34.315602 & -118.577382 & & $\mathrm{~N}$ & $\mathrm{~N}$ & 9/21/1944 & 0 \\
\hline 3700667 & & No & $\mathrm{N}$ & A & Southern California Gas Company & Los Angeles & Aliso Canyon & 34.313137 & -118.574798 & & $\mathrm{~N}$ & $\mathrm{~N}$ & 9/20/1947 & 0 \\
\hline 3700668 & $\mathrm{~N}$ & No & $\mathrm{N}$ & A & Southern California Gas Company & Los Angeles & Aliso Canyon & 34.312596 & -118.57651 & & $\mathrm{~N}$ & $\mathrm{~N}$ & $5 / 16 / 1948$ & 0 \\
\hline 3700669 & & No & $\mathrm{N}$ & A & Southern California Gas Company & Los Angeles & Aliso Canyon & 34.310227 & -118.575053 & & $5 \mathrm{~N}$ & $\mathrm{~N}$ & 9/20/1948 & 0 \\
\hline 3700670 & & No & $\mathrm{N}$ & A & Southern California Gas Company & Los Angeles & Aliso Canyon & 34.313186 & -118.574768 & & $\mathrm{~N}$ & $\mathrm{~N}$ & $<$ Null $>$ & 0 \\
\hline 3700671 & $\mathrm{~N}$ & No & $\mathrm{N}$ & A & Southern California Gas Company & Los Angeles & Aliso Canyon & 34.311197 & -118.57516 & & $3 \mathrm{~N}$ & $\mathrm{~N}$ & $<$ Null $>$ & 0 \\
\hline 3700672 & $\mathrm{~N}$ & No & $\mathrm{N}$ & A & Southern California Gas Company & Los Angeles & Aliso Canyon & 34.310978 & -118.579439 & & $\mathrm{~N}$ & $\mathrm{~N}$ & $<$ Null $>$ & 0 \\
\hline 3700686 & $\mathrm{~N}$ & No & $\mathrm{N}$ & A & Southern California Gas Company & Los Angeles & Aliso Canyon & 34.313176 & -118.540099 & 32 & $\mathrm{~N}$ & $\mathrm{~N}$ & $<$ Null $>$ & 0 \\
\hline 3700687 & $\mathrm{~N}$ & No & $\mathrm{N}$ & A & Southern California Gas Company & Los Angeles & Aliso Canyon & 34.306529 & -118.540877 & 33 & $\mathrm{~N}$ & $\mathrm{~N}$ & $<$ Null $>$ & 0 \\
\hline 3700712 & $\mathrm{~N}$ & No & $\mathrm{N}$ & A & Southern California Gas Company & Los Angeles & Aliso Canyon & 34.316756 & -118.56124 & $25 \mathrm{R}$ & $\mathrm{N}$ & $\mathrm{N}$ & $<$ Null $>$ & 0 \\
\hline
\end{tabular}

Figure 4.3-1 Example Well Completion Date Data for SoCalGas's Aliso Canyon UGS Field

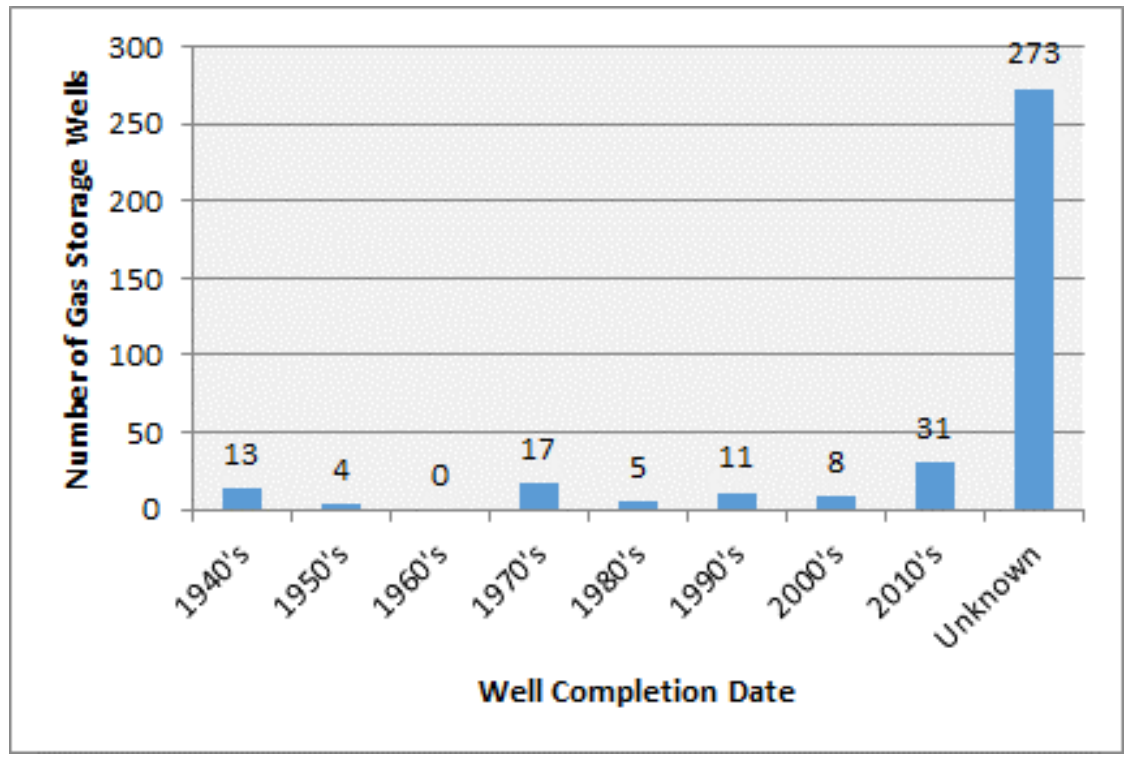

Figure 4.3-2 Well Completion Date Data for UGS Fields in California

${ }^{48}$ Ellison, G., 2016, "Michigan has most underground natural gas storage in U.S.," Mlive.com, January 8, available at http://www.mlive.com/news/index.ssf/2016/01/michigan_has_most_underground.html. 


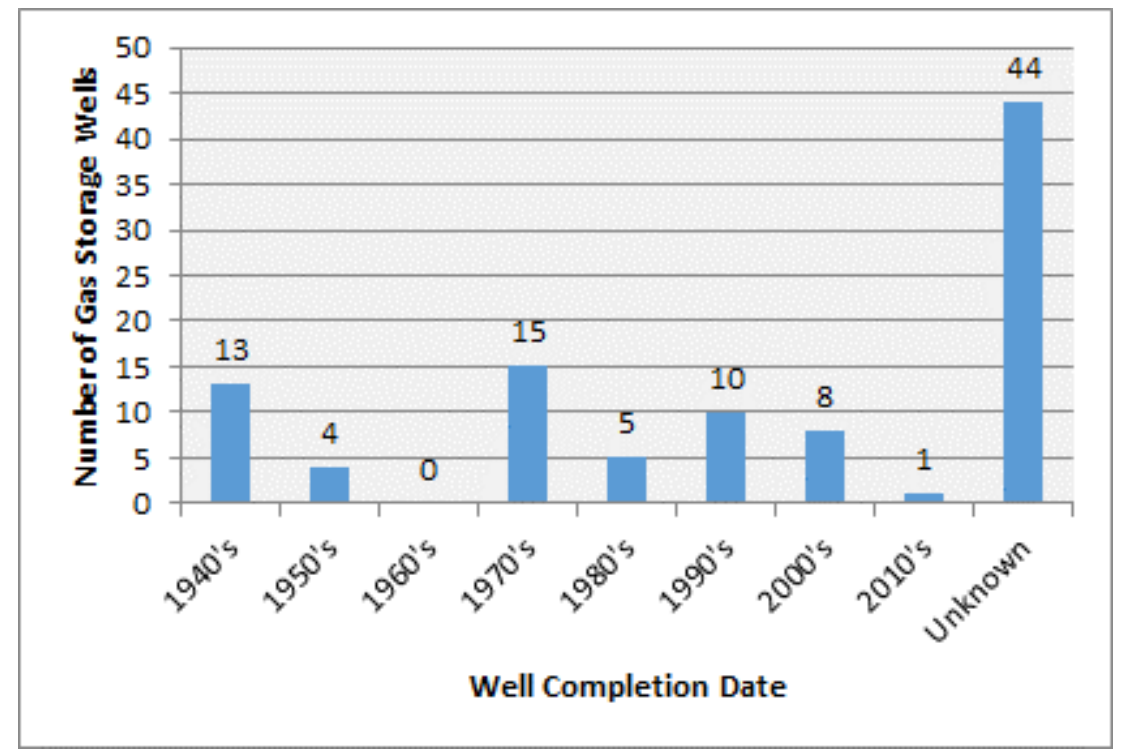

Figure 4.3-3 Well Completion Date Data for SoCalGas's Aliso Canyon UGS Field

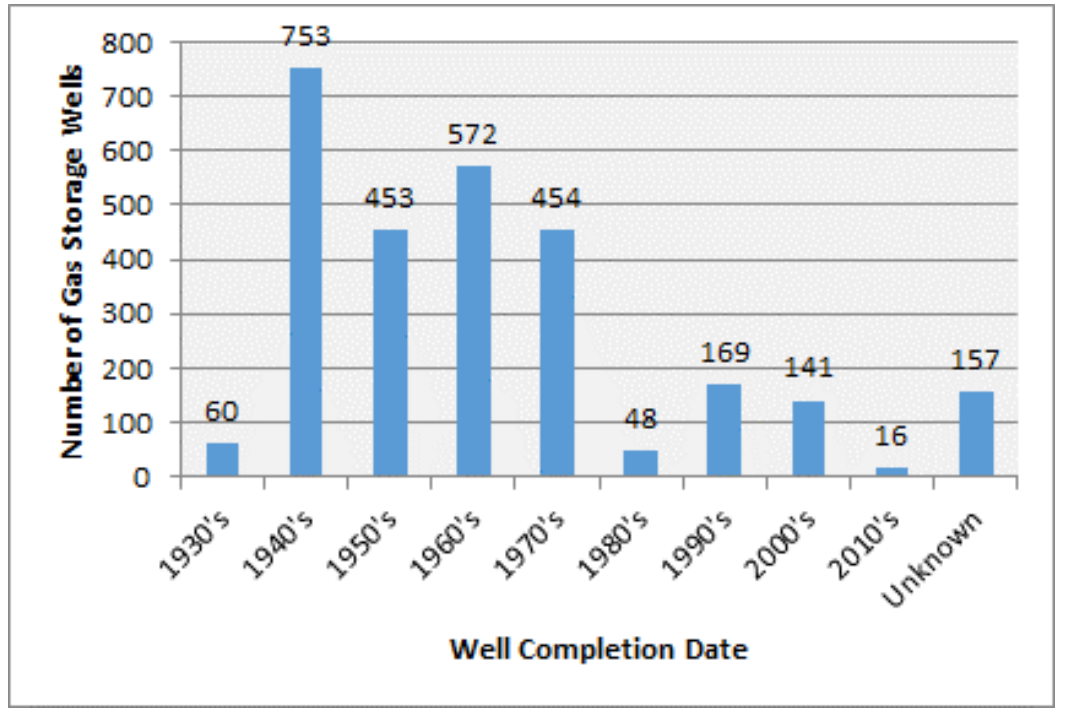

Figure 4.3-4 Well Completion Date Data for UGS Fields in Michigan 


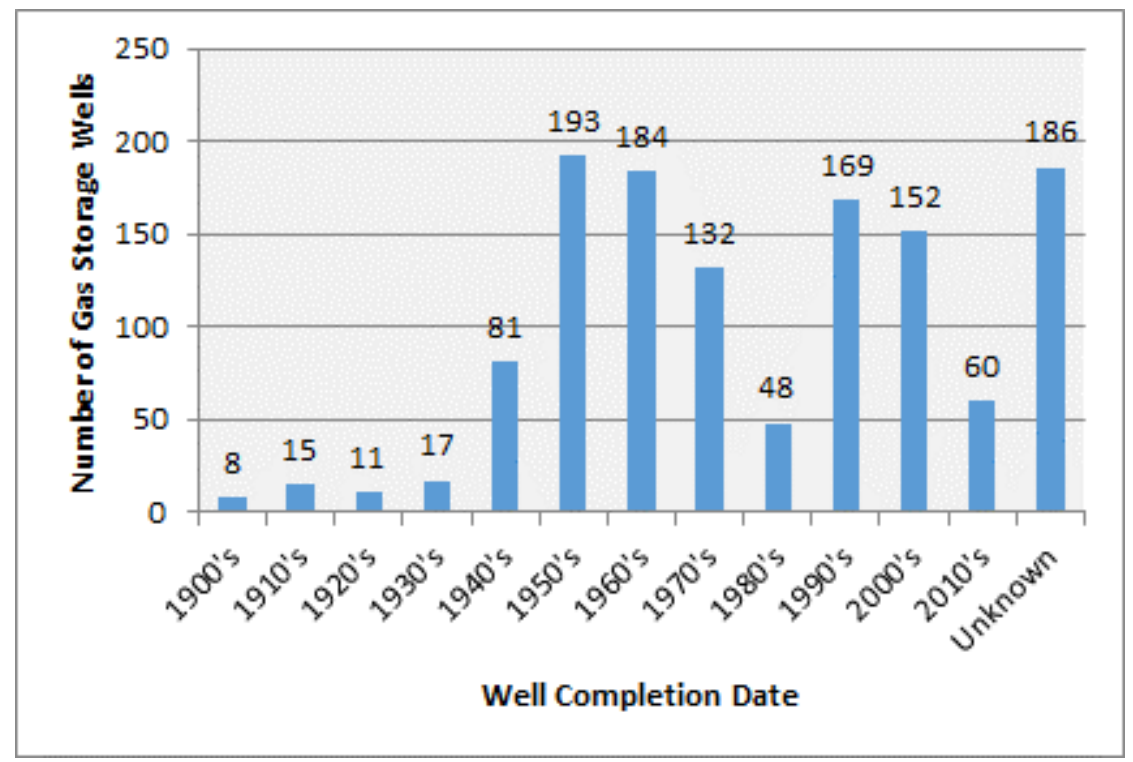

Figure 4.3-5 Well Completion Date Data for UGS Storage Fields in West Virginia

Underground gas storage well data were collected from the appropriate State agencies. Well completion data were then aggregated as a function of decade for each State, as shown in Table 4.3-1 and Figure 4.3-6. Wells associated with monitoring and observation are not included in Table 4.3-1, as these wells do not directly support the active injection and withdrawal of natural gas from the UGS facilities. Well completion date data were publicly unavailable for three States: Maryland, Minnesota, and Texas, and further discussions are needed with these States concerning the availability of well data specific to underground gas storage facilities.

At Aliso Canyon, the well that failed is 63 years old. It is one of more than 100 wells at the site and one of tens of thousands of similar wells at storage units across the country. Further analysis, data, and discussion with asset owners are needed to assess the integrity of the wells. The Aliso Canyon well had been drilled as a production well in 1953 and converted to a natural gas storage well in 1972. EIA data show that Michigan, Illinois, Texas, Pennsylvania, and Louisiana all store more natural gas underground than California.

Table 4.3-1 indicates that Michigan has the greatest number of wells supporting storage operations (approximately $24 \%$ of the total number of wells in Table 4.3-1), which would be expected because Michigan in 2015 had more underground natural gas storage capacity1.1 trillion cubic feet - than any other State in the nation. Michigan has 43 fields storing natural gas in depleted reservoirs and 58 active storage fields (the most of any State) with 2,823 wells tapping those fields. The data in Table 4.3-1 indicate that the majority of wells in Michigan were developed in the 1940s, and thus are more than 70 years old. The oldest of Michigan's UGS facilities was converted from production to storage in 1941. It has been stated by the Michigan Public Service Commission that while some aging wells and pipes have been completely upgraded in Michigan, others likely have not been upgraded since the 1940s. The companies that 
manage storage fields inspect those wells periodically, but it has been noted that there is nothing specific that requires them to file those reports to the State of Michigan. ${ }^{49}$

Table 4.3-1 Breakdown of Completion Dates of Underground Wells Supporting UGS Operations (Injection and Withdrawal)

\begin{tabular}{|c|c|c|c|c|c|c|c|c|c|c|c|c|c|c|}
\hline State & 1900 's & 1910 's & 1920 's & 1930 's & 1940 's & 1950 's & 1960's & 1970 's & 1980 's & 1990's & 2000 's & 2010's & Unknown & TOTAL \\
\hline$A K$ & 0 & 0 & 0 & 0 & 0 & 0 & 0 & 1 & 1 & 1 & 23 & 5 & 0 & 31 \\
\hline $\mathrm{AL}$ & 0 & 0 & 0 & 0 & 0 & 0 & 0 & 0 & 0 & 1 & 4 & 1 & 0 & 6 \\
\hline$A R$ & 0 & 0 & 0 & 0 & 1 & 0 & 2 & 0 & 0 & 1 & 0 & 0 & 0 & 4 \\
\hline$C A$ & 0 & 0 & 0 & 0 & 13 & 4 & 0 & 17 & 5 & 11 & 8 & 31 & 273 & 362 \\
\hline $\mathrm{CO}$ & 0 & 0 & 0 & 0 & 0 & 16 & 27 & 80 & 39 & 28 & 9 & 12 & 19 & 230 \\
\hline $\mathrm{IA}$ & 0 & 0 & 0 & 0 & 24 & 2 & 1 & 0 & 1 & 0 & 6 & 0 & 0 & 34 \\
\hline $\mathrm{IL}$ & 0 & 0 & 0 & 0 & 0 & 62 & 354 & 304 & 7 & 81 & 6 & 30 & 394 & 1,238 \\
\hline IN & 2 & 1 & 1 & 6 & 7 & 126 & 340 & 125 & 31 & 71 & 9 & 2 & 1 & 722 \\
\hline $\mathrm{KS}$ & 0 & 0 & 1 & 2 & 1 & 3 & 0 & 98 & 55 & 34 & 34 & 13 & 38 & 279 \\
\hline $\mathrm{KY}$ & 0 & 0 & 3 & 1 & 5 & 40 & 353 & 346 & 52 & 44 & 15 & 1 & 47 & 907 \\
\hline LA & 0 & 0 & 0 & 0 & 1 & 1 & 1 & 12 & 2 & 6 & 11 & 0 & 0 & 34 \\
\hline $\mathrm{MD}^{\mathrm{a}}$ & & & & & & & & & & & & & & 0 \\
\hline $\mathrm{Ml}$ & 0 & 0 & 0 & 60 & 753 & 453 & 572 & 454 & 48 & 169 & 141 & 16 & 157 & 2,823 \\
\hline $\mathrm{MN}^{\mathrm{b}}$ & & & & & & & & & & & & & & 0 \\
\hline $\mathrm{MO}$ & 0 & 0 & 0 & 0 & 0 & 22 & 19 & 0 & 0 & 0 & 0 & 0 & 14 & 55 \\
\hline MS & 0 & 0 & 0 & 1 & 0 & 15 & 3 & 72 & 7 & 14 & 38 & 10 & 3 & 163 \\
\hline MT & 0 & 3 & 46 & 40 & 62 & 24 & 13 & 5 & 26 & 21 & 13 & 6 & 8 & 267 \\
\hline $\mathrm{NE}$ & 0 & 0 & 0 & 0 & 0 & 3 & 0 & 3 & 0 & 0 & 0 & 0 & 0 & 6 \\
\hline NM & 0 & 0 & 0 & 0 & 0 & 0 & 3 & 6 & 14 & 0 & 0 & 2 & 1 & 26 \\
\hline NY & 4 & 10 & 45 & 154 & 69 & 235 & 92 & 25 & 82 & 31 & 68 & 6 & 11 & 832 \\
\hline $\mathrm{OH}$ & 0 & 21 & 37 & 337 & 0 & 8 & 265 & 0 & 0 & 0 & 0 & 0 & 2 & 670 \\
\hline $\mathrm{OK}$ & 0 & 0 & 0 & 0 & 1 & 0 & 1 & 14 & 0 & 13 & 4 & 0 & 0 & 33 \\
\hline OR & 0 & 0 & 0 & 0 & 0 & 0 & 0 & 0 & 6 & 7 & 8 & 0 & 8 & 29 \\
\hline PA & 0 & 0 & 2 & 0 & 1 & 42 & 56 & 72 & 34 & 50 & 40 & 7 & 1,163 & \begin{tabular}{|l|}
1,467 \\
\end{tabular} \\
\hline $\mathrm{TN}$ & 0 & 0 & 0 & 0 & 0 & 0 & 0 & 0 & 3 & 0 & 0 & 0 & 0 & 3 \\
\hline $\mathrm{TX}^{\mathrm{C}}$ & & & & & & & & & & & & & & 0 \\
\hline UT & 0 & 0 & 1 & 5 & 2 & 1 & 5 & 25 & 22 & 0 & 0 & 0 & 3 & 64 \\
\hline VA & 0 & 0 & 0 & 0 & 1 & 0 & 0 & 0 & 19 & 9 & 0 & 0 & 0 & 29 \\
\hline WA & 0 & 1 & 0 & 0 & 1 & 5 & 40 & 23 & 0 & 15 & 6 & 0 & 1 & 92 \\
\hline WV & 8 & 15 & 11 & 17 & 81 & 193 & 184 & 132 & 48 & 169 & 152 & 60 & 186 & 1,256 \\
\hline WY & 1 & 0 & 6 & 4 & 3 & 2 & 1 & 25 & 10 & 2 & 6 & 4 & 0 & 64 \\
\hline Total & 15 & 51 & 153 & 627 & 1,026 & 1,257 & 2,332 & 1,839 & 512 & 778 & 601 & 206 & 2,329 & 11,726 \\
\hline \multicolumn{15}{|c|}{${ }^{\text {a }}$ Publicly-available well data for UGS facilities in Maryland does not include information on well completion dates. } \\
\hline \multicolumn{15}{|c|}{$\begin{array}{l}\text { b There is no publicly-available well data for UGS facilities in Minnesota, please refer to URL: } \\
\text { http://www.mngeo.state.mn.us/chouse/utilities.html }\end{array}$} \\
\hline \multicolumn{15}{|c|}{$\begin{array}{l}\text { c Oil and gas well data is not publicly-available from Texas and needs to be purchased (see URL: } \\
\text { http://www.rrc.state.tx.us/about-us/resource-center/research/data-sets-available-for-purchase/digital-map- } \\
\text { data/digital-map-data-statewide-prices/). This dataset does not include well completion date. }\end{array}$} \\
\hline
\end{tabular}

UGS well data for Pennsylvania highlights the concern with incompleteness of UGS well data. The completion date is unknown for the majority (approximately 79\%) of the wells in Pennsylvania, as shown in Table 4.3-1. At this time, approximately 60 underground gas storage fields exist in 26 counties in Pennsylvania. The first gas storage field was developed in Pennsylvania by the United Natural Gas Company in Warren and Forest Counties in the 1920s.

49 Ellison, G., 2016, "Michigan has most underground natural gas storage in U.S.," Mlive.com, January 8, available at http://www.mlive.com/news/index.ssf/2016/01/michigan_has_most_underground.html. 
The Pennsylvania PUC does not have license procedures for UGS facilities in the State; it does, however, have the authority to annually review gas utility storage tariffs based upon cost of service. ${ }^{50}$ Information on UGS wells is collected by the Pennsylvania PUC using the PHMSA Form 12 (Gas Storage Field Review), which does not ask for information on well age. ${ }^{51} 52$ It is therefore very difficult to determine the age of the individual UGS wells and investigate whether aging issues may contribute to increased risk of future well failures, similar to that of Aliso Canyon, in Pennsylvania.

West Virginia is similar to Michigan in terms of the availability of UGS well age data (i.e., well age is known for the majority of the wells), but Illinois has a high percentage (approximately $32 \%$ of the total of 1,238 wells) for which the date at which UGS wells were installed and ready for natural gas storage service is unknown. Examination of the Illinois well data indicates that wells with an unknown completion date occur across all UGS operators and are not specific to a single company or organization.

Excluding wells with an unknown age, Figure 4.3-6 indicates that the majority of UGS wells were available for natural gas storage service in the 1960s, making them approximately 50 years old. Approximately 66 UGS wells have apparent ages of 100 years or more, and these wells are located in the States of Indiana, Montana, New York, Ohio, Washington, West Virginia, and Wyoming. An underground gas storage facility is generally considered to have an indefinite useful life, ${ }^{53}$ but it can be expected that as wells age, the potential likelihood for well failure and a controlled release of underground stored gas will increase. Many of these decades-old wells were intended solely to extract the oil and gas originally in the formations, and continued gas injection, just like hydraulic fracturing, routinely subjects oil and gas piping to pressure fluctuations outside of original design considerations.

Individual States were also contacted to collect well incident data for UGS facilities, but in almost all cases, no incident data were readily forthcoming. (Mississippi provided information on a gas leak at Eminence Dome due to solution mining in an adjacent salt cavern and stated that the State was not aware of any other incidents. Data from Illinois and West Virginia may be available in the future.) Regulations vary from State to State. Ohio operators stated that companies monitor pressure at natural gas storage fields for any changes that would indicate a

50 Metro, P., 2003, "Regulatory Framework for Natural Gas Storage in Pennsylvania and Tariff Development for Natural Gas Storage," Pennsylvania Public Utility Commission, available at http://pubs.naruc.org/pub/538938E52354-D714-51B7-7FCDF9266AFB.

51 Pennsylvania Public Utility Commission, 2016, "Pipeline Inspection Forms," available at http://www.puc.state.pa.us/utility industry/transportation/pipeline_safety/pipeline inspection_forms.aspx.

52 Pennsylvania Department of Environmental Protection, 2016, "Underground Gas Fields in Pennsylvania," available at http://www.elibrary.dep.state.pa.us/dsweb/Get/Document-104832/8000-FS-DEP2319.pdf.

53 NW Natural, 2000, “Application for Amendment No. 7 to the Mist Underground Natural Gas Storage Site Certificate,” available at https://www.oregon.gov/energy/Siting/docs/MST/RFA/MST\%20AMD7.pdf. 


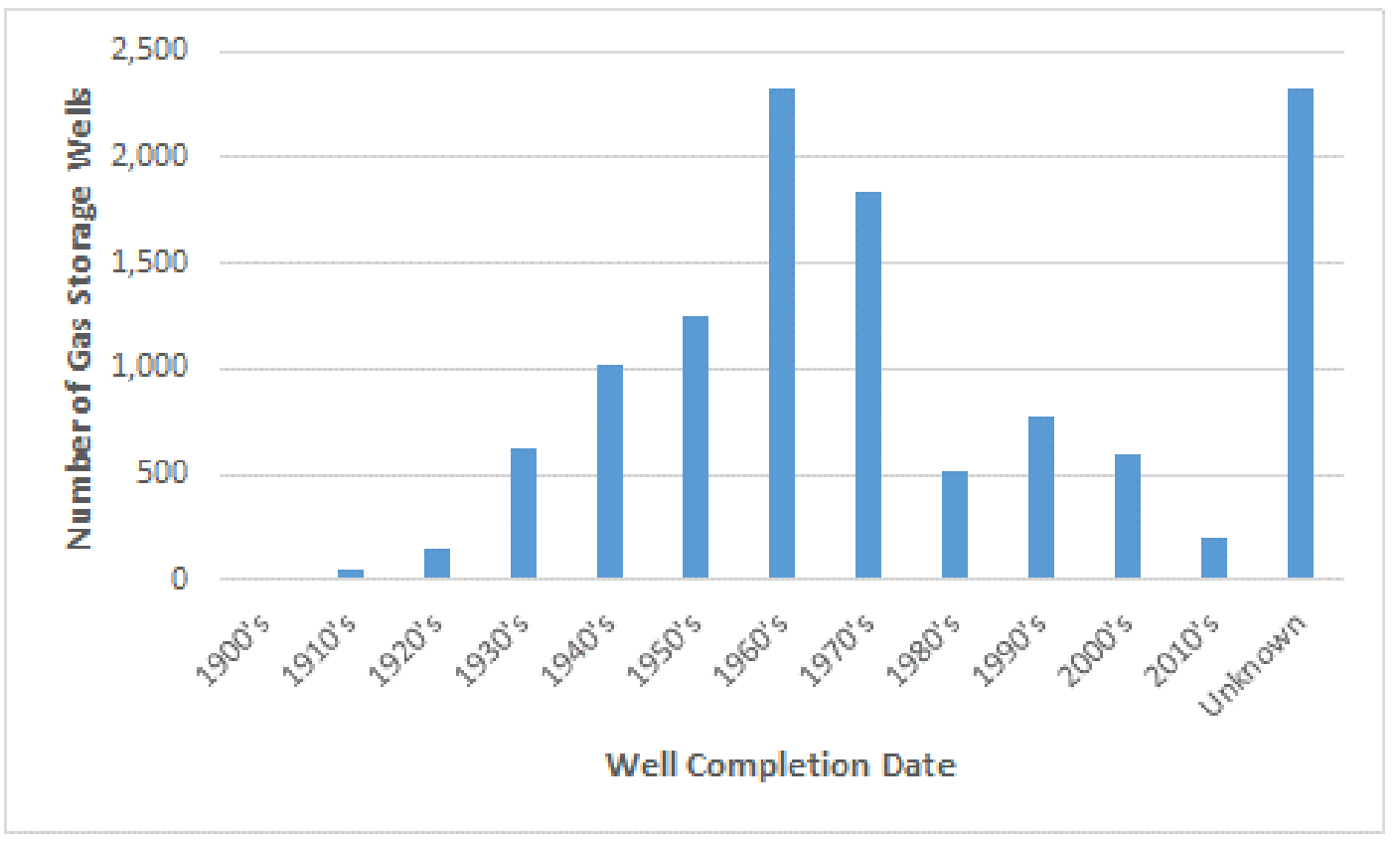

Figure 4.3-6 UGS Well Completion Dates Supporting UGS Operations

leak. However, they are not required by the State to do so, nor are they required to report leaks. ${ }^{54}$ Given the lack of well age and leak data, it was not possible to analytically examine the role of well age on failure rates and gas leakage to the surface. This analysis has collected incident data from significant UGS well releases, but it was not possible to associate the natural gas release with the specific well at the impacted UGS facility. A detailed analysis of well age and failure rates would require collecting well failure data on a consistent basis across all States having UGS facilities, which is currently not performed.

\subsection{Estimated Impact to Electric Generating Plants}

An analysis was performed of the impacts of a disruption of each of the currently active UGS facilities in the United States (390 active out of 418 total existing facilities) on their different owners/operators, quantified in terms of natural gas-fired electric generation capacity potentially affected from the loss of the UGS facility. The methodology and models developed to assess the impacts are summarized in Sections 3.1 and 3.2. All models and analyses are based on publicly available data.

The analysis indicates that the largest potential impact from the loss of the natural gas supply from UGS facilities would be on natural gas-fired power plants. The impact on downstream residential and commercial customers is estimated to be minimal. This analysis predicts $7.8 \mathrm{GW}$ of natural gas-fired capacity potentially affected by a loss of the Aliso Canyon facility in

\footnotetext{
${ }^{54}$ Arenschield, L., 2016, "Ohio has few checks for natural-gas storage leaks," The Columbus Dispatch, January 14, available at http://www.dispatch.com/content/stories/local/2016/01/14/state-has-few-checks-for-natural-gasstorage-leaks.html.
} 
California at peak-month condition. A Joint Workshop predicted approximately $9.8 \mathrm{GW}$ at-risk at peak-day conditions. It is assumed that the difference in the natural gas-fired electric capacity between the two estimates is due to the higher assumed peak-day requirements versus those for peak-month in this study.

This study also finds that Aliso Canyon is not a unique UGS in terms of potential electric power impacts. An unexpected loss of power plant generating capacity usually does not affect electric reliability unless the loss is relatively large ( $2 \mathrm{GW}$ or more). A total of 12 UGS facilities appear to have the potential to affect $2 \mathrm{GW}$ or more of available generation capacity (see Figure 4.4-1). These numbers, however, do not take into account any dual-fuel capabilities at this time. Dualfuel capability is the ability to use alternative sources of fuel (i.e., diesel or equivalent liquid fuels) with access at short notice to sufficient fuel inventories. While some information was compiled on dual-fuel capabilities, these values are very preliminary and are not reflected in the current analysis results because the extent to which this capability can be exercised and capacity impacts from a loss in natural gas mitigated is not known until further analysis is conducted.

The general locations of these UGS facilities are shown in Figure 4.4-1. Two are located in California (one of which is Aliso Canyon). Five are in Mississippi, three in Louisiana, 1 is in Michigan, and one is in New York.

The projected impacts for pipeline-owned UGS facilities were shown to be less than those for third-party independent storage service providers, because the analysis showed that pipelines generally had adequate resources in the form of unreserved pipeline capacity or the potential for additional withdrawals from unaffected pipeline-owned UGS facilities to compensate for the total loss of withdrawals from a single affected UGS facility. The results show that 1 of the top-12 UGS facilities (in terms of impacts to natural gas-fired electricity generating plants) is owned by an interstate pipeline company, with 2 other pipeline-owned UGS facilities estimated to have impacts on electric generation capacity. The results also show that the impacts for underground gas storage facilities owned by interstate pipeline companies would be spread out over a wider area and affect multiple States.

The analysis indicates that nine of the top-12 UGS facilities (in terms of impacts to natural gasfired electricity generating plants) are high-deliverability UGS facility owned by independent storage service providers. The analysis also projects impacts for UGS facilities owned by LDCs, with two of the top-12 UGS facilities owned by LDCs. Both of these top-12 UGS facilities are located in California. The results also show that the impacts for underground gas storage facilities owned by LDCs would be limited to the LDC's service territory. 


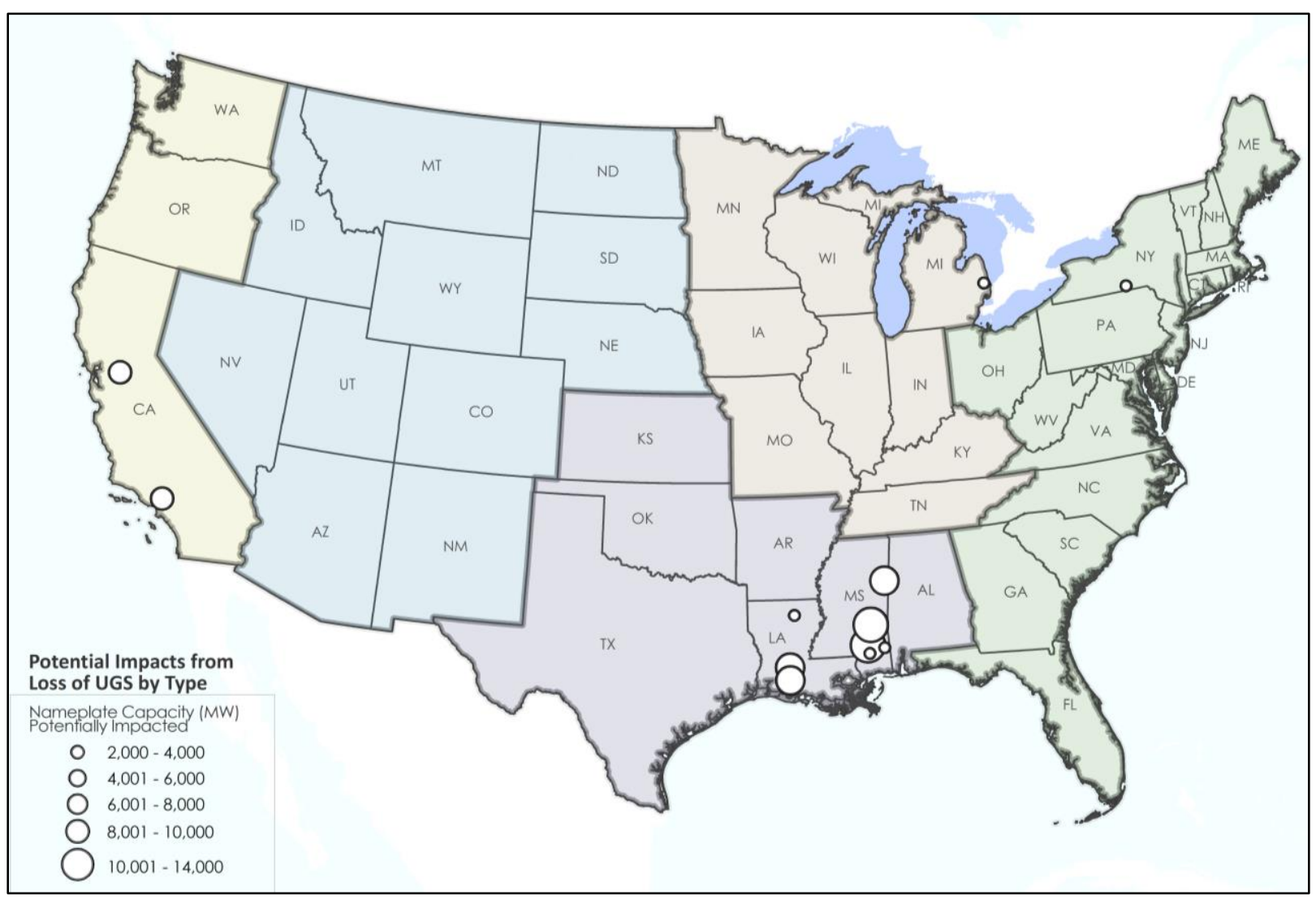

Figure 4.4-1 Locations of 12 UGS Facilities, Disruption of Which Could Potentially Affect 2 GW or More of Generation Capacity

\subsection{Screening-Level Electric Reliability Assessment}

In general, each grid simulation model was run for 3 cases: (1) a baseline run to establish system conditions under business-as-usual operation, (2) an analysis of the impacts of a hypothetical loss of UGS Facility 1 with the potential to affect up $9.1 \mathrm{GW}$ of natural gas-fired capacity, and (3) an analysis of the impacts of a hypothetical loss of UGS Facility 2 with the potential to affect up to 13.8 GW of natural gas-fired capacity.

Both models show the prospect for reliability impacts for both facilities in terms of potential electric customer outages and electric price impacts. Figure 4.5-1 illustrates the results of the power flow analysis and shows the natural gas-fired power plants potentially impacted by the loss of each of the UGS facilities as well as the customer service areas (shaded regions) that might be affected by the potential loss of power plant capacity. 


\subsubsection{Power Flow Modeling}

For UGS Facility 1, it can be noted from Figure 4.5-1 that numerous pockets of power-deficient zones emerge in Louisiana and Mississippi as a result of the loss of this facility. With respect to load curtailments, power-deficient pockets having $80-100 \%$ load curtailments dominate the affected landscape. These pockets were created because of the assumption that the generation dispatch and demand schedules remained the same for the pre-event, during-event, and postevent conditions. The "weak" transmission surrounding these pockets also contributed to the formation of the pockets. A re-dispatch of available generators accompanied by the implementation of necessary line switching schemes could eliminate the emergence of these power-deficient zones.

For UGS Facility 2, it could be noted that the UGS facility is located quite far from the cluster of gas-fired power plants it is contracted to serve. While the facility is located in Mississippi, the potentially affected gas-fired generators are located in Georgia. The pockets of power-deficient areas formed exhibit the highest curtailment severity (80-100\% load curtailment). It is interesting to note that the pockets do not gravitate around the cluster of affected power plants but are dispersed in the region. The pockets were created because the lines serving these areas were overloaded when trying to move replacement power from outside the pockets to load centers within the pockets. An optimal dispatch program, such as AURORAxmp, could re-schedule generation dispatch so as to avoid transmission congestion and could potentially eliminate these power-deficient pockets.

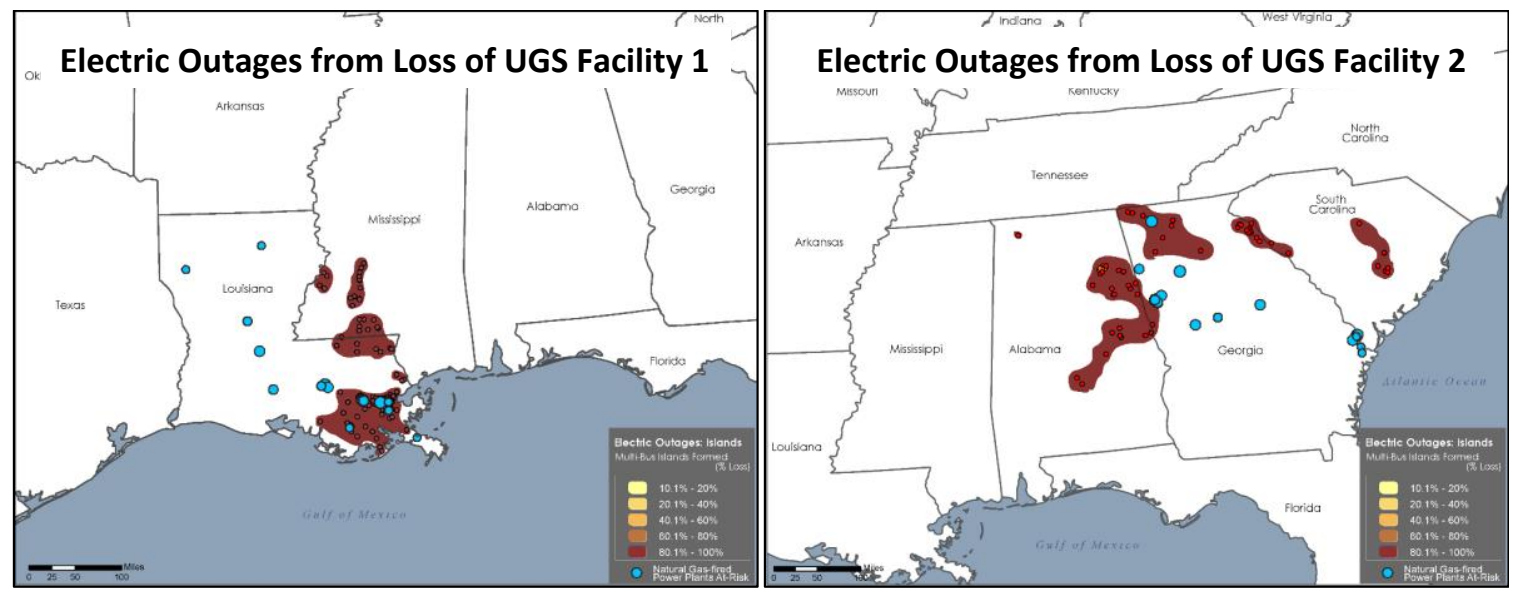

Figure 4.5-1 Potential Electric Reliability Impacts from Hypothetical Loss of UGS Facilities (Potential Electric Outage Areas)

\subsubsection{Operational Modeling}

Figure 4.5-2 presents the market clearing prices that result from the operational unit commitment and economic dispatch model in the two zones of primary interest during the peak load hour (August $10^{\text {th }}$ at 4:00 pm). The model does not project any direct load curtailments due to a combination of sufficient generation capacity available for re-dispatch within the affected zones, as well as inter-regional power transfers from other zones/regions. However, these operational 


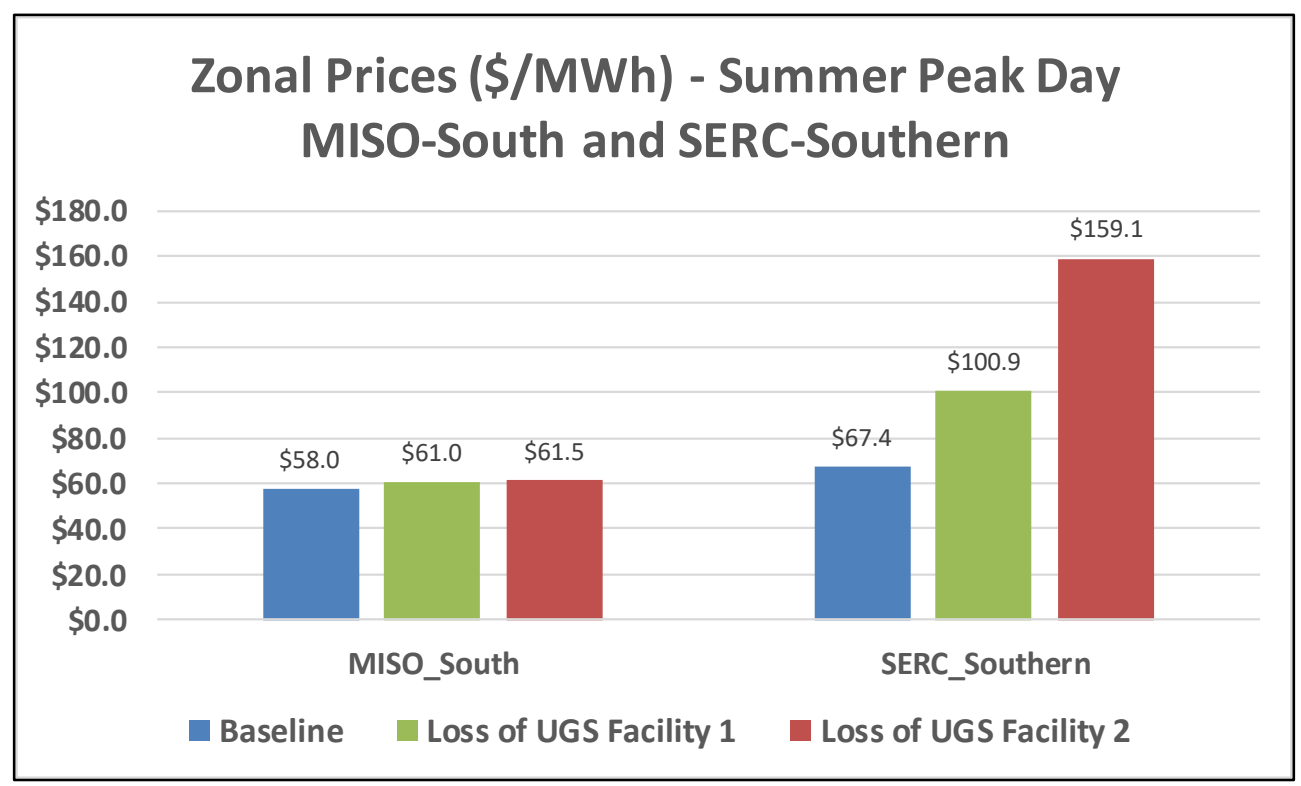

Figure 4.5-2 Potential Electric Reliability Impacts from Hypothetical Loss of UGS Facilities (Affected Market Zones and Potential Price Impacts)

changes affect regional power prices primarily in 2 market zones (MISO South and SERC Southern) with the larger impacts in SERC Southern: a 50-140\% increase in peak price.

Figures 4.5-3 to 4.5-5 show more detailed results in a regional subset of the Eastern Interconnection, the data points in each zone indicate the market clearing price and the net demand (native demand net of imports, exports, and storage energy for storage units) in the peak hour. The transmission links between zones also indicate the amount of power being transmitted during that hour in megawatts. Under baseline conditions, the line that transmits power from MISO South to SERC Southern is already at capacity, contributing to a price differential between these two zones.

During a loss of UGS Facility 1, most of the affected gas-fired capacity is in the MISO South zone. However, the reduced generation capacity is recovered through imports from neighboring zones, and no load is curtailed. This additional power is generated throughout the Eastern Interconnection, with the largest net increases compared to baseline occurring in ComEd and MISO Central. The market clearing price in MISO South increases only modestly from $\$ 58.0 / \mathrm{MWh}$ to $\$ 61.0 / \mathrm{MWh}$ due to the excess generation capacity that is available in Southern Power Pool (SPP) and the high-capacity transmission tie connecting these two zones. However, the market clearing price in SERC Southern increases more significantly, from $\$ 67.4 / \mathrm{MWh}$ to $\$ 100.9 / \mathrm{MWh}$ because of the limited capacity on its transmission ties. The price in Virginia Carolina South also increases from $\$ 71.0 / \mathrm{MWh}$ to $\$ 85.2 / \mathrm{MWh}$, as it becomes a net exporter to SERC Southern as well during the disruption, as opposed to a net importer under baseline conditions. 


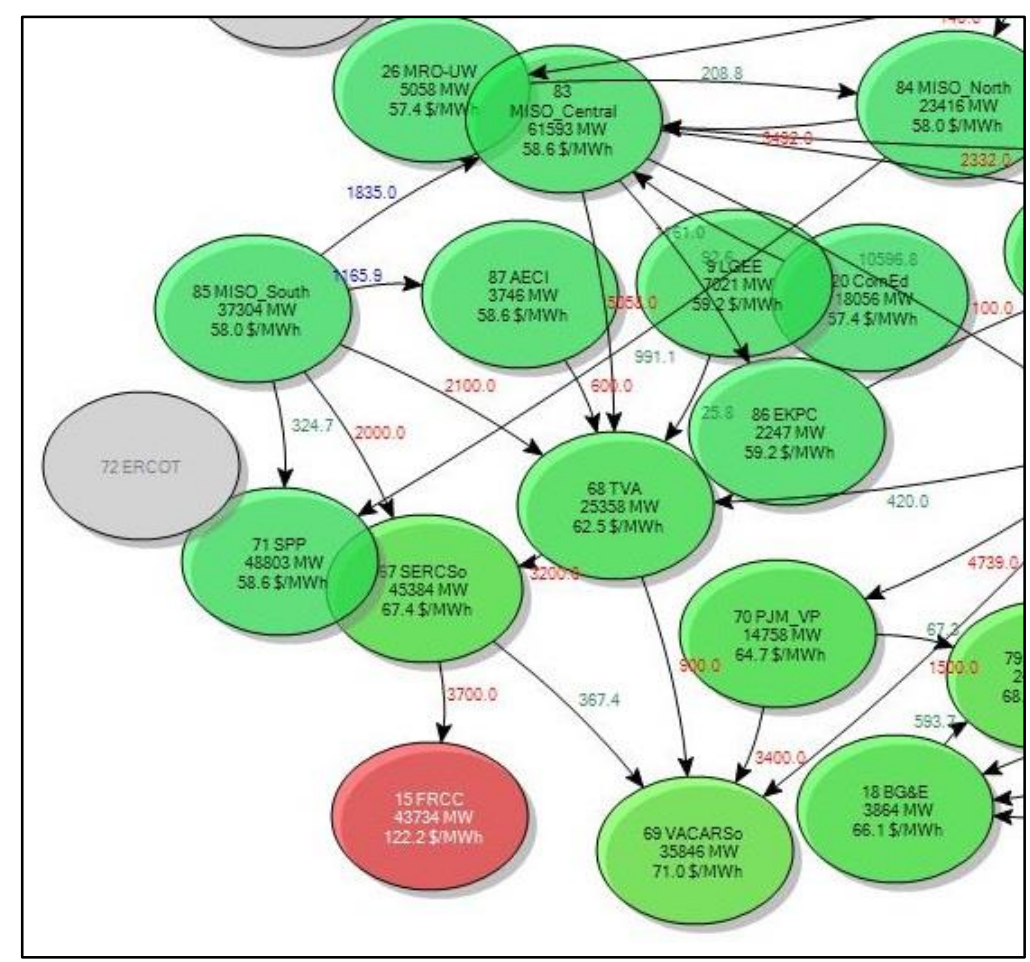

Figure 4.5-3 System Outcome during Peak Load Conditions under Baseline Operating Conditions

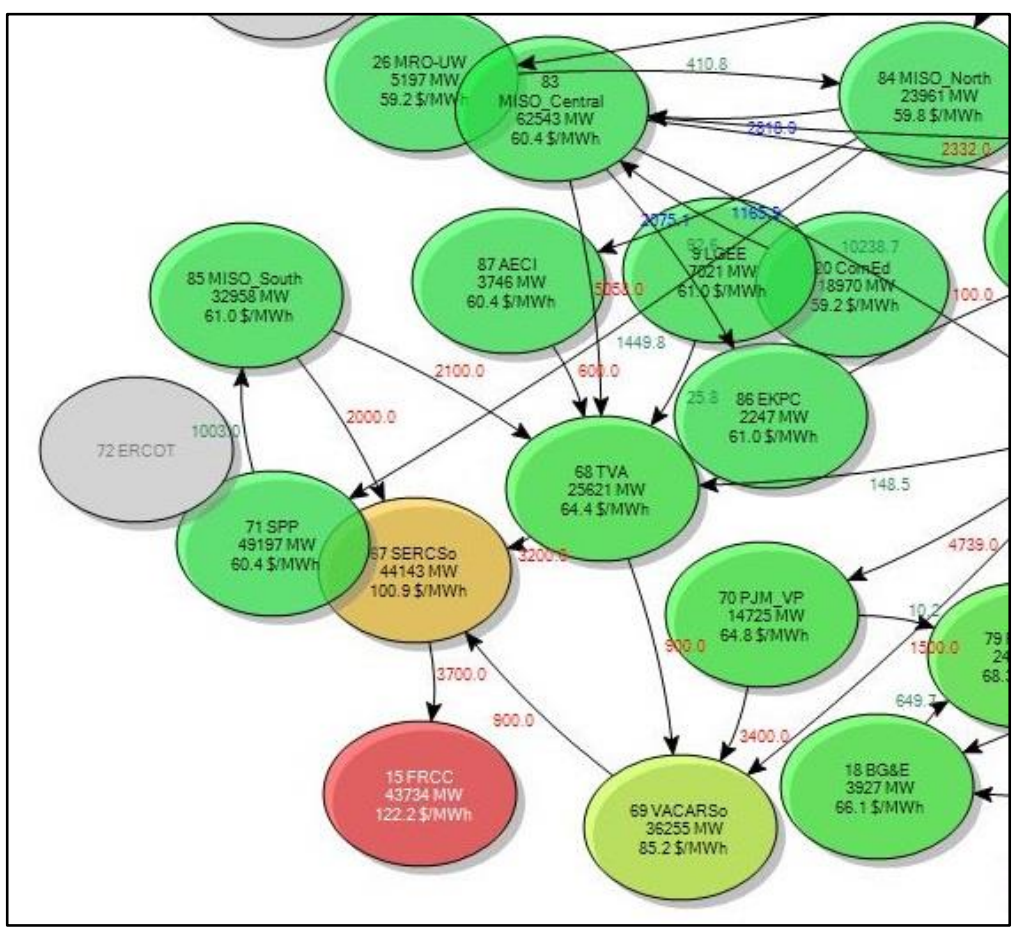

Figure 4.5-4 System Outcome during Peak Load Conditions under a Disruption to UGS Facility 1 


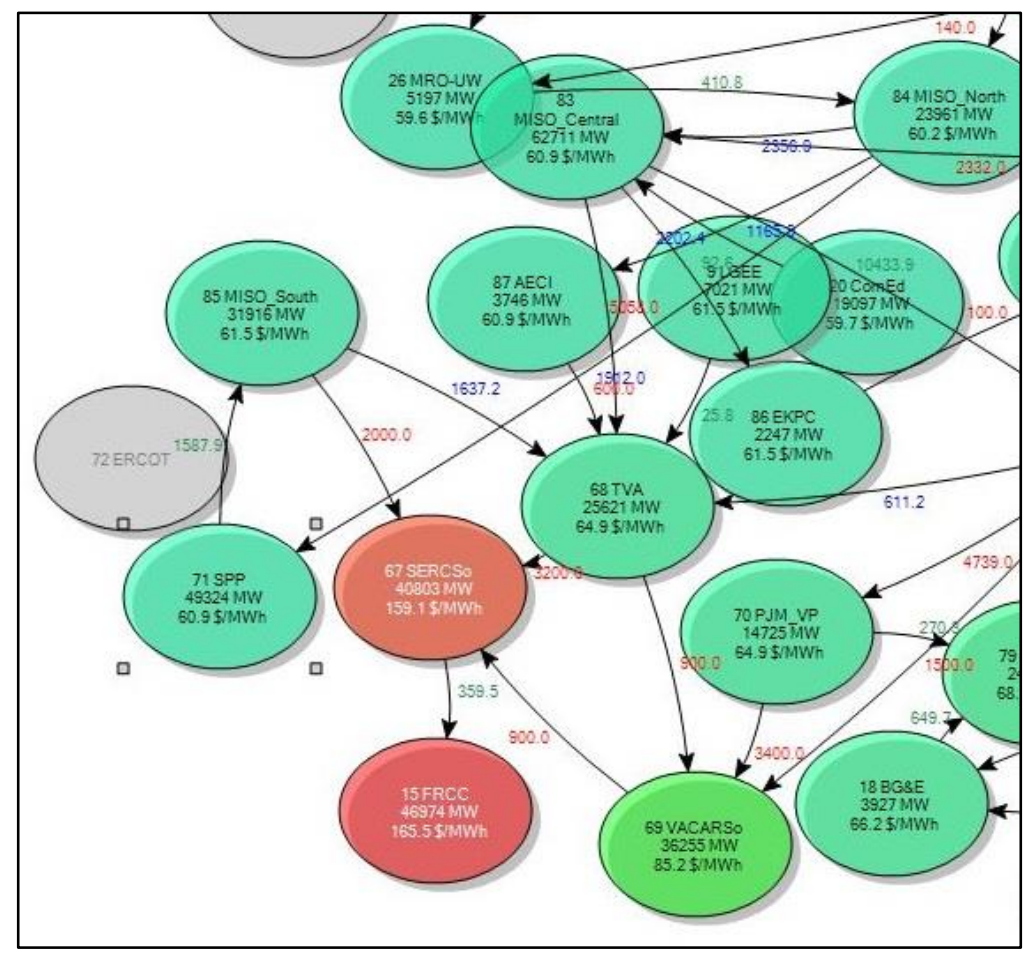

Figure 4.5-5 System Outcome during the Peak Load Conditions under a Disruption to UGS Facility 2

During a loss of UGS Facility 2, most of the impacted gas-fired capacity is located in the SERC Southern zone with some capacity in the MISO South zone. Again, this shortfall is made up by additional generation throughout the Eastern Interconnection, and there is no internal load curtailment. There is a large net increase in generation in the SERC Florida Reliability Coordinating Council (FRCC) zone, as well as large increases in MISO Central and ComEd. The market clearing price in SERC Southern increases from $\$ 67.4 / \mathrm{MWh}$ to $\$ 159.1 / \mathrm{MWh}$ as a result of this disruption due to the transmission congestion issues that are outlined above. The market clearing prices in neighboring SERC FRCC and Virginia Carolina South zones also increase from $\$ 122.2 / \mathrm{MWh}$ to $\$ 165.5$ and from $\$ 71.0 / \mathrm{MWh}$ to $\$ 85.2 / \mathrm{MWh}$, respectively. As is the case with a disruption to UGS Facility 1, the price in MISO South increases modestly from $\$ 58.0 / \mathrm{MWh}$ to $\$ 61.5 / \mathrm{MWh}$, as power can be readily imported through SPP to ease congestion and generation shortfalls.

\subsubsection{Gas-Electric Coordination}

The results of this preliminary screening-level electric reliability assessment indicate the potential to impact electric customer reliability and electric prices from a hypothetical long-term loss of UGS operations. The changing marketplace for electric generation has resulted in a change in SoCalGas' tariff to deal with low levels of flowing supplies during times of natural gas 
system stress. ${ }^{55}$ On June 11, 2015, the California Public Utilities Commission authorized SoCalGas to revise its tariff to implement new low Operational Flow Order (OFO) and Emergency Flow Order (EFO) requirements. These new low OFO and EFO requirements, which will be in effect year-round, replace winter balancing rules in place since the early 1990s with a unified, statewide approach.

When a large gas-fired generator is dispatched to serve electric needs, the pull on the gas system can be great causing changes in pipeline pressures and reducing system flexibility to meet other customer's needs. While many gas-fired generators have contracted for firm pipeline capacity and gas supplies, others especially peaking generators have relied on interruptible capacity and spot market purchases. During periods of peak gas demand, there may be little or no interruptible pipeline capacity available to serve generators that have not contracted for their own capacity, threatening electric reliability. ${ }^{56}$

The California ISO (CAISO) formed a group to look at potential reliability risks to both gas and electricity markets in Southern California due to the limited operation of the Aliso Canyon gas storage facility. Through an expedited stakeholder process, the group created a proposal for tariff changes that addresses gas balancing, electricity and gas scheduling misalignment and marketbased mitigation measures. CAISO's proposal identifies ways to mitigate risks that impact the electric system when rapid ramping will exceed the dynamic capability of the gas system. ${ }^{57}$

The current tariff structure for wholesale gas purchases by utilities may need to be examined to promote generator bids that reflect gas system limitations, to reduce the chance that ISOs/RTOs will dispatch generators in a way that harms gas system reliability, and permit ISOs/RTOs to reserve sufficient internal electric transmission transfer capability to react to changes in the gas system.

While the results of this section indicate that an outage in the natural gas sector can adversely affect the electric sector, the outage at Aliso Canyon is a recent demonstration of how bulk power system (BPS) reliability is affected by the increasing interdependency between the electric and natural gas industries. While the mitigation measures being undertaken by SoCalGas and CAISO will help reduce the risk of electricity service interruptions, they may not eliminate the risk. The challenges faced in California represent a series of risks that have been layered into the system over the past decade including gas system dependency on storage to maintain operating pressure and a lack of clear understanding of natural gas operational characteristics and potential impacts on BPS operations.

${ }^{55}$ Marelli, G., 2016. Application of Southern California Gas Company (U 904 G) and San Diego Gas \& Electric Company $(U 902 \mathrm{G})$ for Authority to Revise their Curtailment Procedures, available at https://www.socalgas.com/regulatory/documents/a-15-06-020/Ch\%201\%20Curtailment\%20Testimony\%20\%20Marelli.pdf, accessed on September 20, 2016.

56 American Gas Association (AGA), 2016. "Gas-Electric Coordination," available at https://www.aga.org/federalregulatory-issues-and-advocacy/gas-electric-coordination, accessed September 20, 2016.

${ }^{57}$ California ISO (CAISO), 2016. Aliso Canyon Gas-Electric Coordination Straw Proposal, available at http://www.caiso.com/Documents/StrawProposal_AlisoCanyonGas_ElectricCoordination.pdf, accessed September 20, 2016. 
Continued coordination between electric and gas industry entities will be critical to mitigating risks and minimizing their impact. The timeframe for nominating natural gas transportation service is generally not synchronized with the timeframe during which electric generators receive confirmation of their bids in the ISO/RTO day-ahead market. Two impactful measures identified by the North American Electric Reliability Corporation (NERC) to help mitigate risk are: tightening the gas balancing rules, and giving generators dispatch information two days in advance so that they can procure gas more accurately. ${ }^{58}$

The results of this section also indicates that further study is needed to address any additional risks to the reliable operation of the BPS from a hypothetical long-term loss of UGS operations.

\subsection{Overall UGS Supply Risk Assessment}

Figure 4.6-1 identifies the UGS facilities with the estimated risk values based on the above methodology. It can be seen that the predicted risk is low (maximum value of approximately 32,000 expected equivalent residential customer outages per year), with most UGS facilities having a predicted risk of less than 1,000 expected equivalent residential customer outages per year.

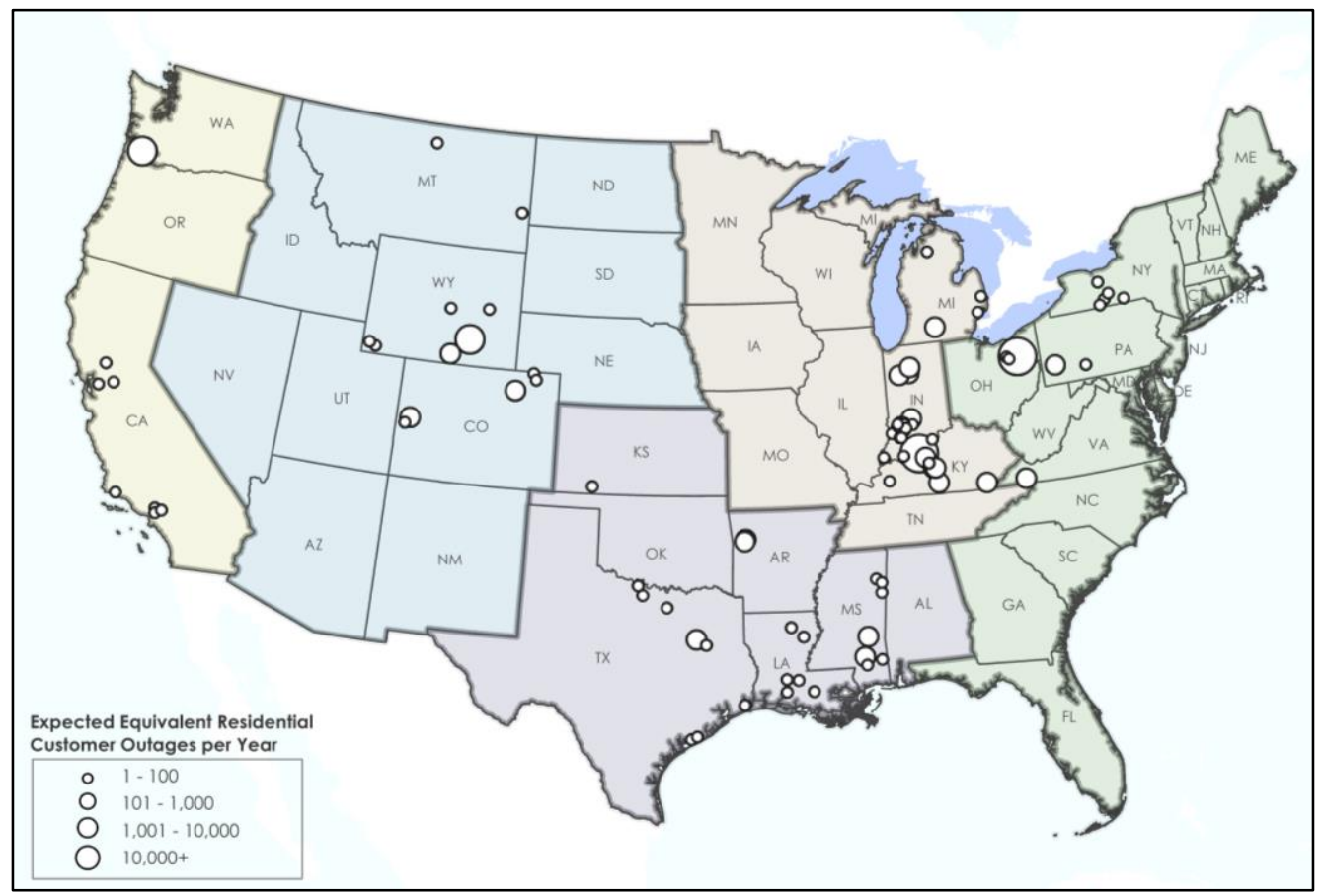

Figure 4.6-1 Locations of UGS Facilities with a Non-Zero Risk Value

58 North American Electric Reliability Corporation (NERC), Short-Term Special Assessment - Operational Risk Assessment with High Penetration of Natural Gas-Fired Generation, available at http://www.nerc.com/pa/RAPA/ra/Reliability\%20Assessments\%20DL/NERC\%20Short-

Term\%20Special\%20Assessment\%20Gas\%20Electric_Final.pdf, accessed September 20, 2016. 
The results in Figure 4.6-1 agree with the observation that the loss of gas service to a large number of customers is a relatively rare occurrence. In the last 35 years in the Chicago Metropolitan Area, the largest number of customers losing gas service at any one time has been on the order of 4,500. ${ }^{59}$ Similarly, the Southwest cold weather event of February 1-5, 2011, led to extensive curtailments of gas service to more than 50,000 customers in New Mexico, Arizona, and Texas. ${ }^{60}$ When compared with customers affected by electric power outages (which can be in excess of 100,000), the estimated number of expected annual customer outages per year in Figure 4.6-1 can be considered to be relatively small.

The majority of the UGS facilities with the highest risk values are located in the Midwest. The predicted consequences in Section 4.1 indicated that the impacts are spread out over a wider area and affect multiple States for UGS facilities owned by interstate pipeline companies. As stated in Section 4.1.2, the unreserved capacity of transmission pipelines was estimated using State-based pipeline capacity data publicly available from the EIA, and more detailed pipeline flow studies may be needed to confirm the validity of the public pipeline capacity dataset.

The UGS facilities with the highest number of equivalent residential customer outages in Figure 4.6-1 are mainly owned by LDCs or pipeline companies. If a list of critical or significant UGS facilities needs to be developed, the results in Figure 4.6-1 indicate that there are 4 UGS facilities with a predicted risk of greater than 1,000 expected equivalent residential customer outages per year.

Based on the analysis, the natural gas transmission and local gas distribution companies can use mitigation actions such as asking their customers to take on voluntary consensus conservation measures to reduce the demand for gas during periods of extreme peak-day demand conditions. From industry experience, these measures have been taken by LDCs where conservation measures by customers have reduced the peak-demand load on the system from 10 to $20 \%$. This mitigation measure can also work during disruption of natural gas from UGS during peakdemand conditions.

\subsection{Federal and Industry Action Response}

On February 2, 2016, the PHMSA released a natural gas storage safety advisory modeled after industry's best practices referencing to American Petroleum Institute (API) Recommended Practices 1170 and 1171. Recommended Practice 1170 specifically outlines how to safely design, store, and operate natural gas in salt caverns, and Recommended Practice 1171 focuses on safe practices for designing, storing, and operating natural gas in depleted oil and gas reservoirs. These two standards address the proper storage of natural gas underground and proper construction methods, materials, and maintenance practices for ensuring safe operations. ${ }^{61}$

${ }^{59}$ URL: http://www.ipd.anl.gov/anlpubs/2003/02/45798.pdf.

${ }^{60}$ URL: http://www.ferc.gov/legal/staff-reports/08-16-11-report.pdf.

${ }^{61}$ API, 2016, "Industry Continues to Enhance Best Practices of Natural Gas Storage Facilities," available at http://www.api.org/news-policy-and-issues/news/2016/02/02/industry-continues-to-enhance-best-pract. 
In response to the Aliso Canyon leak from an underground natural gas storage well that lasted nearly 4 months, federal agencies with oversight of such facilities announced workshops to gather information and solicit input on forthcoming minimum safety regulations. In February 2016, the PHMSA issued an Advisory Bulletin urging operators of underground natural gas storage facilities to ensure that their operations are appropriately safeguarded against disruptions that could result from corrosion, chemical damage, and other structural deficiencies. The PHMSA recommended that operators of storage facilities implement procedures and processes to reduce the risk of accidents. It also recommended that gas storage operators establish emergency plans and mitigation measures to ensure the integrity of storage facilities and perform routine comprehensive assessments of their facilities, taking into account the age of the facilities, maintenance history, and condition of specific components, such as tubes, casings, and valves. The PHMSA advised operators to reference and implement the standards and guidelines set out in PHMSA Advisory Bulletin 97-04, dated July 10, 1997, as well as in various publications by the API and Interstate Oil and Gas Compact Commission (IOGCC). In addition, the PHMSA recommended that operating and maintenance processes be reviewed at least annually and that operators implement the following procedures:

- Verify that the pressure required to inject natural gas does not exceed design pressure limits;

- Monitor wells for the presence of annular gas or liquids;

- Frequently inspect wellhead assemblies and pipelines for potential leaks;

- Conduct periodic functional tests of all valves to confirm their performance in emergency situations;

- Perform risk assessments pursuant to API guidelines;

- Conduct ongoing assessments and verification of the mechanical integrity of all equipment;

- Monitor all equipment for corrosion;

- Establish procedures to evaluate the effects and relationship between fluids in the system and pressure and flow rates;

- Identify all potential threats to the system;

- Establish procedures to verify the integrity of the UGS reservoir or cavern;

- Identify emergency procedures which require the notification of emergency response officials; and 
- Record all procedures, assessments, reassessments, and mitigation measures for the life of the storage well. ${ }^{62}$

In early April, DOE and the PHMSA established an Interagency Task Force on Natural Gas Storage Safety. As part of these efforts, DOE held a workshop July 12-13, 2016, in Broomfield, Colorado, to discuss various issues, including well integrity risks, construction practices, monitoring and testing of subsurface storage integrity, accident response management, and research and development. The PHMSA held a separate public workshop, July 14, 2016, in Broomfield, Colorado, which was open to the public and webcast on the Internet.

On June 22, 2016, the President signed the Protecting our Infrastructure of Pipelines and Enhancing Safety Act of 2016 (PIPES Act) into law to reauthorize the Pipeline Safety Act and PHMSA. Among the requirements of the PIPES Act, PHMSA must establish minimum safety standards for underground natural gas storage by June 21, 2018. In addition, DOE must establish an Aliso Canyon natural gas leak task force by July 7, 2016, including PHMSA, EPA, FERC, the Department of the Interior, and State and local government representatives, among others. This group must submit a final report to Congress by December 19, 2016, on the causes and contributing factors of the Aliso Canyon leak, the impact of the leak, the effectiveness of the measures taken to respond to the leak, agency responses, and recommendations for preventing future leaks. ${ }^{63}$

62 Rooney, Rippie, and Ratnaswamy, LLP, 2013, "PHMSA Issues Advisory Bulletin Regarding Underground Natural Gas Storage Facilities," available at https://www.r3law.com/phmsa-issues-advisory-bulletin-regardingunderground-natural-gas-storage-facilities/.

${ }^{63}$ PipelineLaw.com, 2016, “Agencies Continue Planning for Regulation of Underground Gas Storage," available at https://www.pipelinelaw.com/2016/06/27/agencies-continue-planning-for-regulation-of-underground-gasstorage/. 


\section{Summary of Findings and Recommendations}

Findings and recommendations are shown below and are grouped into the following categories: (1) additional data needs for electric reliability studies, (2) needs for further electric reliability analyses, (3) regulatory requirements and standards, and (4) needs to improve gas/electric industry coordination for reliability.

\subsection{Topic I: Ensuring Electric Reliability and Managing Gas-Electric Interdependency Risks}

\section{Aliso Canyon Event Has Implications Beyond Management of UGS Facilities}

Observation: The Aliso Canyon event was a wake-up call, alerting us to the need to understand better the implications and risks associated with the growing interdependence between the electric and natural gas industries, and the need to take appropriate actions to mitigate such risks.

Discussion: Aliso Canyon is not a unique UGS facility in terms of its potential, if disrupted, to have adverse impacts on electric reliability in the affected area. A total of 12 UGS facilities appear to have the potential to affect $2 \mathrm{GW}$ or more of available generation capacity. Note, however, that these figures are preliminary, because the operators of the affected power plants may or may not have dual-fuel capability (i.e., diesel or equivalent liquid fuels, with sufficient inventories), access at short notice to alternative sources of natural gas, or access to alternative generation via transmission.

\section{Recommendations:}

a) Power system planners and operators, working with their natural gas counterparts, should study and understand the electric reliability impacts of prolonged disruptions of largescale natural gas infrastructure (e.g., storage facilities, processing plants, key pipeline segments and compressor stations, LNG terminals).

b) Power system planners and operators should communicate and share the results of their analyses with State and Federal officials to ensure that policymakers fully understand the risks to electric reliability and can develop appropriate mitigation policies and strategies.

c) Regulators, electric and gas operators, and other market participants should strive to disseminate planning and operational information to all facets of the electric and gas industries, so that key operating parameters, such as those pertaining to gas balancing, are defined, solutions can be developed, and coordination achieved. By sharing information, entities can develop and train on new operating/market procedures, increase situational awareness, prepare to implement procedures to maintain the operation of the electric and gas systems under constrained conditions, and avoid gas and electric curtailments. 


\section{Backup Strategies Can Reduce Risks}

Observation: The availability and use of a back-up fuel source for electricity generation (or some functional equivalent) can enable a generation facility to operate in isolation of a potential natural gas infrastructure disruption.

Discussion: Greater reliance on such measures as dual-fuel capabilities (i.e., diesel or equivalent liquid fuels, with sufficient inventories), energy storage options, and maintaining alternative sources of natural gas may help electricity operators to bridge the gap between the uncertainties of gas availability during extreme events and maintain a reliable source of operable capacity available to meet seasonal peak demands. This approach could include natural gas storage at or near the electric generation plants, if feasible and affordable.

Recommendation: NERC, generators, and Federal and State agencies should consider broader usage of back-up strategies, including dual-fuel capabilities, energy storage options, and alternate sources of natural gas supply, to reduce reliability risks associated with the possible abrupt loss of a major source of natural gas for electricity generation.

\section{Joint Gas/Electric Planning and Coordination Should be Strengthened}

Observation: Opportunities exist for DOE, FERC, NERC, and the electric and gas trade associations to strengthen joint gas-electric planning and coordination, with the objectives of seeing the electric and natural gas systems as interdependent critical infrastructures and minimizing risks (including physical and cybersecurity) to both sectors and their customers.

Discussion: Enhanced operational coordination between the gas and electric industries would decrease the impacts of widespread outages. As an example, joint actions could be taken to optimize real-time gas flows across regional and local systems. (See URL: http://western.wp.naruc.org/wp-content/uploads/sites/2/2016/06/GasSafety-All.pdf.)

Recommendation: Federal and State agencies should work with NERC and the electric and gas trade associations to develop reliability guidelines, as well as identifying best practices for improved procedures, practices, and market designs to reduce and manage the impacts of gas curtailment events and related electricity contingencies.

\subsection{Topic II: Further Analyses and Tools Required}

\section{Analyze a Broader Range of UGS-Related Contingencies}

Observation: The Task Force's current analysis of the potential loss of UGS facilities considered only the loss of one such facility at a time. A wider range of regionally relevant contingencies is plausible and merits review by electric system planners.

Discussion: Earthquakes or other disasters could disable multiple UGS facilities in an affected area, or they could take out combinations of UGS facilities and other important gas supply 
infrastructure. Further, planning to make gas/electric infrastructure more resilient against such events should take into account the need to ensure the availability of adequate "black start" capability in appropriate locations. (In the event of a regional-scale blackout, it is important to have some generation units in the affected area that can be restarted without electricity from an external source; once running, these black-start-capable units can then help reactivate the broader network.)

Recommendation: DOE should work with the Department of Homeland Security (DHS) and other organizations to leverage the capabilities of DHS's National Infrastructure Simulation and Analysis Center (as defined in 6 USC 321) to review a variety of UGS disruption scenarios.

\section{Special Reliability Assessment by NERC}

Observation: The current Task Force analysis of the impacts of losing service from a given UGS facility relied on publicly available information on UGS characteristics and operations. The accuracy and confidence of the analytic results could be improved through the use of additional but proprietary or restricted-access information on UGSs and their relationship to pipeline operations, which is available from sources such as EIA (Form 191, "Monthly Underground Gas Storage Report”) and FERC (Form No. 567, "System Flow Diagrams”).

Discussion: While ensuring appropriate protections for proprietary information, DOE intends to determine how these additional data can be re-analyzed to determine the potential consequences of the disruption of UGS operations - with particular attention to the 12 UGS sites of interest noted above. DOE also plans to work with NERC on its Special Reliability Assessment on Single Points of Disruption to Natural Gas Infrastructure, which will examine transmission-level reliability impacts on the bulk power system in the event of disruptions of service from key UGS facilities.

Recommendation: DOE, NERC, and appropriate National Laboratories should proceed with the proposed analysis (subject to appropriations, as necessary) and give particular attention to those UGS facilities that, if disrupted, appear in the current analysis to have significant potential to create electric reliability problems in affected communities.

\section{Need for Combined gas/Electric Models to Analyze Short-Term Dynamics}

Observation: As delivery systems, the existing pipeline and storage networks must cope with short-term changes in operating conditions that affect the deliverability of gas to wholesale customers, particularly gas-fired generators whose gas requirements are highly changeable from hour to hour. As the interdependence between the industries increases, the need to understand and cope with such rapid changes in both gas demand and gas deliverability becomes more acute.

Discussion: Combined gas/electric models are needed to determine in near-real-time the dynamic capability and adequacy of the combined regional systems. Such models would enable 
planners and operators to identify constraints and potential sources of disruption (e.g., storage facilities, key pipeline segments and compressor stations, LNG terminals), so as to operate both systems reliably. The models could be used to determine what facilities should be added, define adequate operating parameters (such as balancing on the gas system or ramping on the electric system), or estimate the impacts of facility outages, additions, or retirements. The models should include all planning periods (future years) and operations (current year and real-time) so that resource adequacy, steady-state, and dynamic analyses can be performed on both gas and electric systems. This work could include using the pipeline simulation models that interstate pipeline companies use when providing support for their applications to FERC to construct and operate pipeline facilities. In addition, development of pipeline simulation models by local gas distribution companies could be considered.

Recommendation: Power and gas system planners and operators should jointly develop, validate, and apply combined models to improve the capability and ensure the adequacy of the combined infrastructure.

\section{Tools for Analysis of Short-Term Gas Deliverability}

Observation: The electric industry needs the capability to develop quick-response analyses of rapidly changing conditions affecting the short-term deliverability of natural gas for electricity generation.

Discussion: During a July 2016 DOE workshop on resilient electric distribution systems in Washington, DC, electric industry participants identified a need for a real-time tool that would access natural gas system operations data, starting with the existing gas electronic bulletin board (EBB) data. Once developed, this tool or capability could be used to perform quick-response contingency analyses related to the deliverability of natural gas for electricity generation.

Recommendation: DOE (subject to appropriations), in coordination with NERC, the ISOs, and others should consider performing a scoping study to examine the quality and relevance of EBB data and data from other sources for assessing real-time reliability risks, determine the costs of developing and testing a computer-based analytic tool capability for this purpose, examine who would pay to maintain the tool on a long-term basis, and consider whether user fees would be an effective way to fund its maintenance. 


\subsection{Topic III: Data Needed for Additional Gas/Electric Reliability Studies}

\section{Collect Additional Information on EIA Surveys}

Observation: EIA's Form 860 could be modified immediately to collect additional information on connections between individual gas-fired power plants and the natural gas supply system. In addition, currently withheld information on the availability of backup fuel oil at gas-fired power plants could be made public information.

Discussion: Making this information more readily available would aid analysts in determining the potential implications of any future disruptions to natural gas supply infrastructure for regional or local electric reliability.

Recommendation: EIA should consider modifying Form EIA-923 and Form EIA-860 to include additional data that would be useful for analysis of issues related to maintaining the reliability of existing gas-fired electric generation capacity. This information might include, for example, information on the capacity of the pipelines connecting to power plants and data on a plant's reliance on firm and non-firm natural gas transportation.

\subsection{Topic IV: Regulatory Requirements and Standards}

\section{Reduce Likelihood and Impacts of Gas Curtailments}

Observation: Actions may be taken to reduce the likelihood of natural gas curtailments, but curtailments may occur nonetheless due to changes in market conditions, weather, equipment failures, natural disasters, physical attacks, cyber intrusion, etc. The growing interdependence between the gas and electric industries calls for greater preparedness by and among the affected companies to avert potential curtailments and reduce their impacts of those that occur.

Discussion: Natural gas service is generally available to electricity generators, subject to the regulatory and physical constraints of the natural gas system, although "firm" (non-interruptible) service typically costs considerably more than "interruptible" service. Regulators and policymakers need to understand the broad terms of the contractual arrangements for supplying gas to generators in areas under their jurisdictions, and to understand the physical limitations of the natural gas infrastructure for serving the needs of electric generators. Increased coordination between natural gas and power industry regulating agencies could help ensure improved crosscapture of information as the role of natural gas as a fuel source for power generation continues to grow.

\section{Recommendations:}

a) State PUCs or other relevant agencies should consider requiring natural gas LDCs and electric utilities under their jurisdiction to collaborate in the joint development of specific and clear procedures for managing future natural gas curtailments to minimize impacts, and to submit the procedures for regulatory approval. 
b) State PUCs should consider whether to make changes in current LDC tariffs to establish more specific provisions concerning the allocation of gas among electric generators in advance of curtailment of service from an LDC-owned UGS facility. This review should also address the State's end-use curtailment rules, which may include force majeure policies under which service to natural gas-fired power plants with firm contracts could be curtailed.

\section{Managing Short-term Variability of Generators' Demand for Gas}

Observation: Natural gas-fired generators often demand fuel in large quantities at short notice that may strain pipelines' ability to deliver. Many older pipeline systems are not designed to accommodate this pattern of withdrawal behavior on a large scale. However, rising dependence in many areas on natural gas for electricity generation suggests that this strain will become more acute.

Discussion: Tariffs for wholesale gas purchases by utilities that would promote generator bids and reflect gas system limitations are needed, with the aims of reducing the chance that ISOs/RTOs will dispatch generators in a way that harms gas system reliability and permitting ISOs/RTOs to reserve sufficient internal transmission transfer capability to react to changes in the gas system.

Recommendation: Federal and State regulators should consider the operational demand characteristics of natural gas-fired generation when developing or reviewing the regulatory framework for planning, building, and operating the natural gas delivery system.

\section{Avoiding Mismatches Between Nominated Gas Flows and Actual Gas Demand}

Observation: The timing of the nomination processes for the electric and gas markets do not coincide, and this increases the risk of a mismatch between nominated gas flow and actual gas demand.

Discussion: If sufficient gas for electric generation is not procured in advance, the result may be gas procurement, including from UGS facilities, during more illiquid periods and lead to higher costs for electric generation and increased reliability risk. (URL: http://western.wp.naruc.org/wpcontent/uploads/sites/2/2016/06/GasSafety-All.pdf; URL:

https://www.caiso.com/Documents/Agenda_Presentation_AlisoCanyonGasElectricCoordination. pdf.)

Recommendation: Both gas and electric industries should continue to review and improve existing processes and the timing of information flows pertaining to energy bidding and/or gas nomination processes so that both systems are balanced and can operate within their respective reliability parameters. Similarly, the two industries should work together to develop flexible pipeline services to accommodate the changing needs of the electricity industry. 


\section{Appendix A: Common UGS Facility Characteristics}

The natural gas system is generally described in terms of (1) production, (2) processing and purification, (3) transmission and storage, and (4) distribution. Figure A-1 shows a schematic of the natural gas infrastructure from the production wells through to the city gate. The red box focuses on the physical characteristics of UGS facilities, including the associated compressors and other critical natural gas processing and conditioning equipment.

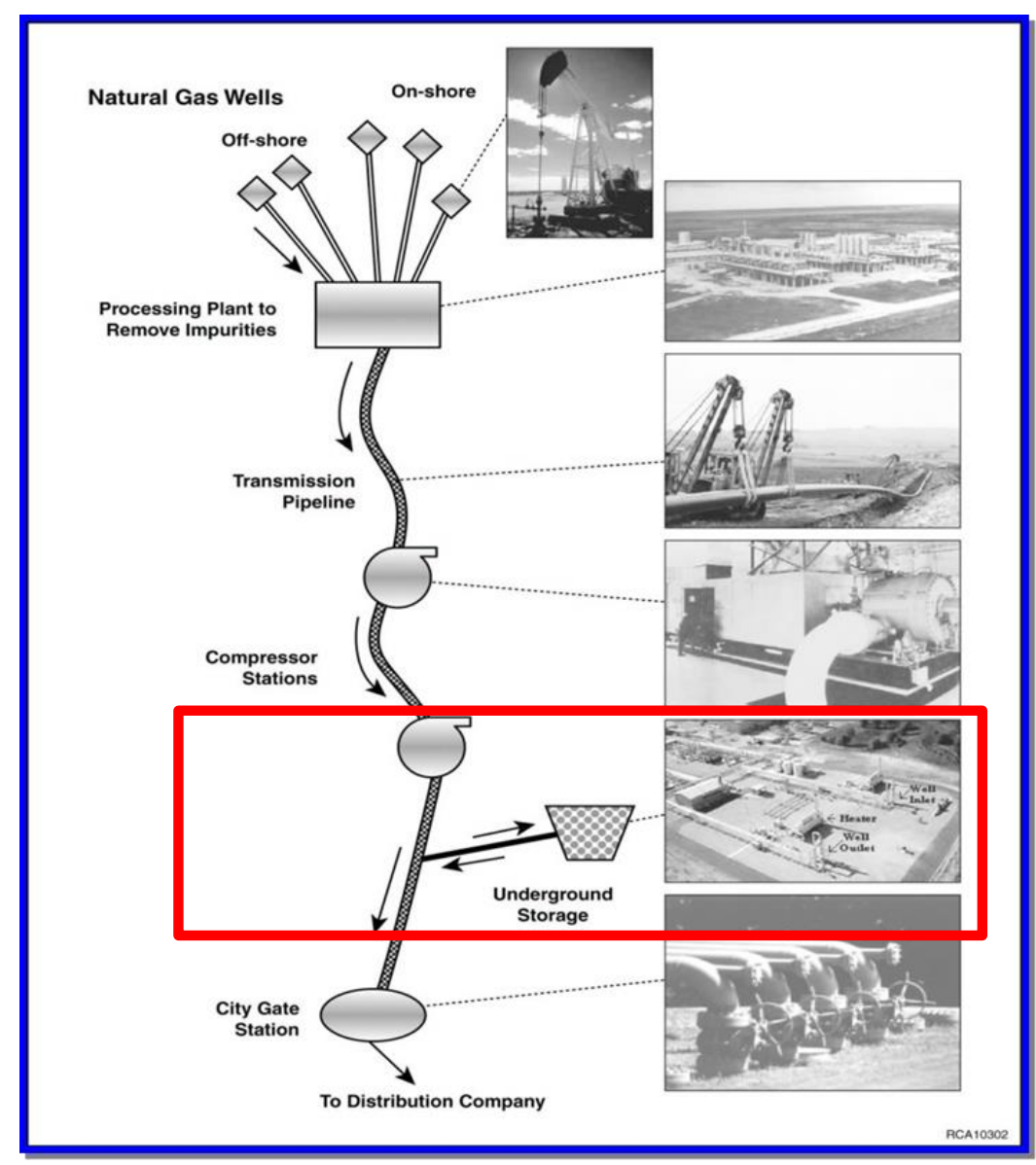

Figure A-1 Schematic of Natural Gas Production, Processing, Transmission, and Storage (Source: Argonne 2002) ${ }^{64}$

${ }^{64}$ Argonne, 2002, Guidelines for Planning for Natural Gas Disruptions, prepared for Chicago Metropolitan Area Critical Infrastructure Protection Program, available at http://www.ipd.anl.gov/anlpubs/2003/02/45798.pdf. 
As stated previously, natural gas is stored in underground geologic formations. Whether these are naturally occurring structures, such as aquifers or depleted hydrocarbon reservoirs, or manmade, such as salt caverns or depleted mines, the surface (aboveground) facilities required for a successful storage operation are basically the same. The following sections describe these facilities and their critical components in more detail.

\section{A.1 Compression Facilities at a UGS Field}

Other than the reservoir itself, compression is the most significant of the components needed for UGS operations. Each storage facility has unique requirements for compression, depending upon the minimum and maximum reservoir pressures, and how these compare to the pressure of gas deliveries into and out of the storage field. In most cases, compression is required for either injection or for withdrawal, and in many cases, for both.

The stations contain valves, pipes, conditioning equipment, and control systems that monitor the functioning of the system. Most compressor stations are fully automated, with operational oversight from a control room either at the storage site or at a remote location. Figure A.1-1 provides an aerial view of a natural gas UGS facility, with large compressor buildings in the center. Compressors are typically housed in one or more metal buildings with pipe appurtenances and other critical elements above ground. Figure A.1-2 shows a close-up of an integral reciprocating compressor, a configuration frequently used in storage operations. Figure A.1-3 shows a turbine-driven centrifugal compressor. Similar units are also frequently used at underground storage facilities.

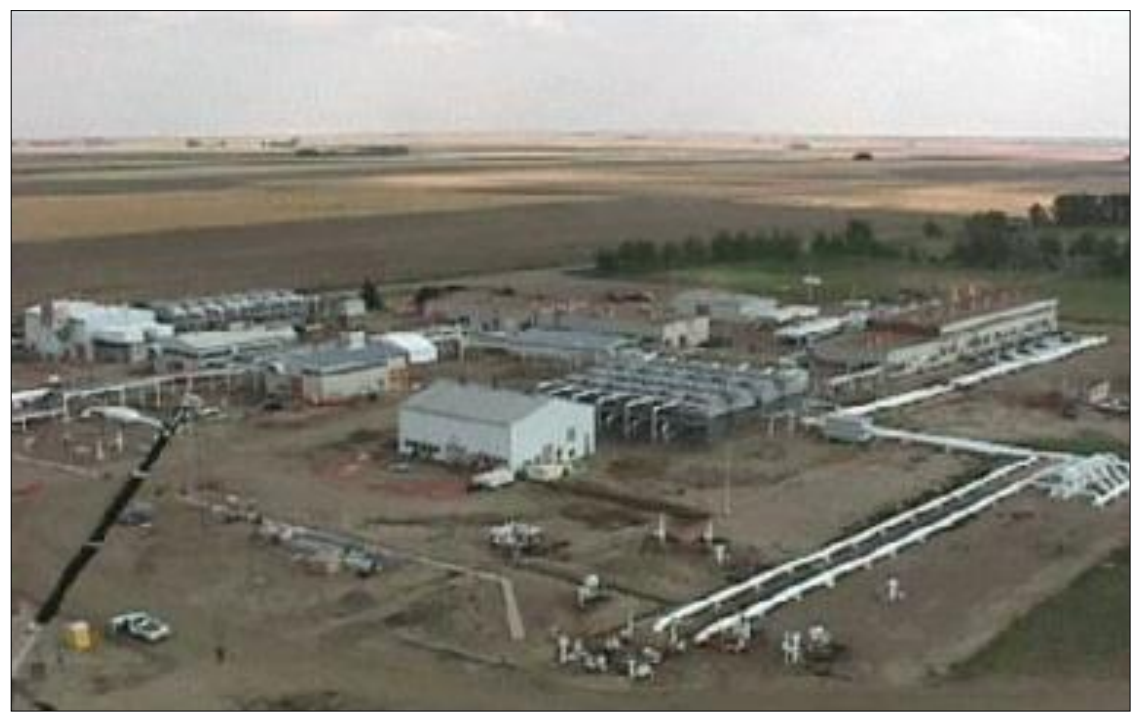

Figure A.1-1 Salt Cavern Underground Natural Gas Storage Station ${ }^{65}$

65 Folga, S., 2007. Natural Gas Pipeline Technology Overview, Argonne National Laboratory, ANL/EVS/TM/08-5, available at http://corridoreis.anl.gov/documents/docs/technical/apt_61034_evs tm_08 5.pdf. 


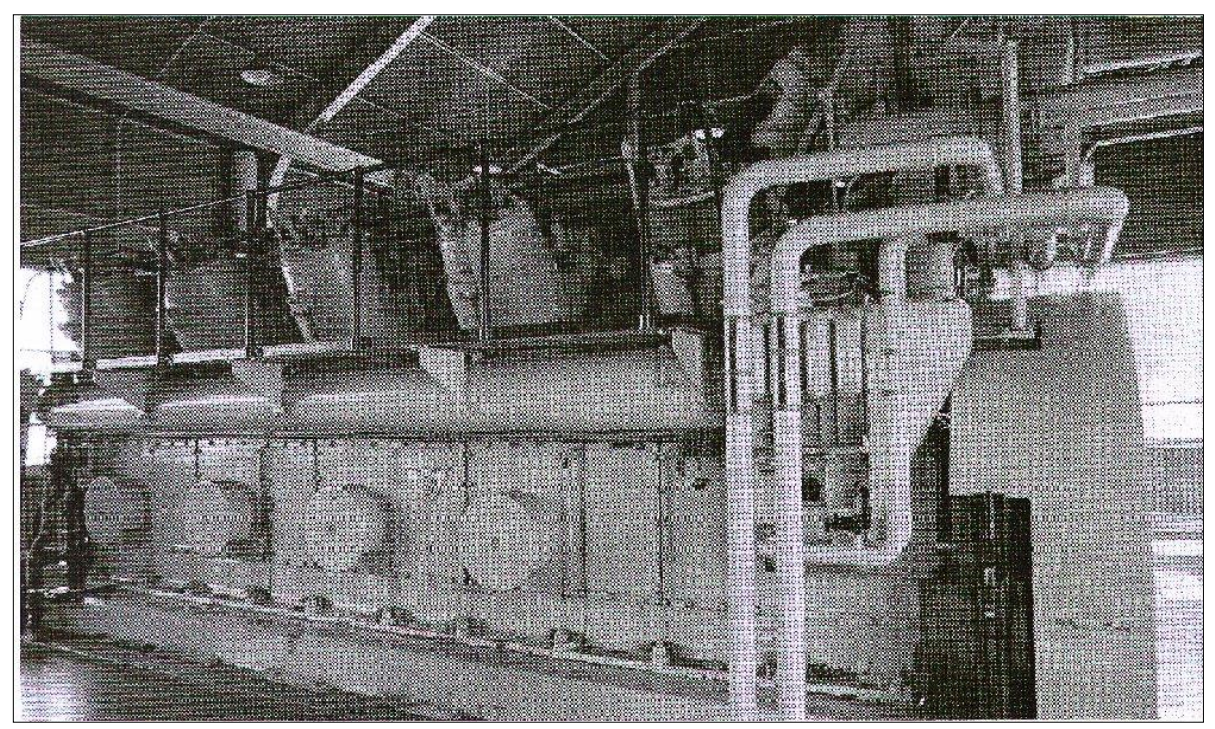

Figure A.1-2 Integral Reciprocating Natural Gas Compressor 66

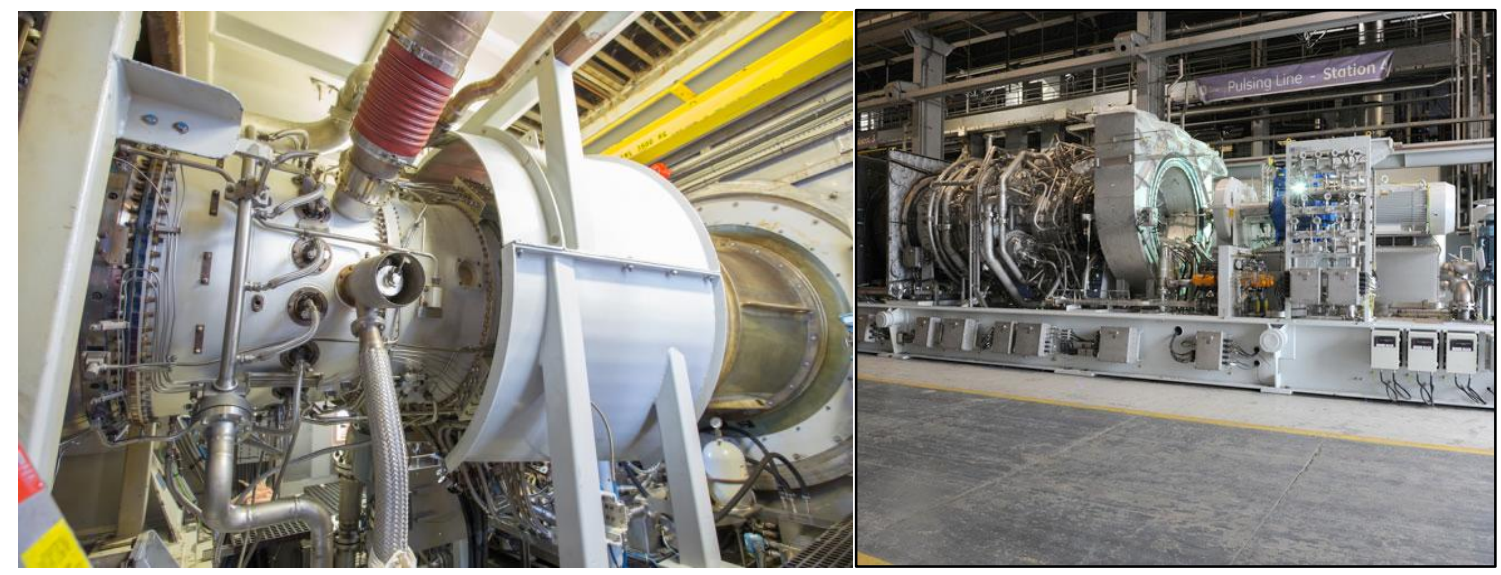

Figure A.1-3 Solar T-1001 Gas Turbine-Driven Centrifugal Gas Compressor 67

\section{A.2 In-line Filtration Equipment}

As gas travels through a piping system, it may entrain significant quantities of dust, pipe scale, and other detritus that are inside the pipe. If this solid material enters the compressor, it can seriously damage the equipment. Filters and separators are used to trap any solids (and, in some cases, liquids) before they reach the compressor. In-line filter/separators or "scrubbers" in Figure A.2-1 are pressure-rated vessels usually installed in the inlet piping to a compressor. These operate in a manner similar to the air cleaner on an automobile, knocking out some particles and trapping the rest.

${ }^{66}$ Folga, S., 2007. Natural Gas Pipeline Technology Overview, Argonne National Laboratory, ANL/EVS/TM/08-5, available at http://corridoreis.anl.gov/documents/docs/technical/apt 61034_evs_tm 08 5.pdf.

${ }^{67}$ Image courtesy of Pichitbo, used under license from Shutterstock.com. 


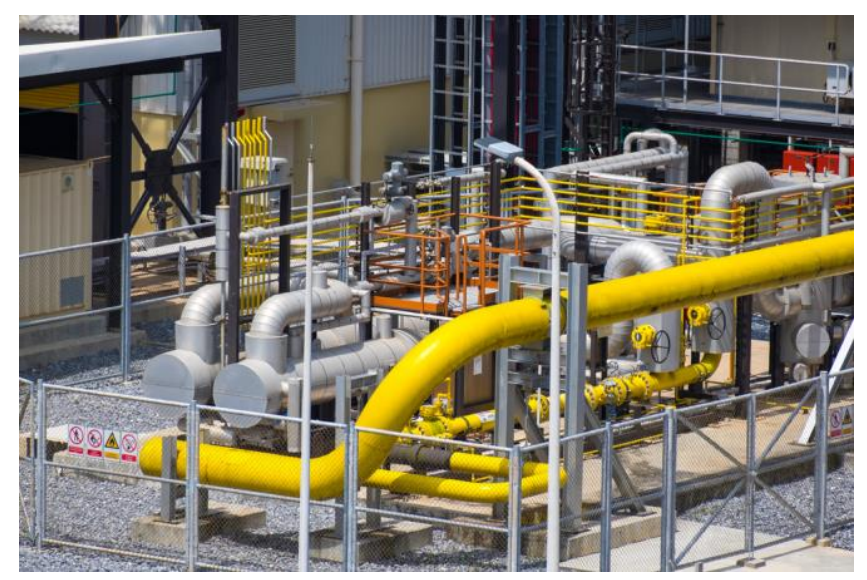

Figure A.2-1 Self-Cleaning Filter Separator 68

\section{A.3 Gas Cooling Equipment}

As predicted by the ideal gas laws, when natural gas undergoes compression, it gains heat. Depending upon the compression ratio, this rise in temperature may threaten the integrity of the coating applied to buried pipe to prevent corrosion. In a UGS station, it may also cause damage to wellbores and to downhole storage formations. Typically, a compression ratio exceeding about 1.15:1 is sufficient to create such conditions. To prevent such occurrences, cooling units known as aftercoolers are included in the discharge piping of most storage compressor installations. Large fans powered by electric motors cool the gas by blowing air across finned coils through which the gas flows. Figure A.3-1 shows a forced-draft aftercooler.

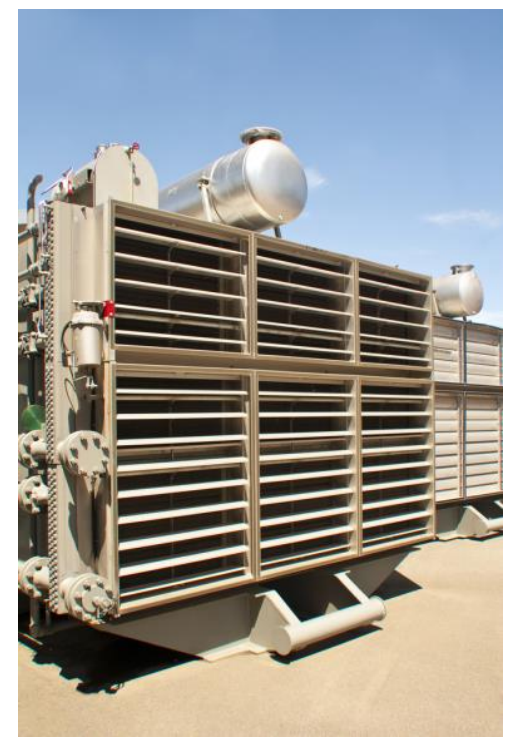

Figure A.3-1 Forced-Draft Gas Aftercooler 69

\footnotetext{
${ }^{68}$ Image courtesy of Pichitbo, used under license from Shutterstock.com.

${ }^{69}$ Image courtesy of Pichitbo, used under license from Shutterstock.com.
} 


\section{A.4 Gas Conditioning at a UGS Facility}

When gas is stored in underground geologic formations, it absorbs formation water. When it is withdrawn, it usually contains a substantial quantity of water, in both entrained and saturated states. Hydrocarbons such as natural gas, when combined with water under high pressure and at moderate to low temperatures, can form ice-like crystals called hydrates. Hydrates can form inside storage field wellbores and gathering lines and cause partial or total blockages. The best way to prevent hydrate formation is to remove the water. The water is removed through a process called dehydration. Dehydration of natural gas is necessary to prevent the formation of hydrates in gas pipelines and equipment, to reduce dew point temperature to meet tariff specifications, to reduce corrosion of pipelines and vessels, and to reduce the load on gas compressors. Two methods of dehydration are typically used in the oil and gas industrieshygroscopic liquid drying agents such as glycol (Figure A.4-1) and solid adsorbent drying media (Figure A.4-2) such as molecular sieves or other dry desiccants, where water vapor in the wet gas is condensed and trapped on the surface of the solid drying medium.

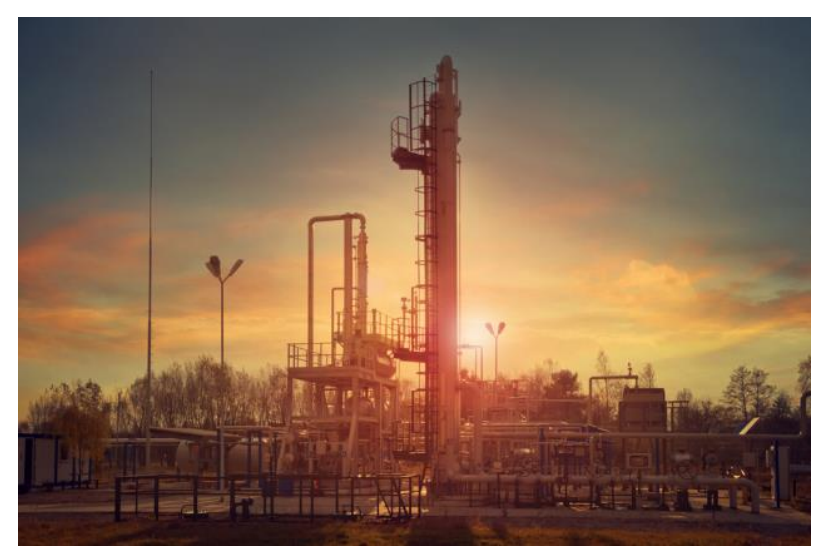

Figure A.4-1 Glycol Dehydration Unit ${ }^{70}$

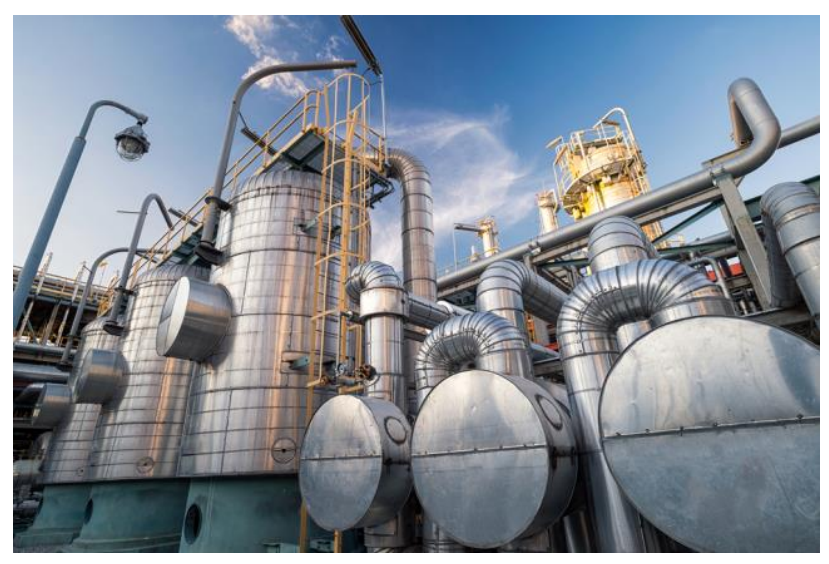

Figure A.4-2 Solid Adsorbent Dehydration System ${ }^{71}$

\footnotetext{
70 Image courtesy of Pichitbo, used under license from Shutterstock.com

${ }^{71}$ Image courtesy of Pichitbo, used under license from Shutterstock.com.
} 


\section{A.5 Indirect Water Bath Heaters}

As discussed in Section A.4 on dehydration, gas withdrawn from storage usually contains a substantial quantity of water, in both entrained and saturated states. Water bath heaters are frequently installed near the withdrawal sites to raise the temperature of the wet gas above the hydrate formation point until it reaches the dehydration tower. This keeps the water in the gas from freezing and plugging the line. Figure A.5-1 shows a large indirect water bath heater installed at a gas processing site. Heaters are often used in gas transmission and distribution applications ahead of pressure regulators. When gas pressure is reduced, the temperature is also reduced. At sub-freezing temperatures, even small amounts of water vapor can freeze in instrument orifices, sometimes causing equipment malfunction or shutdown. Heating the gas before pressure reduction keeps the final temperature above the freezing point.

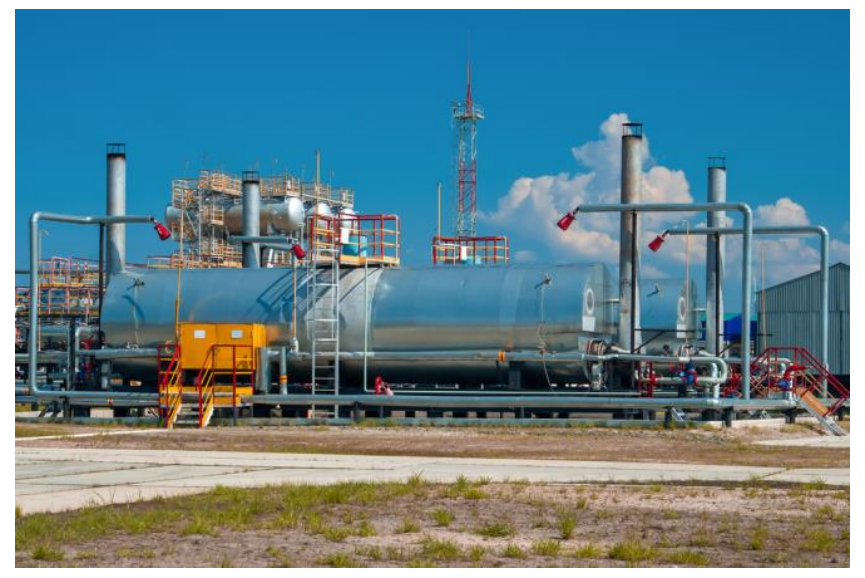

Figure A.5-1 Large Indirect or Water Bath Heater 72

\section{A.6 SCADA Control Centers}

Underground storage facilities that are operated as part of a natural gas transmission or distribution system are usually monitored by the system operator's supervisory control and data acquisition (SCADA) system. The purpose of the SCADA system is to control and watch realtime information that is pertinent to the delivery system operations, including flow rates, pressures, and other characteristics of the natural gas product. The SCADA system continuously monitors, transmits, and processes critical system component information for the control room dispatcher. Equipment status scans are taken every 6 to 90 seconds depending on the communication technology used in the field. Figure A.6-1 shows a SCADA control center for a major pipeline company.

Many storage facilities, especially those operated by independent storage service providers, have their own internal SCADA system. Although these SCADA systems typically are more compact and may have fewer data points than seen in a SCADA system for a large pipeline, they

${ }^{72}$ Image courtesy of Pichitbo, used under license from Shutterstock.com. 
nevertheless are of the same basic design and contain similar hardware and software components.

The main components of any SCADA system are the Master Terminal Unit, or MTU; a number of Remote Terminal Units, or RTUs; and a communication system, either wired or wireless, to transmit data between the field points and the control center.

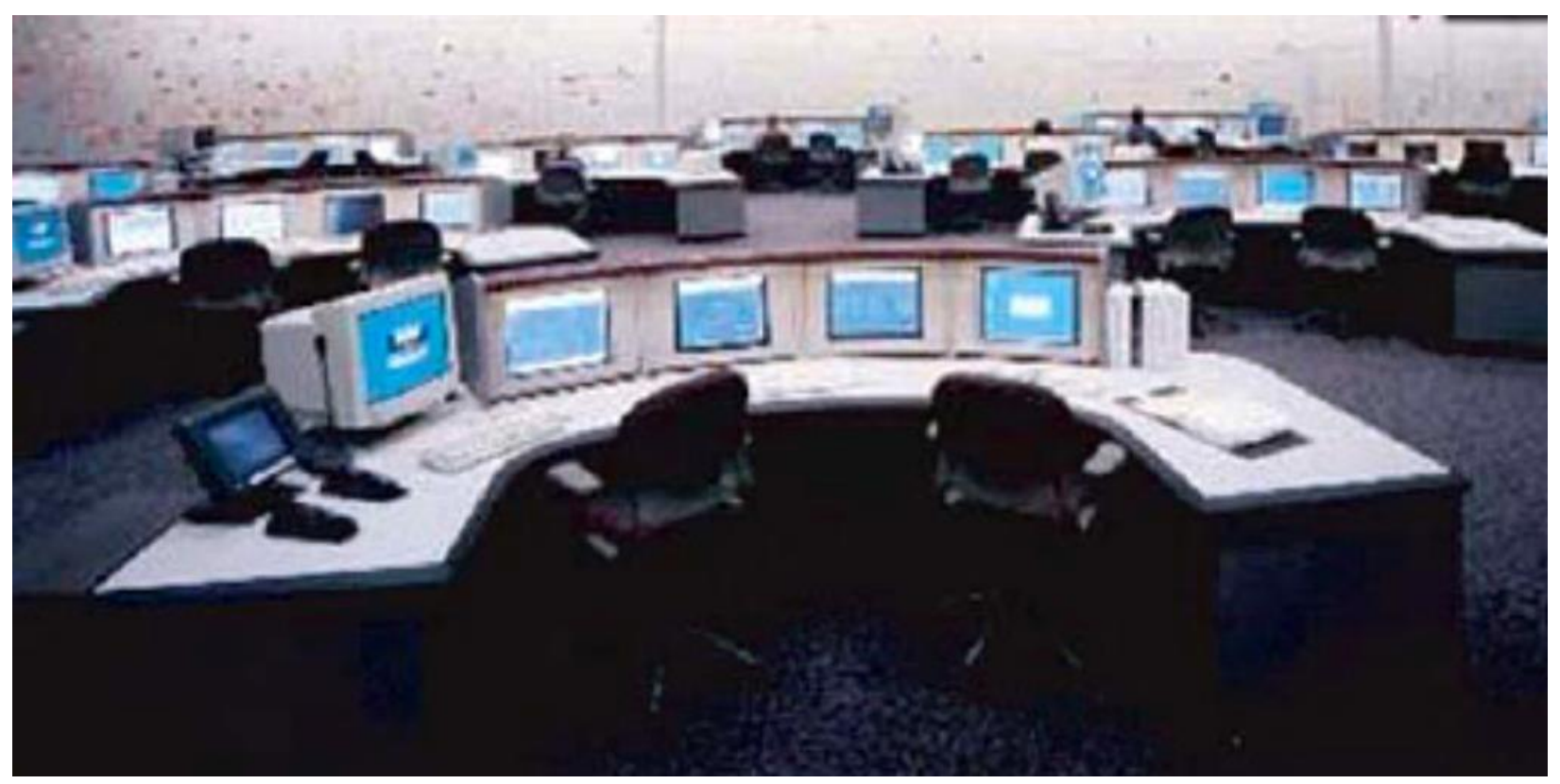

Figure A.6-1 SCADA Operator at the Control Center Console ${ }^{73}$

${ }^{73}$ Folga, S., 2007. Natural Gas Pipeline Technology Overview, Argonne National Laboratory, ANL/EVS/TM/08-5, available at http://corridoreis.anl.gov/documents/docs/technical/apt 61034_evs tm_08 5.pdf. 


\section{Appendix B: Summary of Documented Events Reported at U.S. UGS Facilities Which May Have Led to Leakage and/or Failure}


Table B-1 Summary of Documented Events at Depleted Oil and Gas Underground Storage Facilities, Some of Which Have Led to Leakage and/or Failure

\begin{tabular}{|c|c|c|c|c|c|c|c|c|}
\hline Field Name & $\begin{array}{l}\text { County } \\
\text { Name }\end{array}$ & State & $\begin{array}{l}\text { Current } \\
\text { Operator }\end{array}$ & Date & Impacts & Reported Cause & $\begin{array}{c}\text { Failure } \\
\text { Mechanism } \\
\text { ID }\end{array}$ & Source \\
\hline $\begin{array}{l}\text { Los } \\
\text { Medanos }\end{array}$ & $\begin{array}{l}\text { Contra } \\
\text { Costa }\end{array}$ & CA & $\begin{array}{l}\text { Pacific Gas } \\
\text { and Electric } \\
\text { Company }\end{array}$ & $5 / 25 / 2011$ & No service has been lost. & $\begin{array}{l}\text { During a scheduled hydrotest job, the valve } \\
\text { stem on an inlet fire valve to a regulator station } \\
\text { at } 2445 \text { Garcia Avenue in Mountain View broke } \\
\text { at } 1,745 \text { hours. The valve was being operated to } \\
\text { release water from the line. The valve was } \\
\text { broken in the partially open position causing gas } \\
\text { to escape. }\end{array}$ & 2,11 & PHMSA \\
\hline McDonald & San Joaquin & CA & $\begin{array}{l}\text { Pacific Gas } \\
\text { and Electric } \\
\text { Company }\end{array}$ & 10/1/1993 & $\begin{array}{l}\text { Explosion, causing } \$ 2 \text { million } \\
\text { damage. }\end{array}$ & $\begin{array}{l}\text { Explosion in moisture extraction (gas } \\
\text { conditioning) plant. }\end{array}$ & 2 & $\begin{array}{l}\text { Evans and } \\
\text { Chadwick, } 2009\end{array}$ \\
\hline McDonald & San Joaquin & CA & $\begin{array}{l}\text { Pacific Gas } \\
\text { and Electric } \\
\text { Company }\end{array}$ & 1974 & $\begin{array}{l}\text { Explosion, fire burned for } 19 \\
\text { days, } 15 \text { Mcf consumed. }\end{array}$ & Not available. & 18 & $\begin{array}{l}\text { Evans and } \\
\text { Chadwick, } 2009\end{array}$ \\
\hline El Segundo & Los Angeles & CA & $\begin{array}{l}\text { Standard Oil } \\
\text { Company of } \\
\text { California }\end{array}$ & $\begin{array}{l}\text { Early } \\
1970 s\end{array}$ & $\begin{array}{l}\text { Gas migration-threatening } \\
\text { housing development. }\end{array}$ & $\begin{array}{l}\text { Gas migration from reservoir to surface along } \\
\text { fault lines. Facility finally shut in (pre-1993) but } \\
\text { now abandoned for safety, due to new housing. }\end{array}$ & $4,5,12,13$ & $\begin{array}{l}\text { Evans and } \\
\text { Chadwick, } 2009\end{array}$ \\
\hline $\begin{array}{l}\text { Playa Del } \\
\text { Rey }\end{array}$ & Los Angeles & CA & $\begin{array}{l}\text { Southern } \\
\text { California Gas } \\
\text { Company }\end{array}$ & $1 / 6 / 2013$ & $\begin{array}{l}\text { The soot from the burned gas } \\
\text { caused mist damage to } \\
\text { neighboring homes, } \\
\text { landscaping, and vehicles. } \\
\text { Facility is currently shutdown } \\
\text { during ongoing investigation } \\
\text { and inspection of pipeline } \\
\text { facilities. }\end{array}$ & $\begin{array}{l}\text { At the Playa Del Rey underground storage } \\
\text { facility, an unintentional and momentary } \\
\text { opening of a block valve allowed a release of } \\
\text { high-pressure gas into lower-rated pressure } \\
\text { piping. This resulted in unplanned release of gas } \\
\text { through the relieving valve system and an over- } \\
\text { pressure of certain station piping. The gas } \\
\text { emitted through the relief system ignited. }\end{array}$ & 2,4 & PHMSA \\
\hline $\begin{array}{l}\text { Aliso } \\
\text { Canyon }\end{array}$ & Los Angeles & $\mathrm{CA}$ & $\begin{array}{l}\text { Southern } \\
\text { California Gas } \\
\text { Company }\end{array}$ & $1 / 17 / 1994$ & $\begin{array}{l}\text { Storage well damaged- } \\
\text { crushed. Supply of gas from } \\
\text { Aliso Canyon interrupted for } \\
\text { five days. }\end{array}$ & $\begin{array}{l}\text { Storage well damaged during } 1994 \text { Northridge } \\
\text { Earthquake. }\end{array}$ & 1,17 & $\begin{array}{l}\text { Evans and } \\
\text { Chadwick, } 2009\end{array}$ \\
\hline $\begin{array}{l}\text { Aliso } \\
\text { Canyon }\end{array}$ & Los Angeles & CA & $\begin{array}{l}\text { Southern } \\
\text { California Gas } \\
\text { Company }\end{array}$ & 2008 & \begin{tabular}{|l|} 
High-pressure gas could \\
migrate to the surface in a \\
manner of hours, according \\
to SoCalGas testimony. \\
\end{tabular} & $\begin{array}{l}\text { Corrosion of storage well casing. Surface } \\
\text { annulus of well Porter } 50 \mathrm{~A} \text { had a pressure of } \\
\text { over } 400 \text { psig. }\end{array}$ & 1,11 & $\begin{array}{l}\text { Evans and } \\
\text { Chadwick, } 2009\end{array}$ \\
\hline $\begin{array}{l}\text { Aliso } \\
\text { Canyon }\end{array}$ & Los Angeles & CA & $\begin{array}{l}\text { Southern } \\
\text { California Gas } \\
\text { Company }\end{array}$ & 2013 & $\begin{array}{l}\text { No evidence of the leaks at } \\
\text { the surface or surface casing. }\end{array}$ & $\begin{array}{l}\text { Two wells were found to have leaks in the } \\
\text { production casing at depths adjacent to the } \\
\text { shallower oil production sands. }\end{array}$ & 1,11 & $\begin{array}{l}\text { Evans and } \\
\text { Chadwick, } 2009\end{array}$ \\
\hline
\end{tabular}


Table B-1 Summary of Documented Events at Depleted Oil and Gas Underground Storage Facilities, Some of Which Have Led to Leakage and/or Failure

\begin{tabular}{|c|c|c|c|c|c|c|c|c|}
\hline Field Name & $\begin{array}{l}\text { County } \\
\text { Name }\end{array}$ & State & $\begin{array}{l}\text { Current } \\
\text { Operator }\end{array}$ & Date & Impacts & Reported Cause & $\begin{array}{l}\text { Failure } \\
\text { Mechanism } \\
\text { ID }\end{array}$ & Source \\
\hline $\begin{array}{l}\text { Aliso } \\
\text { Canyon }\end{array}$ & Los Angeles & CA & $\begin{array}{l}\text { Southern } \\
\text { California Gas } \\
\text { Company }\end{array}$ & $2 / 4 / 2006$ & $\begin{array}{l}\text { No injuries resulted from this } \\
\text { incident. Overpressure was } \\
\text { quickly alleviated, and relief } \\
\text { valve reset. }\end{array}$ & $\begin{array}{l}\text { A relief valve triggered on an underground } \\
\text { storage facility wellhead, spraying petroleum } \\
\text { mist on nearby brush and hillside. An } \\
\text { investigation of this incident determined that } \\
\text { while } 400 \text { barrels were being injected into the } \\
\text { well, excessive backpressure during flowback } \\
\text { occurred, tripping a relief valve, as designed, } \\
\text { when pressure exceeded MAOP. }\end{array}$ & 2 & PHMSA \\
\hline $\begin{array}{l}\text { East } \\
\text { Whittier }\end{array}$ & $\begin{array}{l}\text { East } \\
\text { Whittier }\end{array}$ & CA & $\begin{array}{l}\text { Southern } \\
\text { California Gas } \\
\text { Company } \\
\end{array}$ & $1970 \mathrm{~s}$ & $\begin{array}{l}\text { Gas migrated from original } \\
\text { injection site. }\end{array}$ & $\begin{array}{l}\text { Injected gas produced by another company; } \\
\text { facility finally closed in } 2003 \text {. }\end{array}$ & $4,5,12$ & $\begin{array}{l}\text { Evans and } \\
\text { Chadwick, } 2009\end{array}$ \\
\hline $\begin{array}{l}\text { Honor } \\
\text { Rancho }\end{array}$ & Los Angeles & CA & $\begin{array}{l}\text { Southern } \\
\text { California Gas } \\
\text { Company } \\
\end{array}$ & 1992 & $\begin{array}{l}\text { Storage well damaged- } \\
\text { casing shoe leak. }\end{array}$ & $\begin{array}{l}\text { Well inadvertently sidetracked during repair of } \\
\text { casing shoe leak. }\end{array}$ & 1,11 & $\begin{array}{l}\text { Evans and } \\
\text { Chadwick, } 2009\end{array}$ \\
\hline $\begin{array}{l}\text { Honor } \\
\text { Rancho }\end{array}$ & Los Angeles & CA & $\begin{array}{l}\text { Southern } \\
\text { California Gas } \\
\text { Company }\end{array}$ & 1975-2008 & $\begin{array}{l}\text { Gas migration from Castaic } \\
\text { reservoir to adjacent fields } \\
\text { and then to surface. }\end{array}$ & $\begin{array}{l}\text { Gas migrated laterally to shallower Honor } \\
\text { Rancho and Tapia structures, via faults, and } \\
\text { then to surface, killing oak trees-affected oil } \\
\text { production in nearby producing wells. }\end{array}$ & $\begin{array}{c}1,4,12,13 \\
14\end{array}$ & $\begin{array}{l}\text { Evans and } \\
\text { Chadwick, } 2009\end{array}$ \\
\hline Montebello & Los Angeles & CA & $\begin{array}{l}\text { Southern } \\
\text { California Gas } \\
\text { Company }\end{array}$ & $\begin{array}{l}1950 s- \\
1980 s\end{array}$ & $\begin{array}{l}\text { Storage gas lost over } \\
\text { extended period. In 1980, } \\
\text { found within housing estate } \\
\text { above field-led to } \\
\text { evacuation of families on } \\
\text { many occasions. } \\
\end{array}$ & $\begin{array}{l}\text { Storage gas migrated via old, poorly completed } \\
\text { wells and possibly faults. Injection pressure } \\
\text { higher than original oilfield pressure, causing } \\
\text { fracture and damage to old wells. Injection } \\
\text { ceased 1980; facility closed } 2003 .\end{array}$ & $1,5,14$ & $\begin{array}{l}\text { Evans and } \\
\text { Chadwick, } 2009\end{array}$ \\
\hline $\begin{array}{l}\text { Playa Del } \\
\text { Rey }\end{array}$ & Los Angeles & $\mathrm{CA}$ & $\begin{array}{l}\text { Southern } \\
\text { California Gas } \\
\text { Company } \\
\end{array}$ & $4 / 1 / 2003$ & $\begin{array}{l}25 \text { minute release of gas with } \\
\text { a fine mist of oil. }\end{array}$ & Valve in compressor unit broke. & 2 & $\begin{array}{l}\text { Evans and } \\
\text { Chadwick, } 2009\end{array}$ \\
\hline $\begin{array}{l}\text { Playa Del } \\
\text { Rey }\end{array}$ & Los Angeles & CA & $\begin{array}{l}\text { Southern } \\
\text { California Gas } \\
\text { Company }\end{array}$ & 1940s-2008 & $\begin{array}{l}\text { Migration of large amounts of } \\
\text { stored gas. }\end{array}$ & $\begin{array}{l}\text { Stored gas has migrated from PDR structure into } \\
\text { Venice structure from earliest days, connection } \\
\text { between structures, some fault and well- } \\
\text { related. }\end{array}$ & $1,5,12,14$ & $\begin{array}{l}\text { Evans and } \\
\text { Chadwick, } 2009\end{array}$ \\
\hline
\end{tabular}


Table B-1 Summary of Documented Events at Depleted Oil and Gas Underground Storage Facilities, Some of Which Have Led to Leakage and/or Failure

\begin{tabular}{|c|c|c|c|c|c|c|c|c|}
\hline Field Name & $\begin{array}{l}\text { County } \\
\text { Name }\end{array}$ & State & $\begin{array}{l}\text { Current } \\
\text { Operator }\end{array}$ & Date & Impacts & Reported Cause & $\begin{array}{c}\text { Failure } \\
\text { Mechanism } \\
\text { ID }\end{array}$ & Source \\
\hline Wild Goose & Butte & $\mathrm{CA}$ & $\begin{array}{l}\text { Wild Goose } \\
\text { Storage Inc. }\end{array}$ & 2/28/1999 & Not specified. & $\begin{array}{l}\text { Company had been operating the pipeline for } 6 \\
\text { months at } 1,400 \text { psi. Because the operating } \\
\text { pressure would be increasing in the near future, } \\
\text { the decision was made to block in the wells } \\
\text { allowing the pipeline pressure to increase to its } \\
\text { maximum working pressure. When the pipeline } \\
\text { reached a pressure of } 1,580 \text {, a leak between } \\
\text { two flanges was discovered. }\end{array}$ & 2,5 & PHMSA \\
\hline Fort Morgan & Morgan & $\mathrm{CO}$ & $\begin{array}{l}\text { Colorado } \\
\text { Interstate } \\
\text { Gas Company }\end{array}$ & $10 / 1 / 2006$ & $\begin{array}{l}\text { Gas leak, halting storage } \\
\text { operations, } 13 \text { families } \\
\text { evacuated, no personal } \\
\text { injuries. }\end{array}$ & $\begin{array}{l}\text { Casing leak and completion failure, c. } 650-700 \\
\text { MMcf gas lost. }\end{array}$ & 1 & $\begin{array}{l}\text { Evans and } \\
\text { Chadwick, } 2009\end{array}$ \\
\hline Latigo & Arapahoe & $\mathrm{CO}$ & $\begin{array}{l}\text { Colorado } \\
\text { Interstate } \\
\text { Gas Company }\end{array}$ & $7 / 18 / 2015$ & $\begin{array}{l}\text { The instrument air dryer has } \\
\text { been repaired, and the } \\
\text { facility was successfully } \\
\text { placed back into service. }\end{array}$ & $\begin{array}{l}\text { A solenoid valve on the tower switch valve } \\
\text { failed, rendering the air dryer inoperable. This } \\
\text { allowed water to enter the emergency } \\
\text { shutdown device (ESD) system, causing the ESD } \\
\text { vent valve to activate (the water interfered with } \\
\text { the ESD's pneumatic operation). Gas was } \\
\text { released through a 6-in. vent stack into the } \\
\text { atmosphere. }\end{array}$ & 2,5 & PHMSA \\
\hline Latigo & Arapahoe & $\mathrm{CO}$ & $\begin{array}{l}\text { Colorado } \\
\text { Interstate } \\
\text { Gas Company }\end{array}$ & $1 / 2 / 2016$ & $\begin{array}{l}\text { The station was shut in and } \\
\text { isolated; a new air dryer was } \\
\text { installed in the air supply } \\
\text { system; Latigo Station shut in } \\
\text { was terminated 10:00, } \\
01 / 07 / 2016 \text {. }\end{array}$ & $\begin{array}{l}\text { 02:53, CIG Totem Station noticed pressure } \\
\text { change at Latigo Station and called out } \\
\text { technicians to respond; CIG gas control also } \\
\text { noticed pressure change; 03:24, technicians } \\
\text { arrived at Latigo Station and confirmed two } \\
\text { 6-in. vent valves were releasing natural gas. }\end{array}$ & 2 & PHMSA \\
\hline Young & Morgan & $\mathrm{CO}$ & $\begin{array}{l}\text { Colorado } \\
\text { Interstate } \\
\text { Gas Company }\end{array}$ & 6/16/1995 & $\begin{array}{l}\text { The gas ignited and burned } \\
\text { an employee who was } \\
\text { attempting to stop the flow } \\
\text { of gas by closing the } 16 \text {-in. } \\
\text { valve. }\end{array}$ & $\begin{array}{l}\text { Gas escaped from the body cavity vent of a } 16- \\
\text { in., ANSI class } 900 \text { ball valve as the valve was } \\
\text { being opened during routine maintenance. }\end{array}$ & 2,11 & PHMSA \\
\hline Young & Morgan & $\mathrm{CO}$ & $\begin{array}{l}\text { Colorado } \\
\text { Interstate } \\
\text { Gas Company }\end{array}$ & 9/15/2013 & $\begin{array}{l}\text { Force majeure declared; } \\
\text { affected customers included } \\
\text { Public Service Company of } \\
\text { Colorado and Colorado } \\
\text { Springs Utilities. }\end{array}$ & $\begin{array}{l}\text { Heavy rains and flooding exposed Young's Line } \\
\text { No. 59A. }\end{array}$ & 2,4 & FERC \\
\hline
\end{tabular}


Table B-1 Summary of Documented Events at Depleted Oil and Gas Underground Storage Facilities, Some of Which Have Led to Leakage and/or Failure

\begin{tabular}{|c|c|c|c|c|c|c|c|c|}
\hline Field Name & $\begin{array}{l}\text { County } \\
\text { Name }\end{array}$ & State & $\begin{array}{l}\text { Current } \\
\text { Operator }\end{array}$ & Date & Impacts & Reported Cause & $\begin{array}{l}\text { Failure } \\
\text { Mechanism } \\
\text { ID }\end{array}$ & Source \\
\hline Tilden & St. Clair & IL & $\begin{array}{l}\text { Ameren } \\
\text { Illinois }\end{array}$ & $3 / 29 / 1987$ & $\begin{array}{l}\text { Three Illinois Power } \\
\text { observation wells completed } \\
\text { in the abandoned mine were } \\
\text { used to vent the escaping gas } \\
\text { to atmosphere within three } \\
\text { hours to control the pressure } \\
\text { in the abandoned mine. } \\
\text { Numerous attempts to pump } \\
\text { fluid down the well failed to } \\
\text { kill the well and stop the flow } \\
\text { of gas. }\end{array}$ & $\begin{array}{l}\text { Subsidence in a coal mine abandoned in } 1948 \\
\text { caused a leak in the IPC \#2 gas storage well in } \\
\text { Illinois Power's Tilden gas storage field. As a } \\
\text { result of this subsidence, the } 51 / 2 \text {-in. o.d. } \\
\text { production casing and } 85 / 8 \text {-in. o.d. mine casing } \\
\text { were damaged and gas escaped into the } \\
\text { abandoned coal mine. }\end{array}$ & $1,12,15$ & PHMSA \\
\hline Cunningham & Pratt & KS & $\begin{array}{l}\text { Northern } \\
\text { Natural Gas } \\
\text { Company }\end{array}$ & $10 / 1 / 2002$ & Not specified. & $\begin{array}{l}\text { Gas release occurred when the meter run drip } \\
\text { at storage well } \# 36-12 \text { ruptured. Apparent } \\
\text { cause of the rupture is internal corrosion on the } \\
\text { bottom of the } 20 \text { in. diameter drip barrel. }\end{array}$ & 2 & PHMSA \\
\hline Cunningham & Pratt & KS & $\begin{array}{l}\text { Northern } \\
\text { Natural Gas } \\
\text { Company }\end{array}$ & $5 / 24 / 2008$ & $\begin{array}{l}\text { There were no injuries, fire, } \\
\text { or blowing gas associated } \\
\text { with this event; however, it } \\
\text { was reported, as it was } \\
\text { deemed as significant and it } \\
\text { is likely that repair cost will } \\
\text { exceed the } \$ 50,000 \text { reporting } \\
\text { threshold. }\end{array}$ & $\begin{array}{l}\text { Facilities in the Cunningham Storage field were } \\
\text { struck by tornado activity. The re-compressor } \\
\text { building at well \#345 was heavily damaged by } \\
\text { wind. This site is located west of the liquids } \\
\text { plant-south of highway 54, Pratt county, Kansas. } \\
\text { In addition, minor damage was incurred at ob- } \\
\text { well } 26-41 \text { which resulted in a minor leakage of } \\
\text { gas due to lubricator tubing being damaged. } \\
\text { Personnel were able to shut in the piping and } \\
\text { stop the leak upon discovery. }\end{array}$ & 2 & PHMSA \\
\hline $\begin{array}{l}\text { South } \\
\text { Welda }\end{array}$ & Anderson & KS & $\begin{array}{l}\text { Southern Star } \\
\text { Central Gas } \\
\text { Pipeline }\end{array}$ & $8 / 15 / 2008$ & $\begin{array}{l}\text { It was determined that the } \\
\text { primary cause of the rupture } \\
\text { was due to internal metal loss } \\
\text { resulting from carbonic acid } \\
\text { corrosion. }\end{array}$ & $\begin{array}{l}\text { At 3:10 am, gas control shut gates at Welda } \\
\text { Station to isolate South Welda storage field } \\
\text { from the rest of Southern Stars system. At } 4: 15 \\
\text { am, gates were shut in the field to isolate this } \\
\text { section of the line from the rest of the field and } \\
\text { the line blew down. }\end{array}$ & 2 & PHMSA \\
\hline
\end{tabular}


Table B-1 Summary of Documented Events at Depleted Oil and Gas Underground Storage Facilities, Some of Which Have Led to Leakage and/or Failure

\begin{tabular}{|c|c|c|c|c|c|c|c|c|}
\hline Field Name & $\begin{array}{l}\text { County } \\
\text { Name }\end{array}$ & State & $\begin{array}{l}\text { Current } \\
\text { Operator }\end{array}$ & Date & Impacts & Reported Cause & $\begin{array}{l}\text { Failure } \\
\text { Mechanism } \\
\text { ID }\end{array}$ & Source \\
\hline $\begin{array}{l}\text { Borchers } \\
\text { North }\end{array}$ & Meade & KS & $\begin{array}{l}\text { Southwest } \\
\text { Gas Storage } \\
\text { Company }\end{array}$ & $5 / 29 / 2011$ & Not specified. & $\begin{array}{l}\text { Panhandle Eastern Pipe Line Company received } \\
\text { a call from a retired employee reporting } \\
\text { blowing gas at the Borchers Storage field. A } \\
\text { PEPL employee was at the field and isolated the } \\
\text { affected line segment within } 23 \text { minutes. Visual } \\
\text { observation of the failed pipe segment indicates } \\
\text { internal wall loss due to corrosion for } 5 \text { feet in } \\
\text { the vicinity of the fracture immediately } \\
\text { downstream of a 4-in. to } 6 \text {-in. reducer, in a low } \\
\text { point of the pipe. }\end{array}$ & 2 & PHMSA \\
\hline $\begin{array}{l}\text { Hawesville } \\
\mathrm{N} \mathrm{W}\end{array}$ & Hancock & KY & $\begin{array}{l}\text { Atmos Energy } \\
\text { Corporation }\end{array}$ & $6 / 1 / 1992$ & $\begin{array}{l}\text { The gas ignited causing driver } \\
\text { to sustain burns. }\end{array}$ & $\begin{array}{l}\text { Underground gas storage wellhead } 3 / 4 \text {-in. line } \\
\text { struck by a tractor causing a nipple to break and } \\
\text { release gas. }\end{array}$ & 2,10 & PHMSA \\
\hline Hanson & Hopkins & KY & $\begin{array}{l}\text { Texas Gas } \\
\text { Transmission } \\
\text { Corporation }\end{array}$ & 4/24/2011 & Not specified. & $\begin{array}{l}\text { In order to increase the injections into our } \\
\text { Hanson storage field, the gas controller } \\
\text { increased the turbine speed to increase } \\
\text { pressures on the discharge of Slaughters toward } \\
\text { the Hanson storage field. (The Hanson field is } 8 \\
\text { miles from the station on the storage lateral } \\
\text { line.) The gas controller received a high alarm at } \\
\text { the Glenville relief valve. The gas controller } \\
\text { initiated an engine shutdown at Slaughters } \\
\text { Station and shut off the relief valve. }\end{array}$ & 2,5 & PHMSA \\
\hline $\begin{array}{l}\text { West } \\
\text { Greenville }\end{array}$ & Muhlenberg & KY & $\begin{array}{l}\text { Texas Gas } \\
\text { Transmission } \\
\text { Corporation }\end{array}$ & $4 / 1 / 1980$ & $\begin{array}{l}\text { Gas leak and fire, } 2 \text { people } \\
\text { injured ( } 3^{\text {rd }} \text { degree burns). }\end{array}$ & $\begin{array}{l}\text { Tubing failure-slipped and dislodged packer } \\
\text { causing well blow out. 29,000 MMcf gas lost. } \\
\text { Well killed and plugged. Major fire destroyed } \\
\text { vehicles and rig. }\end{array}$ & 1 & $\begin{array}{l}\text { Evans and } \\
\text { Chadwick, } 2009\end{array}$ \\
\hline Bear Creek & Bienville & LA & $\begin{array}{l}\text { Bear Creek } \\
\text { Storage } \\
\text { Company }\end{array}$ & $11 / 29 / 1988$ & Not specified. & Not available. & 18 & PHMSA \\
\hline Bear Creek & Bienville & LA & $\begin{array}{l}\text { Bear Creek } \\
\text { Storage } \\
\text { Company }\end{array}$ & $5 / 11 / 2003$ & Not specified. & $\begin{array}{l}\text { A fire and explosion occurred in the building for } \\
\text { Compressor Unit 1a at the Bear Creek storage } \\
\text { facility. Upon investigation, it was discovered } \\
\text { that the gasket had failed on the discharge } \\
\text { bottle, for Unit 1a, Compressor no.7, resulting in } \\
\text { the incident. }\end{array}$ & 2 & PHMSA \\
\hline
\end{tabular}


Table B-1 Summary of Documented Events at Depleted Oil and Gas Underground Storage Facilities, Some of Which Have Led to Leakage and/or Failure

\begin{tabular}{|c|c|c|c|c|c|c|c|c|}
\hline Field Name & $\begin{array}{c}\text { County } \\
\text { Name }\end{array}$ & State & $\begin{array}{l}\text { Current } \\
\text { Operator }\end{array}$ & Date & Impacts & Reported Cause & $\begin{array}{l}\text { Failure } \\
\text { Mechanism } \\
\text { ID }\end{array}$ & Source \\
\hline Bear Creek & Bienville & LA & $\begin{array}{l}\text { Bear Creek } \\
\text { Storage } \\
\text { Company }\end{array}$ & $11 / 9 / 2015$ & $\begin{array}{l}\text { Repair performed by } \\
\text { replacing a segment of pipe. } \\
\text { Pipeline returned to service } \\
\text { on } 11 / 20 / 2015 \text {. }\end{array}$ & $\begin{array}{l}\text { Contractor was working on row and discovered } \\
\text { bubbles coming up in mud and high-pressure air } \\
\text { coming from ground. Contractor contacted Bear } \\
\text { Creek storage employee. Employee arrived with } \\
\text { gas detector and determined that a gas release } \\
\text { was evident in a creek coming through matting. }\end{array}$ & 2 & PHMSA \\
\hline $\begin{array}{l}\text { Bistineau } \\
\text { Gas S }\end{array}$ & Bienville & LA & $\begin{array}{l}\text { Gulf South } \\
\text { Pipeline }\end{array}$ & $10 / 11 / 2015$ & Not specified. & $\begin{array}{l}\text { Gulf South experienced a failure on its index } \\
901-6 \text { lateral line in Bienville parish, LA, near } \\
\text { Ringgold. The root cause of the event appears } \\
\text { to be internal corrosion. }\end{array}$ & 2 & PHMSA \\
\hline Epps & East Carroll & LA & $\begin{array}{l}\text { Trunkline Gas } \\
\text { Company }\end{array}$ & $\begin{array}{c}1980 s- \\
1990 s\end{array}$ & $\begin{array}{l}\text { Injected gas produced } \\
\text { elsewhere in structure-from } \\
\text { same reservoir. }\end{array}$ & $\begin{array}{l}\text { Gas migrate away from injection footprint- } \\
\text { connection between traps. Facility remained } \\
\text { operational. }\end{array}$ & $4,5,12$ & $\begin{array}{l}\text { Evans and } \\
\text { Chadwick, } 2009\end{array}$ \\
\hline $\begin{array}{l}\text { Lincoln- } \\
\text { Freeman }\end{array}$ & Clare & $\mathrm{Ml}$ & $\begin{array}{l}\text { Anr Pipeline } \\
\text { Company }\end{array}$ & 2/27/1985 & Not specified. & $\begin{array}{l}\text { Part 3-2 in. blow down approx. } 12 \text { in. upstream } \\
\text { of failed valve had been opened to clear } \\
\text { hydrates from } 4 \text { in. lateral. Failed valve had } \\
\text { been closed prior to opening } 2 \text {-in. blow down. } \\
\text { After approx. } 1 \text { minute of blowing, valve failed, } \\
\text { blowing dirt out of ground. When additional dirt } \\
\text { was removed to determine what had failed, a } \\
\text { frost ball was observed below existing frost line, } \\
\text { indicating prior leakage. }\end{array}$ & 2 & PHMSA \\
\hline $\begin{array}{l}\text { Lincoln- } \\
\text { Freeman }\end{array}$ & Clare & $\mathrm{Ml}$ & $\begin{array}{l}\text { Anr Pipeline } \\
\text { Company }\end{array}$ & $5 / 31 / 1985$ & Not specified. & $\begin{array}{l}\text { During routine surveillance, observed sand } \\
\text { humped up and blowing in well leak located } \\
\text { approx. } 250 \mathrm{ft} \text { south of well. Line coated with \#7 } \\
\text { wax wrapper. Replaced approx. } 8 \mathrm{ft} \text { of pipe and } \\
\text { coated with tapecoat \#20. }\end{array}$ & 1,2 & PHMSA \\
\hline Reed City & Osceola & MI & $\begin{array}{l}\text { Anr Pipeline } \\
\text { Company }\end{array}$ & $2 / 21 / 2008$ & $\begin{array}{l}\text { Upon determining the leak } \\
\text { location, a } 50 \text {-foot segment } \\
\text { was removed and replaced. }\end{array}$ & $\begin{array}{l}\text { This event occurred at ANR Pipeline Company's } \\
\text { Reed City compressor station, which is } \\
\text { associated with the Reed City and Loreed gas } \\
\text { storage fields. The fire, which resulted in some } \\
\text { damage to the station electrical system, was } \\
\text { immediately contained and extinguished by } \\
\text { station personnel. }\end{array}$ & 2 & PHMSA \\
\hline
\end{tabular}


Table B-1 Summary of Documented Events at Depleted Oil and Gas Underground Storage Facilities, Some of Which Have Led to Leakage and/or Failure

\begin{tabular}{|c|c|c|c|c|c|c|c|c|}
\hline Field Name & $\begin{array}{l}\text { County } \\
\text { Name }\end{array}$ & State & $\begin{array}{l}\text { Current } \\
\text { Operator }\end{array}$ & Date & Impacts & Reported Cause & $\begin{array}{l}\text { Failure } \\
\text { Mechanism } \\
\text { ID }\end{array}$ & Source \\
\hline Reed City & Osceola & $\mathrm{MI}$ & $\begin{array}{l}\text { Anr Pipeline } \\
\text { Company }\end{array}$ & 9/19/1997 & Not specified. & $\begin{array}{l}\text { Crevice in long seam located on bottom allowed } \\
\text { corrosion products to accumulate causing } \\
\text { pitting and for pits to link up. }\end{array}$ & 2 & PHMSA \\
\hline $\begin{array}{l}\text { Bluewater } \\
\text { Gas S }\end{array}$ & Kalkaska & $\mathrm{MI}$ & $\begin{array}{l}\text { Bluewater } \\
\text { Gas Storage } \\
\text { LLC }\end{array}$ & $6 / 3 / 2014$ & $\begin{array}{l}\text { The line is now available for } \\
\text { service. }\end{array}$ & $\begin{array}{l}\text { Approximately 3,964 Mcf were released when a } \\
\text { third-party contractor hit and ruptured a } 20 \text {-in. } \\
\text { transmission pipeline. Bluewater operators } \\
\text { observed the line pressure dropping and } \\
\text { isolated the segment of pipeline. The segment } \\
\text { was replaced and excavation was back-filled. }\end{array}$ & 2 & PHMSA \\
\hline $\begin{array}{l}\text { Bluewater } \\
\text { Gas S }\end{array}$ & Kalkaska & $\mathrm{MI}$ & $\begin{array}{l}\text { Bluewater } \\
\text { Gas Storage } \\
\text { LLC }\end{array}$ & $6 / 7 / 2014$ & $\begin{array}{l}\text { As the Vector station was } \\
\text { being pressurized, the heat of } \\
\text { compression combined with } \\
\text { the residual air increased the } \\
\text { temperature of the gas to } \\
\text { auto-ignite. The subsequent } \\
\text { ignition of the flammable gas } \\
\text { resulted in a } \\
\text { detonation/over-pressure } \\
\text { inside the pipe. }\end{array}$ & $\begin{array}{l}\text { Approximately 2,484 Mcf of natural gas were } \\
\text { released due to a rupture of underground } \\
\text { compressor station piping; while purging. } \\
\text { Bluewater Gas Storage, LLC, operators remotely } \\
\text { shut-in the station. }\end{array}$ & 2,11 & PHMSA \\
\hline $\begin{array}{l}\text { Bluewater } \\
\text { Gas S }\end{array}$ & St. Clair & MI & $\begin{array}{l}\text { Bluewater } \\
\text { Gas Storage } \\
\text { LLC }\end{array}$ & $1 / 12 / 2011$ & $\begin{array}{l}\text { The entire JT plant operation } \\
\text { has been moved to a safer } \\
\text { location, and all existing } \\
\text { equipment was visually } \\
\text { inspected internally and } \\
\text { externally and was deemed } \\
\text { safe to put back into } \\
\text { operation. }\end{array}$ & $\begin{array}{l}\text { During withdrawal, the gas has to run through a } \\
\text { Joule-Thomson (JT) plant in order to lower the } \\
\text { Btu content of the gas, but also to recover } \\
\text { natural gas liquids from the gas stream. The JT } \\
\text { unit was the location of the incident on } \\
1 / 12 / 11 \text {. There was a release of gas, an } \\
\text { explosion, and a fire in the JT plant. The result } \\
\text { of the gas release was a large explosion and fire. }\end{array}$ & 2 & PHMSA \\
\hline $\begin{array}{l}\text { Cranberry } \\
\text { Lake }\end{array}$ & Clare & $\mathrm{MI}$ & $\begin{array}{l}\text { Consumers } \\
\text { Energy } \\
\text { Company }\end{array}$ & $5 / 15 / 2015$ & $\begin{array}{l}\text { A 1-ft section of the pipeline } \\
\text { was cut out and a pinhole } \\
\text { leak discovered. Preliminary } \\
\text { analysis identified corrosion } \\
\text { as a possible leak source. } \\
\text { Approximate gas loss of } 3.6 \\
\text { MMcf. }\end{array}$ & $\begin{array}{l}\text { A Consumers Energy (CE) employee installing } \\
\text { pipeline markers at the Cranberry storage field } \\
\text { observed bubbling from a standing water } \\
\text { puddle and a frost ball in an area above lateral } \\
60 \text { west between wells c } 270 \text { and c } 367 \text {. }\end{array}$ & 2 & PHMSA \\
\hline
\end{tabular}


Table B-1 Summary of Documented Events at Depleted Oil and Gas Underground Storage Facilities, Some of Which Have Led to Leakage and/or Failure

\begin{tabular}{|c|c|c|c|c|c|c|c|c|}
\hline Field Name & $\begin{array}{l}\text { County } \\
\text { Name }\end{array}$ & State & $\begin{array}{l}\text { Current } \\
\text { Operator }\end{array}$ & Date & Impacts & Reported Cause & $\begin{array}{c}\text { Failure } \\
\text { Mechanism } \\
\text { ID }\end{array}$ & Source \\
\hline $\begin{array}{l}\text { Cranberry } \\
\text { Lake }\end{array}$ & Clare & MI & $\begin{array}{l}\text { Consumers } \\
\text { Energy } \\
\text { Company }\end{array}$ & $10 / 25 / 2015$ & \begin{tabular}{|l|} 
A 4 -ft section of pipeline was \\
cut out and an oval hole \\
approximately . $25 \times .50$ was \\
discovered. The leak was \\
visually examined and \\
preliminary analysis identified \\
corrosion as a possible leak \\
source. Gas loss of \\
approximately 37 MMcf.
\end{tabular} & $\begin{array}{l}\text { Consumers Energy gas control was notified by a } \\
\text { landowner of a possible gas leak at the } \\
\text { cranberry storage field. A gas system mechanic } \\
\text { identified blowing gas on lateral } 60 \text { west. The } \\
\text { leak location was approximately } 1,750 \text { feet } \\
\text { north of well } 367 \text {. }\end{array}$ & 2 & PHMSA \\
\hline Overisel & Allegan & MI & $\begin{array}{l}\text { Consumers } \\
\text { Energy } \\
\text { Company }\end{array}$ & $10 / 8 / 2007$ & $\begin{array}{l}\text { The line ruptured, ignited, } \\
\text { and was shut in by storage } \\
\text { field personnel by closing } \\
\text { system valves. The system } \\
\text { was shut in and the fire was } \\
\text { extinguished in } 27 \text { minutes } \\
\text { from the time of rupture. }\end{array}$ & $\begin{array}{l}\text { The pipeline failure occurred on a } 12 \text {-in. storage } \\
\text { field line operating in a class } 1 \text { area and was in a } \\
\text { normal operating position at the time of the } \\
\text { failure. The pipeline was a section of the main } \\
\text { line between the compressor station and the } \\
\text { storage field. }\end{array}$ & 2 & PHMSA \\
\hline Overisel & Allegan & MI & $\begin{array}{l}\text { Consumers } \\
\text { Energy } \\
\text { Company }\end{array}$ & $3 / 15 / 2014$ & $\begin{array}{l}\text { The lateral currently remains } \\
\text { out of service until } \\
\text { investigation and } \\
\text { remediation has been } \\
\text { completed. A telephonic } \\
\text { report was initially filed with } \\
\text { National Response Center } \\
\text { (NRC) due to a potential for } \\
\text { gas losses in excess of } 3 \\
\text { MMcf (million cubic feet). }\end{array}$ & $\begin{array}{l}\text { At approximately 9:45 am on March } 15,2014 \text {, } \\
\text { near well o-119 at Overisel storage field in } \\
\text { Hamilton, MI, a nearby property owner } \\
\text { reported a suspected natural gas leak. } \\
\text { Consumers Energy crews arrived on site and } \\
\text { discovered a natural gas leak on lateral \#6, } \\
\text { approximately } 90 \text { yards from well o-119. } \\
\text { Lateral \#6 was isolated by closing all valves } \\
\text { affecting gas flow to the lateral. }\end{array}$ & 2 & PHMSA \\
\hline Columbus & $\begin{array}{l}\text { St. Clair } \\
\text { County }\end{array}$ & MI & $\begin{array}{l}\text { Michigan } \\
\text { Consolidated } \\
\text { Gas Company }\end{array}$ & 6/1/1993 & $\begin{array}{l}\text { Explosion, } 1 \text { injured, several } \\
\text { homes evacuated (c. 15-20 } \\
\text { people) }\end{array}$ & Not available. & 18 & $\begin{array}{l}\text { Evans and } \\
\text { Chadwick, } 2009\end{array}$ \\
\hline $\begin{array}{l}\text { Bluewater } \\
\text { Gas S }\end{array}$ & St. Clair & MI & $\begin{array}{l}\text { Vector } \\
\text { Pipeline }\end{array}$ & $6 / 7 / 2014$ & $\begin{array}{l}\text { Restriction to zero of all } \\
\text { receipts and deliveries at the } \\
\text { Lenox Interconnection with } \\
\text { Bluewater Gas Storage; did } \\
\text { not identify affected } \\
\text { customers. }\end{array}$ & Not provided. & 18 & FERC \\
\hline
\end{tabular}


Table B-1 Summary of Documented Events at Depleted Oil and Gas Underground Storage Facilities, Some of Which Have Led to Leakage and/or Failure

\begin{tabular}{|c|c|c|c|c|c|c|c|c|}
\hline Field Name & $\begin{array}{c}\text { County } \\
\text { Name }\end{array}$ & State & $\begin{array}{l}\text { Current } \\
\text { Operator }\end{array}$ & Date & Impacts & Reported Cause & $\begin{array}{c}\text { Failure } \\
\text { Mechanism } \\
\text { ID }\end{array}$ & Source \\
\hline Baker & Fallon & MT & $\begin{array}{l}\text { Williston } \\
\text { Basin } \\
\text { Interstate } \\
\text { Pipeline }\end{array}$ & $3 / 16 / 2011$ & $\begin{array}{l}\text { It was finally determined } \\
\text { through modeling that the } \\
\text { gas loss did exceed } 3 \mathrm{MMcf} \\
\text { and is reported in this } \\
\text { incident report as } 3.6 \mathrm{MMcf} \text {. } \\
\text { The well line was shut off } \\
\text { until the area dried out and } \\
\text { the line was repaired. }\end{array}$ & $\begin{array}{l}\text { This incident occurred at a } 3 \text {-in. storage well line } \\
\text { span over the south fork of Cabin Creek on the } \\
\text { evening of March 16th. The } 3 \text {-in. line failed due } \\
\text { to external forces from water, ice, and debris } \\
\text { from a localized spring thaw/flood event. }\end{array}$ & 2 & PHMSA \\
\hline Huntsman & Cheyenne & NE & $\begin{array}{l}\text { Kinder } \\
\text { Morgan } \\
\text { Interstate } \\
\text { Gas Trnamis } \\
\end{array}$ & $\begin{array}{c}\text { Not } \\
\text { available }\end{array}$ & $\begin{array}{l}\text { Gas migrated laterally from } \\
\text { injection footprint out of } \\
\text { structure and into adjoining } \\
\text { field. }\end{array}$ & $\begin{array}{l}\text { Gas migrated across bounding fault previously } \\
\text { thought to be gas-tight. Migrated gas cycled } \\
\text { several times. }\end{array}$ & $4,5,12,14$ & $\begin{array}{l}\text { Evans and } \\
\text { Chadwick, } 2009\end{array}$ \\
\hline $\begin{array}{l}\text { Washington } \\
\text { Ranch }\end{array}$ & Eddy & NM & $\begin{array}{l}\text { El Paso } \\
\text { Natural Gas } \\
\text { Company }\end{array}$ & $12 / 18 / 1990$ & Not specified. & $\begin{array}{l}\text { A 1/2-in. diameter glycol hose (fuel line) to the } \\
\text { dehydrator on the Stanolind gas com. \#1a gas } \\
\text { well broke and ignited, setting fire to the } \\
\text { dehydrator. The gas well was shut-in and the } \\
\text { fire was dying out when the Navajo Dam } \\
\text { volunteer fire department arrived at the scene. }\end{array}$ & 2 & PHMSA \\
\hline $\begin{array}{l}\text { Limestone } \\
\text { Stor }\end{array}$ & Cattaraugus & NY & $\begin{array}{l}\text { National Fuel } \\
\text { Gas Supply } \\
\text { Corp }\end{array}$ & $6 / 22 / 2013$ & $\begin{array}{l}\text { Facility shut down; did not } \\
\text { identify affected customers. }\end{array}$ & Pipe wall rupture. & 2 & FERC \\
\hline $\begin{array}{l}\text { Beech Hill } \\
\text { Stor }\end{array}$ & Allegany & NY & $\begin{array}{l}\text { National Fuel } \\
\text { Gas Supply } \\
\text { Corporation }\end{array}$ & $3 / 5 / 2015$ & $\begin{array}{l}\text { The regulator was replaced, } \\
\text { and the station was back in } \\
\text { service at 15:50 on March } 6 .\end{array}$ & $\begin{array}{l}\text { Beech Hill compressor station starting gas } \\
\text { regulator malfunctioned, raising the } \\
\text { downstream pressure above the } 175 \text { psig set } \\
\text { point to } 341 \text { psig. The over-pressurization } \\
\text { caused the rupture disc rated at } 311 \text { psig to } \\
\text { burst. }\end{array}$ & 2 & PHMSA \\
\hline $\begin{array}{l}\text { Colden } \\
\text { Storage }\end{array}$ & Erie & NY & $\begin{array}{l}\text { National Fuel } \\
\text { Gas Supply } \\
\text { Corporation }\end{array}$ & 9/7/1994 & $\begin{array}{l}\text { Changes to property damage: } \\
\text { total of } \$ 111,135.00, \text { with gas } \\
\text { lost amount }=\$ 44,460 \\
\text { property damage }=\$ 10,066, \\
\text { and replacement cost }= \\
\$ 56,429 .\end{array}$ & $\begin{array}{l}\text { On 09/07/1994, at 4:36 pm, line c- } 46 \text { ruptured } \\
\text { and ignited. Line is storage pipeline for Colden } \\
\text { storage. Storage was on injection at } 897 \text { psig. } \\
\text { National Fuel notified at 4:40 pm responded, } \\
\text { shutting valve tz56, closing line down. Fire out } \\
\text { at 5:18 pm. }\end{array}$ & 2 & PHMSA \\
\hline
\end{tabular}


Table B-1 Summary of Documented Events at Depleted Oil and Gas Underground Storage Facilities, Some of Which Have Led to Leakage and/or Failure

\begin{tabular}{|c|c|c|c|c|c|c|c|c|}
\hline Field Name & $\begin{array}{l}\text { County } \\
\text { Name }\end{array}$ & State & $\begin{array}{l}\text { Current } \\
\text { Operator }\end{array}$ & Date & Impacts & Reported Cause & $\begin{array}{c}\text { Failure } \\
\text { Mechanism } \\
\text { ID }\end{array}$ & Source \\
\hline $\begin{array}{l}\text { Limestone } \\
\text { Stora }\end{array}$ & Cattaraugus & NY & $\begin{array}{l}\text { National Fuel } \\
\text { Gas Supply } \\
\text { Corporation }\end{array}$ & $6 / 22 / 2013$ & $\begin{array}{l}\text { No personal injuries or } \\
\text { property damage beyond the } \\
\text { pipeline resulted from the } \\
\text { incident. }\end{array}$ & $\begin{array}{l}\text { An alarm on the SCADA system for compressor } \\
\text { shutdown at the limestone storage field station. } \\
\text { Storage field was potentially experiencing an } \\
\text { abnormal decline in pressure, and a rupture was } \\
\text { discovered at well line fw } 7013 \text {, which was } \\
\text { isolated and made safe. }\end{array}$ & 2 & PHMSA \\
\hline Holmes & Holmes & $\mathrm{OH}$ & $\begin{array}{l}\text { Columbia Gas } \\
\text { Transmission } \\
\text { LLC }\end{array}$ & $8 / 22 / 2015$ & $\begin{array}{l}\text { Facility shutdown; did not } \\
\text { identify affected customers. }\end{array}$ & Corrosion failure & 2,4 & FERC \\
\hline Guernsey & Guernsey & $\mathrm{OH}$ & $\begin{array}{l}\text { Columbia Gas } \\
\text { Transmission } \\
\text { LLC }\end{array}$ & $7 / 12 / 2011$ & Not specified. & $\begin{array}{l}\text { Incident occurred on line so-1451, a natural gas } \\
\text { storage field mainline. A metallurgical analysis } \\
\text { performed by an outside consultant determined } \\
\text { that the cause of the incident was internal } \\
\text { corrosion. }\end{array}$ & 2 & PHMSA \\
\hline Holmes & Holmes & $\mathrm{OH}$ & $\begin{array}{l}\text { Columbia Gas } \\
\text { Transmission } \\
\text { LLC }\end{array}$ & $8 / 22 / 2015$ & $\begin{array}{l}\text { Necessary safety measures } \\
\text { were taken to isolate all } \\
\text { wells, storage field lines for } \\
\text { Holmes and Wayne storage } \\
\text { field. The affected storage } \\
\text { line was isolated and material } \\
\text { stopped flowing into } \\
\text { atmosphere in less than an } \\
\text { hour from the time the first } \\
\text { responder arrived on site. }\end{array}$ & $\begin{array}{l}\text { On the morning of August 22, 2015, a drip } \\
\text { installed along line sl-2481 failed leading to an } \\
\text { unintended amount of natural gas (material) to } \\
\text { vent into atmosphere, exceeding the incident } \\
\text { reporting threshold. This pipeline is located } \\
\text { within the Holmes storage field. }\end{array}$ & 2 & PHMSA \\
\hline $\begin{array}{l}\text { Zane } \\
\text { Storage }\end{array}$ & Muskingum & $\mathrm{OH}$ & $\begin{array}{l}\text { Columbia Gas } \\
\text { Transmission } \\
\text { LLC }\end{array}$ & 7/1/1995 & $\begin{array}{l}\text { No personal injuries were } \\
\text { sustained, and damage to the } \\
\text { facility was estimated at } \\
\text { approximately } \$ 285,000 \text {. }\end{array}$ & $\begin{array}{l}\text { On July } 1,1995 \text {, a fire occurred at an } \\
\text { unattended National Gas \& Oil Corporation } \\
\text { storage compressor station damaging a metal } \\
\text { building and engine/compressor. The } \\
\text { Emergency Shutdown Device (ESD) was } \\
\text { activated, and the gas fire was extinguished in } \\
\text { approximately } 10 \text { minutes. }\end{array}$ & 2 & PHMSA \\
\hline
\end{tabular}


Table B-1 Summary of Documented Events at Depleted Oil and Gas Underground Storage Facilities, Some of Which Have Led to Leakage and/or Failure

\begin{tabular}{|c|c|c|c|c|c|c|c|c|}
\hline Field Name & $\begin{array}{l}\text { County } \\
\text { Name }\end{array}$ & State & $\begin{array}{l}\text { Current } \\
\text { Operator }\end{array}$ & Date & Impacts & Reported Cause & $\begin{array}{l}\text { Failure } \\
\text { Mechanism } \\
\text { ID }\end{array}$ & Source \\
\hline $\begin{array}{l}\text { Stark- } \\
\text { Summit }\end{array}$ & Stark & $\mathrm{OH}$ & $\begin{array}{l}\text { Dominion } \\
\text { East Ohio }\end{array}$ & $7 / 22 / 2013$ & $\begin{array}{l}\text { Analysis concluded the cause } \\
\text { of the failure was determined } \\
\text { to be internal selective seam } \\
\text { weld corrosion of the low- } \\
\text { frequency electric-resistance } \\
\text { welded seam. }\end{array}$ & $\begin{array}{l}\text { On July } 22,2013, \text { at approximately } 6: 01 \text { am, an } \\
\text { 8-in. storage line operating at } 1,483 \text { psig located } \\
\text { in New Franklin, Ohio, ruptured. At } \\
\text { approximately 6:30 am on July } 22,2013, \\
\text { Dominion arrived on scene and isolated the } \\
\text { section of pipeline that ruptured at } \\
\text { approximately 7:02 am. }\end{array}$ & 2 & PHMSA \\
\hline $\begin{array}{l}\text { Stuart } \\
\text { Storage }\end{array}$ & Hughes & OK & $\begin{array}{l}\text { Enable } \\
\text { Midstream } \\
\text { Partners/ } \\
\text { Enogex }\end{array}$ & 12/10/1998 & $\begin{array}{l}\text { The well was brought back } \\
\text { into control by } 4 \mathrm{pm} \text { the } \\
\text { following day. There were no } \\
\text { fires, no personal injuries, } \\
\text { and no property damage } \\
\text { other than the loss of an } \\
\text { estimated } 7-10 \text { MMcf of gas. }\end{array}$ & $\begin{array}{l}\text { On December 10, 1998, Central Oklahoma Oil } \\
\text { and Gas Corp. (operator) was in the process of } \\
\text { reworking one of its existing underground } \\
\text { natural gas storage wells located in the Stuart } \\
\text { natural gas storage facility in Hughes county, } \\
\text { Oklahoma. }\end{array}$ & 1,2 & PHMSA \\
\hline Wetumka & Hughes & OK & $\begin{array}{l}\text { Enable } \\
\text { Midstream } \\
\text { Partners/ } \\
\text { Enogex }\end{array}$ & $4 / 19 / 2010$ & $\begin{array}{l}\text { The line remained isolated } \\
\text { until repair completed on } \\
\text { May } 5,2010 . \text { Localized } \\
\text { corrosion pitting was } \\
\text { discovered on the internal } \\
\text { wall of the pipe. }\end{array}$ & $\begin{array}{l}\text { Bubbling in a puddle of water that was on the } \\
\text { right of way adjacent to the iw- } 3 \text { well pad. Well } \\
\text { was shut in and the line isolated. }\end{array}$ & 2 & PHMSA \\
\hline Depew & Creek & OK & $\begin{array}{l}\text { Oneok Gas } \\
\text { Storage LLC }\end{array}$ & $1 / 6 / 2014$ & $\begin{array}{l}\text { Natural gas service was } \\
\text { disrupted to } 48 \text { utility } \\
\text { customers in Milfay, and } 13 \\
\text { rural farm tap customers } \\
\text { were also impacted. A new } \\
\text { section of pipe was installed } \\
\text { and the pipeline returned to } \\
\text { service on January } 9,2014 \text {. }\end{array}$ & $\begin{array}{l}\text { The Oneok Gas Transportation (OGT) line a-26 } \\
\text { pipeline failed, and escaping gas ignited } \\
\text { approximately } 1.5 \text { miles south of Milfay, OK, at } \\
1057 \text { hours on January } 6,2014 \text {. }\end{array}$ & 2 & PHMSA \\
\hline
\end{tabular}


Table B-1 Summary of Documented Events at Depleted Oil and Gas Underground Storage Facilities, Some of Which Have Led to Leakage and/or Failure

\begin{tabular}{|c|c|c|c|c|c|c|c|c|}
\hline Field Name & $\begin{array}{l}\text { County } \\
\text { Name }\end{array}$ & State & $\begin{array}{l}\text { Current } \\
\text { Operator }\end{array}$ & Date & Impacts & Reported Cause & $\begin{array}{l}\text { Failure } \\
\text { Mechanism } \\
\text { ID }\end{array}$ & Source \\
\hline Edmond & Logan & $\mathrm{OK}$ & $\begin{array}{l}\text { Oneok Gas } \\
\text { Storage LLC }\end{array}$ & $5 / 24 / 2011$ & $\begin{array}{l}\text { The lines to the launcher and } \\
\text { all four wells were shut in and } \\
\text { blown down by } 1905 \text { hours. } \\
\text { Repairs have been completed } \\
\text { on the launcher, and the } \\
\text { pipeline has been restored to } \\
\text { service. All wells are back in } \\
\text { service, but facility repairs } \\
\text { are ongoing. }\end{array}$ & $\begin{array}{l}\text { An EF- } 5 \text { tornado came through the Oneok Gas } \\
\text { Storage's Edmond storage facility at } \\
\text { approximately } 1655 \text { hours on } 24 \text { May2011. } \\
\text { Oneok personnel verified a leak caused by a } \\
\text { missing vent stack on the f-352 pig launcher } \\
\text { located approximately } 1.5 \text { miles west of the } \\
\text { Edmond Storage compressor station (damage } \\
\text { included missing vent stack and fencing). } \\
\text { Further field investigation revealed other } \\
\text { damage (measurement, cathodic protection, } \\
\text { fencing, pipe guards, corrosion coupon holders, } \\
\text { electric service) at four storage wells (Bridal h-1, } \\
\text { Bridal h-2, Messenbaugh s-1, Messenbaugh s-2). }\end{array}$ & 2 & PHMSA \\
\hline Artemas A & Bedford & PA & $\begin{array}{l}\text { Columbia Gas } \\
\text { Transmission } \\
\text { LLC }\end{array}$ & $7 / 2 / 2000$ & $\begin{array}{l}\text { Preliminary results from the } \\
\text { ongoing investigation indicate } \\
\text { microbiologically influenced } \\
\text { corrosion (mic). }\end{array}$ & $\begin{array}{l}\text { This failure occurred in an isolated area with no } \\
\text { ignition source or fire. The rupture was } \\
\text { contained within one joint of pipe adjacent to } \\
\text { pipeline equipment associated with a storage } \\
\text { well. The force of the rupture destroyed the } \\
\text { well site pipeline equipment. }\end{array}$ & 2 & PHMSA \\
\hline Greenlick & Clinton & PA & $\begin{array}{l}\text { Dominion } \\
\text { Transmission } \\
\text { Inc. }\end{array}$ & $\begin{array}{c}\text { Early } 1988- \\
\text { May } 1989\end{array}$ & $\begin{array}{l}\text { Gas shows in shallow } \\
\text { observation wells during } \\
\text { early 1988; gas found in new } \\
\text { observation well in May } \\
1989 .\end{array}$ & $\begin{array}{l}\text { Not available, but follows the problems with } \\
\text { casing that were reported in } 1985 . \text { Gas in } \\
\text { observation well completed in May } 1989 \text { flowed } \\
1,597 \text { Mcf. }\end{array}$ & 12,18 & $\begin{array}{l}\text { Evans and } \\
\text { Chadwick, } 2009\end{array}$ \\
\hline Greenlick & Clinton & PA & $\begin{array}{l}\text { Dominion } \\
\text { Transmission } \\
\text { Inc. }\end{array}$ & $7 / 17 / 1975$ & $\begin{array}{l}\text { Continuous gas bubbling in } \\
\text { Kettle Creek Lake. Adjacent } \\
\text { water well silts up and leaks } \\
\text { gas. }\end{array}$ & $\begin{array}{l}\text { Investigation revealed the Downs Storage field } \\
\text { initially thought to connect to Tamarack Storage } \\
\text { Field. Found not to be true, and injection caused } \\
\text { over-pressuring of the Downs Storage field. }\end{array}$ & 5,12 & $\begin{array}{l}\text { Evans and } \\
\text { Chadwick, } 2009\end{array}$ \\
\hline $\begin{array}{l}\text { Leidy } \\
\text { Tamarack }\end{array}$ & Potter & PA & $\begin{array}{l}\text { Dominion } \\
\text { Transmission } \\
\text { Inc. }\end{array}$ & $\begin{array}{l}\text { Sept-Oct } \\
2009\end{array}$ & $\begin{array}{l}\text { Gas well fire burned for } \\
\text { number of weeks. No } \\
\text { casualties reported. }\end{array}$ & Not available-under investigation as of 2008. & 18 & $\begin{array}{l}\text { Evans and } \\
\text { Chadwick, } 2009\end{array}$ \\
\hline
\end{tabular}


Table B-1 Summary of Documented Events at Depleted Oil and Gas Underground Storage Facilities, Some of Which Have Led to Leakage and/or Failure

\begin{tabular}{|c|c|c|c|c|c|c|c|c|}
\hline Field Name & $\begin{array}{c}\text { County } \\
\text { Name }\end{array}$ & State & $\begin{array}{l}\text { Current } \\
\text { Operator }\end{array}$ & Date & Impacts & Reported Cause & $\begin{array}{l}\text { Failure } \\
\text { Mechanism } \\
\text { ID }\end{array}$ & Source \\
\hline $\begin{array}{l}\text { Leidy } \\
\text { Tamarack }\end{array}$ & Potter & PA & $\begin{array}{l}\text { Dominion } \\
\text { Transmission } \\
\text { Inc. }\end{array}$ & 8/9/1969 & $\begin{array}{l}\text { Gas migrated from storage, } \\
\text { escaping via Kettle Creek. } \\
\text { High pressure underground } \\
\text { blowout, with gas migrating } \\
\text { to shallow sands, uplifting } \\
\text { and fracturing rocks over } \\
\text { square miles. No explosion, } \\
\text { fire, or casualties. }\end{array}$ & $\begin{array}{l}\text { Gas initially escaped from storage well. Uplifting } \\
\text { and fracturing of rock led to severing of casing } \\
\text { in } 30 \text { other wells and caused extensive surface } \\
\text { blowouts of natural gas in gas wells, water } \\
\text { wells, fractures, and outcrops. Incident took } 6 \\
\text { weeks to bring under control. Estimated 4,000 } \\
\text { MMcf of gas lost. }\end{array}$ & $1,5,12$ & $\begin{array}{l}\text { Evans and } \\
\text { Chadwick, } 2009\end{array}$ \\
\hline Oakford & $\begin{array}{l}\text { Westmorel } \\
\text { and }\end{array}$ & PA & $\begin{array}{l}\text { Dominion } \\
\text { Transmission } \\
\text { Inc. }\end{array}$ & $9 / 30 / 2008$ & $\begin{array}{l}\text { Pipeline was placed back into } \\
\text { service on October } 3,2008 . \\
\text { Report indicates that the } \\
\text { cause of the failure was } \\
\text { internal corrosion (mic). }\end{array}$ & $\begin{array}{l}\text { Stepladder drip on pipeline jp45 in the Oakford } \\
\text { Storage Pool ruptured. The pressure on the } \\
\text { pipeline at the time was 1,179 psig (MAOP = } \\
\text { 1,225 psig). The ruptured segment was isolated } \\
\text { by 5:00 pm. }\end{array}$ & 2 & PHMSA \\
\hline $\begin{array}{l}\text { Belmouth } \\
\text { Storage }\end{array}$ & Elk & PA & $\begin{array}{l}\text { National Fuel } \\
\text { Gas Supply } \\
\text { Corporation }\end{array}$ & $7 / 11 / 1986$ & $\begin{array}{l}\text { All 4-in. pipe has been } \\
\text { replaced. }\end{array}$ & $\begin{array}{l}\text { Two-inch and four-inch pipe was to be laid in } \\
\text { the gathering system of Belmouth Storage Field, } \\
\text { a remote area in Elk County, PA. When tested, a } \\
\text { total of five failures were found. }\end{array}$ & 2 & PHMSA \\
\hline $\begin{array}{l}\text { Summit } \\
\text { Storage }\end{array}$ & Erie & PA & $\begin{array}{l}\text { National Fuel } \\
\text { Gas Supply } \\
\text { Corporation }\end{array}$ & $10 / 12 / 2004$ & Not specified. & $\begin{array}{l}\text { Silhouette minivan struck and damaged a } \\
\text { National Fuel Pipeline valve causing extensive } \\
\text { damage and gas loss. The incident took place in } \\
\text { the National Fuel Summit Storage Field. }\end{array}$ & 2,10 & PHMSA \\
\hline Hebron & Potter & PA & $\begin{array}{l}\text { Tennessee } \\
\text { Gas Pipeline } \\
\text { Company }\end{array}$ & $1 / 23 / 2014$ & Not specified. & $\begin{array}{l}\text { Extremely cold temperatures }\left(0^{\circ} \mathrm{F}\right) \text { froze off } \\
\text { instrumentation/supply equipment for a relief } \\
\text { valve at the Tennessee Gas Pipeline Hebron } \\
\text { Storage Little Acre meter station, causing the } \\
\text { relief valve to activate prematurely. Natural gas } \\
\text { was released through the relief valve's outlet } \\
\text { port. }\end{array}$ & 2 & PHMSA \\
\hline
\end{tabular}


Table B-1 Summary of Documented Events at Depleted Oil and Gas Underground Storage Facilities, Some of Which Have Led to Leakage and/or Failure

\begin{tabular}{|c|c|c|c|c|c|c|c|c|}
\hline Field Name & $\begin{array}{l}\text { County } \\
\text { Name }\end{array}$ & State & $\begin{array}{l}\text { Current } \\
\text { Operator }\end{array}$ & Date & Impacts & Reported Cause & $\begin{array}{l}\text { Failure } \\
\text { Mechanism } \\
\text { ID }\end{array}$ & Source \\
\hline $\begin{array}{l}\text { South } \\
\text { Bryson }\end{array}$ & Jack & TX & $\begin{array}{l}\text { Energy } \\
\text { Transfer Fuel } \\
\text { LP }\end{array}$ & $8 / 19 / 2013$ & $\begin{array}{l}\text { There were no fatalities, } \\
\text { injuries, evacuations, road } \\
\text { closures, explosions, fire, } \\
\text { media interest, spills, or any } \\
\text { response by an emergency } \\
\text { official. All permanent repairs } \\
\text { were completed and the line } \\
\text { was brought back in service } \\
\text { on Oct. } 23,2013 . \\
\end{array}$ & $\begin{array}{l}\text { Rupture on the Simpson Heirs 8-in. lateral in the } \\
\text { Bryson underground storage facility in Jack } \\
\text { County, near Bryson, Texas. The pipeline is an } \\
\text { intrastate natural gas transmission pipeline. }\end{array}$ & 2 & PHMSA \\
\hline $\begin{array}{l}\text { Pottsville } \\
\text { South }\end{array}$ & Hamilton & TX & $\begin{array}{l}\text { Enstor Katy } \\
\text { Storage }\end{array}$ & $12 / 23 / 2014$ & $\begin{array}{l}\text { The total release time was } \\
\text { approximately } 40 \text { seconds } \\
\text { with an estimated release } \\
\text { volume of } 197,000 \text { Scf of } \\
\text { natural gas. }\end{array}$ & $\begin{array}{l}\text { Enstor Katy Gas Storage Facility was on injection } \\
\text { mode using two compressors to inject natural } \\
\text { gas into the reservoir via } 3 \text { storage wells and } 2 \\
\text { compressors. A programmable logic controller } \\
\text { fault caused the facility to ESD, as designed. This } \\
\text { ESD correctly acted to fully block and bleed and } \\
\text { flare-to-vent; however, a control valve on the } \\
\text { vent side failed to open causing an over- } \\
\text { pressure event which relieved via a pressure } \\
\text { relief valve, as designed. }\end{array}$ & 2,4 & PHMSA \\
\hline Hil Lake & Eastland & TX & $\begin{array}{l}\text { Hill Lake Gas } \\
\text { Storage LLC }\end{array}$ & 11/9/1984 & $\begin{array}{l}\text { There were no injuries, fire, } \\
\text { or damage of equipment } \\
\text { other than the pipeline. Six } \\
\text { consumers were out of gas } \\
\text { for } 19 \text { hours, and three } \\
\text { sources of gas were shut out } \\
\text { during repairs. }\end{array}$ & $\begin{array}{l}\text { Leak was located at station } \# 453+15 \text { at the jct. } \\
\text { Ofwt-3036-2".wt } 3036 \text { was hit at by a dozer that } \\
\text { was clearing right of way for the construction of } \\
\text { Pride's refinery. }\end{array}$ & 2 & PHMSA \\
\hline
\end{tabular}


Table B-1 Summary of Documented Events at Depleted Oil and Gas Underground Storage Facilities, Some of Which Have Led to Leakage and/or Failure

\begin{tabular}{|c|c|c|c|c|c|c|c|c|}
\hline Field Name & $\begin{array}{l}\text { County } \\
\text { Name }\end{array}$ & State & $\begin{array}{l}\text { Current } \\
\text { Operator }\end{array}$ & Date & Impacts & Reported Cause & $\begin{array}{c}\text { Failure } \\
\text { Mechanism } \\
\text { ID }\end{array}$ & Source \\
\hline $\begin{array}{l}\text { North } \\
\text { Lansing }\end{array}$ & Harrison & TX & $\begin{array}{l}\text { Natural Gas } \\
\text { Pipeline Co of } \\
\text { America }\end{array}$ & $10 / 12 / 2014$ & $\begin{array}{l}\text { Normal emergency shut- } \\
\text { down (ESD) restoration } \\
\text { process can take up to } 3 \\
\text { hours or more depending on } \\
\text { the circumstances. It took } \\
\text { NGPL approximately } 5 \text { hours } \\
\text { to verify the cause of the ESD } \\
\text { and determine that no } \\
\text { damage existed to any of the } \\
\text { facilities before bringing the } \\
\text { entire station back into } \\
\text { service. }\end{array}$ & $\begin{array}{l}\text { Station ESD was determined to be caused by } \\
\text { lightning storms in the area. The electromagnet } \\
\text { disturbances in the uv and ir range tripped the } \\
\text { heat and light flash sensors at the station } \\
\text { resulting in the ESD. NGPL's North Lansing } \\
\text { Storage Field has a maximum peak-day } \\
\text { withdrawal rate of } 1,240 \text { MMcf per day, and the } \\
\text { Compressor Station no. } 388 \text { near Longview, } \\
\text { Texas is comprised of seven compressor units } \\
\text { totaling } 36,000 \text { hp, two } \mathrm{CO}_{2} \text { extraction plants, } \\
\text { and four dehydrator skids. }\end{array}$ & 4 & PHMSA \\
\hline Loop & Gaines & TX & $\begin{array}{l}\text { Oneok Texas } \\
\text { Gas Storage } \\
\text { LP }\end{array}$ & $5 / 6 / 1993$ & Not specified. & Not available. & 18 & PHMSA \\
\hline Loop & Gaines & TX & $\begin{array}{l}\text { Oneok Texas } \\
\text { Gas Storage } \\
\text { LP }\end{array}$ & $5 / 31 / 1993$ & Not specified. & $\begin{array}{l}\text { 1/2-in. xh pipe nipple (sch } 40 \text { ) broke off at } \\
\text { threads. If metallurgical report differs from } \\
\text { initial findings, a supplemental report will be } \\
\text { submitted. }\end{array}$ & 2 & PHMSA \\
\hline Ripley & Jackson & WV & $\begin{array}{l}\text { Columbia Gas } \\
\text { Transmission } \\
\text { LLC }\end{array}$ & $8 / 18 / 2005$ & $\begin{array}{l}\text { Analysis of the internal } \\
\text { corrosion characteristics will } \\
\text { require destructive } \\
\text { techniques, and therefore } \\
\text { repair costs will exceed } \\
\$ 50 \mathrm{kK} \text {. }\end{array}$ & $\begin{array}{l}\text { A leak was found on line } x 59 \text { w7338 in the } \\
\text { Ripley Storage Field. Upon subsequent } \\
\text { excavation, the leak was identified to be on the } \\
12 \text {-in. barrel of an underslung drip adjacent to } \\
\text { the storage well. }\end{array}$ & 2 & PHMSA \\
\hline Ripley & Jackson & WV & $\begin{array}{l}\text { Columbia Gas } \\
\text { Transmission } \\
\text { LLC }\end{array}$ & $11 / 16 / 2009$ & $\begin{array}{l}\text { No fire was involved in this } \\
\text { event. Failed valve was } \\
\text { removed from the site, and } \\
\text { the storage line was plugged } \\
\text { and capped at both ends. }\end{array}$ & $\begin{array}{l}\text { Gas leak on a well line in Ripley Storage Field. } \\
\text { Valve was isolated to stop the release of gas. } \\
\text { Storage line was isolated, and the leak was } \\
\text { determined to be from a pig valve. }\end{array}$ & 2 & PHMSA \\
\hline
\end{tabular}


Table B-1 Summary of Documented Events at Depleted Oil and Gas Underground Storage Facilities, Some of Which Have Led to Leakage and/or Failure

\begin{tabular}{|c|c|c|c|c|c|c|c|c|}
\hline Field Name & $\begin{array}{l}\text { County } \\
\text { Name }\end{array}$ & State & $\begin{array}{l}\text { Current } \\
\text { Operator }\end{array}$ & Date & Impacts & Reported Cause & $\begin{array}{l}\text { Failure } \\
\text { Mechanism } \\
\text { ID }\end{array}$ & Source \\
\hline Victory A & Marshall & WV & $\begin{array}{l}\text { Columbia Gas } \\
\text { Transmission } \\
\text { LLC }\end{array}$ & 8/23/1999 & $\begin{array}{l}\text { Preliminary assessment of } \\
\text { the damage is } 5-7 \text { acres of } \\
\text { farmland burned, heat } \\
\text { damage to a garage, roof } \\
\text { damage to a mobile home, } \\
\text { and damage to a gravel State } \\
\text { road (fish ridge road). There } \\
\text { were no injuries. }\end{array}$ & $\begin{array}{l}\text { On 8/23/99, } 16 \text {-in. storage line } 29104 \text { ruptured, } \\
\text { with an ensuing fire. }\end{array}$ & 2 & PHMSA \\
\hline Victory A & Marshall & WV & $\begin{array}{l}\text { Columbia Gas } \\
\text { Transmission } \\
\text { LLC } \\
\end{array}$ & $1 / 21 / 2012$ & Not specified. & $\begin{array}{l}\text { Causal factor was the compressed air used in } \\
\text { the pilot air system that is part of the } \\
\text { compressor station ESD system. }\end{array}$ & 4 & PHMSA \\
\hline Bridgeport & Harrison & WV & $\begin{array}{l}\text { Dominion } \\
\text { Transmission } \\
\text { Inc. }\end{array}$ & $7 / 3 / 2005$ & Not specified. & $\begin{array}{l}\text { Lost Creek Storage Field main line failed while } \\
\text { operating in storage injection service. Failure } \\
\text { occurred in an area that has been prone to } \\
\text { ground movement (slips) for several years. }\end{array}$ & 2,17 & PHMSA \\
\hline $\begin{array}{l}\text { Kennedy } \\
\text { Lost Cr }\end{array}$ & Lewis & WV & $\begin{array}{l}\text { Dominion } \\
\text { Transmission } \\
\text { Inc. }\end{array}$ & $11 / 9 / 2006$ & $\begin{array}{l}\text { Repairs were performed, and } \\
\text { the line was purged and } \\
\text { placed back into service } \\
\text { around 10:00 pm. }\end{array}$ & $\begin{array}{l}\text { Dispatcher paged supervisor at 1:44 pm on } \\
\text { November } 9,2006 \text {, to report that someone had } \\
\text { hit a pipeline in Sweeney Storage Field. } \\
\text { Supervisor traveled with utility and field person } \\
\text { to discover that a brush hog had broken a 1-in. } \\
\text { syphon on a drip. }\end{array}$ & 2,10 & PHMSA \\
\hline $\begin{array}{l}\text { Racket New } \\
\text { Ber }\end{array}$ & Ritchie & WV & $\begin{array}{l}\text { Dominion } \\
\text { Transmission } \\
\text { Inc. }\end{array}$ & $5 / 7 / 2009$ & No fire or explosion occurred. & $\begin{array}{l}\text { While working a well road near well \#2186 in } \\
\text { Racket Newberne Storage Field, a dozer } \\
\text { operator punctured pipeline tl } 286 \text {. }\end{array}$ & 2,10 & PHMSA \\
\hline Comet & Taylor & WV & Equitrans LP & $11 / 19 / 2014$ & $\begin{array}{l}\text { Gas loss was greater than the } \\
3 \text { MMcf for reporting. The } \\
\text { initial ESD was determined to } \\
\text { be caused by a bad gas } \\
\text { detector sensor which was } \\
\text { replaced. It appears the valve } \\
\text { did not close due to moisture } \\
\text { in the supply gas line causing } \\
\text { freeze off. }\end{array}$ & $\begin{array}{l}\text { ESD had activated; an ESD valve had not closed } \\
\text { and gas was venting at the station site. } \\
\text { Applicable valves were shut which stopped the } \\
\text { venting. }\end{array}$ & 4 & PHMSA \\
\hline
\end{tabular}


Table B-1 Summary of Documented Events at Depleted Oil and Gas Underground Storage Facilities, Some of Which Have Led to Leakage and/or Failure

\begin{tabular}{|c|c|c|c|c|c|c|c|c|}
\hline Field Name & $\begin{array}{l}\text { County } \\
\text { Name }\end{array}$ & State & $\begin{array}{l}\text { Current } \\
\text { Operator }\end{array}$ & Date & Impacts & Reported Cause & $\begin{array}{c}\text { Failure } \\
\text { Mechanism } \\
\text { ID }\end{array}$ & Source \\
\hline Rhodes & Lewis & WV & Equitrans LP & $12 / 8 / 1987$ & Not specified. & $\begin{array}{l}\text { Contractor cut gas service line while trenching } \\
\text { to install electric cable. Gas ignited and } \\
\text { destroyed the trenching machine. Natural gas } \\
\text { blew for approximately thirty-six hours until it } \\
\text { was discovered at } 0930 \text { hours on December } 7 \text {, } \\
\text { 1987, at which time the storage pool was shut- } \\
\text { in. }\end{array}$ & 2,10 & PHMSA \\
\hline & $\begin{array}{l}\text { Not } \\
\text { available }\end{array}$ & WV & Not available & $\begin{array}{c}\text { Not } \\
\text { available }\end{array}$ & Casing leaks. & Well bore remediation work undertaken. & 1 & $\begin{array}{l}\text { Evans and } \\
\text { Chadwick, } 2009\end{array}$ \\
\hline $\begin{array}{l}\text { Ryckman } \\
\text { Creek }\end{array}$ & Uinta & WY & $\begin{array}{l}\text { Ryckman } \\
\text { Creek } \\
\text { Resources } \\
\text { LLC }\end{array}$ & $4 / 20 / 2013$ & $\begin{array}{l}\text { UGS had the limited ability to } \\
\text { receive and deliver gas. One } \\
\text { firm storage customer } \\
\text { affected (unnamed). }\end{array}$ & Fire at the Nitrogen Rejection Unit at UGS. & 2 & FERC \\
\hline $\begin{array}{l}\text { Ryckman } \\
\text { Creek }\end{array}$ & Uinta & WY & $\begin{array}{l}\text { Ryckman } \\
\text { Creek } \\
\text { Resources } \\
\text { LLC }\end{array}$ & $7 / 8 / 2014$ & $\begin{array}{l}\text { Force majeure declared and } \\
\text { all services suspended; did } \\
\text { not identify affected } \\
\text { customers. }\end{array}$ & Possible construction defects. & 4 & FERC \\
\hline $\begin{array}{l}\text { Ryckman } \\
\text { Creek }\end{array}$ & Uinta & WY & $\begin{array}{l}\text { Ryckman } \\
\text { Creek } \\
\text { Resources } \\
\text { LLC }\end{array}$ & $1 / 11 / 2016$ & $\begin{array}{l}\text { UGS able to inject gas and } \\
\text { wheel gas, but all } \\
\text { withdrawals are shut-in. }\end{array}$ & Overheating of thermal oxidizer. & 2 & FERC \\
\hline
\end{tabular}


Table B-2 Summary of Documented Events at Aquifer Underground Storage Facilities, Some of Which Have Led to Leakage and/or Failure

\begin{tabular}{|c|c|c|c|c|c|c|c|c|}
\hline $\begin{array}{l}\text { Field } \\
\text { Name }\end{array}$ & $\begin{array}{l}\text { County } \\
\text { Name }\end{array}$ & State & $\begin{array}{l}\text { Current } \\
\text { Operator }\end{array}$ & Date & Impacts & Reported Cause & $\begin{array}{c}\text { Failure } \\
\text { Mechanism } \\
\text { ID }\end{array}$ & Source \\
\hline Redfield & Dallas & IA & $\begin{array}{l}\text { Northern } \\
\text { Natural Gas } \\
\text { Co. }\end{array}$ & $1 / 10 / 2010$ & $\begin{array}{l}\text { There was no explosion, no } \\
\text { injuries, no evacuations, and } \\
\text { no loss of service to } \\
\text { customers. }\end{array}$ & $\begin{array}{l}\text { On January } 10,2010 \text {, at approximately } 21: 24 \text { pm, a fire } \\
\text { was discovered, by a Northern Natural Gas Company } \\
\text { employee, at the Redfield underground storage field, } \\
\text { located near Redfield, lowa, in the SL Peter } \\
\text { underground storage formation at what is called the } \\
\text { Maher \#3 well site. }\end{array}$ & 2 & PHMSA \\
\hline Redfield & Dallas & IA & $\begin{array}{l}\text { Northern } \\
\text { Natural Gas } \\
\text { Co. }\end{array}$ & $8 / 28 / 2012$ & $\begin{array}{l}\text { There were no injuries, no } \\
\text { evacuations, and no loss of } \\
\text { service to customers. Two } \\
\text { MidAmerican Energy } \\
\text { Company utility power poles } \\
\text { were damaged. }\end{array}$ & $\begin{array}{l}\text { On August 7, 2012, at approximately 9:15 am, local } \\
\text { time, a section of 10-inch diameter pipeline identified as } \\
\text { rdu30801 near mile post } 0.34 \text { at the Redfield, lowa, } \\
\text { underground storage facility ruptured. The pipeline } \\
\text { failure resulted in a fire which was extinguished at } \\
\text { 10:51 am. }\end{array}$ & 2 & PHMSA \\
\hline Sciota & Sciota & IL & $\begin{array}{l}\text { Central Illinois } \\
\text { Public Service } \\
\text { Company } \\
\end{array}$ & 1971-1974 & $\begin{array}{l}\text { Testing and injection 1971- } \\
1972\end{array}$ & $\begin{array}{l}\text { Ineffective seal provided by cap rock, facility was } \\
\text { abandoned in } 1974 .\end{array}$ & $4,12,13$ & $\begin{array}{l}\text { Evans and } \\
\text { Chadwick, } \\
2009\end{array}$ \\
\hline Hillsboro & St. Clair & IL & $\begin{array}{l}\text { Illinois Power } \\
\text { Co. }\end{array}$ & $12 / 16 / 2000$ & Not specified. & $\begin{array}{l}\text { A 50,000-gallon water holding tank was dislodged from } \\
\text { its foundation and moved approximately } 300 \text { feet, } \\
\text { causing damage to the Fields Regulator Station, } 2 \text { gas } \\
\text { dehydration towers, and nearby cable trays. A nearby } \\
\text { primary electric line was also damaged. }\end{array}$ & 2 & PHMSA \\
\hline Brookville & Brookville & IL & $\begin{array}{l}\text { Natural Gas } \\
\text { Pipeline Co. } \\
\text { of America }\end{array}$ & 1963-1966 & $\begin{array}{l}\text { Water pump and injection } \\
\text { tests reveal leak from } \\
\text { reservoir. }\end{array}$ & Faulting, cap rock leakage, facility abandoned. & $4,12,14$ & $\begin{array}{l}\text { Evans and } \\
\text { Chadwick, } \\
2009\end{array}$ \\
\hline Herscher & Kankakee & IL & $\begin{array}{l}\text { Natural Gas } \\
\text { Pipeline Co. } \\
\text { of America }\end{array}$ & $\begin{array}{l}\text { April-July } \\
1953\end{array}$ & $\begin{array}{l}\text { Gas found in shallow wells } \\
\text { within } 5 \text { weeks of operation. }\end{array}$ & $\begin{array}{l}\text { Cap rock leakage, injection ceased, relief wells drilled- } \\
\text { withdrew water from periphery and injected into } \\
\text { overlying formations to increase hydrostatic pressure. }\end{array}$ & $4,12,13$ & $\begin{array}{l}\text { Evans and } \\
\text { Chadwick, } \\
2009\end{array}$ \\
\hline Loudon & Fayette & IL & $\begin{array}{l}\text { Natural Gas } \\
\text { Pipeline Co. } \\
\text { of America }\end{array}$ & 2/7/1997 & $\begin{array}{l}\text { Explosion and fire; } 3 \\
\text { employees injured. }\end{array}$ & $\begin{array}{l}\text { Inadvertent strike of gas from UGS reservoir during } \\
\text { drilling of oil well; no blowout preventer installed, and } \\
\text { drilling continued while well unsafe. }\end{array}$ & $1,4,10$ & $\begin{array}{l}\text { Evans and } \\
\text { Chadwick, } \\
2009\end{array}$ \\
\hline Loudon & Fayette & IL & $\begin{array}{l}\text { Natural Gas } \\
\text { Pipeline Co. } \\
\text { of America }\end{array}$ & $10 / 28 / 2009$ & Not specified. & $\begin{array}{l}\text { A fire started in relation to a produced water process } \\
\text { tank at a gas storage field location. The fire originated in } \\
\text { conjunction with a welding operation on the exterior of } \\
\text { the tank. }\end{array}$ & 2 & PHMSA \\
\hline
\end{tabular}


Table B-2 Summary of Documented Events at Aquifer Underground Storage Facilities, Some of Which Have Led to Leakage and/or Failure

\begin{tabular}{|c|c|c|c|c|c|c|c|c|}
\hline $\begin{array}{l}\text { Field } \\
\text { Name }\end{array}$ & $\begin{array}{l}\text { County } \\
\text { Name }\end{array}$ & State & $\begin{array}{l}\text { Current } \\
\text { Operator }\end{array}$ & Date & Impacts & Reported Cause & $\begin{array}{l}\text { Failure } \\
\text { Mechanism } \\
\text { ID }\end{array}$ & Source \\
\hline Pontiac & Livingston & IL & $\begin{array}{l}\text { Northern } \\
\text { Illinois Gas } \\
\text { Co. }\end{array}$ & $12 / 21 / 2010$ & Not specified. & $\begin{array}{l}\text { 12-in. pipeline connecting gas storage } \\
\text { injection/withdrawal wells (aquifer-type storage } \\
\text { reservoir) to a central storage station ruptured with } \\
\text { subsequent ignition. }\end{array}$ & 2 & PHMSA \\
\hline Ancona & Livingston & IL & $\begin{array}{l}\text { Northern } \\
\text { Illinois Gas } \\
\text { Company }\end{array}$ & $6 / 1 / 1999$ & $\begin{array}{l}\text { Small leak and fire led to } \\
\text { damage to control fittings and } \\
\text { facility. }\end{array}$ & $\begin{array}{l}\text { Small leak ignited by lightning led to damage to facility } \\
\text { control fittings, building exteriors, and gas conditioning } \\
\text { equipment at compressor station. }\end{array}$ & 2 & $\begin{array}{l}\text { Evans and } \\
\text { Chadwick, } \\
2009\end{array}$ \\
\hline Pontiac & Livingston & IL & $\begin{array}{l}\text { Northern } \\
\text { Illinois Gas } \\
\text { Company } \\
\end{array}$ & $1963-1974$ & $\begin{array}{l}\text { Testing and injection with } \\
\text { inert combustion gas in } 1970 .\end{array}$ & $\begin{array}{l}\text { Ineffective seal provided by cap rock, facility was } \\
\text { inactive in } 1974 .\end{array}$ & $4,12,13$ & $\begin{array}{l}\text { Evans and } \\
\text { Chadwick, } \\
2009\end{array}$ \\
\hline $\begin{array}{l}\text { Troy } \\
\text { Grove }\end{array}$ & La Salle & IL & $\begin{array}{l}\text { Northern } \\
\text { Illinois Gas } \\
\text { Company } \\
\end{array}$ & 1957-1959 & $\begin{array}{l}\text { Gas migration from reservoir } \\
\text { known since early } \\
\text { development. }\end{array}$ & $\begin{array}{l}\text { Cap rock leakage, gas withdrawn from higher levels and } \\
\text { re-injected at depth. Facility still operational. }\end{array}$ & $4,12,13$ & $\begin{array}{l}\text { Evans and } \\
\text { Chadwick, } \\
2009\end{array}$ \\
\hline $\begin{array}{l}\text { Manlove } \\
\text { Field }\end{array}$ & Champaign & IL & $\begin{array}{l}\text { Peoples Gas } \\
\text { Light \& Coke } \\
\text { Co. }\end{array}$ & 1961-1963 & $\begin{array}{l}\text { Gas migrated from } 2 \text { upper } \\
\text { reservoirs into glacial drift } \\
\text { deposits. }\end{array}$ & $\begin{array}{l}\text { Cap rock leakage, reservoirs abandoned, but third } \\
\text { deeper one later developed. }\end{array}$ & $4,12,13$ & $\begin{array}{l}\text { Evans and } \\
\text { Chadwick, } \\
2009\end{array}$ \\
\hline $\begin{array}{l}\text { Manlove } \\
\text { Field }\end{array}$ & Champaign & IL & $\begin{array}{l}\text { Peoples Gas } \\
\text { Light \& Coke } \\
\text { Co. }\end{array}$ & $12 / 16 / 2015$ & $\begin{array}{l}\text { Calculations on the size of the } \\
\text { release were completed, and } \\
\text { the estimated release was } \\
11.756 \text { million } \mathrm{ft}^{3} \text {. }\end{array}$ & $\begin{array}{l}\text { At approximately 9:40 pm on Saturday November 21, } \\
2015 \text {, an emergency vent valve on the emergency } \\
\text { shutdown system, for the storage facility at the } \\
\text { Manlove Storage Field spuriously opened and emitted } \\
\text { gas for } 10 \text { minutes until operating personnel closed } \\
\text { block valves, terminating the release. }\end{array}$ & 2 & PHMSA \\
\hline $\begin{array}{l}\text { Manlove } \\
\text { Field }\end{array}$ & Champaign & IL & $\begin{array}{l}\text { Peoples Gas } \\
\text { Light \& Coke } \\
\text { Co. }\end{array}$ & $4 / 11 / 2007$ & $\begin{array}{l}\text { The leak caused no injuries, } \\
\text { and there was no damage to } \\
\text { any property other than the } \\
\text { company facilities that were } \\
\text { involved. }\end{array}$ & $\begin{array}{l}\text { A natural gas leak was discovered on a section of } \\
\text { transmission system piping in Champaign County. The } \\
\text { piping section was brought to } 0 \text { psig within an hour by } \\
\text { venting gas into the atmosphere through connections at } \\
\text { a nearby gas storage well. }\end{array}$ & 2 & PHMSA \\
\hline Waverly & Morgan & IL & $\begin{array}{l}\text { Southwest } \\
\text { Gas Storage } \\
\text { Company }\end{array}$ & $1960 \mathrm{~s}$ & $\begin{array}{l}\text { Gas migration to shallower } \\
\text { levels. }\end{array}$ & $\begin{array}{l}\text { Cap rock leakage; gas was either recycled into reservoir } \\
\text { or produced. }\end{array}$ & $4,12,13$ & $\begin{array}{l}\text { Evans and } \\
\text { Chadwick, } \\
2009\end{array}$ \\
\hline Waverly & Morgan & IL & $\begin{array}{l}\text { Southwest } \\
\text { Gas Storage } \\
\text { Company }\end{array}$ & $8 / 27 / 2007$ & Not specified. & $\begin{array}{l}\text { The line which is part of the Waverly Storage Field had } \\
\text { an area of reduced wall thickness at a low spot due to } \\
\text { internal corrosion. }\end{array}$ & 2 & PHMSA \\
\hline
\end{tabular}


Table B-2 Summary of Documented Events at Aquifer Underground Storage Facilities, Some of Which Have Led to Leakage and/or Failure

\begin{tabular}{|c|c|c|c|c|c|c|c|c|}
\hline $\begin{array}{l}\text { Field } \\
\text { Name }\end{array}$ & $\begin{array}{l}\text { County } \\
\text { Name }\end{array}$ & State & $\begin{array}{l}\text { Current } \\
\text { Operator }\end{array}$ & Date & Impacts & Reported Cause & $\begin{array}{l}\text { Failure } \\
\text { Mechanism } \\
\text { ID }\end{array}$ & Source \\
\hline Doe Run & Meade & IN & $\begin{array}{l}\text { Louisville Gas } \\
\text { \& Electric Co. }\end{array}$ & $11 / 6 / 2014$ & Not specified. & $\begin{array}{l}\text { A 4-inch pipeline in Doe Run Indiana natural gas storage } \\
\text { field ruptured resulting in the accidental release of } \\
\text { natural gas, brine water, and debris. }\end{array}$ & 2 & PHMSA \\
\hline Doe Run & Meade & IN & $\begin{array}{l}\text { Louisville Gas } \\
\text { \& Electric Co. }\end{array}$ & $10 / 22 / 2015$ & Not specified. & $\begin{array}{l}\text { A failure on a pipe segment in Doe Run Storage Field, } \\
\text { located downstream of an unattended field compressor, } \\
\text { occurred on October 22, 2015. Review of recorded } \\
\text { pressure data found the field compressor discharge } \\
\text { pressure dropped suddenly at approximately } 12: 50 \mathrm{pm} \text {, } \\
\text { resulting in the automatic shutdown of the field } \\
\text { compressor. }\end{array}$ & 2 & PHMSA \\
\hline $\begin{array}{l}\text { Not } \\
\text { Available }\end{array}$ & $\begin{array}{l}\text { Northern } \\
\text { Indiana }\end{array}$ & IN & Not Available & $\begin{array}{l}\text { Not } \\
\text { available }\end{array}$ & Gas escape. & $\begin{array}{l}\text { Reservoir selected too shallow; number of water wells } \\
\text { were affected by natural gas. }\end{array}$ & $4,6,12,13$ & $\begin{array}{l}\text { Evans and } \\
\text { Chadwick, } \\
2009\end{array}$ \\
\hline Leesville & Lawrence & IN & $\begin{array}{l}\text { Texas Gas } \\
\text { Transmission } \\
\text { Corporation }\end{array}$ & $\begin{array}{l}\text { Not } \\
\text { available }\end{array}$ & Well blowout. & Not available. & 1,18 & $\begin{array}{l}\text { Evans and } \\
\text { Chadwick, } \\
2009\end{array}$ \\
\hline $\begin{array}{l}\text { Chalk } \\
\text { Creek }\end{array}$ & Summit & UT & $\begin{array}{l}\text { Questar } \\
\text { Pipeline } \\
\text { Company }\end{array}$ & 1970 s & $\begin{array}{l}\text { Soil gas surveys detect gas } \\
\text { over storage areas. }\end{array}$ & Possibility of gas migrating up out of reservoir via faults. & $4,12,13,14$ & $\begin{array}{l}\text { Evans and } \\
\text { Chadwick, } \\
2009\end{array}$ \\
\hline Coalville & Summit & UT & $\begin{array}{l}\text { Questar } \\
\text { Pipeline } \\
\text { Company }\end{array}$ & 1970s & $\begin{array}{l}\text { Soil gas surveys detect gas } \\
\text { over storage areas. }\end{array}$ & Possibility of gas migrating up out of reservoir via faults. & $4,12,13,14$ & $\begin{array}{l}\text { Evans and } \\
\text { Chadwick, } \\
2009\end{array}$ \\
\hline Leroy & Uinta & WY & $\begin{array}{l}\text { Questar } \\
\text { Pipeline } \\
\text { Company }\end{array}$ & $\begin{array}{l}\text { 1973-mid } \\
\text { 1980s }\end{array}$ & $\begin{array}{l}\text { Numerous incidents of gas } \\
\text { escaping. Found bubbling up } \\
\text { in streams and ponds. }\end{array}$ & Corroded well casing and over-pressuring of aquifer. & 2,5 & $\begin{array}{l}\text { Evans and } \\
\text { Chadwick, } \\
2009\end{array}$ \\
\hline Leroy & Uinta & WY & $\begin{array}{l}\text { Questar } \\
\text { Pipeline } \\
\text { Company }\end{array}$ & $12 / 4 / 2011$ & $\begin{array}{l}\text { The Dehy Facility was repaired } \\
\text { and placed into service on } \\
\text { May 31, } 2012 \text {. }\end{array}$ & $\begin{array}{l}\text { The Leroy Storage Field was on stand-by for withdrawal. } \\
\text { Sometime prior to the fire, a } 1 / 4 \text {-in. diameter tubing line } \\
\text { on the bottom of a glycol pump broke, releasing a glycol } \\
\text { and gas mixture inside the Dehy unit building. At some } \\
\text { point, the glycol and gas were ignited and the resulting } \\
\text { fire damaged the Dehy unit. }\end{array}$ & 2 & PHMSA \\
\hline
\end{tabular}


Table B-3 Summary of Documented Events at Salt Cavern Underground Storage Facilities, Some of Which Have Led to Leakage and/or Failure

\begin{tabular}{|c|c|c|c|c|c|c|c|c|}
\hline Field Name & County Name & State & $\begin{array}{l}\text { Current } \\
\text { Operator }\end{array}$ & Date & Impacts & Reported Cause & $\begin{array}{c}\text { Failure } \\
\text { Mechanism } \\
\text { ID }\end{array}$ & Source \\
\hline Yaggy & $\begin{array}{l}\text { Hutchinson/ } \\
\text { Yaggy }\end{array}$ & KS & $\begin{array}{l}\text { Oneok Gas } \\
\text { Storage LLC }\end{array}$ & $1 / 1 / 2001$ & base & $\begin{array}{l}\text { Casing failure-damaged during re-entry } \\
\text { operations. } \$ 5.25 \text { million in punitive } \\
\text { damages. }\end{array}$ & 1,4 & $\begin{array}{l}\text { Evans and } \\
\text { Chadwick, } \\
2009\end{array}$ \\
\hline $\begin{array}{l}\text { Magnolia Gas } \\
\text { Storage }\end{array}$ & $\begin{array}{l}\text { Magnolia, } \\
\text { Napoleonville }\end{array}$ & LA & $\begin{array}{l}\text { Gulf South } \\
\text { Pipeline }\end{array}$ & $12 / 24 / 2003$ & $\begin{array}{l}\text { Gas bubbling to surface led to } \\
\text { gas leak. } 0.35 \mathrm{MMcf} \text { gas released } \\
\text { in a few hours; } 30 \text { evacuated. }\end{array}$ & $\begin{array}{l}\text { Casing failure; crack in the casing of a } \\
\text { well near the top of a cavern. Cavern } \\
\text { operations ceased. }\end{array}$ & 1 & $\begin{array}{l}\text { Evans and } \\
\text { Chadwick, } \\
2009\end{array}$ \\
\hline Grand Bayou & Assumption & LA & $\begin{array}{l}\text { Pontchartrain } \\
\text { Natural Gas } \\
\text { System }\end{array}$ & $8 / 3 / 2012$ & $\begin{array}{l}\text { The crosstex facility remains out } \\
\text { of service until assessment of } \\
\text { third-party storage cavern is } \\
\text { complete. }\end{array}$ & $\begin{array}{l}\text { A sink hole had formed near crosstex's } \\
36 \text {-in. pipeline at Bayou Corne. Crosstex } \\
\text { built a 5-mile loop around the sink hole } \\
\text { area and on May } 21,2014, \text { at } 22: 00 \text { hrs., } \\
\text { the pipeline was placed back into } \\
\text { service. }\end{array}$ & 16 & PHMSA \\
\hline Eminence & Covington & MS & $\begin{array}{l}\text { Transcontinental } \\
\text { Gas Pipeline } \\
\text { Company }\end{array}$ & $\begin{array}{l}\text { Early-mid } \\
\text { 1980s }\end{array}$ & $\begin{array}{l}\text { Natural gas leakages, no reports } \\
\text { of casualties. }\end{array}$ & $\begin{array}{l}4 \text { caverns at facility; wells of } 2 \text { found to } \\
\text { be leaking due to poor cementing. }\end{array}$ & 1 & $\begin{array}{l}\text { Evans and } \\
\text { Chadwick, } \\
2009\end{array}$ \\
\hline Eminence & Covington & MS & $\begin{array}{l}\text { Transcontinental } \\
\text { Gas Pipeline } \\
\text { Company }\end{array}$ & 4/1/1972 & $\begin{array}{l}2 \text { caverns lost capacity. Closed in } \\
\text { the early } 1980 \text { s, but volume has } \\
\text { been regained and is presently } \\
\text { operating. }\end{array}$ & $\begin{array}{l}\text { Salt creep-operating pressure range } \\
\text { too low. }\end{array}$ & $5,7,9$ & $\begin{array}{l}\text { Evans and } \\
\text { Chadwick, } \\
2009\end{array}$ \\
\hline Spindletop & Jefferson & TX & $\begin{array}{l}\text { Centana } \\
\text { Interstate } \\
\text { Pipeline LLC }\end{array}$ & $12 / 1 / 2007$ & $\begin{array}{l}\text { Modifications of operating } \\
\text { pressures/conditions. }\end{array}$ & $\begin{array}{l}\text { Communication of No. } 1 \text { cavern with } \\
\text { nearby brine cavern. }\end{array}$ & 8 & $\begin{array}{l}\text { Evans and } \\
\text { Chadwick, } \\
2009\end{array}$ \\
\hline $\begin{array}{l}\text { Stratton } \\
\text { Ridge }\end{array}$ & Brazoria & TX & Dow PI Co. & $1990 \mathrm{~s}$ & Cavern failure. & Leak_failed MIT. & 3 & $\begin{array}{l}\text { Evans and } \\
\text { Chadwick, } \\
2009\end{array}$ \\
\hline $\begin{array}{l}\text { Moss Bluff } \\
\text { Storage }\end{array}$ & Moss Bluff & $\mathrm{TX}$ & $\begin{array}{l}\text { Texas Eastern } \\
\text { Transmission LP }\end{array}$ & $\begin{array}{l}\text { August 19- } \\
26,2004\end{array}$ & $\begin{array}{l}\text { Fire and explosion, circa } 360 \\
\text { evacuated, } 6 \text { Bcf of natural gas } \\
\text { released and burnt. Fire left to } \\
\text { burn and self-extinguish. }\end{array}$ & $\begin{array}{l}\text { Initial separation and breach of } 8 \text { 5/8-in. } \\
\text { well string inside the cavern led to } \\
\text { pressure sure to well and breach of } \\
\text { corroded pipe above ground. Escaping } \\
\text { gas ignited; resultant fire caused } \\
\text { wellhead to fail. Fire too hot to close } \\
\text { valve. }\end{array}$ & 1,2 & $\begin{array}{l}\text { Evans and } \\
\text { Chadwick, } \\
2009\end{array}$ \\
\hline Bethel & Anderson & TX & $\begin{array}{l}\text { Energy Transfer } \\
\text { Fuel LP }\end{array}$ & $8 / 1 / 2007$ & $\begin{array}{l}\text { Repair to well required, requiring } \\
\text { cavern filled with water. }\end{array}$ & Casing damage in well. & 1 & $\begin{array}{l}\text { Evans and } \\
\text { Chadwick, } \\
2009\end{array}$ \\
\hline
\end{tabular}


Table B-3 Summary of Documented Events at Salt Cavern Underground Storage Facilities, Some of Which Have Led to Leakage and/or Failure

\begin{tabular}{|c|c|c|c|c|c|c|c|c|}
\hline Field Name & County Name & State & $\begin{array}{l}\text { Current } \\
\text { Operator }\end{array}$ & Date & Impacts & Reported Cause & $\begin{array}{l}\text { Failure } \\
\text { Mechanism } \\
\text { ID }\end{array}$ & Source \\
\hline Boling & Wharton & TX & $\begin{array}{l}\text { Enterprise } \\
\text { Products } \\
\text { Operating LLC }\end{array}$ & $10 / 1 / 2005$ & $\begin{array}{l}\text { Casing damage found in } 3 \text { of } 4 \\
\text { natural gas storage caverns. }\end{array}$ & $\begin{array}{l}\text { Casing damage found and repaired, with } \\
\text { wells returned to active storage. }\end{array}$ & 1 & $\begin{array}{l}\text { Evans and } \\
\text { Chadwick, } \\
2009\end{array}$ \\
\hline Boling & Wharton & TX & $\begin{array}{l}\text { Enterprise } \\
\text { Products } \\
\text { Operating LLC }\end{array}$ & $7 / 26 / 2012$ & Not specified. & $\begin{array}{l}\text { Landowner in Wharton County } \\
\text { discovered leak on pipeline right of way. }\end{array}$ & 2 & PHMSA \\
\hline Boling & Wharton & TX & $\begin{array}{l}\text { Enterprise } \\
\text { Products } \\
\text { Operating LLC }\end{array}$ & $1 / 4 / 2013$ & Not specified. & $\begin{array}{l}\text { At } 04: 30 \text { am on January } 4,2013 \text {, field } \\
\text { operations found a crack on the station } \\
\text { blow down line at the Wilson storage } \\
\text { facility. }\end{array}$ & 2 & PHMSA \\
\hline Boling & Wharton & TX & $\begin{array}{l}\text { Enterprise } \\
\text { Products } \\
\text { Operating LLC }\end{array}$ & $11 / 21 / 2014$ & Not specified. & $\begin{array}{l}\text { On 10/29/2014 at } 23: 55 \text {, Wilson storage } \\
\text { compressor unit\# } 897 \text { was started for } \\
\text { delivering natural gas into storage. An } \\
\text { enterprise employee discovered that } \\
\text { natural gas was venting from the unit } \\
\text { blow down valve. Operations shut down } \\
\text { the compressor. }\end{array}$ & 2 & PHMSA \\
\hline Spindletop & Jefferson & TX & $\begin{array}{l}\text { Golden Triangle } \\
\text { Storage Inc. }\end{array}$ & post-2001 & $\begin{array}{l}\text { Gas leak into salt, details } \\
\text { unavailable. }\end{array}$ & Possible well failure. & 18 & $\begin{array}{l}\text { Evans and } \\
\text { Chadwick, } \\
2009\end{array}$ \\
\hline Dayton North & Liberty & TX & $\begin{array}{l}\text { Kinder Morgan } \\
\text { Texas Pipeline } \\
\text { Co. }\end{array}$ & $11 / 1 / 2007$ & $\begin{array}{l}\text { Suspension of gas injection } \\
\text { operations. }\end{array}$ & $\begin{array}{l}\text { Temperature anomalies during MIT and } \\
\text { wing valve malfunction; required work } \\
\text { over of Hiltpold no. } 2 \text { well. }\end{array}$ & 1,11 & $\begin{array}{l}\text { Evans and } \\
\text { Chadwick, } \\
2009\end{array}$ \\
\hline Dayton North & Liberty & TX & $\begin{array}{l}\text { Kinder Morgan } \\
\text { Texas Pipeline } \\
\text { Co. }\end{array}$ & $6 / 1 / 2006$ & $\begin{array}{l}\text { Problems developing } 1 \text { cavern, } \\
\text { development suspended. }\end{array}$ & $\begin{array}{l}\text { Cavern development beset by multiple } \\
\text { problems. }\end{array}$ & 18 & $\begin{array}{l}\text { Evans and } \\
\text { Chadwick, } \\
2009\end{array}$ \\
\hline Dayton North & Liberty & TX & $\begin{array}{l}\text { Kinder Morgan } \\
\text { Texas Pipeline } \\
\text { Co. }\end{array}$ & $10 / 4 / 2010$ & Not specified. & $\begin{array}{l}\text { On September 17, 2010, a Kinder } \\
\text { Morgan Texas Pipeline employee was } \\
\text { assigned the task of removing } 1 / 2 \text {-in. } \\
\text { tubing that was installed on September } \\
14,2010 .\end{array}$ & 2 & PHMSA \\
\hline Salado & Gaines & TX & $\begin{array}{l}\text { Oneok Texas Gas } \\
\text { Storage LP }\end{array}$ & $9 / 1 / 2003$ & $\begin{array}{l}\text { Permit altered, reducing } \\
\text { maximum operating pressure; } \\
\text { gradient and subsidence } \\
\text { monitoring required. }\end{array}$ & Cavern roof migration in well 1128. & $5,8,9$ & $\begin{array}{l}\text { Evans and } \\
\text { Chadwick, } \\
2009\end{array}$ \\
\hline
\end{tabular}


Table B-3 Summary of Documented Events at Salt Cavern Underground Storage Facilities, Some of Which Have Led to Leakage and/or Failure

\begin{tabular}{|l|l|c|c|c|l|l|l|}
\hline Field Name & County Name & State & $\begin{array}{c}\text { Current } \\
\text { Operator }\end{array}$ & Date & $\begin{array}{l}\text { Failure } \\
\text { Impacts } \\
\text { ID }\end{array}$ & \multicolumn{1}{|c|}{ Source } \\
\hline Salado & Gaines & TX & $\begin{array}{l}\text { Oneok Texas Gas } \\
\text { Storage LP }\end{array}$ & $\begin{array}{l}\text { Cavern roof collapse. Could be } \\
\text { cavern (and well 1128) in which } \\
\text { permit modifications were } \\
\text { imposed in Sept. 2008 to reduce } \\
\text { max operating pressure gradient. }\end{array}$ & $\begin{array}{l}\text { Cavern roof fall occurred prior to } \\
\text { December 2001, causing cavern roof to } \\
\text { move up circa 60-meters. Sonar and MIT } \\
\text { surveys conducted and storage } \\
\text { resumed. }\end{array}$ \\
\hline
\end{tabular}



Argonne

Global Security Sciences Division

Energy Systems Division

Argonne National Laboratory

9700 South Cass Avenue

Argonne, IL 60439-4854

www.anl.gov 